University of Louisville

ThinkIR: The University of Louisville's Institutional Repository

Electronic Theses and Dissertations

$8-2020$

\title{
Mechanisms of chromate-induced suppression of RAD51: a one environmental health approach.
}

Rachel M. Speer

University of Louisville

Follow this and additional works at: https://ir.library.louisville.edu/etd

Part of the Medical Pharmacology Commons, and the Medical Toxicology Commons

\section{Recommended Citation}

Speer, Rachel M., "Mechanisms of chromate-induced suppression of RAD51: a one environmental health approach." (2020). Electronic Theses and Dissertations. Paper 3485.

https://doi.org/10.18297/etd/3485

This Doctoral Dissertation is brought to you for free and open access by ThinkIR: The University of Louisville's Institutional Repository. It has been accepted for inclusion in Electronic Theses and Dissertations by an authorized administrator of ThinkIR: The University of Louisville's Institutional Repository. This title appears here courtesy of the author, who has retained all other copyrights. For more information, please contact thinkir@louisville.edu. 


\title{
MECHANISMS OF CHROMATE-INDUCED SUPPRESSION OF RAD51: A ONE ENVIRONMENTAL HEALTH APPROACH
}

\author{
By
}

\author{
Rachel M. Speer \\ B.S., Rochester Institute of Technology, 2013 \\ M.S., University of Louisville, 2017

\begin{abstract}
A Dissertation
Submitted to the Faculty of the

School of Medicine of the University of Louisville

In Partial Fulfillment of the Requirements

For the Degree of
\end{abstract}

Doctor of Philosophy in Pharmacology and Toxicology

Department of Pharmacology and Toxicology

University of Louisville

Louisville, Kentucky

August 2020 
Copyright 2020 by Rachel M. Speer

All Rights Reserved 

MECHANISMS OF CHROMATE-INDUCED SUPPRESSION OF RAD51: A ONE ENVIRONMENTAL HEALTH APPROACH

By

Rachel M. Speer

B.S. Rochester Institute of Technology, 2013

M.S., University of Louisville, 2017

A Dissertation Approved on

June 25, 2020

by the following Dissertation Committee:

John Pierce Wise, Sr., Ph.D.

Levi Beverly, Ph.D.

Lu Cai, Ph.D.

J. Christopher States, Ph.D.

Qunwei Zhang, Ph.D. 


\section{DEDICATION}

This dissertation is dedicated to all the sea turtles, whales, alligators, and other wildlife that have made the experience of my Ph.D. such an amazing adventure. It has been an exceptional pleasure to get to relish in the majesty of 50-ton whales gliding gently alongside the boat or watching baby sea turtles emerge from a nest to make their way to the ocean for the first time. The experiences with these incredible creatures provided much-needed respite and I carried those moments with me whenever times were especially difficult. To all the alligators I wrestled, lionfish I caught (and ate), and whales I revered, although you didn't make it into these pages, you still hold a special place in my heart as a part of my experience of the past 5 years. 


\section{ACKNOWLEDGEMENTS}

First, I must thank my advisor, Dr. John Wise, who has been so incredible supportive over the past 7 years. We have had quite an adventure from the beginning, and I am so grateful for the opportunity I had to move to Louisville from Maine and be a part of the lab. I could not have imagined all of the incredible opportunities I have had because of John's support and confidence in my ability to succeed. I am especially grateful for the many opportunities to attend conferences, all the incredible field work I got to be a part of, and always making an extra effort to apply for awards and other opportunities. John has provided excellent guidance over the years and has never steered me in a wrong direction.

I would also like to thank my doctoral committee: Dr. Levi Beverly, Dr. Lu Cai, and Dr. Chris States, and Dr. Qunwei Zhang for all their knowledge, guidance, and suggestions as I worked my way through developing my dissertation. Thank you to Dr. Hein for all the guidance and support over the past 5 years as a leader of the Department of Pharmacology and Toxicology, and to everyone in the Department for the opportunity to learn so much more through the research you do and inspiration over the years.

I must also thank the collaborators of the work accomplished in this dissertation. Although the work in this dissertation is my own, it is written in plural first person due to the collaborative effort that went into its completion. I must thank 
my fellow lab members who contributed to third experiment repeat analysis: Tayler Croom-Pérez, Jennifer Toyoda, Idoia Meaza, Johnny Wise, and Haiyan Lu. I also thank Jennifer Toyoda and Idoia Meaza for their contributions to the RNAseq analysis. I also thank Dr. Ron Walter and Dr. Yuan Lu for their help in the bioinformatic analysis of the RNAseq data and Dr. Maiying Kong and Qian Xu for their help with the biostatistical analysis of the RNAseq data. The leatherback sea turtle work would not have been possible without our collaborators at the U.S. Fish and Wildlife Service, Vieques and the Vieques Conservation and historical trust. Specifically, I want to thank Mike Barandiaran and Erick Bermúdez for all the long hours in the field collecting samples and learning about their work. The depth of Erick's knowledge on all the flora and fauna in Vieques is something I was always treasure. I would also like to thank Lirio Marquez for always welcoming me into the Trust and to participate in the great work you do. To Mark Martin Bras, I thank you for all of the unforeseen problem solving that goes along with field work, all the guidance on navigating through precarious situations, and of course the amazing opportunities to explore, learn, and make the world a more magical place.

I have also had the opportunity to work in a great lab over the years. I thank Dr. Amie Homes for the excellent training she provided to me as a brand-new scientist early on. I also want to thank the members of the lab who have provided guidance and suggestions over the years: Jamie Young, Jeny Toyoda, Idoia Meaza, Haiyan Lu, Cyndi Browning, Tayler Croom-Pérez, Adam Pérez, Sean Raph, Johnny Wise, and Sandy Wise. I specifically want to thank Cyndi Browning 
for all her support both personally and research-related since our times together in the lab and beyond that.

Finally, I must thank my family and friends who have always been supportive. Thank you for always having confidence in my ability to succeed and providing so much support. To my partner, Suli who has always pushed me to be better and offered so much advice and perspective. I have grown so much with your help. I also want to thank Sharlie for all the support and keeping me well fed over these past 5 years. A special thanks is due to my mom and dad for your undying support and love. I am so grateful for everything you have ever done for me.

This dissertation would not have been possible without all the financial support provided by several different sources. The Integrated Programs in Biomedical Sciences and the Department of Pharmacology and Toxicology provided my first two years of support at the University of Louisville. I was supported for two years by the National Institute of Environmental Health Sciences T32 Training Grant [T32ES0111564-12] (to J.P.W. and R.M.S.). My last semester I have been supported by the Dissertation Completion Award from the University of Louisville's Graduate School. I also received numerous travel and research awards from the University of Louisville and Society of Toxicology that allowed me to present my work at conferences around the country. This work was supported by the National Institute of Environmental Health Sciences [ES016893 to J.P.W] and the Jewish Heritage Foundation for Excellence (to J.P.W.). 


\section{ABSTRACT \\ MECHANISMS OF CHROMATE-INDUCED SUPPRESSION OF RAD51: A ONE ENVIRONMENTAL HEALTH APPROACH}

Rachel M. Speer

June 25, 2020

Lung cancer is the leading cause of cancer death. Lung cancer is commonly associated with smoking, however, 1 in 5 women and 1 in 12 men who develop lung cancer are never-smokers. Environmental exposures, therefore, account for a significant portion of lung cancer cases. Hexavalent chromium $[\mathrm{Cr}(\mathrm{VI})]$ is a global environmental contaminant and known human lung carcinogen. $\mathrm{Cr}(\mathrm{VI})$ and other carcinogenic metals induce chromosome instability, an early event in lung cancer. Structural chromosome instability arises in part due to failed DNA repair. Particulate $\mathrm{Cr}(\mathrm{VI})$, the most potent form of $\mathrm{Cr}(\mathrm{VI})$, induces DNA double strand breaks and inhibits the high-fidelity DNA repair mechanism, homologous recombination. Specifically, the effector step of homologous recombination is affected shown by RAD51 failure.

RAD51 failure is due to inhibited expression, inhibited localization to double strand breaks, or a combination of these two mechanisms. Little is known about the mechanisms of $\mathrm{Cr}(\mathrm{VI})$-inhibited expression. However, $\mathrm{Cr}(\mathrm{VI})$ exposure results in downregulation of global expression, and it has been suggested epigenetic changes affect expression profiles after $\mathrm{Cr}(\mathrm{VI})$ exposure. Studies show changes in 
acetylation of the RAD51 promoter affect E2F1-mediated RAD51 transcription by altering the "histone code" as potential epigenetic mechanisms of inhibited expression. Studies also show changes in microRNAs are an additional epigenetic mechanism of $\mathrm{Cr}(\mathrm{VI})$-altered expression, and this may provide an additional mechanism of inhibited RAD51 expression.

The mechanisms of particulate $\mathrm{Cr}(\mathrm{VI})$-induced RAD51 failure were investigated in a human lung cells, and key events were confirmed in a wildlife model, leatherback sea turtle (Dermochelys coriacea) cells. The leatherback model was included as a part of the One Environmental Health Approach to investigate particulate $\mathrm{Cr}(\mathrm{VI})$ carcinogenesis across species. This type of analysis is used to identify how two species with different environmental adaptations may have alternative responses to chemical exposures. Therefore, the hypothesis of this dissertation is: Prolonged exposure to particulate $\mathrm{Cr}(\mathrm{VI})$ inhibits RAD51 expression through E2F1-inhibited transcription and alteration of microRNA expression profiles, and these effects are paralleled in a leatherback sea turtle model.

We found particulate $\mathrm{Cr}(\mathrm{VI})$ inhibits RAD51 and E2F1 nuclear and whole cell protein and mRNA levels in human lung cells. Therefore, we aimed to show E2F1 modulates the RAD51 response to particulate $\mathrm{Cr}(\mathrm{VI})$. We found E2F1 overexpression did not rescue particulate $\mathrm{Cr}(\mathrm{VI})$-induced RAD51-failure after prolonged (120 h) exposure. However, when we knocked down E2F1 we found E2F1 knockdown does not inhibit RAD51 mRNA or protein expression but does reduce nuclear foci formation after acute $(24 \mathrm{~h})$ particulate $\mathrm{Cr}(\mathrm{VI})$ exposure when 
RAD51 is normally functional. These results suggest E2F1 may affect RAD51 localization to double strand breaks, but not expression after $\mathrm{Cr}(\mathrm{VI})$ exposure. As an alternative mechanism of inhibited RAD51 expression we next performed RNA sequencing (RNAseq) analysis to asses $\mathrm{Cr}(\mathrm{VI})$-altered microRNA (miRNA) expression. This study showed $\mathrm{Cr}(\mathrm{VI})$ significantly affected global miRNA expression, a subset of which target homologous recombination genes and RAD51 expression directly. These data advance our understanding of how $\mathrm{Cr}$ interferes with a critical cellular pathway that contributes to carcinogenesis.

We previously reported particulate $\mathrm{Cr}(\mathrm{VI})$ induces structural chromosome instability in leatherback lung cells similarly to data in human lung cells with some differences. In this dissertation we confirmed particulate $\mathrm{Cr}(\mathrm{VI})$ induces DNA double strand breaks in leatherback lung cells. In analysis of DNA repair we found lower levels RAD51 foci after prolonged particulate $\mathrm{Cr}(\mathrm{VI})$ exposure compared to acute exposure in leatherback lung cells. However, the sister chromatid exchange assay showed homologous recombination is functional after prolonged particulate $\mathrm{Cr}(\mathrm{VI})$ exposure. These results are dissimilar to results in human lung cells indicating there are significant differences in the mechanistic response to particulate $\mathrm{Cr}(\mathrm{VI})$ exposure between human and leatherback lung cells. 


\section{TABLE OF CONTENTS}

DEDICATION............................................................................

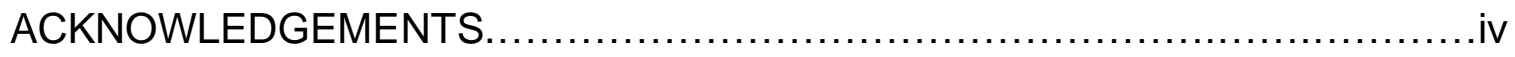



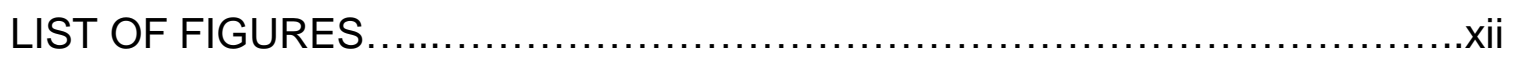

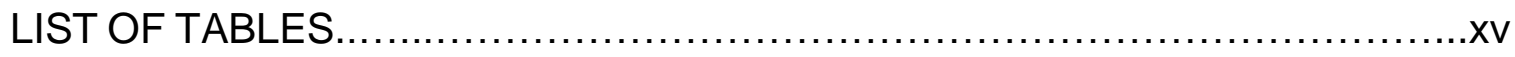

CHAPTER 1: INTRODUCTION.................................................

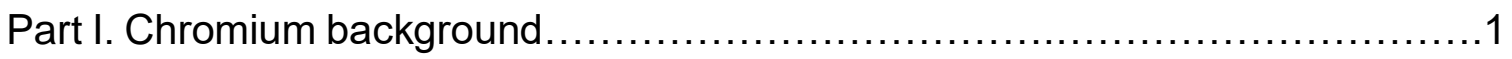

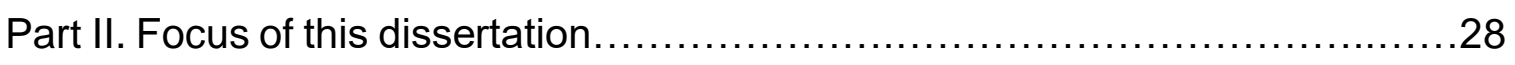

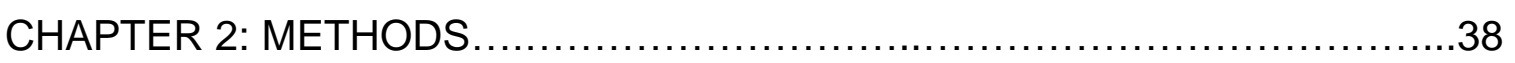

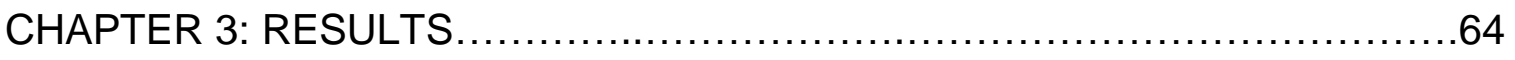

Aim 1: Determine if E2F1 modulates the RAD51 response to particulate $\mathrm{Cr}(\mathrm{VI})$

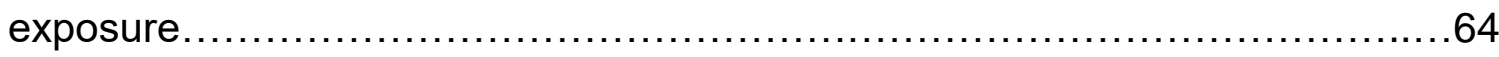

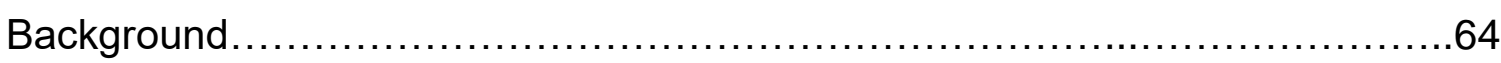

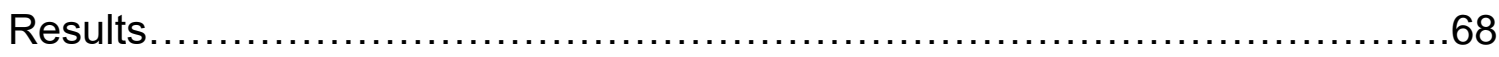

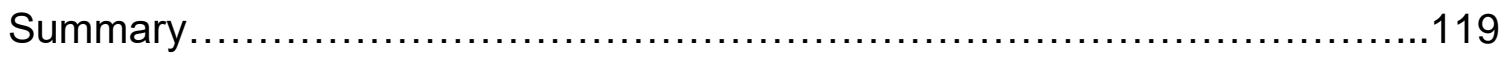

Aim 2: Identify particulate $\mathrm{Cr}(\mathrm{VI})$-altered miRNAs involved in RAD51 regulation and

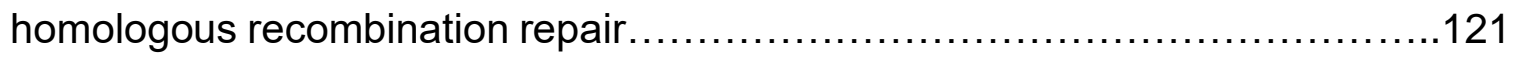

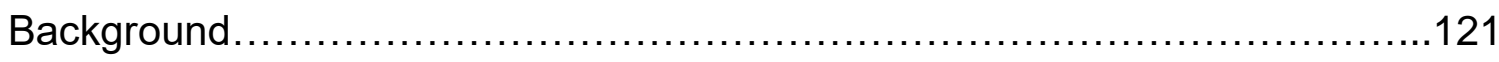

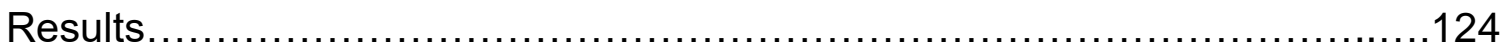


Summary.

Aim 3: Characterize the effects of particulate $\mathrm{Cr}(\mathrm{VI})$ on homologous recombination in leatherback sea turtle lung cells. 177

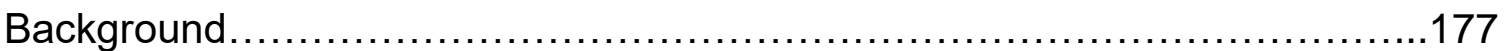





CHAPTER 4: DISCUSSION .....................................................

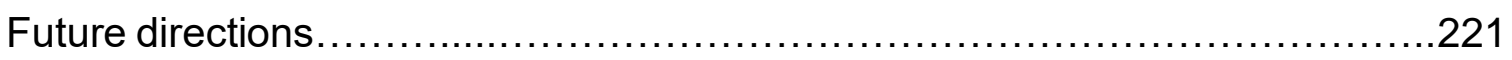

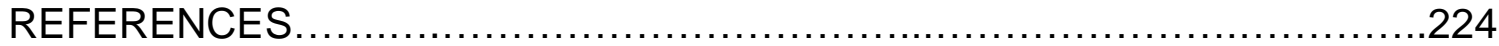



APPENDIX 2: ABBREVIATIONS ..........................................262

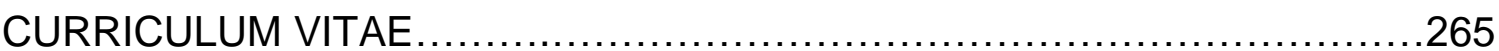




\section{LIST OF FIGURES}

1.1. Mechanisms of intracellular $\mathrm{Cr}(\mathrm{VI})$ reduction..............................18

1.2. Mechanisms of numerical and structural chromosome instability in $\mathrm{Cr}(\mathrm{VI})$ carcinogenesis. .23

2.1. Exposure paradigm for E2F1 overexpression experiments following $120 \mathrm{~h}$

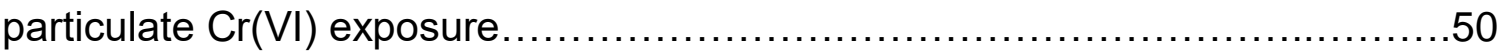

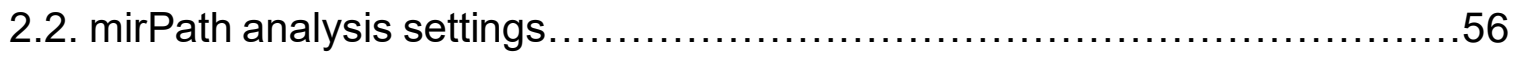

2.3. Exposure paradigm for E2F1 siRNA transfection after $24 \mathrm{~h}$ particulate $\mathrm{Cr}(\mathrm{VI})$

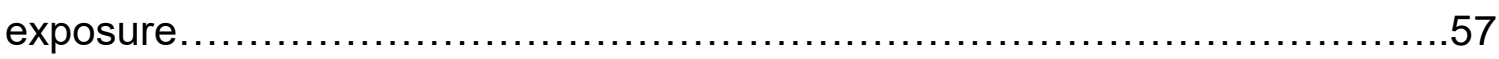

3.1. Working model of the RAD51 promoter...................................66

3.2. Prolonged exposure to particulate $\mathrm{Cr}(\mathrm{VI})$ reduces $\mathrm{RAD} 51$ whole cell protein

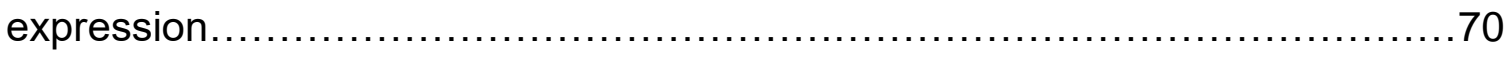

3.3. Particulate $\mathrm{Cr}(\mathrm{VI})$ has little effect on RAD51 protein half-life ..................73

3.4. Particulate $\operatorname{Cr}(\mathrm{VI})$ inhibits RAD51 mRNA. This figure shows after prolonged and $120 \mathrm{~h}$ exposure zinc chromate inhibits RAD51 mRNA levels..................77

3.5. Prolonged particulate $\mathrm{Cr}(\mathrm{VI})$ inhibits $\mathrm{E} 2 \mathrm{~F} 1$ whole cell protein $\ldots \ldots \ldots \ldots \ldots \ldots . . . . . .80$

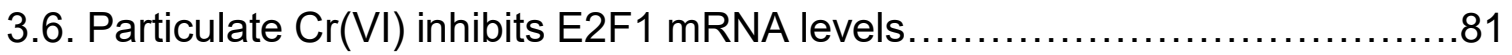

3.7. Transfection with E2F1 overexpression plasmid increases E2F1 whole cell

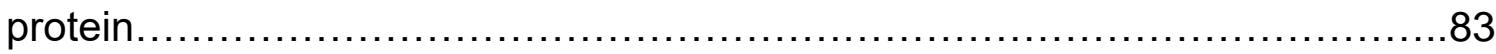

3.8. E2F1 overexpression does not prevent particulate $\mathrm{Cr}(\mathrm{VI})$-induced RAD51 cytoplasmic accumulation 
3.9. Particulate $\operatorname{Cr}(\mathrm{VI})$-inhibited RAD51 nuclear foci is not rescued by E2F1

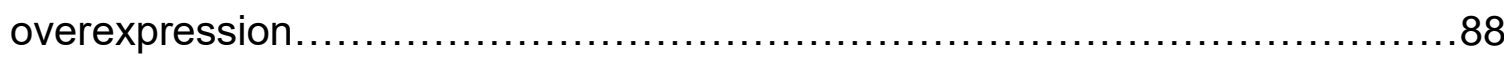

3.10. E2F1 overexpression does not rescue particulate $\mathrm{Cr}(\mathrm{VI})$-inhibited RAD51

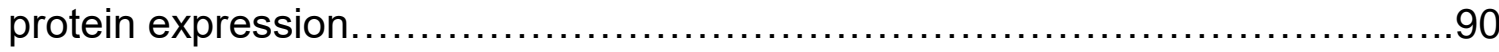

3.11. Knockdown of E2F1 inhibits E2F1 protein levels .........................93

3.12. E2F1 knockdown does not induce RAD51 cytoplasmic accumulation after 24

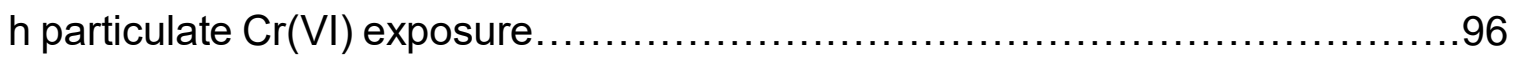

3.13. E2F1 knockdown decreases RAD51 nuclear foci after acute particulate $\mathrm{Cr}(\mathrm{VI})$ exposure. .98

3.14. E2F1 knockdown does not inhibit RAD51 protein after $24 \mathrm{~h}$ particulate $\mathrm{Cr}(\mathrm{VI})$ exposure. 100

3.15. E2F1 knockdown does not consistently RAD51 mRNA expression........103

3.16. Particulate $\mathrm{Cr}(\mathrm{VI})$ does not affect E2F1 nuclear protein levels.............106 3.17. Prolonged particulate $\mathrm{Cr}(\mathrm{VI})$ exposure decreases EGR1 whole cell protein

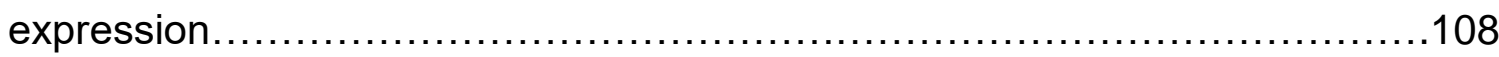

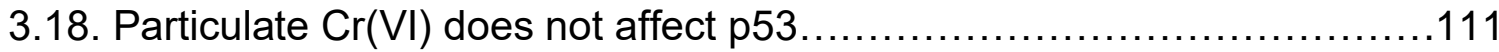

3.19. Particulate $\mathrm{Cr}(\mathrm{VI})$ decreases total and phospho-p130 protein levels......114

3.20. Particulate $\mathrm{Cr}(\mathrm{VI})$ increases the ratio of E2F4 to E2F1 ..................117

3.21. Particulate $\mathrm{Cr}(\mathrm{VI})$ exposure increases global downregulation of miRNAs..127

3.22. Particulate $\mathrm{Cr}(\mathrm{VI})$ alters the expression of miRNAs.

3.23. miRNAs significantly altered by particulate $\mathrm{Cr}(\mathrm{VI})$ with a fold change greater than 2 . 134 3.24. Venn diagrams of up- and down-regulated miRNAs across particulate $\mathrm{Cr}(\mathrm{VI})$ concentrations 137 
3.25. Euclidean hierarchical clustering of miRNAs altered by particulate $\mathrm{Cr}(\mathrm{VI})$

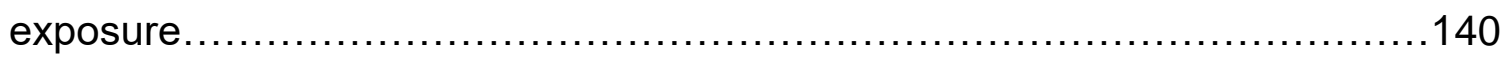

3.26. K-clustering of miRNAs altered by particulate $\mathrm{Cr}(\mathrm{VI})$ exposure...........142 3.27. Comparison of the number of genes targeted by particulate $\mathrm{Cr}(\mathrm{VI})$-up or down-regulated miRNAs in pathways of $\mathrm{Cr}(\mathrm{VI})$ carcinogenesis.................152

3.28. Comparison of the number of particulate $\operatorname{Cr}(\mathrm{VI})$-up or down-regulated miRNAs targeting genes in pathways of $\mathrm{Cr}(\mathrm{VI})$ carcinogenesis................159

3.29. Particulate $\mathrm{Cr}(\mathrm{VI})$ upregulates miRNAs that target RAD51...............167 3.30. Trends in the upregulation of RAD51-targeting miRNAs by particulate $\mathrm{Cr}(\mathrm{VI})$


3.31. Particulate $\operatorname{Cr}(\mathrm{VI})$ does not increase $\mathrm{DNA}$ damage by neutral comet

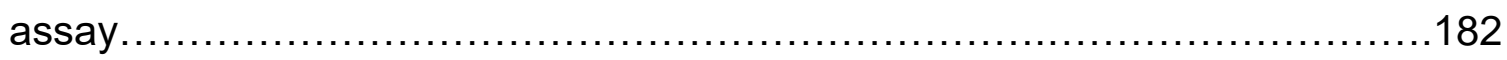

3.32. Particulate $\mathrm{Cr}(\mathrm{VI})$ increases gamma-H2AX foci in leatherback lung cells. 180

3.33. RAD51 nuclear foci increase after acute but not prolonged particulate $\mathrm{Cr}(\mathrm{VI})$

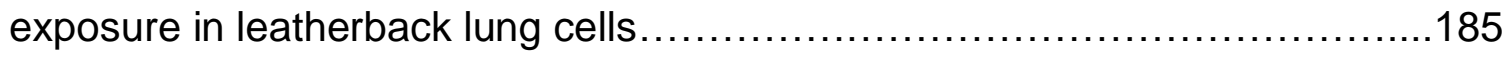

3.34. Particulate $\mathrm{Cr}(\mathrm{VI})$ induces sister chromatid exchanges in leatherback lung cells. 188 


\section{LIST OF TABLES}

1.1. Studies on methods for evaluating $\mathrm{Cr}$ exposure .......................... 10

2.1. Reverse Transcription Conditions .......................................62

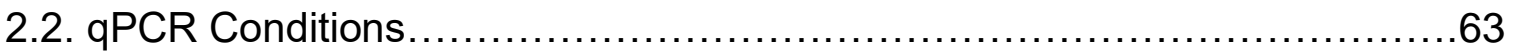

3.1. RAD51 transcriptions factor activity .....................................65

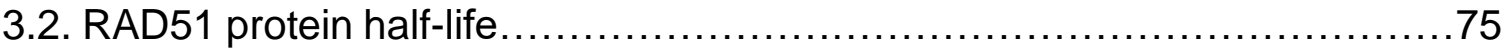

3.3 Distribution of significantly altered miRNAs by particulate $\mathrm{Cr}(\mathrm{VI})$ exposure...125

3.4 Number of significantly up- or down-regulated miRNAs with a fold change greater than 2 after particulate $\mathrm{Cr}(\mathrm{VI})$ exposure............................... 133

3.5. Articles used to populate pathways of $\mathrm{Cr}(\mathrm{VI})$ carcinogenesis................145

3.6. KEGG networks of $\mathrm{Cr}(\mathrm{VI})$ carcinogenesis................................ 147

3.7A. Number of genes targeted by $\mathrm{Cr}(\mathrm{VI})$-upregulated miRNAs in cancer related

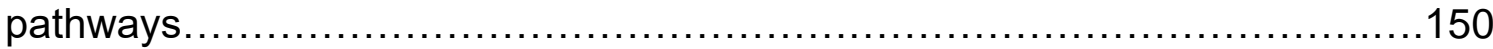

3.7B. Number of $\mathrm{Cr}(\mathrm{VI})$-upreguated miRNAs targeting genes in cancer related



3.8A. Number of genes targeted by $\mathrm{Cr}(\mathrm{VI})$-upregulated miRNAs in signaling pathways. 150

3.8B. Number of $\mathrm{Cr}(\mathrm{VI})$-upregulated miRNAs targeting genes in signaling......151 3.9A. Number of genes targeted by $\mathrm{Cr}(\mathrm{VI})$-upregulated miRNAs in cellular processes pathways 
3.9B. Number of $\mathrm{Cr}(\mathrm{VI})$-upregulated miRNAs targeting genes in cellular processes pathways. 151

3.10A. Number of genes targeted by $\mathrm{Cr}(\mathrm{VI})$-upregulated miRNAs in DNA repair pathways. 152

3.10B. Number of $\mathrm{Cr}(\mathrm{VI})$-upregulated miRNAs targeting genes in DNA repair pathways. 152

3.11. Particulate $\mathrm{Cr}(\mathrm{VI})$-upregulated miRNAs and their targets in the homologous recombination pathway. 165 3.12. RAD51 mRNA binding site information of significantly upregulated miRNAs by particulate $\mathrm{Cr}(\mathrm{VI})$ exposure. 


\section{CHAPTER 1: INTRODUCTION}

\section{Part I: Chromium background}

Metals are associated with both industrial uses and biological processes. Some metals like iron $(\mathrm{Fe})$, copper $(\mathrm{Cu})$ and magnesium $(\mathrm{Mg})$ are essential and have well characterized roles in biology. Other metals such as mercury $(\mathrm{Hg})$ and lead $(\mathrm{Pb})$ have no known biological functions but have been widely used in industry. Chromium $(\mathrm{Cr})$ has extensive commercial uses and used to be considered an essential nutrient (Vincent, 2017). Cr has been used in a diverse range of applications for more than 200 years leading to industrial and societal advancements. The physical and chemical properties of $\mathrm{Cr}$ including its varying degrees of solubility, valence states and bright colors make it a desirable and useful resource. Consequently, the ever increasing and ubiquitous use of $\mathrm{Cr}$ has led to global environmental contamination and associated increased health risks. Negative health risks have been documented and associated with $\mathrm{Cr}$ exposure for well over a century dating back to the 1800s (IARC, 1980; Newman, 1980). However it wasn't until 1980 that $\mathrm{Cr}$ was classified as a human carcinogen, and since then there have been several large assessments that aimed to better identify risk associated with Cr exposure (ATSDR, 2000; ATSDR, 2012; IARC, 1980; IARC, 1990). 


\section{Chemical and physical properties}

$\mathrm{Cr}$ is a transition metal that occurs in the environment from natural and anthropogenic sources. The EPA's Toxics Release Inventory Program reported in $201612,259,441 \mathrm{lbs}$ of $\mathrm{Cr}$ and 50,433,180 lbs of $\mathrm{Cr}$ compounds were released into the environment by anthropogenic means accounting for approximately $90 \%$ of the total release of $\mathrm{Cr}$ in the environment (TRI, 2016). Anthropogenic sources of $\mathrm{Cr}$ consist of the burning of fossil fuels and industrial processes notably the chrome plating industry, electroplating, cement work, leather tanneries and the production of dyes and pigments.

Cr comes in many different forms ranging in solubility and valence state forming compounds with other elements including potassium (K), sodium $(\mathrm{Na}), \mathrm{Pb}$, zinc $(\mathrm{Zn})$, barium $(\mathrm{Ba})$ among others. The valence states of $\mathrm{Cr}$ range from $(-2)$ to (+6) with trivalent $[\mathrm{Cr}(\mathrm{III})]$ and hexavalent $\mathrm{Cr}[\mathrm{CrVI})]$ being the most prevalent and stable valence states (Kotas and Stasicka, 2000). Cr is found in the environment predominantly in the trivalent state. However, the desirable properties of $\mathrm{Cr}$ are associated with $\mathrm{Cr}(\mathrm{VI})$. Therefore, $\mathrm{Cr}(\mathrm{III})$ from the environment is converted into $\mathrm{Cr}(\mathrm{VI})$ compounds through a chemical process using sodium ash to produce soluble sodium chromate (ATSDR, 2012; Barnhart, 1997). Then, sodium chromate is converted to other particulate or soluble chromate compounds. As a result $\mathrm{Cr}(\mathrm{VI})$ in the environment is predominantly anthropogenic and is found in air, water and soil.

Studies show the major form of $\mathrm{Cr}$ in water is hexavalent, in soil is trivalent, and $1 / 3$ of $\mathrm{Cr}$ released into the air is hexavalent (Kotas and Stasicka, 2000; Pettine 
and Millero, 1990). However, the ratio of different valence states of $\mathrm{Cr}$ in the environment vary depending on $\mathrm{pH}$ and the presence of reducing agents (CesponRomero et al., 1996). When considering human health, $\operatorname{Cr}(\mathrm{III})$ and $\operatorname{Cr}(\mathrm{VI})$ are considered to be the physiologically relevant forms due to their stability and widespread exposure to them.

\section{Chromate-worker exposures and regulations}

$\mathrm{Cr}$ is mined from the Earth's crust predominantly in the trivalent form and is then processed into $\mathrm{Cr}(\mathrm{VI})$. Exposure in the $\mathrm{Cr}$ industry begins with the processing where the high temperatures required to convert $\mathrm{Cr}(\mathrm{III})$ to $\mathrm{Cr}(\mathrm{VI})$ create inhalation exposures (IARC, 1990; Langard and Norsheth, 1975). However, exposure to $\mathrm{Cr}(\mathrm{VI})$ extends far beyond this where it is used in many other industrial applications. The United States remains one of the largest chromate producers and users (Papp, 2015). Thus, there are occupational regulations aimed to decrease health risks associated with $\mathrm{Cr}(\mathrm{VI})$ exposure.

The Occupational Safety and Health Administration's (OSHA) permissible exposure level for $\mathrm{Cr}(\mathrm{VI})$ is $5 \mathrm{ug} / \mathrm{m}^{3}$ as an 8-hour time weighted average (OSHA, 2006). OSHA assumes a working lifetime is 45 years. In sum, this evaluation means over the course of a working lifetime a chromate worker would experience $225 \mathrm{ug} / \mathrm{m}^{3}$ work years of exposure. These health standards were last updated in 2006 leaving 14 years of $\mathrm{Cr}(\mathrm{VI})$ research unaccounted for in the OSHA health assessment. It is important to also remember different types of $\mathrm{Cr}(\mathrm{VI})$ occupations have different levels and types of risk of exposure. Additionally, worldwide regulations for $\mathrm{Cr}$ exposure vary widely. There are large $\mathrm{Cr}$ industries in many 
countries like Pakistan and China, which have less regulations than the United States posing significant health risk to $\mathrm{Cr}$ workers. For example, in China total atmospheric $\mathrm{Cr}$ emissions has grown at an average rate of $8.8 \%$ from 1990 to 2009 (Cheng et al., 2014). This growth also creates an elevated worldwide health risk.

Health risks have been associated with $\mathrm{Cr}$ exposure since the early $19^{\text {th }}$ century when a Scottish chrome pigment worker was identified with nasal tumors (Bagchi et al., 1995). Since then, over $80 \mathrm{Cr}$ occupations have arisen leading to extensive occupational exposure (IARC, 1990). Accordingly, there have been many epidemiology studies indicating high incidences of cancers associated with chromate workers (Davies, 1984; Davies et al., 1991; Gibb et al., 2015; Gibb et al., 2000; Langard and Vigander, 1983; Machle and Gregorius, 1948; Mancuso and Hueper, 1951). It is important to note these studies include only male subjects, which is a factor of societal limitations as men were and still are the primary employees of the chromate industry.

\section{Methods for evaluating Cr exposure}

Assessing $\mathrm{Cr}$ exposure in chromate workers can be challenging, however there have been many studies investigating the different methods used for these analyses (Table 1.1). There are currently several methods to track $\mathrm{Cr}$ exposure in workers including assessing exhaled breath condensate and measuring $\mathrm{Cr}$ in red blood cells, plasma, and urine. However, each of these methods has limitations and we will discuss these limitations with each method. In general, it can be difficult to compare between studies that evaluate $\mathrm{Cr}$ exposure due to the lack of detail in the study methods used. For instance, the length of time workers used ventilation 
masks throughout the day may not be reported or specific details on the collection methods may be vague.

Exhaled breath condensate has been used to assess $\mathrm{Cr}$ speciation in chromate workers and to assess biomarkers that might be used in exposure assessments. Goldoni et al., 2006 aimed to evaluate soluble $\mathrm{Cr}(\mathrm{VI})$ in exhaled breath condensate from chromate workers and in environmental air (Goldoni et al., 2006). Previous studies suggest $\mathrm{Cr}(\mathrm{VI})$ could be reduced to $\mathrm{Cr}(\mathrm{III})$ in the respiratory tract extracellularly, but a $\mathrm{Cr}(\mathrm{VI}) / \mathrm{Cr}(\mathrm{III})$ equilibrium was not determined (Caglieri et al., 2005; De Flora et al., 1996; Petrilli et al., 1986). Therefore, this study aimed to determine if $\mathrm{Cr}(\mathrm{VI})$ persists in the lung. They found $15 \mathrm{~h}$ post workplace exposure $\mathrm{Cr}(\mathrm{VI})$ was detectable in the exhaled breath condensate of chromate workers indicating $\mathrm{Cr}(\mathrm{VI})$ does persist in the lung.

Studies evaluating $\mathrm{Cr}$ speciation in exhaled breath condensate are limited in their ability to stabilize $\mathrm{Cr}$ in its different valence states and the sensitivity of the analysis. Leese et al., 2016 aimed at establishing methodologies to improve this type of exposure assessment and implemented their methods in a 2017 study evaluating exhaled breath condensate in chromate and non-chromate workers (Leese et al., 2016). They measured the differences in $\mathrm{Cr}(\mathrm{VI})$ in exhaled breath condensate at the beginning of the workweek (Monday morning) and again at the end of the workweek (Thursday afternoon) and found chromate workers had a significant increase of $\mathrm{Cr}(\mathrm{VI})$ and $\mathrm{Cr}(\mathrm{III})$ in their exhaled breath condensate compared to non-chromate workers (Leese et al., 2017). While measuring $\operatorname{Cr}(\mathrm{VI})$ 
in exhaled breath condensate has been successful, it still has experimental hurdles to overcome and is best used in conjunction with other monitoring methods.

Another method for monitoring $\mathrm{Cr}(\mathrm{VI})$ exposure is by measuring $\mathrm{Cr}$ concentrations in red blood cells. $\mathrm{Cr}$ in red blood cells is representative of $\mathrm{Cr}$ that reaches the bloodstream in the hexavalent state whereas measuring $\mathrm{Cr}$ in plasma represents $\mathrm{Cr}$ that reached the blood stream in the reduced state, $\mathrm{Cr}$ (III) (Goldoni et al., 2010). Devoy et al., 2016 evaluated the selectivity of red blood cells accumulating $\mathrm{Cr}$ after $\mathrm{Cr}(\mathrm{VI})$ exposure using whole blood samples (Devoy et al., 2016). They found $\mathrm{Cr}$ levels in red blood cells are a good candidate to indicate internal dosing from a recent exposure of approximately 8-10 weeks. However, this study used an in vitro system and was limited by its applicability of exposure periods. Minoia and Cavalleri, 1988 compared Cr levels in red blood cells between individuals who worked primarily with $\mathrm{Cr}(\mathrm{VI})$ and workers who worked primarily with $\mathrm{Cr}$ (III) compounds (Minoia and Cavalleri, 1988). They found $\mathrm{Cr}$ red blood cell and plasma concentrations were significantly higher in $\mathrm{Cr}(\mathrm{VI})$ workers whereas only plasma $\mathrm{Cr}$ concentrations increased in $\mathrm{Cr}$ (III) workers. This outcome confirms $\mathrm{Cr}(\mathrm{VI})$ can reach the bloodstream, $\mathrm{Cr}(\mathrm{VI})$ readily enters cells while $\mathrm{Cr}(\mathrm{III})$ does not and red blood cells can be used to monitor $\mathrm{Cr}(\mathrm{VI})$ exposure.

Perhaps, the most widely used method to evaluate $\mathrm{Cr}$ exposure has been monitoring urine $\mathrm{Cr}$ levels. Unexposed reference ranges have been evaluated by several studies to find a range of 0.24 to $1.8 \mathrm{ug} / \mathrm{L}$ (OSHA, 2006). However humans exposed to 0.01 to $0.1 \mathrm{mg} / \mathrm{m}^{3} \mathrm{Cr}(\mathrm{VI})$ for an 8-hour time-weighted average had urinary excretion levels from 24.7 to $37 \mathrm{mg} / \mathrm{L} \mathrm{Cr}$ (OSHA, 2006). Tola et al., 1977 
found measuring $\mathrm{Cr}$ in the urine was an accurate predictor of short-term exposure to soluble $\mathrm{Cr}$ (Tola et al., 1977). Several other studies have evaluated $\mathrm{Cr}$ levels in urine over the years showing elevated levels in chromate industry workers (Pesch et al., 2018; Saner et al., 1984; Stridsklev et al., 2004). The type of chromate work has been shown to influence post-exposure levels of $\mathrm{Cr}$ in the urine as described by Lindberg and Vesterberg, 1989 (Lindberg and Vesterberg, 1989). They found reported urinary $\mathrm{Cr}$ levels did not decrease in chrome platers to the same extent as other studies urinary levels decrease in welders of Cr-alloyed stainless steel (Tossavainen et al., 1980). This result further highlights differences between occupational exposures. Despite widespread use of monitoring $\mathrm{Cr}$ exposure by $\mathrm{Cr}$ urine levels it has its limitations including it is relatively unreliable for chronic exposure measurements and it cannot be used to discern between $\operatorname{Cr}(I I I)$ and $\mathrm{Cr}(\mathrm{VI})$ exposure.

\section{Non chromate-worker exposures}

$\mathrm{Cr}(\mathrm{VI})$ is ubiquitous in the environment due to its widespread use and the lack of regulations concerning $\operatorname{Cr}(\mathrm{VI})$ waste and air pollution for many decades after the industrial revolution began. Today, $\mathrm{Cr}(\mathrm{VI})$ is continually released in to the environment through the burning of fossil fuels and regulated release from many different industrial sources (IARC, 1990). Regulation of $\mathrm{Cr}(\mathrm{VI})$ waste in some countries is not as strict as it is in the United States further increasing the risk of exposure.

Studies show $\mathrm{Cr}$ released into the atmosphere can travel through air currents and around the world. Urban and rural areas in the United States have 
been monitored for $\mathrm{Cr}$ levels in ambient air and found to range from 0.001 to 0.1 $\mathrm{ug} / \mathrm{m}^{3}$. Levels of $\mathrm{Cr}$ taken over the Atlantic have ranged from 0.007 to $1.1 \mathrm{ng} / \mathrm{m}^{3}$, in Hawaii were measured to be $67 \mathrm{ug} / \mathrm{m}^{3}$ and in the Baltimore harbor $226 \mathrm{ug} / \mathrm{m}^{3}$ (Bowen, 1979; Fishbein, 1976; IARC, 1990). Additionally, Cr travels through groundwater and is found throughout the world's oceans (Fishbein, 1976). $\operatorname{Cr}(\mathrm{VI})$ has been shown to be the predominant form of $\mathrm{Cr}$ in sea water (Pettine and Millero, 1990). Further, many studies in urban areas have assessed $\operatorname{Cr}(\mathrm{VI})$ in air considering the proximity of factories that use $\mathrm{Cr}(\mathrm{VI})$ and indicate elevated levels of $\mathrm{Cr}(\mathrm{VI})$ in these areas (Khlystov and $\mathrm{Ma}, 2006)$. Nonetheless, $\mathrm{Cr}(\mathrm{VI})$ is also found far removed from industry-heavy regions where air pollution is expected to be relatively low (Rowbotham et al., 2000). A recent study in Korea found particulate lead chromate is a specific source of atmospheric $\operatorname{Cr}(\mathrm{VI})$ pollution due to its widespread use in traffic paint and other applications, and the use of lead chromate was a specific source of concern for public health (Lee et al., 2006). These studies confirm $\mathrm{Cr}(\mathrm{VI})$ is ubiquitous in the environment and exposure to it is widespread and can contribute to co-exposures.

The environmental contamination of $\mathrm{Cr}(\mathrm{VI})$ raises concern of exposure to non-chromate workers and as such there is an urgent need to investigate the effects of low, long term exposures. Currently, many low-dose, long-term $\mathrm{Cr}(\mathrm{VI})$ studies focus on $\mathrm{Cr}(\mathrm{VI})$ in drinking water. However, inhalation is considered to be primary route of $\mathrm{Cr}(\mathrm{VI})$ exposure. Few studies have measured the effects of $\mathrm{Cr}(\mathrm{VI})$ in non-chromate workers. However, Hwang et al., 2017 measured $\mathrm{Cr}$ in the blood of individuals who lived near a cement plant in Korea where $\mathrm{Cr}$ is used and found 
their mean Cr levels to be $3.8 \mathrm{ug} / \mathrm{L}$ which is above estimated levels in other studies which range from $0.12 \mathrm{ug} / \mathrm{L}$ to $2.37 \mathrm{ug} / \mathrm{L}$ (Hwang et al., 2017; Kim, 2004; Nisse et al., 2017). Nonetheless, much more research needs to be done evaluating the risks of $\mathrm{Cr}(\mathrm{VI})$ exposure in the general population. 
Table 1.1. Studies on Methods for Evaluating Cr Exposures

\begin{tabular}{|c|c|c|c|}
\hline $\begin{array}{c}\text { Study } \\
\text { Population }\end{array}$ & Methodology & Study Findings & Reference \\
\hline $\begin{array}{l}24 \text { chrome- } \\
\text { plating workers }\end{array}$ & $\begin{array}{l}\text { Exhaled breath } \\
\text { condensate collected } \\
\text { before and after a } \\
\text { Friday work shift and } \\
\text { before the work shift } \\
\text { the following Monday. }\end{array}$ & $\begin{array}{l}\text { Cr- exhaled breath condensate } \\
\text { levels increased from before } \\
\text { shift to after shift ( } 5.3 \mathrm{ug} / \mathrm{L} \text { to } 6.4 \\
\text { ug/L) on Friday but were } \\
\text { considerably lower the following } \\
\text { Monday morning ( } 2.8 \mathrm{ug} / \mathrm{L}) .\end{array}$ & $\begin{array}{l}\text { Caglieri et } \\
\text { al., } 2006\end{array}$ \\
\hline $\begin{array}{l}\text { Human whole } \\
\text { blood samples }\end{array}$ & $\begin{array}{l}\text { Whole blood was } \\
\text { incubated with } \mathrm{Cr}(\mathrm{VI}) \\
\text { or } \mathrm{Cr}(\mathrm{III}) \text { then } \mathrm{Cr} \text { was } \\
\text { measured in red blood } \\
\text { cells. }\end{array}$ & $\begin{array}{l}\mathrm{Cr}(\mathrm{VI}) \text { but not } \mathrm{Cr}(\mathrm{III}) \\
\text { accumulated in red blood cells } \\
\text { and there was a strong } \\
\text { correlation between } \mathrm{Cr}(\mathrm{VI}) \\
\text { added to a blood sample the red } \\
\text { blood cell-Cr levels. }\end{array}$ & $\begin{array}{l}\text { Devoy et } \\
\text { al., } 2016\end{array}$ \\
\hline $\begin{array}{l}10 \text { chromate } \\
\text { plating workers }\end{array}$ & $\begin{array}{l}\text { Exhaled breath } \\
\text { condensate collected } \\
\text { immediately post-shift } \\
\text { and } 15 \text { h later. }\end{array}$ & $\begin{array}{l}\mathrm{Cr}(\mathrm{VI}) \text { was reduced by } 50 \% \text { in } \\
\text { airway lining fluid at the end of } \\
\text { exposure and there was a } \\
\text { further } 50 \% \text { reduction after } \\
\text { about } 15 \mathrm{~h} \text {. }\end{array}$ & $\begin{array}{l}\text { Goldoni et } \\
\text { al., } 2006\end{array}$ \\
\hline $\begin{array}{l}14 \text { non-smoking } \\
\text { male chrome } \\
\text { plating workers } \\
\text { exposed to } \\
\text { Cr(VI) }\end{array}$ & $\begin{array}{l}\text { Exhaled breath } \\
\text { condensate and urine } \\
\text { were collected at the } \\
\text { beginning and end of } \\
\text { working shifts. }\end{array}$ & $\begin{array}{l}\text { Urine-Cr correlated with plasma- } \\
\mathrm{Cr} \text { at the end of the working } \\
\text { shift, red blood cell-Cr correlated } \\
\text { with exhaled breath condensate } \\
\text {-Cr at the beginning of the shift. }\end{array}$ & $\begin{array}{l}\text { Goldoni et } \\
\text { al., } 2010\end{array}$ \\
\hline $\begin{array}{l}58 \text { workers } \\
\text { occupationally } \\
\text { exposed to } \\
\mathrm{Cr}(\mathrm{VI}) \\
\text { compounds and } \\
22 \text { unexposed } \\
\text { controls }\end{array}$ & $\begin{array}{l}\text { Urine and Exhaled } \\
\text { breath condensate } \\
\text { samples were } \\
\text { collected at the start } \\
\text { of a shift Monday } \\
\text { morning (pre-work } \\
\text { week) and on } \\
\text { Thursday afternoon } \\
\text { (post-work week). }\end{array}$ & $\begin{array}{l}\text { Exhaled breath condensate from } \\
\text { workers has higher levels of } \\
\mathrm{Cr}(\mathrm{III}) \text { and } \mathrm{Cr}(\mathrm{VI}) \text { than the } \\
\text { control group and higher levels } \\
\text { of total Cr in their urine. There } \\
\text { was no significant difference } \\
\text { between pre- and post-work } \\
\text { week exhaled breath } \\
\text { condensate samples for } \mathrm{Cr}(\mathrm{III}) \\
\text { or } \mathrm{Cr}(\mathrm{VI}) \text {. }\end{array}$ & $\begin{array}{l}\text { Leese et } \\
\text { al., } 2017\end{array}$ \\
\hline $\begin{array}{l}10 \text { chrome } \\
\text { platers over a } \\
\text { weekend and } 23 \\
\text { chrome platers } \\
\text { over } 31 \text { days of } \\
\text { vacation }\end{array}$ & $\begin{array}{l}\text { Urine was collected in } \\
\text { the weekend group } \\
\text { and from the last } \\
\text { working day before } \\
\text { vacation and on the } \\
\text { first working day after } \\
\text { vacation in the } \\
\text { vacation group. }\end{array}$ & $\begin{array}{l}\text { Urine-Cr was }>0.5 \mathrm{ug} / \mathrm{L} \text { in all } \\
\text { individuals. The half-time of } \mathrm{Cr} \text { in } \\
\text { the weekend group was } 65 \mathrm{~h} \text {. } \\
\text { Urine-Cr in the vacation group } \\
\text { decreased from } 4.2 \mathrm{ug} / \mathrm{L} \text { at the } \\
\text { beginning of exposure break to } \\
1.0 \mathrm{ug} / \text { liter at the end of the } \\
\text { break. }\end{array}$ & $\begin{array}{l}\text { Lindberg } \\
\text { and } \\
\text { Vesterberg, } \\
1989\end{array}$ \\
\hline $\begin{array}{l}\text { Fifty male steel } \\
\text { welders from } 14 \\
\text { companies }\end{array}$ & $\begin{array}{l}\text { Respirable welding } \\
\text { fume was collected in } \\
\text { the breathing zone of } \\
\text { the welders during a } \\
\text { working shift and urine }\end{array}$ & $\begin{array}{l}\mathrm{Cr} \text { content in pre-shift urine was } \\
\text { a stronger determinant than } \\
\text { airborne shift exposure when } \\
\text { correlating with post-shift urinary } \\
\mathrm{Cr} \text {. The proportion of } \mathrm{Cr}(\mathrm{VI}) \text { in }\end{array}$ & $\begin{array}{l}\text { Pesch et } \\
\text { al., } 2018\end{array}$ \\
\hline
\end{tabular}




\begin{tabular}{|c|c|c|c|}
\hline & $\begin{array}{l}\text { samples were } \\
\text { collected before and } \\
\text { after the work shift. }\end{array}$ & $\begin{array}{l}\text { total Cr varied considerably in } \\
\text { the welding fumes collected. }\end{array}$ & \\
\hline $\begin{array}{l}12 \text { normal } \\
\text { adults; } \\
34 \text { male tannery } \\
\text { workers }\end{array}$ & $\begin{array}{l}\text { Hair samples were } \\
\text { taken from the } \\
\text { suboccipital area of } \\
\text { the head. } 24 \mathrm{~h} \text { urine } \\
\text { samples were } \\
\text { obtained }\end{array}$ & $\begin{array}{l}\text { Compared with normal adult } \\
\text { values, urine-Cr concentration, } \\
\mathrm{Cr} / \mathrm{Creatinine} \text { ratio, daily } \mathrm{Cr} \\
\text { excretion, and hair-Cr were } \\
\text { significantly higher in } \mathrm{Cr} \\
\text { workers. }\end{array}$ & $\begin{array}{l}\text { Saner et } \\
\text { al., } 1984\end{array}$ \\
\hline $\begin{array}{l}7 \text { welders } \\
\text { monitored up to } \\
1 \text { week }\end{array}$ & $\begin{array}{l}\text { Whole-day air } \\
\text { measurements, Blood } \\
\text { was collected pre- and } \\
\text { post-work Monday, } \\
\text { Wednesday and } \\
\text { Friday. Urine was } \\
\text { collected } 3 \text { times } \\
\text { daily. }\end{array}$ & $\begin{array}{l}\text { Air concentrations had a mean } \\
\text { of } 200 \mathrm{ug} / \mathrm{m}^{3} \text { total } \mathrm{Cr} \text { and } 11.3 \\
\mathrm{ug} / \mathrm{m}^{3} \mathrm{Cr}(\mathrm{VI}) \text {. Mean levels of } \mathrm{Cr} \\
\text { after work in whole blood, } \\
\text { plasma and erythrocytes were } \\
1.25 \text {, and } 1.68 \text { and } 0.9 \mathrm{ug} / \mathrm{L} \text {, } \\
\text { respectively. The mean level for } \\
\mathrm{Cr} \text { in urine after work was } 3.96 \\
\mathrm{ug} / \mathrm{g} \text { creatinine. }\end{array}$ & $\begin{array}{l}\text { Stridsklev } \\
\text { et al., } 2004\end{array}$ \\
\hline $\begin{array}{l}6 \text { high alloy } \mathrm{Cr}- \\
\text { Ni steel welders }\end{array}$ & $\begin{array}{l}\text { Air was collected each } \\
\text { day in the morning } \\
\text { and afternoon ( } 5 \\
\text { days). Urine samples } \\
\text { were collected } 3 \text { times } \\
\text { per day ( } 5 \text { days). } \\
\text { Blood was collected } 2 \\
\text { days. }\end{array}$ & $\begin{array}{l}\text { The proportion of } \mathrm{Cr}(\mathrm{VI}) \text { in the } \\
\text { air was higher than } 50 \% \text { of total } \\
\mathrm{Cr} \text { during welding with coated } \\
\text { electrodes and less than } 10 \% \\
\text { produced during metal-inert gas } \\
\text { welding was } \mathrm{Cr}(\mathrm{VI}) \text {. Cr in urine } \\
\text { correlated with air exposures. }\end{array}$ & $\begin{array}{l}\text { Tola et al., } \\
1977\end{array}$ \\
\hline
\end{tabular}




\section{$\mathrm{Cr}(\mathrm{VI})$ and respiratory cancer}

The lung is considered to be a primary target of $\mathrm{Cr}(\mathrm{VI})$ carcinogenesis and there are many studies supporting the carcinogenic risks associated with inhalation of $\mathrm{Cr}(\mathrm{VI})$. In 1948 an epidemiology study evaluating chromate workers found $21.8 \%$ of chromate worker deaths were attributed to respiratory cancers; 16 times higher than expected in the control population (Machle and Gregorius, 1948). Since then numerous epidemiology studies on chromate workers have shown increased incidences of respiratory cancers associated with $\mathrm{Cr}(\mathrm{VI})$ exposure (Davies, 1984; Davies et al., 1991; Gibb et al., 2015; Gibb et al., 2000; Languard and Vigander, 1983). While many of these studies specifically found lung cancer to be the carcinogenic endpoint, some studies also revealed an increased risk for nasal and sinus cancers (ATSDR, 2012).

It is well known the solubility of $\mathrm{Cr}(\mathrm{VI})$ plays a role in the carcinogenic potential of chromate compounds. The less soluble forms persist in the lung leading to lung cancers and are believed to be the more potent form of $\mathrm{Cr}(\mathrm{VI})$ (Ishikawa et al., 1994a; Ishikawa et al., 1994b). There have been few epidemiology studies that have been able to target a specific chromate compound due to the complexity of occupational exposures. However, a factory that worked specifically with zinc chromate pigments found an increased incidence of chromate tumors in its workers (Langard and Vigander, 1983). Further, a zinc chromate production factory where workers were exposed to sodium chromate (a raw material to produce zinc chromate) and zinc chromate found an increase in the incidence of bronchial carcinomas (Langard and Norseth, 1975). These epidemiology studies 
support $\mathrm{Cr}(\mathrm{VI})$-induced lung cancer and are further supported by animal models and cell culture studies.

Inhalation and intratracheal deposition studies in mice and rats have confirmed the carcinogenicity of $\mathrm{Cr}(\mathrm{VI})$ in the lung (Levy and Vennitt, 1986; Takahashi et al., 2005; Toya et al., 1999). Levy and Venitt, 1986 found only particulate and not soluble $\mathrm{Cr}(\mathrm{VI})$ intrabronchial implantation increased tumors in rats (Levy et al., 1986). Cell culture studies further confirm the carcinogenicity of particulate and soluble $\mathrm{Cr}(\mathrm{VI})$. Wise et al., 2002 and Wise et al., 2006a found particulate lead chromate was more cytotoxic and genotoxic to human lung cells than soluble sodium chromate. Similarly, lead chromate induced neoplastic transformation of $\mathrm{C} 3 \mathrm{H} 10 \mathrm{~T} 1 / 2$ mouse embryo cells while soluble calcium chromate did not further supporting the conclusion less soluble chromate compounds are more carcinogenic (Patierno et al., 1988). More recently lung epithelial BEAS-2B cells have been shown to be transformed with $\mathrm{Cr}(\mathrm{VI})$ compounds in several studies (Azad et al., 2010; Park et al., 2016; Sun et al., 2011; Wise et al., 2006a). These studies indicate $\mathrm{Cr}(\mathrm{VI})$ has carcinogenic potential, but further insight into mechanistic information is ongoing.

To date most studies have assessed $\mathrm{Cr}(\mathrm{VI})$ carcinogenicity using soluble chromate compounds despite the evidence that the particulate form is more carcinogenic creating a clear information gap. Therefore, $\mathrm{Cr}(\mathrm{VI})$ research requires the expansion of studies using particulate forms of $\mathrm{Cr}(\mathrm{VI})$ in addition to including more mechanistic data concerning $\mathrm{Cr}(\mathrm{VI})$ carcinogenesis. Other data gaps lie in investigating respiratory cancers associated with exposures to substances that 
contain $\mathrm{Cr}(\mathrm{VI})$. While the studies above directly evaluated $\mathrm{Cr}(\mathrm{VI})$ compounds, other types of studies involving welding fumes that are known to contain $\mathrm{Cr}(\mathrm{VI})$ as a primary component have also been evaluated. A recent study investigated metal arc-stainless steel welding fume found increased lung tumorigenesis in $A / J$ mice (Falcone et al., 2017). The welding fume in this study was collected from the actual welding process characterized to predominantly contain metal-rich particulate matter of which a main constituent is $\mathrm{Cr}(\mathrm{VI})$. Further, this exposure closely models exposures that chromate workers in stainless steel welding may experience. These data have been valuable in the risk assessment for $\mathrm{Cr}(\mathrm{VI})$. However, risk assessment has more recently been requiring mechanistic data to better understand risk.

\section{Mechanisms of $\mathrm{Cr}(\mathrm{VI})$ carcinogenesis}

Investigation into the mechanisms underlying $\mathrm{Cr}(\mathrm{VI})$ carcinogenesis have been ongoing for decades. However, due to the complexities of carcinogenesis and the dynamisms of $\mathrm{Cr}$ inside cells much remains to be understood about the overall mechanism and its details. While some of the processes of $\mathrm{Cr}(\mathrm{VI})$ carcinogenesis align with well understood mechanisms of carcinogenesis, others are specific to metals and others unique interactions between $\mathrm{Cr}$ and cellular components. There are three drivers of carcinogenesis that are well accepted among researchers: mutations, epigenetic changes, and genomic instability. There is scientific evidence that the key drivers of $\mathrm{Cr}(\mathrm{VI})$ carcinogenesis most likely are epigenetic changes and genomic instability. $\mathrm{Cr}(\mathrm{VI})$ is known to be a weak mutagen and does not induce mutations in key tumor suppressor or oncogenes suggesting 
mutations are not a strong driver of $\mathrm{Cr}(\mathrm{VI})$ carcinogenesis (Ewis et al., 2001; Holmes, et al., 2008; Kondo et al., 1997; Wise, 2012). We will discuss key features that have been investigated in these drivers of carcinogenesis and the events that lead to their development. Additionally, we will briefly consider malignant cell transformation and second stage carcinogenesis that are hypothesized to contribute to the progression of $\mathrm{Cr}(\mathrm{VI})$-induced tumors.

\section{Physical-chemical mechanisms}

The specific valence states of $\mathrm{Cr}$ play a significant role in the toxicity of $\mathrm{Cr}$ compounds. First, consideration is given to the exposure route of $\mathrm{Cr}(\mathrm{VI}) . \mathrm{Cr}(\mathrm{VI})$ can enter the body through ingestion, dermal absorption and inhalation. If ingested $\mathrm{Cr}(\mathrm{VI})$ is largely reduced in the gut to $\mathrm{Cr}(\mathrm{III})$, which is poorly absorbed through the mucosal membranes and poses little health risk (De Flora et al., 1997; Donaldson, 1966). However, this topic is controversial. Dermal absorption and inhalation of $\mathrm{Cr}(\mathrm{VI})$ both result in the internalization and cellular exposure to $\mathrm{Cr}(\mathrm{VI})$.

Studies show $\mathrm{Cr}(\mathrm{VI})$ compounds dissolve extracellularly and the chromate oxyanion enters cells using anion transport channels (Wise et al., 1993; Xie et al., 2004). Once inside the cell $\mathrm{Cr}(\mathrm{VI})$ is rapidly reduced to $\mathrm{Cr}(\mathrm{III})$ by Nicotinamide adenine dinucleotide phosphate (NAPDH), ascorbate, glutathione (GSH), and thiol groups on cysteine (Figure 1.1) (Quievryn et al., 2003, Quievryn et al., 2006; Cai et al., 2012, Zhitkovich et al., 2002). If $\mathrm{Cr}(\mathrm{VI})$ is reduced by ascorbate the $\operatorname{Cr}(\mathrm{V})$ intermediate is not formed and only $\mathrm{Cr}(\mathrm{IV})$ forms as an intermediate. However, other reducing agents result in both $\mathrm{Cr}(\mathrm{V})$ and $\mathrm{Cr}(\mathrm{IV})$ intermediates. The reduction process results in the release of reactive oxygen species that can cause oxidative 
damage to critical molecules in the cell including DNA, RNA, protein, and lipids (Leonard et al., 2004; Wang et al., 2011). It is widely accepted that the reduction process is a key process in $\mathrm{Cr}(\mathrm{VI})$ carcinogenesis. However, if a chromate particle enters the cell through phagocytosis there appears to be no toxic effect and no apparent effect of the cation (Xie et al., 2004).

There have been considerable studies into whether and how $\mathrm{Cr}$ (in any valence state) can interact or bind with the major constituents of the body (i.e. lipids, proteins, and nucleic acids) resulting in damage. For example, several in vitro studies where DNA molecules are combined with $\mathrm{Cr}$ in test tubes show $\mathrm{Cr}$ (III) and $\operatorname{Cr}(\mathrm{V})$ can bind to DNA molecules (Standeven et al., 1992; Stearns et al., 1995). However, cell model systems and in vivo studies are less clear. This ambiguity is due to the difficultly in measuring the $\mathrm{Cr}$ intermediates as they are short lived and assays to measure them are insensitive.

Several studies showed $\mathrm{Cr}$ can bind to DNA directly altering its conformation or in the event of DNA replication lead to a DNA breaks (Borges et al., 1991; Cupo and Wetterhahn, 1985; Madhusudanan et al., 1999; Tsapakos et al., 1983; Standeven et al., 1992; Zhitkovich et al., 1996). Studies on the binding of $\mathrm{Cr}$ with DNA reveal there are inconsistencies in the binding mechanism and exactly where $\mathrm{Cr}$ can bind is uncertain. Recently, Zhou et al., 2016 sought to investigate the binding of $\mathrm{Cr}(\mathrm{III})$ with both the phosphate backbone of DNA and the nucleobases. They found $\operatorname{Cr}(I I I)$ could weakly bind to the DNA phosphate backbone in a reversible interaction likely through electrostatic forces. However, $\mathrm{Cr}$ (III) also interacted with nucleobases forming stable cross-links. It is important 
to note when neutral or high $\mathrm{pH}$ was restored in these experiments $\mathrm{Cr}$ (III) gradually lost its binding ability likely due to hydrolysis. This study reveals some binding kinetics about $\mathrm{Cr}$ to DNA, but whether it is physiologically relevant remains elusive. There has been little other research into the direct interaction of $\mathrm{Cr}$ with cellular molecules, and this part of the $\mathrm{Cr}(\mathrm{VI})$ carcinogenesis mechanism remains uncertain. 


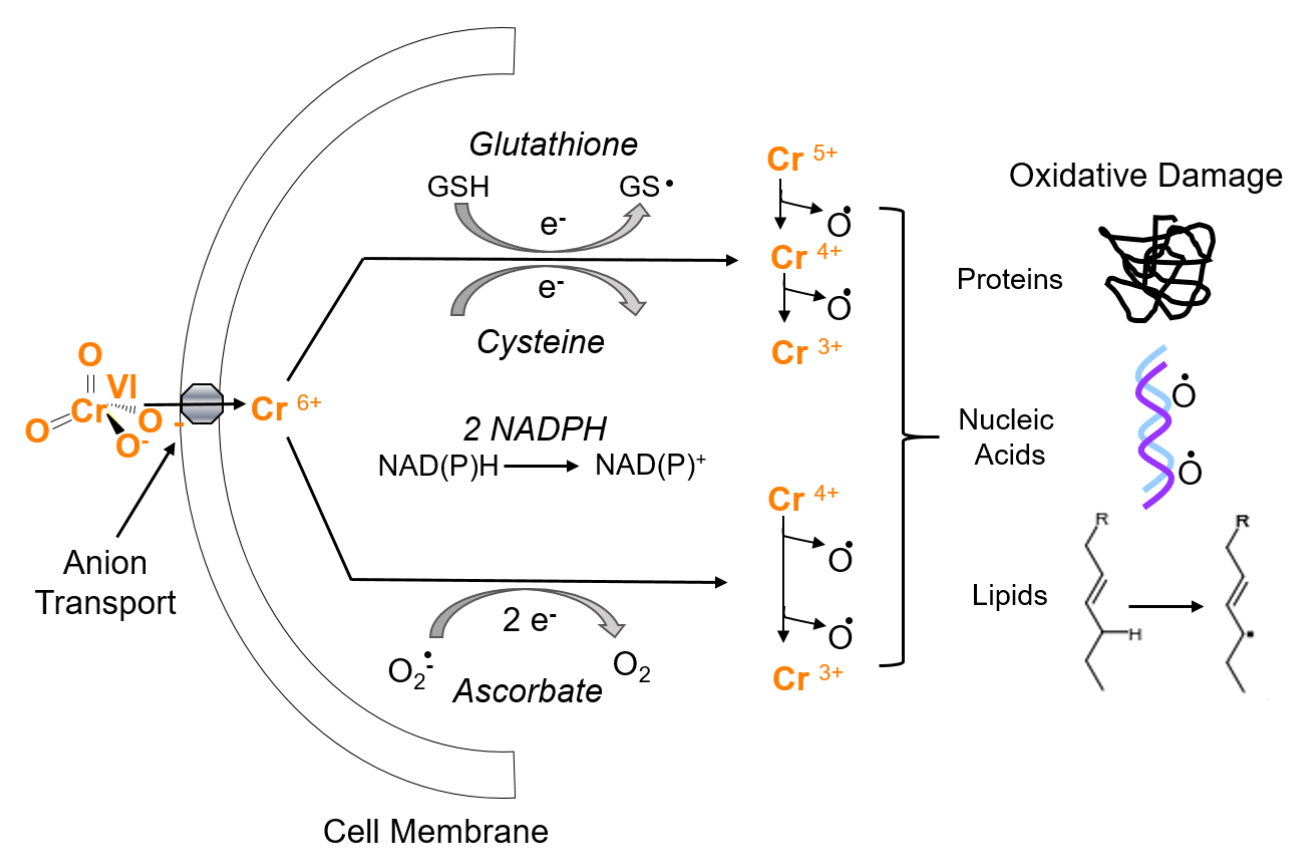

Figure 1.1. Mechanisms of intracellular $\mathrm{Cr}(\mathrm{VI})$ reduction. This figure shows the mechanisms by which $\mathrm{Cr}(\mathrm{VI})$ is reduced to $\mathrm{Cr}(\mathrm{III})$ inside the cell. Glutathione can reduce $\mathrm{Cr}(\mathrm{VI})$ in a one- or two-electron reaction whereas cysteine is almost exclusively considered to reduce $\mathrm{Cr}(\mathrm{VI})$ in a one-electron reaction with NADPH providing electrons. Ascorbate reduces $\mathrm{Cr}(\mathrm{VI})$ in a twoelectron reaction skipping the $\mathrm{Cr}(\mathrm{V})$ intermediate and immediately forming $\mathrm{Cr}(\mathrm{IV})$. As a result of all these reductions reactive oxygen species are formed which can lead to oxidative damage to nucleic acids, proteins and lipids. 
The range in the solubility of $\mathrm{Cr}$ compounds further affects how $\mathrm{Cr}$ interacts with biological systems. Particulate forms of $\mathrm{Cr}(\mathrm{VI})$ are considered to be the more hazardous form because $\mathrm{Cr}(\mathrm{VI})$ is first and foremost considered a lung carcinogen (Holmes et al., 2010; Patierno et al., 1988; Xie et al., 2004). When soluble Cr(VI) is inhaled it can be cleared by the lung whereas inhalation of $\mathrm{Cr}(\mathrm{VI})$ particles leads to their deposition at bifurcation sites (Ishikawa et al., 1994a; Ishikawa et al., 1994b). Here, the $\mathrm{Cr}(\mathrm{VI})$ particles slowly dissolve over time releasing $\mathrm{Cr}(\mathrm{VI})$ oxyanions leading to prolonged exposures. While soluble and particulate chromate compounds can both induce respiratory cancers solubility plays a significant role in potency.

\section{DNA damage and chromosome instability}

One of the key results of intracellular $\mathrm{Cr}(\mathrm{VI})$ reduction is the induction of DNA damage. DNA breaks may result from direct or indirect oxidative damage and DNA double strand breaks are well documented following $\operatorname{Cr}(\mathrm{VI})$ exposure (Qin et al., 2014; Wise et al., 2003; Wise et al., 2002; Xie et al., 2009). DNA double strand breaks can arise due to the collapse of a replication fork or the conversion of a single strand break to a double strand breaks during the replication process. $\mathrm{Cr}(\mathrm{VI})$ has been shown to affect mismatch repair which is used to repair Cr-DNA adducts (Zecevic et al., 2009). Failure of this process can lead to a stalled replication fork and ultimately double strand breaks (Barbour, 2003). DNA double strand breaks can lead to chromosomal instability if left unresolved (Masuda and Takahashi, 2002). Chromosome instability is known to occur in a majority of lung cancers and has been specifically documented in chromate-induced tumors (Maeng et al., 
2004). Chromosome instability can occur in the form of numerical chromosome instability as a change in the number of chromosomes or as structural chromosome instability in the form of translocations or DNA breaks contributing to $\mathrm{Cr}(\mathrm{VI})$ carcinogenesis (Albertson et al., 2003). First, we will focus on structural chromosome instability and the current known mechanisms of $\mathrm{Cr}(\mathrm{VI})$-induced structural chromosome instability and then follow with a discussion of numerical structural chromosome instability.

$\mathrm{Cr}(\mathrm{VI})$ causes DNA double strand breaks. Interestingly, $\mathrm{Cr}(\mathrm{VI})$-induced DSBs develop in late $S$ and $G 2$ of the cell cycle resulting in a G2 arrest Luczak et al., 2015; Reynolds et al., 2004; Xie et al., 2009). If these breaks were repaired structural chromosome instability would not occur. Therefore, investigators have been researching how $\mathrm{Cr}(\mathrm{VI})$ interferes with DNA repair mechanisms. There are two primary DNA double strand break repair pathways; homologous recombination and non-homologous end joining. non homologous end joining is considered a low fidelity pathway due to the loss of genetic material in the repair process. Further, a study by Camyre et al., 2007 found non homologous end joining is not critical in protecting cells against $\mathrm{Cr}(\mathrm{VI})$ exposure. Homologous recombination is considered a high-fidelity repair mechanism and has been shown to be critical in preventing chromosome instability. Additionally, several studies have shown homologous recombination is impaired following $\mathrm{Cr}(\mathrm{VI})$ exposure and is critical in maintaining genomic stability (Bryant et al., 2006; Stackpole et al., 2007; Tamblyn et al., 2009; Tian et al., 2016). This effect occurs after prolonged exposures and there is a specific loss of the effector step of homologous recombination through the loss of RAD51 (Browning et al., 2016; Qin et al., 2014). While $\mathrm{Cr}(\mathrm{VI})$ is known to affect 
homologous recombination, the underlying mechanisms in this pathway remain to be determined.

Numerical chromosome instability has been well documented in lung tumors with 70 to $80 \%$ of tumors exhibiting severe aneuploidy (Masuda and Takahashi, 2002). Many cell culture studies support this finding especially following chronic exposures to $\mathrm{Cr}(\mathrm{VI})$ and were characterized by hypodiploidy, hyperdiploidy, polyploidy and tetraploidy (Guerci et al., 2000; Holmes et al., 2010, Rodrigues et al., 2009; Seoane et al., 2002). Since these findings, investigation into the mechanisms of numerical chromosome instability have also been investigated. Numerical chromosome instability can arise because of improper segregation during mitosis and impaired centrosome regulation. Specifically, the spindle assembly checkpoint is critical in maintaining proper division. Spindle assembly checkpoint bypass has been observed in $\mathrm{Cr}(\mathrm{VI})$ exposed cells and is associated with aneuploidy (Holmes et al., 2010; Seoane et al., 2002). $\operatorname{Cr}(\mathrm{VI})$ exposure caused a decrease in MAD2, which is a key component in regulating the spindle assembly checkpoint (Wise et al., 2006b).

Another key component required for correct chromosome separation during cell division are centromeres. Centromeres are responsible for pulling the chromosomes to the two poles of a cell during division to ensure proper chromosomal segregation. However, Holmes et al., 2010 found chronic $\mathrm{Cr}(\mathrm{VI})$ resulted in an increase in supernumerary centromeres. Ultimately, this outcome means during segregation chromosomes can be pulled to multiple poles resulting in abnormal numbers of chromosomes in the daughter cells. Further, Martino et 
al., 2015 found there was a correlation between supernumerary centrosomes and numerical chromosome instability and critical proteins in centrosome regulated were impaired following $\mathrm{Cr}(\mathrm{VI})$ exposure. This study further demonstrated key structural components required to prevent premature centromere separation are also compromised following prolonged $\mathrm{Cr}(\mathrm{VI})$ exposure.

Taken together there is significant evidence both structural and numerical chromosome instability play a role in the mechanism of $\mathrm{Cr}(\mathrm{VI})$-induced carcinogenesis. Ultimately, abnormal numbers of chromosomes or deletions or insertions in whole chromosomes or genes can result in aberrant gene expression that leads to carcinogenic outcomes. While the specific pathways involved in maintaining fidelity in these mechanisms are still being investigated, there is significant evidence genomic instability is a key driver of $\mathrm{Cr}(\mathrm{VI})$ carcinogenesis. Figure 1.2 illustrates proposed mechanisms of $\mathrm{Cr}(\mathrm{VI})$ carcinogenesis. 


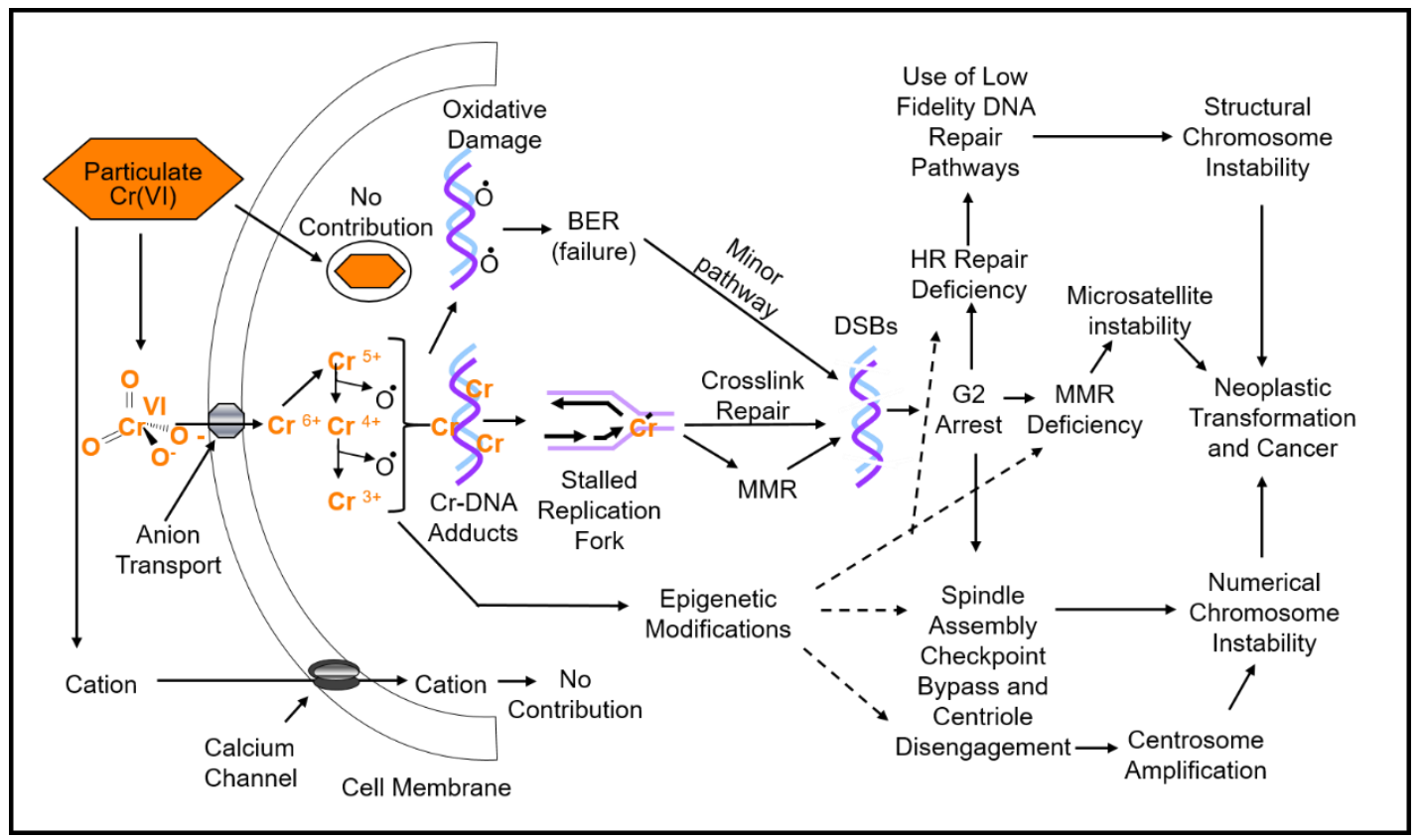

Figure 1.2. Mechanisms of numerical and structural chromosome instability in $\mathrm{Cr}(\mathrm{VI})$ carcinogenesis. This figure shows some of the major mechanisms underlying chromosome instability in our proposed mechanism of $\mathrm{Cr}(\mathrm{VI})$ carcinogenesis. Particulate $\mathrm{Cr}(\mathrm{VI})$ dissolves extracellularly and if the cation enters the cell there is no contribution to the effect. Similarly, if the $\mathrm{Cr}(\mathrm{VI})$ particle enters the cell by phagocytosis there is also no contribution to the effect. When the $\mathrm{Cr}(\mathrm{VI})$ oxyanion enters the cell it is reduced to $\mathrm{Cr}(\mathrm{III})$ and ROS are produced. The reactive oxygen species can induce oxidative damage which base excision repair (BER) attempts to repair. However, if it fails double strand breaks form. Positively charged $\mathrm{Cr}$ intermediates and $\mathrm{Cr}$ (III) form as result of the intracellular reduction process potentially binding to cellular elements including the formation of DNA-Cr adducts or crosslinks and consequentially stalled replication forks and the formation of a DNA double strand break. Crosslink repair or mismatch repair (MMR) can attempt 
to resolve these effects, but if they fail will result in double strand breaks. The formation of double strand breaks results in a G2 arrest as the attempts to repair the damage. $\mathrm{Cr}(\mathrm{VI})$-impaired homologous recombination repair leads to the use of a low fidelity repair mechanism and structural chromosome instability. At the same time, $\mathrm{Cr}(\mathrm{VI})$ induces spindle assembly checkpoint bypass and premature centriole disengagement leading to centrosome amplification and numerical chromosome instability. Underlying structural and numerical chromosome instability are $\mathrm{Cr}(\mathrm{VI})$-induced epigenetic alterations, which have yet to be elucidated. Finally, taken together structural and numerical chromosome instability contribute to the neoplastic transformation of $\mathrm{Cr}(\mathrm{VI})$ exposed and cancer. 


\section{Alterations in epigenetics and gene expression}

Another major driver of carcinogenesis is epigenetic changes. Changes in the epigenome can result in gene expression changes and ultimately carcinogenesis. Epigenetic modifications are involved in the upregulation and downregulation of genes though DNA methylation, histone modifications, histone variants, miRNA expression and nucleosome repositioning (Sharma et al., 2010). Gene expression and epigenetic studies are ongoing in $\mathrm{Cr}(\mathrm{VI})$ carcinogenesis. There is limited information about changes in gene expression in $\mathrm{Cr}(\mathrm{VI})$-induced tumors and epigenetic alterations, but cell culture analysis has uncovered complex alterations.

Studies in chromate tumors have revealed limited information about changes in gene expression. Takahashi et al., 2005 found MLH1 and MLH2 expression was decreased in chromate tumors. Similarly, other changes in gene expression in chromate tumors have been seen including increased cyclin D1 and decreased survivin (Halasova et al., 2010; Katabami, 2000). Interestingly, 61.3\% of chromate tumors were found to have gene variants in the surfactant $B$ gene in a study by Ewis et al., 2006.

Cell culture studies have revealed numerous changes in gene expression following $\mathrm{Cr}(\mathrm{VI})$ exposure (Sun et al., 2009; Sun et al., 2011, Ye and Shi, 2001). Recently, BEAS-2B cells were evaluated using single-cell RNA sequencing for changes in gene expression following a chronic 2 month exposure to $\mathrm{Cr}(\mathrm{VI})$ (Park et al., 2017). This study found $\mathrm{Cr}(\mathrm{VI})$ with or without a CRISPR/cas9 deletion of Gene 33, a protein involved in transformation, induced differential expression of 
over 80 genes. Interestingly, these genes were involved in cell adhesion, oxidative stresses, protein ubiquitination, epithelial-mesenchymal transition/metastasis and WNT signaling (Park et al., 2017).

Gene expression is widely regulated by epigenetic mechanisms, however, studies on epigenetic changes in tumors has been limited and are focused on methylation changes. For example, Ali et al., 2011 found tumors from those exposed to $\mathrm{Cr}$ had increased aberrant methylation of tumor suppressor genes at a higher frequency than in tumors from unexposed individuals. Additionally, methylation in multiple tumor suppressor genes has also been found in tumors derived from ex-chromate workers (Kondo et al., 2006; Toya et al., 1999). A recent study found mitochondrial DNA isolated from the blood of chromate workers was hypomethylated, however, this study was focused on using this endpoint as a biomarker for $\mathrm{Cr}(\mathrm{VI})$ exposure (Linging et al., 2016). Hu et al., 2018 found hypermethylation of CpG sites in DNA repair genes, including RAD51, increased in $\mathrm{Cr}(\mathrm{VI})$ exposed workers compared to non-exposed workers and this outcome correlated with blood Cr levels. Further this study confirmed these results in $16 \mathrm{HBE}$ cells treated with $\mathrm{Cr}(\mathrm{VI})$. Methylation changes have also been observed in other cell culture studies. Hu et al., 2016 found hypermethylation of the CpG islands of the tumor suppressor p16 in $16 \mathrm{HBE}$ cells treated with $\mathrm{Cr}(\mathrm{VI})$ which correlated with decreased expression of $\mathrm{p} 16$. More broadly, both particulate and soluble $\mathrm{Cr}(\mathrm{VI})$ was investigated in genome-wide methylation of DNA in human B lymphoblastoid cells. This study found DNA methylation changes only correlated with the 
expression of a subset of genes indicating there are multiple mechanisms controlling their expression (Lou et al., 2015).

Changes in histone modifications are also being investigated in $\operatorname{Cr}(\mathrm{VI})$ carcinogenesis. Wei et al., 2004 found $\mathrm{Cr}(\mathrm{VI})$ can crosslink a histone deacetylase to inducible promoters resulting in decreased gene expression. Additionally, acetylation of histone tails is commonly associated with increased gene expression. The acetylation of histone $\mathrm{H} 4$ of the stressor protein Nupr1 was found to be downregulated following $\mathrm{Cr}(\mathrm{VI})$ exposure in BEAS-2B cells and was associated with increased expression of Nupr1 protein, of which overexpression is associated with cancers (Chen et al., 2016). Another epigenetic histone modification is biotinylation. Xia et al., 2014 found differential histone biotinylation and differential distribution of biotinidase in $16 \mathrm{HBE}$ cells depending on the concentration of $\mathrm{Cr}(\mathrm{VI})$. Furthermore, they found histone deacetylation plays a role in histone biotinylation further adding to complexity of these mechanisms.

No studies to date have investigated miRNAs in chromate tumors. However, one study evaluated miRNAs in the blood of chromate workers but found only decreased miR-3940-5p levels were associated with blood $\mathrm{Cr}$ (Li et al., 2014). There are limited but increasing numbers of cell culture studies that support the involvement of miRNAs in $\mathrm{Cr}(\mathrm{VI})$ carcinogenesis. Li et al., 2016 investigated miR3940-5p and its involvement in homologous recombination using $16 \mathrm{HBE}$ cells. This study found miR-3940-5p enhanced the homologous recombination response following treatment with $\mathrm{Cr}(\mathrm{VI})$. He et al., 2013 found changes in miRNA expression associated with $\mathrm{Cr}(\mathrm{VI})$-transformed BEAS-2B cells and the reduction 
was associated with the upregulation of several proteins involved in proliferation and angiogenesis. A recent study in BEAS-2B cells found $\mathrm{Cr}(\mathrm{VI})$ exposure induced malignant cell transformation associated with increased miR-21 expression and the inhibition of a tumor suppressor (Pratheeshkumar et al., 2017). These studies highlight the complexities and connectedness between different mechanisms of carcinogenesis. Specifically, miRNAs and other epigenetic alterations affect gene expression and vital pathways that lead to proper cell homeostasis.

\section{Part II: Focus of this dissertation}

\section{Repair of $\mathrm{Cr}(\mathrm{VI})$-induced double strand breaks}

$\mathrm{Cr}(\mathrm{VI})$ induces DNA double strand breaks, and the predominant repair pathway for these breaks is homologous recombination. Several studies have shown the importance of homologous recombination repair following $\mathrm{Cr}(\mathrm{VI})$ exposure. One study investigated the protein Mus81, involved in resolving Holiday junctions, a final step in the homologous recombination pathway (Tamblyn et al., 2009). They found in Mus81-deficient cells $\mathrm{Cr}(\mathrm{VI})$ induced higher levels of phosphorylated $\mathrm{H} 2 \mathrm{AX}$ (gamma-H2AX) foci indicating resolution of double strand breaks was inhibited. Tamblyn et al., 2009 complemented this study showing delayed RAD51 foci removal in Mus81-deficient cells. Ultimately, exposure to a DNA double strand break-inducing agent and inhibition of homologous recombination repair results in structural chromosome instability. Two studies confirmed this mechanism showing $\mathrm{Cr}(\mathrm{VI})$ increased chromosome aberrations in BRCA2 or RAD51C-deficient cell lines (Bryant et al., 2006, Stackpole et al., 2007). 
These studies highlight the importance of homologous recombination repair in preventing structural chromosome aberrations following $\mathrm{Cr}(\mathrm{VI})$ exposure.

There are three main steps in the homologous recombination pathway: the sensing step, transducing step, and the effecting step. Double strand breaks are sensed by the MRN complex (MRE11, RAD50, and NBS1), which acts to resect the ends of the break using the nuclease activity of MRE11 (D'Amours and Jackson, 2002; Williams et al., 2007). Studies show the sensing step of homologous recombination repair is activated after $\mathrm{Cr}(\mathrm{VI})$ exposure and remains active through prolonged exposures (Browning et al., 2016; Qin et al., 2014; Xie et al., 2008; Xie et al., 2009). The sensing step by MRN is initiated by the phosphorylation of $\mathrm{H} 2 \mathrm{AX}$ on either side of a double strand break signaling downstream recruitment of repair factors ( $\mathrm{Li}$ and Heyer, 2008). This signal is further transduced by ATM and ATR, which reciprocally leads to amplification of the gamma-H2AX signal (Li and Heyer, 2008). Studies show $\mathrm{Cr}(\mathrm{VI})$ increases signal transduction by gamma-H2AX, ATM, and ATR indicating these steps in the homologous recombination pathway are activated and remain functional after acute $\mathrm{Cr}(\mathrm{VI})$ exposure (Bryant et al., 2006, Luczak et al., 2015; Ha et al., 2004; Qin et al., 2014; Xie et al., 2008; Xie et al., 2009; Wakeman et al., 2004) and prolonged exposure (Browning et al., 2016; Qin et al., 2014; Xie et al., 2008; Xie et al., 2009).

After end resection the single stranded DNA of the break is coated with RPA to protect the ends during downstream signaling and while further repair factors are recruited (Georgaki and Hubscher, 1992). In the effecting step of homologous recombination, RAD51 is recruited and loaded onto the single-stranded DNA 
replacing RPA (Baumann et al., 1996; Sung \& Robberson, 1995). RAD51 recruitment is facilitated by the BRCA2/BARD1 protein complex and RAD51C, which transport RAD51 into the nucleus and onto single stranded-DNA forming a RAD51 nucleofilament (Amunugama et al., 2013; Liu et al., 2010; Sigurdsson et al., 2001; Zhang et al., 2009). The RAD51 nucleofilament is then involved with the search for a homologous sequence of DNA with RAD54 and strand invasion resulting in high-fidelity repair of the double stranded break through Holiday junction resolution (Constantinou et al., 2001).

We have shown while earlier steps in the homologous recombination pathway remain functional following prolonged $\mathrm{Cr}(\mathrm{VI})$ exposure the key effector, RAD51, is inhibited (Browning et al., 2016, Bryant et al., 2006; Qin et al., 2014). Specifically, these studies reveal three major RAD51 effects after prolonged particulate $\mathrm{Cr}(\mathrm{VI})$ exposure: 1) inhibited nuclear foci formation, 2) accumulation of RAD51 protein in the cytoplasm and 3) reduced RAD51 protein levels. Qin et al., 2014 and Bryant et al, 2006 showed RAD51 nuclear foci increased after $24 \mathrm{~h} \mathrm{Cr}(\mathrm{VI})$ exposure. However, Qin et al., 2014 further identified RAD51 nuclear foci was strongly inhibited after prolonged 72 and $120 \mathrm{~h}$ exposures and it accumulated in the cytoplasm. Similarly, RAD51 nuclear and whole cell protein levels decrease after prolonged exposure (Browning et al., 2016). Browning et al., 2017a investigated proteins involved in the transport and loading of RAD51 to form the nucleofilament essential to complete homologous recombination repair. They revealed one mechanism of inhibited-RAD51 function is through impaired RAD51 nuclear import mediator proteins. Specifically, $\mathrm{Cr}(\mathrm{VI})$ exposure reduced RAD51C 
nuclear localization and RAD51C deficiency resulted in cytoplasmic accumulation of RAD51. However, $\mathrm{Cr}(\mathrm{VI})$ did not affect the interaction of RAD51 with RAD51C or its other import partner, BRCA2. These results partially explain RAD51 dysfunction, however, mechanism of $\mathrm{Cr}(\mathrm{VI})$-inhibited RAD51 protein levels have yet to be elucidated.

\section{Expression of RAD51}

E2F1 is a primary transcription factor for RAD51 and is involved in homologous recombination repair. Studies show loss of E2F1 leads to RAD51 and homologous recombination failure inducing effects similar to those observed following prolonged $\mathrm{Cr}(\mathrm{VI})$ exposure (Chen et al., 2011; Choi and Kim, 2019; Wu et al., 2014). One study by Kachap et al., 2010 showed histone deacetylase inhibitors specifically inhibited E2F1-regulated transcription of RAD51 and induced RAD51 cytoplasmic accumulation, which is a phenotype observed after prolonged $\mathrm{Cr}(\mathrm{VI})$ exposure. However, no studies have investigated the effects of $\operatorname{Cr}(\mathrm{VI})$ on E2F1 or the transcriptional control of RAD51.

The expression of RAD51 not only depends on the transcriptional control of the gene, but also post-transcriptional processes. miRNAs play an important role in the control of expression by targeting mRNA transcripts for degradation and inhibiting translation to protein. They are short non-coding RNA transcripts known to regulate about $60 \%$ of protein-coding transcripts (Friedman et al., 2009). It is well known multiple miRNAs target a single mRNA transcript, and each miRNAs has multiple transcript targets. However, the expression and balance of miRNAs can determine how they regulate specific targets for post-transcriptional control. 
Studies have investigated miRNAs targeting RAD51 that also lead to inhibition of homologous recombination repair (Gasparini et al., 2013; Huang et al., 2013; Lai et al,. 2016; Wang et al., 2012). While $\mathrm{Cr}(\mathrm{VI})$ is known to effect the expression of miRNAs no studies have investigated $\mathrm{Cr}(\mathrm{VI})$-altered miRNAs that target RAD51 or homologous recombination in general.

\section{One Environmental Health approach}

To understand how environmental toxicants, affect health it is important to consider multiple perspectives. Environmental toxicants affect human health, wildlife health, and ecosystem health. Traditionally, research has focused on evaluating the effects of environmental toxicants from one of these three perspectives. However, important information can be identified by incorporating research perspectives from more than one area of health. This is especially true for risk assessment purposes and developing a comprehensive view of how environmental toxicants affect overall health. This idea of incorporating human, animal, and ecosystem health developed into the One Health initiative, which

originally was termed based on comparing the study of infectious diseases in animals with humans (Gibbs, 2014; Zinsstag et al., 2011). The concept of One Health has expanded, and new subsets have emerged to accommodate a wide range of disciplines and goals.

One Environmental Health is a subset of One Health specifically focused on the study of toxicants (Pérez and Wise 2018). As a global environmental pollutant, $\mathrm{Cr}(\mathrm{VI})$ is an excellent candidate for applying the One Environmental Health approach. We have applied this approach to $\mathrm{Cr}(\mathrm{VI})$ research using several 
methods and model organisms. One advantage to the One Environmental Health approach is investigating molecular mechanisms across species. This is especially important in $\mathrm{Cr}(\mathrm{VI})$ research because the mechanisms of $\mathrm{Cr}(\mathrm{VI})$ carcinogenesis are currently not well understood. Throughout evolution individual species have developed adaptations to deal with different environments and challenges they have been exposed to. These adaptations, in part, explain why cancer rates do not always correlate with organism body size and life span.

Cancer arises through the accumulation of mutations and other genomic alterations. Therefore, in theory, the larger an organism (i.e. the more cells they contain) the more likely it is they would develop cancer. Additionally, the longer the lifespan of an organism the more time there would be for these mutations and genomic alterations to occur (Caulin and Maley, 2011). While these theories hold true within species such as dogs and humans, it is not the case across species (Hawley et al., 2013; Mwacalimba et al., 2015). Instead, cancer is most seen in mammalian species with a wide range of sizes and lifespans (Hubbard et al., 1983). These discoveries led to the concept of Peto's Paradox, which says the incidence of cancer does not correlate with the number of cells in an organism (Leroi et al., 2003; Peto et al., 1975). One example of this is whales, which are much larger and have similar lifespans as humans but develop cancers at much lower rates (Nagy et al., 2007). Indeed, Li Chen et al., 2012 found $\operatorname{Cr}(\mathrm{VI})$ induced lower levels of genomic instability in whale cell lines compared to human cell lines. Further, Browning et al., 2017b found $\mathrm{Cr}(\mathrm{VI})$ does not inhibit homologous recombination repair in North Atlantic right whale (Eublalaena glacialis) lung cells. 
Other groups have investigated mechanisms of carcinogenesis based on these types of observations. For example, Sulak et al., 2016 identified copy number expansion of TP53 in elephants, another large and long-lived species with lower cancer rates than humans. TP53 plays an important role in the DNA damage response. Therefore, having multiple copies may serve as a protective mechanism against DNA damage-induced genomic alterations that lead to carcinogenesis.

While much research is done in mammalian species to investigate how different organisms may be protected against carcinogenesis, reptiles offer unique research opportunities. Reptiles range widely in size and longevity and have unique physiological adaptations that may impact how they evolved protective mechanisms against carcinogenesis (Allen et al., 2017; Harris et al., 2017). Chiari et al., 2018 propose reptiles are an excellent parallel system to evaluate differences and similarities with humans regarding carcinogenesis. Therefore, we have included leatherback sea turtles (Dermochelys coriacea) as a reptilian model in our research to apply the One Environmental Health approach.

\section{Summary and dissertation aims}

It has been well established $\mathrm{Cr}(\mathrm{VI})$ is a global environmental pollutant and human lung carcinogen. $\mathrm{Cr}(\mathrm{VI})$ particles are inhaled and lodge at bifurcation sites in the lung resulting in the long term dissolution of chromate anions. These chromate anions enter cells and are reduced to the next stable valence state, $\mathrm{Cr}$ (III) leading to the induction of DNA double strand breaks. We have previously shown prolonged particulate $\mathrm{Cr}(\mathrm{VI})$ exposure inhibits the high-fidelity DNA repair pathway, homologous recombination, by inhibiting RAD51 protein expression. 
The mechanisms of how $\mathrm{Cr}(\mathrm{VI})$ inhibits RAD51 expression have not been investigated. E2F1 is considered the predominant transcription factor for RAD51, however, the effects of $\mathrm{Cr}(\mathrm{VI})$ on E2F1-driven RAD51 expression are unknown. Expression of RAD51 may also be mediated by miRNAs. It is currently unknown how $\mathrm{Cr}(\mathrm{VI})$ affects miRNAs that target RAD51. Given the importance of RAD51 in protecting genomic stability it is critical to understand how $\mathrm{Cr}(\mathrm{VI})$ may be affecting RAD51 expression, and potential protective mechanisms to prevent this effect.

To better understand mechanisms of $\mathrm{Cr}(\mathrm{VI})$ carcinogenesis key outcomes observed in human models can be explored in other organisms. Leatherback sea turtles provide a unique model to evaluate $\mathrm{Cr}(\mathrm{VI})$ toxicity and determine if $\mathrm{Cr}(\mathrm{VI})$ may pose a threat to leatherback health. Our previous studies show $\operatorname{Cr}(\mathrm{VI})$ is cytotoxic and genotoxic to leatherbacks cells at similar levels to human cells, however, there were some observable differences. Investigating the mechanisms of $\mathrm{Cr}(\mathrm{VI})$-induced genotoxicity in leatherbacks may provide important information to better understand which mechanisms are conserved across species and adaptations that may provide a biological advantage in one species over another to cope with genotoxic insult.

Therefore, the central hypothesis of this project is: Prolonged exposure to particulate $\mathrm{Cr}(\mathrm{VI})$ inhibits RAD51 expression through E2F1-inhibited transcription and alteration of miRNA expression, and key events are paralleled in a leatherback sea turtle model. This hypothesis will be tested by the following aims: 
Aim 1: Determine if E2F1 modulates the RAD51 response to particulate $\operatorname{Cr}(V I)$ exposure.

This aim seeks to determine if E2F1 is critical for facilitating the RAD51 response to particulate $\mathrm{Cr}(\mathrm{VI})$ exposure. First, particulate $\mathrm{Cr}(\mathrm{VI})$ effects on $\mathrm{RAD51}$ mRNA levels and protein half-life will be investigated to confirm altered transcription is the predominant mechanism of reduced RAD51 protein. Next, particulate $\mathrm{Cr}(\mathrm{VI})$ effects on $\mathrm{E} 2 \mathrm{~F} 1$ will be investigated. Finally, we will test if E2F1 overexpression can rescue particulate $\operatorname{Cr}(\mathrm{VI})$-induced $\mathrm{RAD51}$ failure after prolonged exposure and if knocking down E2F1 can induce RAD51 failure after acute particulate $\mathrm{Cr}(\mathrm{VI})$ exposure when RAD51 is normally functional.

Aim 2: Identify particulate $\mathrm{Cr}(\mathrm{VI})$-altered miRNAs involved in RAD51 regulation and homologous recombination repair.

This aim focuses on miRNAs altered by particulate $\mathrm{Cr}(\mathrm{VI})$ exposure. First, global changes in miRNA expression patterns will be evaluated using RNAseq analysis. Second, differential expression of miRNAs will be investigated to determine their potential role in pathways of $\mathrm{Cr}(\mathrm{VI})$ carcinogenesis. Finally, $\mathrm{Cr}(\mathrm{VI})$ altered miRNAs involved in RAD51 and homologous recombination will be further investigated to determine which of these miRNAs may play a significant role in $\mathrm{Cr}(\mathrm{VI})$-inhibited DNA repair. 
Aim 3: Characterize the effects of particulate $\mathrm{Cr}(\mathrm{VI})$ on homologous recombination in leatherback sea turtle lung cells.

In this aim, the effects of particulate $\mathrm{Cr}(\mathrm{VI})$ exposure in leatherback lung cells will be evaluated. First, DNA damage will be measured following acute and prolonged $\mathrm{Cr}(\mathrm{VI})$ exposure. Second, the effects of particulate $\mathrm{Cr}(\mathrm{VI})$ on $\mathrm{RAD} 51$ will be determined. Finally, homologous recombination repair function will be assessed following particulate $\mathrm{Cr}(\mathrm{VI})$ exposure. 


\section{CHAPTER 2: MATERIALS AND METHODS}

This section contains the methods for all three aims of this dissertation. The methods are arranged in alphabetical order and include a brief background of each method.

\section{Cell Culture}

The lung is the primary target of particulate $\mathrm{Cr}(\mathrm{VI})$ with exposures occurring via inhalation. Epidemiology studies in chromate workers show chromate-induced tumors arise as cancers of the epithelium, primarily as squamous cell carcinomas (Hirose et al., 2002; Ishikawa et al., 1994a). While epithelial cells are the ultimate cell type transformed by $\mathrm{Cr}(\mathrm{VI})$ one study found $\mathrm{Cr}$ accumulates in fibroblasts in the stromal layer of the lung, not the epithelial cells from which $\mathrm{Cr}(\mathrm{VI})$-induced cancers arise (Kondo et al., 2003). These data suggest fibroblasts accumulate $\mathrm{Cr}$ and create an unhealthy microenvironment for adjacent epithelial cells, which may contribute to their transformation into cancer cells. Indeed, the literature shows in many different types of cancers fibroblasts play a key role altering the microenvironment by releasing growth factors, chemokines, and other components that contribute to carcinogenesis.

Epithelial cells are difficult to immortalize while maintaining normal characteristics and chromosome structure. This dissertation considers the effects 
of $\mathrm{Cr}(\mathrm{VI})$ on chromosomes as a primary target of $\mathrm{Cr}(\mathrm{VI})$ exposure and therefore the currently available immortalized epithelial cells are not suitable for this work. Additionally, primary epithelial cells cannot be maintained long enough to carry out the exposures required in this dissertation with consistency. Therefore, because of these issues with epithelial cell culture and because fibroblasts have been shown to be a key target of $\mathrm{Cr}(\mathrm{VI})$ exposure (Kondo et al., 2003), the primary cell line used in this study is an hTERT immortalized human lung fibroblast cell line. This cell line (from here on called WTHBF-6) was developed by the Wise Laboratory from primary lung fibroblasts derived from healthy lung tissue of a 67year old Caucasian male. These cells have a normal diploid karyotype (46 chromosomes), normal growth parameters, and the same toxicological response to metals as their parent primary cell line (Wise, et al., 2004).

WTHBF-6 cells were maintained in DMEM/F12 (Corning) supplemented with $15 \%$ cosmic calf serum (Hyclone Laboratories), $1 \%$ penicillin/streptomycin (Corning), 1\% L-alanyl-L-glutamine (Corning), and $0.1 \mathrm{mM}$ sodium pyruvate (Hyclone Laboratories). They were cultured as adherent monolayers in a humidified incubator at $37^{\circ} \mathrm{C}$ and $5 \% \mathrm{CO}_{2}$. WTHBF- 6 cells were fed every 2 days and split every $3-4$ days using $0.25 \%$ trypsin/1 mM EDTA (Gibco). Experiments were performed on logarithmically growing cells.

Leatherback sea turtle lung cells (PGDC9-1LU cells) were used in experiments where the One Environmental Health Approach was applied. These primary cells were established by the Wise Laboratory from a leatherback sea turtle embryo at our field site in Vieques, Puerto Rico (Speer et al., 2018). These 
cells exhibit a normal diploid karyotype (56 chromosomes) and normal growth parameters. PGDC9-1LU cells were cultured in DMEM/F12 supplemented with $10 \%$ fetal bovine serum (Avantor), $1 \%$ penicillin/streptomycin, $1 \%$ L-alanyl-Lglutamine, and $0.1 \mathrm{mM}$ sodium pyruvate. Cells were cultured as adherent monolayers in a humidified incubator at $26^{\circ} \mathrm{C}$ and $5 \% \mathrm{CO}_{2}$. Cells were fed every 2-3 days and split at least once per week using $0.1 \%$ trypsin-EDTA. Experiments were performed on logarithmically growing cells.

Cell authentication and validation was continuously carried out for both cell lines. Cells were confirmed to be mycoplasma negative monthly and monitored for any growth or morphological changes. All cells were karyotyped when thawed for use and again after every 3 months of continuous culture to ensure authenticity. WTHBF-6 cells underwent standard tandem repeat analysis yearly. Short tandem repeat analysis is currently not available for leatherback cells.

\section{Cell equivalent protein extractions}

Protein was extracted from cells for western blot analysis. It is well known $\mathrm{Cr}(\mathrm{VI})$ causes global changes in expression and this is reflected by differences in the amount of protein quantified in $\mathrm{Cr}(\mathrm{VI})$-treated cells compared to control cells. Therefore, cell equivalents were used as a measure to load the same number of cells-worth of protein for each sample for western blot analysis. The extraction method below, therefore, includes counting the number of cells in each sample and adding the appropriate amount of extraction buffer to allow equal cell loading. 
WTHBF-6 cells were seeded and allowed to reenter logarithmic growth for $48 \mathrm{~h}$ before treating with zinc chromate for 24,72 , or $120 \mathrm{~h}$. For protein half-life experiments, at the end of the zinc chromate treatment $10 \mathrm{ug} / \mathrm{ml}$ cycloheximide was added to all dishes and cells were harvested immediately $(0 \mathrm{~h})$ then 1, 2, 4, 6, 8,10 , and $12 \mathrm{~h}$ following. At the end of treatment media was aspirated and cells were rinsed once with 1X PBS without calcium and magnesium. Cells were trypsinized and the reaction was neutralized using fresh media. Cells were centrifuged for 5 minutes at $1000 \mathrm{rpm}\left(4^{\circ} \mathrm{C}\right)$, the supernatant was aspirated, and cells were resuspended in cold-PBS. Cells were counted using a Beckman Coulter Multisizer 3 and centrifuged. The PBS was aspirated to $1 \mathrm{ml}$ and $1 \mathrm{ml}$ of cold-PBS was used to dislodge the pellet and transfer the cells to a microcentrifuge tube. Cells were centrifuged in a microcentrifuge 5 minutes at $3500 \mathrm{rpm}\left(4^{\circ} \mathrm{C}\right)$. The PBS was gently aspirated, and samples were placed on ice.

Whole cell protein was extracted using cold Pierce RIPA buffer (Thermo cat: 89900 ) with $10 \%$ phosphatase and protease inhibitors added immediately before use. The volume of extraction buffer added to each sample was calculated based on cell number resulting in the same number of cells per volume extraction buffer. Extraction buffer was added to the cell pellet and pipetted up and down to resuspend the pellet. Samples were placed on ice for 20 minutes, vortexing every 5 minutes at max speed for 5 seconds. Samples were then centrifuged at max speed $(14 \times \mathrm{g})$ for 10 minutes $\left(4^{\circ} \mathrm{C}\right)$. The supernatant with the protein sample was transferred to a fresh tube. Protein was quantified using the Pierce Rapid Gold BCA kit and BSA standards (Thermo cat: A53227) on a Biotek microplate reader. 
Samples were boiled with $4 \mathrm{X}$ loading buffer $+10 \%$ 2-mercaptoethanol (Sigma Aldrich) 5 minutes at $95^{\circ} \mathrm{C}$ and stored at $-20^{\circ} \mathrm{C}$.

Nuclear protein was extracted using the NE-PER Nuclear and Cytoplasmic Extraction Reagents kits (Thermo cat: 78833) using the manufacturer's instructions with some modifications. After treatment, cells were collected using the methods above to a cell pellet. Then, ice-cold cytoplasmic extraction buffer I (plus $10 \%$ phosphatase and protease inhibitors) was added to each sample, vortexed 15 seconds and placed on ice 10 minutes. Ice-cold cytoplasmic extraction buffer II was added, vortexed 5 seconds and placed on ice 1 minute. The samples

were vortexed again 5 seconds and centrifuged at maximum speed $(14 \times$ g) 5 minutes. The supernatant with cytoplasmic protein was transferred to a fresh tube. The pellet (nuclear fraction) was resuspended with ice-cold nuclear extraction buffer and vortexed every 10 minutes for 15 seconds for a total of 40 minutes. The samples were centrifuged at maximum speed $(14 \times \mathrm{g}) 10$ minutes and the supernatant (nuclear protein) was transferred to fresh tubes. The supernatant with the protein sample was transferred to a fresh tube. Protein was quantified using the Pierce Rapid Gold BCA kit and BSA standards on a Biotek microplate reader. Samples were boiled with $4 \mathrm{X}$ loading buffer $+10 \%$ 2-mercaptoethanol 5 minutes at $95^{\circ} \mathrm{C}$ and stored at $-20^{\circ} \mathrm{C}$.

\section{Cell equivalent western blot analysis}

Immunoblotting or western blot analysis is a technique used to separate and visualize specific proteins from a sample for quantification. In this method, proteins are denatured, and the charges are neutralized to prevent charge-based 
interferences. The proteins are transferred through a gel matrix using electrophoresis to separate the proteins based on size. Following electrophoresis, the proteins are transferred to a membrane, which is then probed using antibodies for a specific protein of interest. Fluorophores either directly attached to the primary antibody or through secondary antibodies are then applied to quantitate the protein of interest in the sample. We have specifically used cell-equivalent loading so that each sample per experiment has the same number of cells-worth of protein to accurately quantitate protein levels across samples.

Protein was loaded using cell equivalents and resolved on $10 \%$ Bis-Tris SDS-PAGE gels $(\sim 1 \mathrm{~h})$ and transferred to $0.45 \mathrm{uM}$ nitrocellulose membranes (Thermo cat: 88018) ( 1.5 h). Immunoblots were dried $(\sim 1 \mathrm{~h})$, rehydrated with $1 \mathrm{X}$ tris buffered saline (TBS), and blocked with Odyssey blocking buffer (TBS) (Li-cor) diluted 1:1 with TBS $1 \mathrm{~h}$. Immunoblots were probed with RAD51 (Santa Cruz sc8349; 1:1000), E2F1 (Santa Cruz sc-251; 1:500), EGR1 (Cell Signaling clone 15F7 Cat: \#4153, 1:1000), p130 (Santa Cruz clone A10 sc-374521, 1:500), phosphop130 (Invitrogen Cat: PA5-64769, 1:1000), p53 (BD Pharm 554294, 1:500), phospho-p53 (Ser15) (Cell Signaling 9284, 1:500), or E2F4 (Cell Signaling clone E3G2G Cat: \#40291, 1:1000) in odyssey blocking buffer (TBS) diluted 1:1 with TBS $+0.2 \%$ tween-20 (Sigma Adrich) overnight. Equal loading was confirmed by GAPDH (Genetex GT293; 1:500), H3 (Cell Signaling \#9715, 1:500), or alphatubulin (GeneTex GT114, 1:1000) in odyssey blocking buffer (TBS) diluted 1:1 with TBS $+0.2 \%$ tween-20. Immunoblots were incubated with IRDye secondary antibodies (Li-Cor, 1:15,000) in odyssey blocking buffer (TBS) diluted 1:1 with TBS 
$+0.2 \%$ tween-20 $1 \mathrm{~h}$ and imaged on a Li-Cor Odyssey CLx. Results were normalized to their respective loading control and then represented relative to the untreated $\left(0 \mathrm{ug} / \mathrm{cm}^{2}\right.$ zinc chromate) control at each time point, respectively.

\section{$\mathrm{Cr}(\mathrm{VI})$ preparation and treatment}

The particulate $\mathrm{Cr}(\mathrm{VI})$ compounds are considered to be the most toxic and carcinogenic. Zinc chromate was used as the representative particulate chromate compound in this dissertation. Zinc chromate is a partially soluble particulate chromate compound and epidemiology studies show it alone can induce lung cancer (Kano et al., 1993). It has wide industrial use, especially as a rust inhibitor and in pigment applications.

Zinc chromate (99.7\% purity; CAS\# 13530-65-9) was prepared according to our published methods by washing twice with deionized $\mathrm{H}_{2} \mathrm{O}$ to remove water soluble contaminants, rinsed twice with acetone (99.5\% purity, Sigma Aldrich) to remove organic contaminants, and thoroughly dried. Before use zinc chromate was suspended in cold, sterile deionized $\mathrm{H}_{2} \mathrm{O}$ and stirred overnight at $4^{\circ} \mathrm{C}$. Dilutions were prepared the day of use and administered to cells as a suspension of particles using a vortex. Zinc chromate treatments are represented as $\mathrm{ug} / \mathrm{cm}^{2}$ to account for particles treatment across different exposure vessels. Cells were treated with $0.1-0.3 \mathrm{ug} / \mathrm{cm}^{2}$ zinc chromate for WTHBF-6 cells and $0.1-0.4 \mathrm{ug} / \mathrm{cm}^{2}$ zinc chromate for PGDC9-1LU cells, which represents a sub lethal range of cytotoxicity in each cell line, respectively. This range of concentrations also represents documented exposures in the literature (Danadevi et al., 2004; Ishikawa et al., 1994). 


\section{Immunofluorescence}

Analysis using immunofluorescence allows for visualization of native protein localization, quantity in specific compartments of the cell, and interactions between proteins among other applications. This technique involves using antibodies conjugated to fluorescent dyes to visualize the target of interest. Immunofluorescence was applied in this dissertation to identify protein foci and localization in the cytoplasm or nucleus of the cell.

WTHBF-6 or PGDC9-1LU cells were seeded on glass chamber slides precoated with FNC (Athenaes) and allowed to reenter logarithmic growth for $48 \mathrm{~h}$ before treating with zinc chromate for 24,72 , or $120 \mathrm{~h}$. At harvest, cells were fixed with $4 \%$ paraformaldehyde for 10 minutes, permeabilized with $0.2 \%$ triton-X-100 for 5 minutes and blocked with 10\% goat serum and 1\% BSA in PBS with calcium and magnesium for $1 \mathrm{~h}$. Cells were incubated with RAD51 antibody (Santa Cruz sc-8349; 1:200) or gamma-H2AX antibody (Cell Signaling \#2577) in 1\% BSA overnight, washed with PBS 3 times 5 minutes each, and incubated with secondary Alexa Fluor 488 rabbit 1:2000 (RAD51) or Alexa Fluor 594 1:2000 (gamma-H2AX) $1 \mathrm{~h}$. Cells were washed with PBS 5 times for 5 minutes each and coverslips were mounted with DAPI diamond (Thermo cat: P36962). RAD51 or gamma-H2AX nuclear foci were scored visually in 100 cells per condition per time point using fluorescent microscopy. Results were expressed as the percentage of cells with $>10$ or $>5$ foci so that untreated controls had less than $5 \%$ of cells with this level of foci. 
RAD51 nuclear and cytoplasmic protein quantification was assessed using confocal microscopy. Images of 50 cells per condition per time point were obtained with a Nikon A1 confocal laser microscope. Z-stack images were taken with a 60X objective with a step size of 0.5 um. All camera settings were the same across all images per experiment. Images were processed using the Denoise.ai noise reduction technology in NIS-Elements software (Nikon) and maximum image projections (MaxIPs) were created. The MaxIP images were analyzed in NISElements software using the auto-detect (region of interest) ROI program to automatically detect nuclei. Then the outline of the cell was traced manually to compare nuclear and cytoplasmic RAD51 total intensity levels at the single cell level. Cells were considered positive for cytoplasmic accumulation if the cytoplasmic intensity was greater than $95 \%$ of control cells.

\section{Karyotype analysis}

Karyotype analysis is a cytogenetic technique used to assess chromosomal arrangements and can be used to confirm cell line authenticity or alterations made to chromosomes after exposure to chemicals. We used g-banding (Giemsa banding) karyotype analysis to confirm cell line authenticity throughout this project. This method results in dark staining of adenine and thymine-rich heterochromatic regions and light staining of euchromatic regions rich in guanine and cytosine resulting in a banding pattern.

Cells were seeded immediately from a thawed cryovial or from growing cells. Colcemid was added to cells to arrest in metaphase 1 or 4 hours before harvest WTHBF-6 and PGDC9-1LU cells, respectively. At harvest, the media was 
collected to avoid loss of any loosely attached mitotic cells. Cells were washed with PBS (without calcium and magnesium) and trypsin was added to lift cells off the dishes. Cells were collected and centrifuged at $1000 \mathrm{rpm}$ for 5 minutes at $4^{\circ} \mathrm{C}$. The supernatant was aspirated, and the cell pellet was resuspended with $10 \mathrm{ml}$ of $0.75 \mathrm{M} \mathrm{KCl}$ for 17 minutes. One $\mathrm{ml}$ fixative (methanol:acetic acid; $3: 1$ ) was added and the cells were pelleted again by centrifugation 5 minutes at $4^{\circ} \mathrm{C}$ and $1000 \mathrm{rpm}$. The pellet was resuspended in $10 \mathrm{ml}$ fixative 20 minutes at room temperature, the fixative was changed twice, and cells were dropped onto wet microscope slides.

Slides were stained by digesting the cells with trypsin (1:250) in Gurr's buffer approximately 30 seconds -1 minute which was stopped by dipping 3-4 times in $2 \%$ fetal bovine serum in Gurr's buffer (Gibco). Slides were dipped 3-4 times in Gurr's buffer ( $\mathrm{pH} 7.0$ ) then $70 \%$ ethanol, $95 \%$ ethanol and Gurr's buffer $(\mathrm{pH}$ 6.8) before staining approximately 3 minutes in Wright's stain (Carolina Biological). Slides were cover-slipped and imaged using an Applied Spectral Imaging microscope and software. Ten metaphases were assessed per analysis.

\section{Neutral comet assay}

The comet assay is a method to measure DNA damage using single-cell gel electrophoresis. The neutral comet assay specifically measures double strand breaks. This assay is a sensitive measurement of DNA damage based on the principle negatively charged DNA fragments (created as a result of DNA damage) will migrate in an electrical current out of the cell creating a 'comet tail'. Therefore, more DNA damage in a cell the results in longer and/or more intense comet tails. PDGC9-1LU cells were seeded in 6 well plates and allowed to rest $48 \mathrm{~h}$ before the 
media was replaced with fresh, warm media and cells were treated with $0,0.1,0.2$, 0.3 and $0.4 \mathrm{ug} / \mathrm{cm}^{2}$ zinc chromate for 24 or $120 \mathrm{~h}$.

At harvest, media was aspirated, and cells were washed with PBS (without calcium and magnesium) before trypsin was used to collect cells. Cells were centrifuged at $1000 \mathrm{rpm}$ for 5 minutes at $4^{\circ} \mathrm{C}$. The supernatant was aspirated, cells were resuspended in PBS and counted. Cells were diluted to 100,000 cells $/ \mathrm{ml}$ in PBS and added to low melting point agarose at a ratio of 1:10. The cell-agarose mixture was added to CometAssay ${ }^{\circledR}$ slides (R\&D Systems) and chilled at $4^{\circ} \mathrm{C} 20$ minutes. Slides were submerged in CometAssay® lysis solution (Trevigen) 30 minutes, rinsed with distilled water and submerged in enzyme digestion solution with proteinase $\mathrm{K}(1 \mathrm{mg} / \mathrm{ml})$ for $2 \mathrm{~h}$ at $37^{\circ} \mathrm{C}$. Slides were rinsed and immersed in chilled neutral electrophoresis buffer for 10 minutes. Electrophoresis was carried out in CometAssay ${ }^{\circledR}$ units (Trevigen) at $21 \mathrm{~V}$ in neutral electrophoresis buffer at $4^{\circ} \mathrm{C}$ for 20 minutes. Slides were sensed with distilled water and immersed in DNA precipitation solution for 30 minutes at room temperature. Cells were brought into a single plane by immersing in freshly prepared $70 \%$ ethanol for 5 minutes at room temperature. Slides dried overnight and were stained with SYBR green (Sigma Aldrich) 30 minutes.

Slides were analyzed using Comet Assay IV software (Instem). One hundred cells per concentration per time point were analyzed for tail intensity. Tail intensity measures the total intensity of the DNA in the tail. 


\section{Overexpression transfections}

Under certain conditions cells may have loss of protein expression that affects other functions in the cell. Overexpression plasmids that contain high copy numbers of a specific gene of interest can be transfected into cells to assess the effects reconstituting or overexpressing a specific gene. Specifically, plasmid vectors contain the gene of interest, the regulatory sequences required for transcription (enhancer and promoter regions) and antibiotic resistance sequences. These antibiotic resistance sequences allow for the correct selection of bacteria for expansion and isolation of plasmids to transfect into cells. Additionally, antibiotic resistance can be used to select for cells that were successfully transfected.

An E2F1 expression plasmid (HA-E2F1 wt-pRcCMV plasmid; Addgene21667) and CMV500 vector control (Addgene-33348) were acquired as bacterial stabs from Addgene. HA-E2F-1 wt-pRcCMV was a gift from William Kaelin (Addgene plasmid \# 21667; http://n2t.net/addgene:21667; RRID: Addgene_21667) (Krek et al., 1994). CMV500 empty vector was a gift from Charles Vinson (Addgene plasmid \# 33348; http://n2t.net/addgene:33348; RRID: Addgene_33348) (Rishi et al., 2004). Bacteria were streaked on agar plates and single colonies were selected for expansion in LB broth with ampicillin. The QIAGEN plasmid midi kit was used to isolate plasmids from bacteria according to the manufacturer's instructions. Briefly, Bacteria cultures were centrifuged at 6,000 $x \mathrm{~g}$ for 15 minutes at $4^{\circ} \mathrm{C}$. The pellet was resuspended in buffer, and DNA was eluted and precipitated. Concentration and purity were confirmed using a 
NanoDrop ND-1000 spectrophotometer. Plasmids were assessed for appropriate size by resolution on a DNA gel.

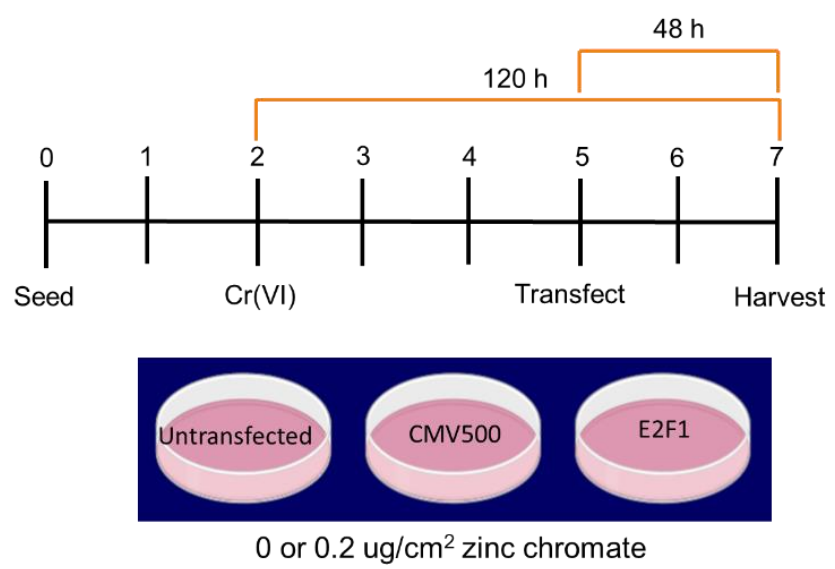

Figure 2.1. Exposure paradigm for E2F1 overexpression experiments following 120 h particulate $\mathrm{Cr}(\mathrm{VI})$ exposure.

WTHBF-6 cells were seeded and allowed to reenter logarithmic growth for $48 \mathrm{~h}$ before treating with zinc chromate. After $72 \mathrm{~h}$ zinc chromate treatment cells were transfected with Dharmafect kb transfection reagent (Horizon Discovery) per the manufacturer's instructions. Final concentration of plasmids were $1 \mathrm{ug} / \mathrm{ml}$ and final Dharmafect kb was $3 \mathrm{ul} / \mathrm{ml}$. After transfection cells were allowed to rest $48 \mathrm{~h}$ (total $120 \mathrm{~h}$ zinc chromate and $48 \mathrm{~h}$ plasmid treatment) and harvested for whole cell protein and immunofluorescence staining.

\section{RNAseq Analysis}

RNAseq is a genome wide expression profiling technique that uses nextgeneration sequencing and can be used to identify expression profiles of different types of RNAs or identify novel RNA transcripts. Here we have used RNAseq 
specifically to probe for miRNAs after treating WTHBF-6 cells with particulate $\mathrm{Cr}(\mathrm{VI})$. The goal was to identify which miRNAs are significantly upregulated or downregulated in response to $\mathrm{Cr}(\mathrm{VI})$ exposure, then identify the targets of those miRNAs, and which cellular pathways were targeted the most.

RNA isolation and next generation sequencing

WTHBF-6 cells were seeded, allowed to rest $48 \mathrm{~h}$ and treated with zinc chromate for 24,72 , or $120 \mathrm{~h}$. At harvest cells were harvested with the mirVana ${ }^{\mathrm{TM}}$ miRNA Isolation Kit (Thermo cat: AM1560) using manufacturer's instructions for the protocol to isolate total RNA. Briefly, cells were lysed directly in the culture plates and homogenized. RNA was extracted using acid-phenol:chloroform and the aqueous phase was transferred to filter cartridges. Total RNA was washed several times using ethanol and eluted into a fresh tube.

Samples were sent to the University of Louisville CGeMM DNA Facility Core for analysis. Library prep was performed using the TruSeq Small RNA Library Prep Kit v2 (Illumina) with gel purification followed by library validation and quantification to create miRNA libraries from $0.5-2$ ug total RNA. $1 \times 75$ bp sequencing was performed using NextSeq 500 High Output v2 (75 cycles) kit on the Illumina NextSeq500 instrument. Ten million reads per sample were generated.

\section{Bioinformatics}

RNA sequencing (RNA-Seq) reads were first filtered using fastx-toolkit (http://hannonlab.cshl.edu/fastx toolkit/) (Hannon, 2010). Adaptor sequence contamination, if it appeared in sequencing reads, were first removed. Base calls 
that show a Phred score $<20$ (i.e., base call error rate $>1 \%$ ) were subsequently trimmed from both ends of a sequencing read to preserve the longest section of a high-quality sequence read. Finally, sequencing reads that show base call quality $<20$ for over $25 \%$ of the remaining base calls were removed. For all data filter steps, sequencing reads with lengths $<15$ nucleotides were discarded. Filtered sequencing reads were mapped to human non-coding RNA reference transcriptome (Ensembl GRCh38) using Bowtie2 (Kim et al., 2013) 'end-to-end' mode, followed by discarding transcriptome mapping results that yielded mapping score $<20$ (i.e., > 1\% error rate) using samtools (Li et al., 2009; Li and Durbin, 2009). Expression profiles of all samples were next established using custom Perl scripts (Lu et al., 2017; Lu et al., 2018). Only transcripts identified as "miRNA" in Ensembl "transcript_biotype" database (Ensembl Version 98) were kept for further analyses.

\section{Differentially expressed miRNA analysis}

In order to identify differentially expressed miRNAs after $\mathrm{Cr}(\mathrm{VI})$ exposure raw read counts were normalized to fit a linear mixed effect model. miRNAs were removed from the analysis if the sum of the raw reads across all conditions was less than 10. Each raw read was divided by the sum of all the read counts in that sample and multiplied by $1,000,000$ (i.e. gene 1 normalized read $=$ raw read count of gene $1 /(\text { sum raw read of gene } 1+2+3+\ldots . . n)^{*} 1,000,000$. Adjusted $p$ values were determined using the Benjamini-Hochberg false discovery rate (FDR)-controlling method for multiple hypothesis testing. miRNAs were considered significant if they had an adjusted $p$ value less than 0.01 . 
Each treatment concentration $\left(0.1,0.2,0.3 \mathrm{ug} / \mathrm{cm}^{2}\right.$ zinc chromate) was compared to the $0 \mathrm{ug} / \mathrm{cm}^{2}$ zinc chromate control at its respective timepoint. These analyses were done using GraphPad Prism v8.4.2 to create volcano plots for each comparison. miRNAs were considered significantly up- or down-regulated for fold change if the $-\log _{10}$ (adjusted $p$-value) was greater than 2 and the $\log _{2}($ Fold change) was less than $\log _{2}(-2)$ or greater than $\log _{2}(2)$.

Venn diagrams were created to determine miRNAs significantly affected across treatment concentrations using the online tool Venny v2.1 (https://bioinfogp.cnb.csic.es/tools/venny/) (Oliveros, 2007-2015).

The Morpheus online data analysis tool (https://software.broadinstitute.org/morpheus/) (Broad Institute) was used to create heatmaps to visualize fold-change trends across treatments. miRNAs were included in this analysis if they had a p-value less than 0.01 and a fold change greater than 2 in at least one condition. Euclidean clustering using the average linkage method was applied. In a separate analysis Euclidean k-clustering using the average linkage method and a $\mathrm{k}=3$ was applied.

In some cases, the mean counts of miRNAs were reported as ' 0 ' in the control or treated concentrations. Therefore, errors occur in the fold change calculations. To deal with this issue ' 0.1 ' was added to all miRNA means (i.e. $0+$ $0.1=0.1 ; 20.2+0.1=20.3)$ for fold change analysis. Similarly, some adjusted $p$ values are reported as 0 because of the software analysis reporting methods. This means the adjusted $p$-value for that miRNA was less than 0.001 . Therefore, in 
order to avoid calculation errors in the Log(adjusted p-value) calculations 0.0001 was added to all the adjusted p-values.

\section{Pathway analysis}

For this analysis we performed a literature review of recent review papers on $\mathrm{Cr}(\mathrm{VI})$ to identify pathways involved in $\mathrm{Cr}(\mathrm{VI})$ carcinogenesis. Pathways involved in $\mathrm{Cr}(\mathrm{VI})$ carcinogenesis were then correlated to pathways identified in the Kyoto Encyclopedia of Genes and Genetics (KEGG) online database (https://www.genome.jp/kegg/). KEGG is an online resource used to understand high-level functions and relationships in biological systems. This database incorporates large-scale molecular datasets to identify relationships in biological systems to better understand interactions.

For each condition lists of miRNAs that fit within the parameters set for the volcano plot analysis (adjusted $p$-value $<0.01$, fold change $>2$ ) were populated. The DIANA TOOLS mirPath v.3 (http://snf-515788.vm.okeanos.grnet.gr/) was used to analyze the lists of miRNAs for each concentration at each timepoint (Vlachos et al., 2015). mirPath is a web-based pathway analysis software that uses statistical analysis of predicted or experimentally validated datasets of miRNAgene interactions and associates those interactions with pathways. The analysis can be performed using the KEGG analysis function or gene ontology (GO) analysis function. We were focused on pathway analysis and so the KEGG analysis function was applied. The analysis can be performed using either Tarbase v7.0, microT-CDS (v5.0), or TargetScan databases. Tarbase v7.0 accesses more than 65,000 miRNA-gene interactions from experimentally validated datasets. 
microT-CDS predicts miRNA Recognition Elements (MREs) in the CDS or 3'UTR regions of target genes. TargetScan is another predictive database that determines the biological targets of miRNAs including 8mer, $7 \mathrm{mer}$, and $6 \mathrm{mer}$ sites matching the seed region of miRNAs and 3' UTR sites on targets.

In this analysis we chose to use TargetScan in the mirPath analysis. The annotations for each significantly up- or down-regulated miRNA at each concentration and time point were converted from Ensembl Gene IDs (ENSG00000283751) to the miRBase ID annotation (hsa-miR-xxx) using the Biomart ensembl tool (https://useast.ensembl.org/info/data/biomart/index.html) (Hunt et al., 2018). The miRBase annotations were linked to the miRBase webpage where the MIMAT annotation determined and recorded for each miRNA. The MIMAT annotation was used for uploading the miRNA lists to the mirPath web page for analysis. Then the species was set to human, and the Targetscan database was selected for the analysis. The $p$-value threshold was set to 0.05 , the TargetScan Score Type was set to "Context + " with a score of -0.4 , and false discovery rate (FDR) correction was selected. Hierarchical clustering and miRNAKEGG heatmaps were created using the "Significance Clusters/Heatmaps" function, which utilizes the exact significance levels generated in the analysis. The Fisher's Exact Test (Hypergeometric Distribution) was applied as the enrichment analysis method and pathways were merged using the 'pathways union' function.

The pathways targeted by miRNAs in each timepoint and concentration in the mirPath results were cross-referenced with the pathways of $\mathrm{Cr}(\mathrm{VI})$ carcinogenesis identified in the KEGG database. 


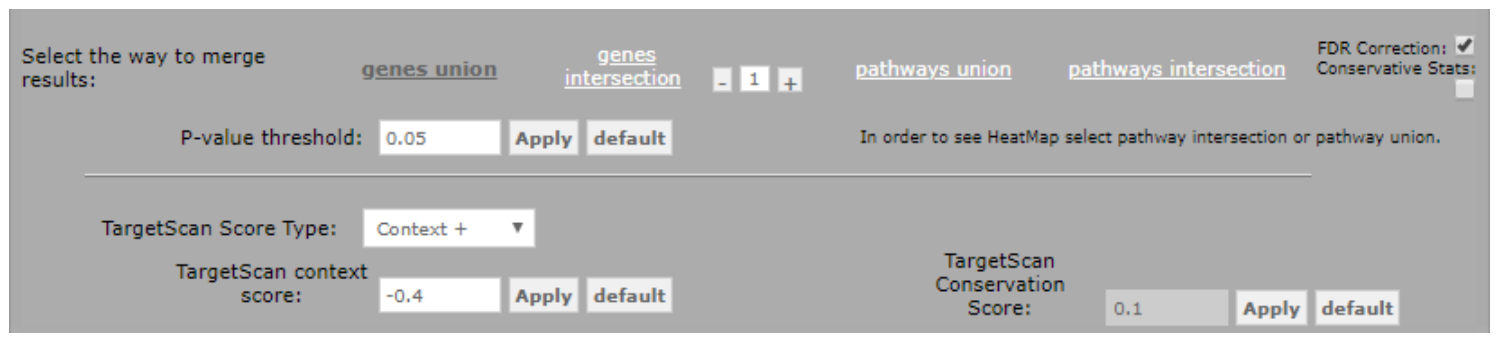

Figure 2.2. mirPath analysis settings.

Target gene analysis

Analysis was performed to assess miRNAs identified in the RNA seq analysis that affect RAD51. The online web software, miRSystem (http://mirsystem.cgm.ntu.edu.tw/index.php) was used to identify miRNAs that target RAD51 (Tzu-Pin et al., 2012). This database uses both miRNA target gene prediction programs (DIANA, miRanda, miRBRidge, PicTar, PITA, rna22, and TargetScan) and validated experimental data programs (TarBase and miRecords) to determine miRNA-gene associations. miRSystem has the ability to search data from miRNAs to target genes or target genes to miRNAs. For this analysis we used the "target genes to miRNAs" function to search for miRNAs that target RAD51. The results were downloaded which include all the miRNAs that regulate the target based on the 7 predictive programs and 2 experimental validation programs. The list of miRNAs from miRSystem was compared to the list of differentially expressed miRNAs determined in the RNA seq analysis at each time point and concentration. The list was separated by up- or down-regulated miRNAs.

We sought to characterize how well miRNAs significantly upregulated by $\mathrm{Cr}(\mathrm{VI})$ match (align) to the RAD51 mRNA transcript. This was done using an online 
platform, (http://www.microrna.org/microrna/home.do), which determines miRNA target sites on mRNA transcripts using the miRanda algorithm (Koppal et al., 2008, Enright et al., 2005) and mirSVR scores to determine the likelihood of binding (Koppal et al., 2010).

\section{siRNA transfections}

Small interfering RNAs (siRNAs) are short, non-coding RNA molecules usually about 20-25 base pairs in length that interfere in expression within the RNA interference pathway in cells. This mechanism has been adapted as a molecular technology developed to allow for testing the effects of loss of a target on cellular function. As a molecular tool, siRNAs are designed to be complementary to a target mRNA sequence. The siRNA binds to mRNA transcripts of target genes promoting degradation and preventing translation.

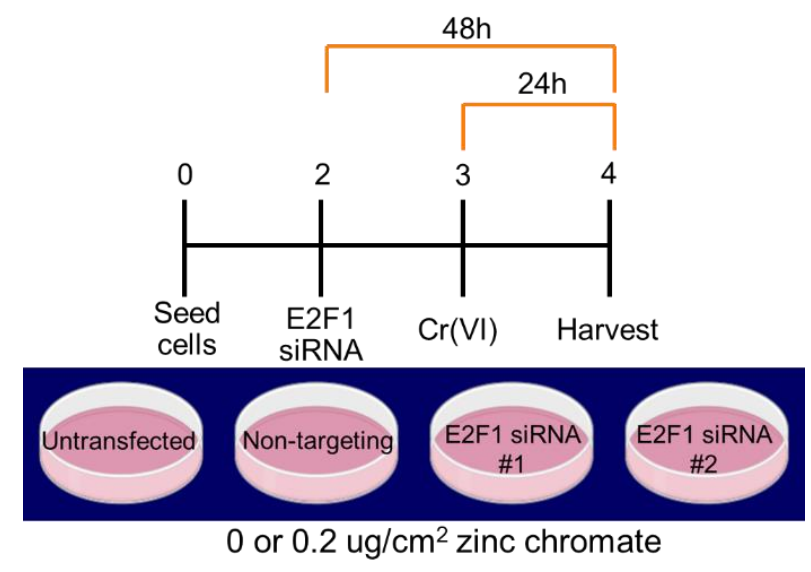

Figure 2.3. Exposure paradigm for E2F1 siRNA transfection after $24 \mathrm{~h}$ particulate $\mathrm{Cr}(\mathrm{VI})$ exposure. 
WTHBF-6 cells were seeded and allowed to reenter logarithmic growth for $48 \mathrm{~h}$ before siRNA transfection. Transfections were carried out per the manufacturer's suggestions with slight modifications. Dharmafect transfection reagent 1 (Dharmacon, Lafayette, CO) and E2F1 ON-TARGET plus siRNA \#09 (Dharmacon; J-003259-09-0005), E2F1 ON-TAREGET plus siRNA \#10 (Dharmacon; J-003259-10-0005), E2F1 ON-TARGET plus siRNA \#11 (Dharmacon; J-003259-11-0005), E2F1 ON-TARGET plus siRNA \#12 (Dharmacon; J-003259-12-0005), and ON-TARGET plus non-targeting control siRNA \#1 (Dharmacon; D-001810-01-05) were combined with serum-free and antibiotic free media 5 minutes separately. The siRNAs were then combined with the Dharmafect 20 minutes and added to the cells with antibiotic-free media. Final concentrations of Dharmafect and siRNAs were $2 \mathrm{ul} / \mathrm{ml}$, and $25 \mathrm{nM}$, respectively. After $24 \mathrm{~h}$ media was replaced, and cells were treated with zinc chromate for $24 \mathrm{~h}$ (48 $\mathrm{h}$ total transfection time). Cells were harvested for total RNA, whole cell protein, and immunofluorescence staining.

\section{Sister chromatid exchange assay}

The sister chromatid exchange assay is used as an indirect measure of homologous recombination repair (Sonoda et al 1999). This method involves the incorporation of 5-bromodeoxyuridine (BrdU) into DNA to visualize the reciprocal exchange of DNA that occurs during the crossing over of sister chromatids in homologous recombination repair. As a result, cells that have gone through two rounds of replication have chromosomes with one sister chromatid with BrdU incorporation. When these cells are stained the BrdU sister chromatid is visually 
light while the sister chromatid without BrdU is stained visibly dark resulting in harlequin staining. If homologous recombination occurred there is reciprocal exchange of DNA between the two chromatids. This method has been validated as a measure of homologous recombination repair, although it does not represent all possible repair products of homologous recombination repair due to variations in the resolution of holiday junctions.

For $24 \mathrm{~h}$ treatments PDGC9-1LU cells were seeded in $100 \mathrm{~mm}$ dishes with $0.6 \mathrm{ug} / \mathrm{ml} \mathrm{BrdU}$. Cells were allowed to rest for $48 \mathrm{~h}$ before replacing the media with fresh, warm media (with $0.6 \mathrm{ug} / \mathrm{ml} \mathrm{BrdU}$ also added fresh) and treating with 0, 0.1, $0.15,0.2,0.3$, and $0.4 \mathrm{ug} / \mathrm{cm}^{2}$ zinc chromate. For $120 \mathrm{~h}$ treatments PDGC9-1LU cells were seeded in $100 \mathrm{~mm}$ dishes and allowed to rest $48 \mathrm{~h}$ before replacing media with fresh, warm media and treating with $0,0.10 .15,0.2$, and $0.3 \mathrm{ug} / \mathrm{cm}^{2}$ zinc chromate. No metaphases were observed at $0.4 \mathrm{ug} / \mathrm{cm}^{2}$ zinc chromate after $120 \mathrm{~h}$ exposure and so was not included. $\mathrm{BrdU}(0.6 \mathrm{ug} / \mathrm{ml})$ was added $72 \mathrm{~h}(0,0.1$ and $0.15 \mathrm{ug} / \mathrm{cm}^{2}$ zinc chromate) and $96 \mathrm{~h}\left(0.2\right.$ and $0.3 \mathrm{ug} / \mathrm{cm}^{2}$ zinc chromate) before the end of treatment due to slowed growth rate at the higher concentrations.

Four hours before the end of the treatment time demecolcine was added to arrest cells in metaphase. At harvest, the media was collected to avoid loss of any loosely attached mitotic cells. Cells were washed with PBS (without calcium and magnesium) and trypsin was added to lift cells off the dishes. Cells were collected and centrifuged at $1000 \mathrm{rpm}$ for 5 minutes at $4^{\circ} \mathrm{C}$. The supernatant was aspirated, and the cell pellet was resuspended with $10 \mathrm{ml}$ of $0.75 \mathrm{M} \mathrm{KCl}$ for 17 minutes. One ml fixative (methanol:acetic acid; 3:1) was added and the cells were pelleted again 
by centrifugation 5 minutes at $4^{\circ} \mathrm{C}$ and $1000 \mathrm{rpm}$. The pellet was resuspended in $10 \mathrm{ml}$ fixative 20 minutes at room temperature, the fixative was changed twice, and cells were dropped onto wet microscope slides. Slides were dried overnight, soaked in PBS 5 minutes, and stained with $0.5 \mathrm{ug} / \mathrm{ml}$ Hoechst 33258 trihydrochloride trihydrate solution (Sigma Aldrich) for 10 minutes at room temperature. Excess solution was tapped off and several drops of $25 \mathrm{ug} / \mathrm{ml}$ Hoechst 33258 trihydrochloride trihydrate solution was added and a coverslip was added. Slides were incubated under fluorescent lights (27 W) for 10-12 hours in a humidified chamber $5 \mathrm{~cm}$ from the light source. At the end of the incubation the coverslips were washed off with distilled water and incubated in 2X sodium chloride/sodium citrate solution 15 minutes at $60^{\circ} \mathrm{C}$. Slides were rinsed with distilled water, stained with $4 \%$ Giemsa stain in Gurr's buffer 6 minutes, and coverslips were added with mounting medium. The average number of sister chromatid exchanges per chromosome was analyzed in 50 diploid cells with harlequin staining per concentration per time point.

\section{Statistics}

Results in Aims 1 and 3 are expressed as the mean +/- SEM (standard error of the mean) of at least 3 independent experiments unless otherwise noted. 2-way ANOVA with Tukey post-hoc analysis was used to determine the significance of $\mathrm{Cr}(\mathrm{VI})$ concentrations between exposure times (i.e. $24 \mathrm{~h} 0.1 \mathrm{ug} / \mathrm{cm}^{2} \mathrm{vs} .120 \mathrm{~h} 0.1$ $\mathrm{ug} / \mathrm{cm}^{2}$ zinc chromate) or between $\mathrm{Cr}(\mathrm{VI})$ concentrations within a single exposure time (i.e. $24 \mathrm{~h} 0 \mathrm{ug} / \mathrm{cm}^{2}$ zinc chromate vs. 24 h $0.1 \mathrm{ug} / \mathrm{cm}^{2}$ zinc chromate). When comparing between only 2 exposure concentrations Sidak's post-hoc analysis was 
used. Statistical significance was set at $p<0.5$. Statistical analysis was performed using GraphPad Prism v8.4.2.

In Aim 2, mean read counts are expressed as the mean of 3 independent experiments with 4 technical repeats resulting in an $n=12$. A linear mixed effect model was fit in R (https://www.r-project.org/) with the 'nlme' package (R core team, 2013). The Benjamini-Hochberg FDR-controlling method for multiple hypothesis testing was applied to determine adjusted $p$-values. Statistical significance was set at adjusted $p$-value $<0.01$. Statistical analysis was performed in $\mathrm{R}$ using the 'stats' package.

\section{Total RNA Isolation and qPCR}

Quantitative real-time polymerase chain reaction ( $q P C R$ ) is a technique used to quantify levels of RNA transcripts in a sample to better understand changes in expression. This technique requires isolating RNA, which is reverse transcribed to cDNA. The cDNA is then used in a polymerase chain reaction (PCR) to amplify the number of cDNA transcripts. One technique to quantitatively assess this PCR reaction is using Taqman tools. Taqman uses primer-probe assays that target specific sequences with attached fluorescent probes and a quencher inhibiting fluorescent signaling. During the amplification process the primer-probe binds its target sequence and after polymerization the fluorescent probe is cleaved and separated from the attached quencher resulting in a fluorescent signal. This signal is then detected by the qPCR machine to quantitate the level of transcripts present. 
WTHBF-6 cells were seeded and allowed to reenter logarithmic growth for $48 \mathrm{~h}$ before treating with zinc chromate for 24,72 , or $120 \mathrm{~h}$. Total RNA was isolated from WTHBF-6 cells using the mirVana ${ }^{\mathrm{TM}}$ miRNA Isolation Kit. The protocol for total RNA was applied. Briefly, cells were lysed directly in the culture plates and homogenized. RNA was extracted using acid-phenol:chloroform and the aqueous phase was transferred to filter cartridges. Total RNA was washed several times using ethanol and eluted into a fresh tube. RNA quality and concentration was measured using a NanoDrop ND-1000 spectrophotometer.

cDNA synthesis was carried out using a High Capacity cDNA Reverse Transcription Kit (Thermo Fisher Inc.) per the manufacturer's instructions with slight modifications. Briefly, 2X RT master mix was prepared using random primers, combined with 2 ug total RNA (per 20 ul reaction), and loaded onto a 96well plate. A no reverse transcriptase control and no RNA control were included in each reverse transcription reaction. Reverse transcription was carried out as shown in Table 2.1.

Table 2.1. Reverse Transcription Conditions

\begin{tabular}{|l|c|c|c|c|}
\hline & Step 1 & Step 2 & Step 3 & Step 4 \\
\hline $\begin{array}{l}\text { Temperature } \\
\text { (으) }\end{array}$ & 25 & 37 & 85 & 4 \\
\hline Time & $10 \mathrm{~min}$ & $120 \mathrm{~min}$ & $5 \mathrm{~min}$ & $\infty$ \\
\hline
\end{tabular}

qPCR analysis was carried out using the TaqMan RNA assays per the manufacturer's instructions with slight modifications. Briefly, TaqMan RNA primers (E2F1- Hs00153451_m1; RAD51-Hs00947967_m1; GAPDH- Hs02786624_g1 or 
Hs02758991_g1) were combined with TaqMan ${ }^{\text {TM }}$ Fast Advanced Master Mix (Thermo Fisher Inc.) and cDNA in triplicate in a 96 well plate. The no RNA and no reverse transcriptase controls from cDNA synthesis and a no cDNA control were included in all qPCR runs. qPCR was carried out using a StepOnePlus Real-Time PCR system (Applied Biosystems) using conditions shown in Table 2.2. The CT threshold was set by the instrument's calculations and results are displayed as $\Delta \Delta \mathrm{Ct}$ values relative to the untreated $\left(0 \mathrm{ug} / \mathrm{cm}^{2}\right.$ zinc chromate) control for each time point, respectively.

Table 2.2. qPCR Conditions

\begin{tabular}{|l|c|c|c|c|}
\hline \multicolumn{2}{|c|}{} & \multicolumn{2}{c|}{ Cycle (40 cycles) } \\
\hline $\begin{array}{l}\text { Temperature } \\
\text { (으) }\end{array}$ & 50 & 95 & 95 & 60 \\
\hline Time & $2 \mathrm{~min}$ & $10 \mathrm{~min}$ & $15 \mathrm{sec}$ & $60 \mathrm{sec}$ \\
\hline
\end{tabular}




\section{CHAPTER 3: RESULTS}

\section{Aim 1: Determine if E2F1 modulates the RAD51 response to particulate $\mathrm{Cr}(\mathrm{VI})$ exposure.}

\section{Background}

Data show chromosome instability is a primary driver of $\mathrm{Cr}(\mathrm{VI})$ carcinogenesis (Chen et al., 2019; Rager et al., 2019; Wise et al., 2018). However, the mechanisms of $\mathrm{Cr}(\mathrm{VI})$-induced structural chromosome instability are not fully elucidated. $\mathrm{Cr}(\mathrm{VI})$ induces DNA double strand breaks resulting in structural chromosome instability (Holmes et al., 2008). We showed $\mathrm{Cr}(\mathrm{VI})$ inhibits the effector step of homologous recombination repair by interfering with RAD51 (Qin et al., 2014; Browning et al., 2016; Browning et al., 2017a). Reduced protein expression is a key effect of particulate $\mathrm{Cr}(\mathrm{VI})$ exposure that at a fundamental level can affect other particulate $\mathrm{Cr}(\mathrm{VI})$-induced RAD51 phenotypes including loss of nuclear foci formation. However, mechanisms of RAD51 protein loss after $\mathrm{Cr}(\mathrm{VI})$ exposure are not known.

There are two possible mechanisms for reduced RAD51 protein levels increased protein degradation or decreased protein production. Particulate $\mathrm{Cr}(\mathrm{VI})$ can induce increased protein degradation. Indeed, Bruno et al., 2016 found protein degradation pathways were deregulated following $\operatorname{Cr}(\mathrm{VI})$ exposure in $\mathrm{BEAS}-2 \mathrm{~B}$ cells. Particulate $\mathrm{Cr}(\mathrm{VI})$ can interfere with protein production by inhibiting 
transcription. Numerous studies show $\mathrm{Cr}(\mathrm{VI})$ causes global downregulation of expression (Andrew et al., 2003; Wetterhahn and Hamilton, 1989; Ye et al., 2001). Downregulation of factors involved in DNA repair has been observed following $\mathrm{Cr}(\mathrm{VI})$ exposure (Hodges and Chipman, 2002; Hu et al., 2018). For example, Hu et al., 2018 found $\operatorname{Cr}(\mathrm{VI})$ exposure inhibited transcription of MGMT, XRCC1, ERCC3, and RAD51 in 16HBE cells.

RAD51 expression is tightly regulated in normal cells. Studies show overexpression of RAD51 can lead to aberrant recombinase activity and RAD51 binding to chromatin resulting in genomic instability (Raderschall et al., 2002). Meanwhile, adequate RAD51 protein levels must be maintained to enable a response to DNA double strand breaks from both endogenous and exogenous insults. Therefore, understanding transcriptional regulation of RAD51 is critical to understand how $\mathrm{Cr}(\mathrm{VI})$ is affecting RAD51 expression.

Hasselbach et al., 2005 characterized the RAD51 promoter and identified transcription factors ETS1/PEA3, E2F,TP53, EGR1, and STAT5 bind to the RAD51 promoter. These transcription factors have different numbers of binding sites and are either activating or repressive (Table 3.1).

Table 3.1. RAD51 transcriptions factor activity

\begin{tabular}{|l|c|c|}
\hline $\begin{array}{c}\text { Transcription } \\
\text { Factor }\end{array}$ & $\begin{array}{c}\text { Activating or } \\
\text { Repressive }\end{array}$ & $\begin{array}{c}\text { Number of } \\
\text { Binding Sites }\end{array}$ \\
\hline ETS1/PEA3 & Activating & 1 \\
\hline E2F & Activating & 4 \\
\hline p53 & Repressive & 3 \\
\hline EGR1 & Activating & 2 \\
\hline STAT5 & Activating & 1 \\
\hline
\end{tabular}


RAD51 has a TATA-less and GC-rich promoter that ranges from base pairs - 543 to +204 (747 total base pairs) relative to the transcription start site. There are 3 cis-sequence elements responsible for RAD51 transcription, 1 for basal expression and 2 that limit the expression. The core promoter element is located from base pairs -204 to -5 and shares a consensus sequence for transcription factor binding also found in the BRCA1 promoter that is specifically targeted by the E2F family of transcription factors (Bindra and Glazer 2007; Hegan et al., 2009; Xie et al., 2013) (Figure 3.1).

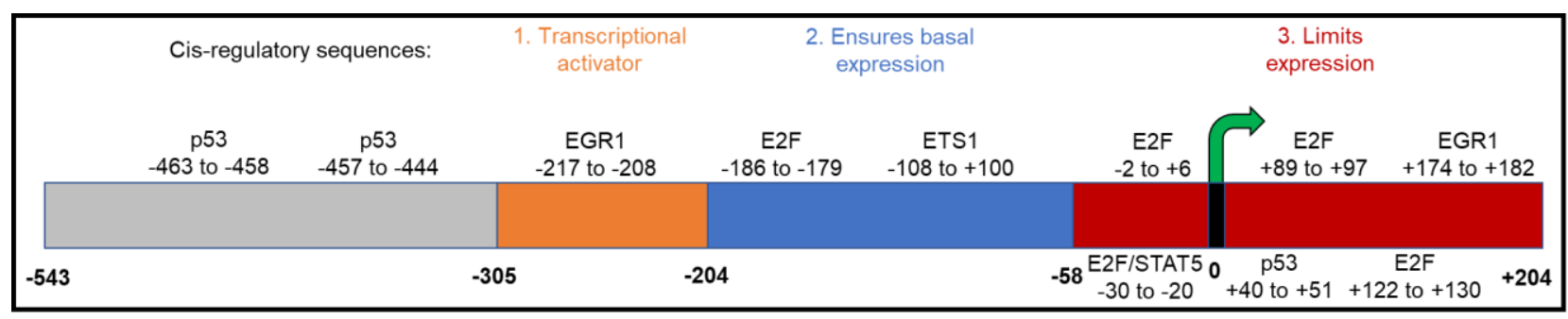

Figure 3.1. Working model of the RAD51 promoter. This figure shows a model of the RAD51 promoter elements that regulate expression based on data from Hasselbach et al., 2005. It shows 3 cis-regulatory elements; one that may limit expression (-305 to -204) one that enhances expression (-204 to -58) and one that limits expression (58 to +204$)$. It also shows the binding sites of each transcription factor identified.

E2F1 is a transcription factor involved in the expression of RAD51 and in the recruitment and stability of DNA repair proteins at double strand breaks. Studies have identified E2F1 as the predominant transcription factor for RAD51 and show knockdown of E2F1 results in loss of RAD51 protein, mRNA, and nuclear foci (Chen et al., 2011; Choi and Kim, 2019; Wu et al., 2014). 
E2F1 is normally held in a transcriptionally inactive state by the retinoblastoma (RB) pocket protein. Phosphorylation of RB releases E2F1, which can then perform its transcriptional function (Liao et al., 2010; Rubin, 2013). In addition to release from RB, E2F1 is stabilized by post-translational modifications following genotoxic stress increasing E2F1's ability to assist in DNA repair through transcription activation of DNA repair proteins, and direct involvement in the repair process (Glorian et al 2017; lanari et al., 2004).

E2F4 is a repressive member of the E2F family of transcription factors and has been shown to directly compete with E2F1 for promoter binding. Indeed, Bindra et al., 2007 showed E2F1 and E2F4 bind to the same region of the RAD51 promoter. E2F4 is a part of the DREAM complex, which includes the pocket protein p130. Hypophospho-p130 binds to E2F4, which then translocates to promoters. The hypo-phosphorylation of p130 enhances the formation of the DREAM complex and is facilitated by p53. However, p53 has also been shown to directly repress RAD51 transcription by binding the promoter itself (Hine et al., 2014; Arias-Lopez et al., 2005; Hannay et al., 2007). The repressive DREAM complex can displace the activating E2F1 complex at promoters leading to transcriptional repression, although this mechanism is not well understood. Studies show the DREAM complex downregulates DNA repair and facilitates a G2 arrest following DNA damage (Fischer et al., 2014; Jaber et al., 2016).

Other transcription factors have been less characterized for RAD51 transcription. Hasselbach et al., 2005 reported ETS1/PEA3 was included as a transcription factor at the RAD51 promoter, but acknowledges this protein is often a co-enhancer of transcription instead of being the predominant activator. While 
Hasselbach et al., 2005 suggested EGR1 may be inhibitory, Hine et al., 2014 found deletion of the EGR1 binding site reduced RAD51 expression by $40 \%$. Hine et al., 2014 also characterized the RAD51 promoter with slightly different results than Hasselbach et al., 2005. This may be due to the different cell types each used and preparation of the constructs in their experiments.

Although studies have begun to characterize transcriptional control of the RAD51 promoter it is still unknown if RAD51 transcription is inhibited following $\mathrm{Cr}(\mathrm{VI})$ exposure. We determined if particulate $\mathrm{Cr}(\mathrm{VI})$-induced reduction of RAD51 protein is due to altered protein half-life or reduced expression (Objective 1). Because E2F1 is the predominant transcription factor for RAD51 we assessed the effects of particulate $\mathrm{Cr}(\mathrm{VI})$ exposure on E2F1 (Objective 2). Finally, to further explore the role of E2F1 in the RAD51 response we assessed if E2F1 could modulate RAD51 after particulate $\mathrm{Cr}(\mathrm{VI})$ exposure (Objectives 3-4). All experiments in this aim were done in WTHBF-6 cells.

\section{Results}

Objective 1: Particulate Cr(VI)-induced reduction of RAD51 protein is a result of inhibited expression

We showed particulate $\mathrm{Cr}(\mathrm{VI})$ reduces RAD51 whole cell protein (Browning et al., 2016). We confirmed this effect using the cell-equivalence western blot method. Figure 3.2A shows representative western blots of whole cell RAD51 protein. RAD51 whole cell protein is unaffected after $24 \mathrm{~h}$ particulate $\mathrm{Cr}(\mathrm{VI})$ exposure, but decreases after prolonged 72 and $120 \mathrm{~h}$ exposure in a concentration- and time-dependent manner (Figure 3.2B) consistent with previous results. Specifically, $24 \mathrm{~h}$ exposure to $0.1,0.2$ and $0.3 \mathrm{ug} / \mathrm{cm}^{2}$ zinc chromate 
increased then decreased RAD51 whole cell protein to 109,90 , and $81 \%$ of control. RAD51 whole cell protein was decreased to 70,28 , and $11 \%$ after $72 \mathrm{~h}$ and further to 40,20 , and $6 \%$ of control after $120 \mathrm{~h}$ at $0.1,0.2$ and $0.3 \mathrm{ug} / \mathrm{cm}^{2}$ zinc chromate, respectively. All zinc chromate concentrations RAD51 protein levels were significantly reduced compared to the control after prolonged 72 and $120 \mathrm{~h}$ exposure $(p<0.0001)$. However, the small reductions observed after $24 \mathrm{~h}$ zinc chromate exposure were not statistically significant. 
A. Zinc chromate conc. (ug/ $\mathrm{cm}^{2}$ )

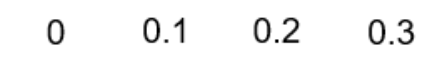

$24 \mathrm{~h}$
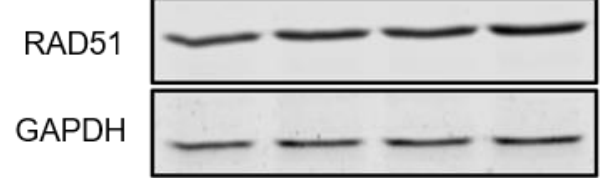

RAD51

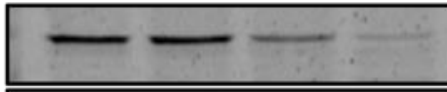

GAPDH

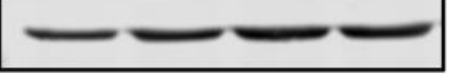

RAD51

$120 \mathrm{~h}$

GAPDH



B.

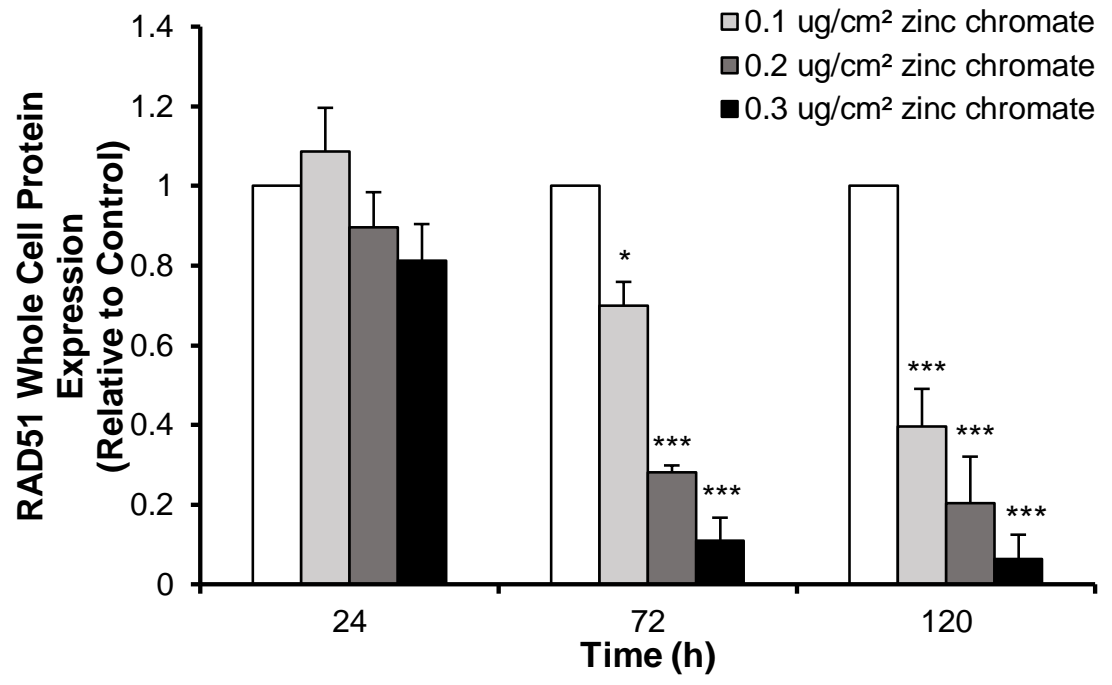

Figure 3.2. Prolonged exposure to particulate $\mathrm{Cr}(\mathrm{VI})$ reduces RAD51 whole cell protein expression. This figure shows $(A)$ representative western blot images of whole cell RAD51 and (B) RAD51 whole cell protein (relative to control) decreased with concentration and time after 72 and $120 \mathrm{~h}$, but not $24 \mathrm{~h}$ exposure. GAPDH was used as a loading control. When comparing zinc chromate concentrations between time points all concentrations were statistically significant $(p<0.01)$ between 24 and $72 \mathrm{~h}$ or 24 and $120 \mathrm{~h}$ exposure. Data 
represent the mean of three experiments. Error bars = standard error

of the mean. Statistically different from the control: ${ }^{*} p<0.05$;

${ }^{* * *} p<0.0001$. 
RAD51 protein reduction after particulate $\mathrm{Cr}(\mathrm{VI})$ exposure could be due to an increase in protein degradation. One component of assessing protein degradation is protein half-life. To assess if $\mathrm{Cr}(\mathrm{VI})$ affects RAD51 protein half-life cells were treated with 0 or $0.2 \mathrm{ug} / \mathrm{cm}^{2}$ zinc chromate for 24 or $120 \mathrm{~h}$ and at the end of treatment a protein translation inhibitor, cycloheximide $(\mathrm{CHX})$, was added and a $12 \mathrm{~h}$ time course was performed to harvest protein. Figure 3.3A shows a representative western blot for RAD51 whole cell protein after 24 or $120 \mathrm{~h}$ zinc chromate exposure and a $12 \mathrm{~h} \mathrm{CHX}$ treatment time course. RAD51 whole cell protein levels decreased significantly beginning at $4 \mathrm{~h}$ after the addition of $\mathrm{CHX}$ after $24 \mathrm{~h} 0$ and $0.2 \mathrm{ug} / \mathrm{cm}^{2}$ zinc chromate exposure compared to the $0 \mathrm{~h}$ time point (Figure 3.3B). RAD51 protein was significantly reduced 4 and $6 \mathrm{~h}$ hours after the addition of $\mathrm{CHX}$ in 0 and $0.2 \mathrm{ug} / \mathrm{cm}^{2}$ zinc chromate treated cells, respectively (Figure 3.3C). There was no difference in RAD51 protein half-life comparing 0.2 $\mathrm{ug} / \mathrm{cm}^{2}$ zinc chromate to the control or between exposure time points. Table 3.2 shows the calculated half-life of RAD51 after 24 or $120 \mathrm{~h}$ zinc chromate exposure compared to the controls and confirms $\mathrm{Cr}(\mathrm{VI})$ has little effect on RAD51 protein half-life. 



Time (h)



Time (h)

Figure 3.3. Particulate $\mathrm{Cr}(\mathrm{VI})$ has little effect on RAD51 protein halflife. This figure shows (A) representative images of RAD51 whole cell 
protein (relative to the $0 \mathrm{~h} \mathrm{CHX}$ control for either the 0 or $0.2 \mathrm{ug} / \mathrm{cm}^{2}$ zinc chromate condition) after 24 and $120 \mathrm{~h}$ zinc chromate exposure and $12 \mathrm{~h} \mathrm{CHX}$ exposure. Data represent the mean of three experiments. Error bars = standard error of the mean. Exposure to (B) 24 and (C) $120 \mathrm{~h}$ zinc chromate has little effect on RAD51 protein half-life. GAPDH was used as a loading control. RAD51 whole cell protein significantly decreased compared to $0 \mathrm{~h} \mathrm{CHX}$ following the addition of $\mathrm{CHX}$ in all conditions. Statistically different compared to 0 h CHX: ${ }^{* *} p<0.01 ;{ }^{* * *} p<0.0001$. 
Table 3.2. RAD51 protein half-life

\begin{tabular}{|c|c|c|}
\hline $\begin{array}{c}\text { Zinc chromate } \\
\text { conc. }\left(\mathbf{u g} / \mathbf{c m}^{2}\right)\end{array}$ & $\mathbf{2 4} \mathbf{~ h}$ & $\mathbf{1 2 0} \mathbf{~ h}$ \\
\hline $\mathbf{0}$ & $5.17 \mathrm{~h}$ & $5.59 \mathrm{~h}$ \\
\hline $\mathbf{0 . 2}$ & $4.35 \mathrm{~h}$ & $5.92 \mathrm{~h}$ \\
\hline
\end{tabular}

Table 3.2. shows RAD51 protein half-life in hours after 24 or $120 \mathrm{~h}$ exposure to 0 or $0.2 \mathrm{ug} / \mathrm{cm}^{2}$ zinc chromate. 
The RAD51 protein half-life data indicates protein degradation is not significantly contributing to the reduction of RAD51 protein observed after prolonged particulate $\mathrm{Cr}(\mathrm{VI})$ exposure suggesting the effect is on protein production. To test this possibility, we measured RAD51 mRNA levels using qPCR. Particulate $\mathrm{Cr}(\mathrm{VI})$ inhibited RAD51 mRNA moderately after $24 \mathrm{~h} 0.1,0.2$, and 0.3 $\mathrm{ug} / \mathrm{cm}^{2}$ zinc chromate exposure to 83,73 , and $62 \%$ compared to control although none were significant (Figure 3.4). Prolonged exposure of 72 and $120 \mathrm{~h} 0.1,0.2$ and $0.3 \mathrm{ug} / \mathrm{cm}^{2}$ zinc chromate reduced RAD51 mRNA to 49,31 , and $16 \%$ and 53 , 21 and $24 \%$ of control, respectively. After prolonged exposure of both 72 and 120 h RAD51 mRNA was significantly reduced at all concentrations compared to control and compared to the respective concentration after $24 \mathrm{~h}$ exposure. 


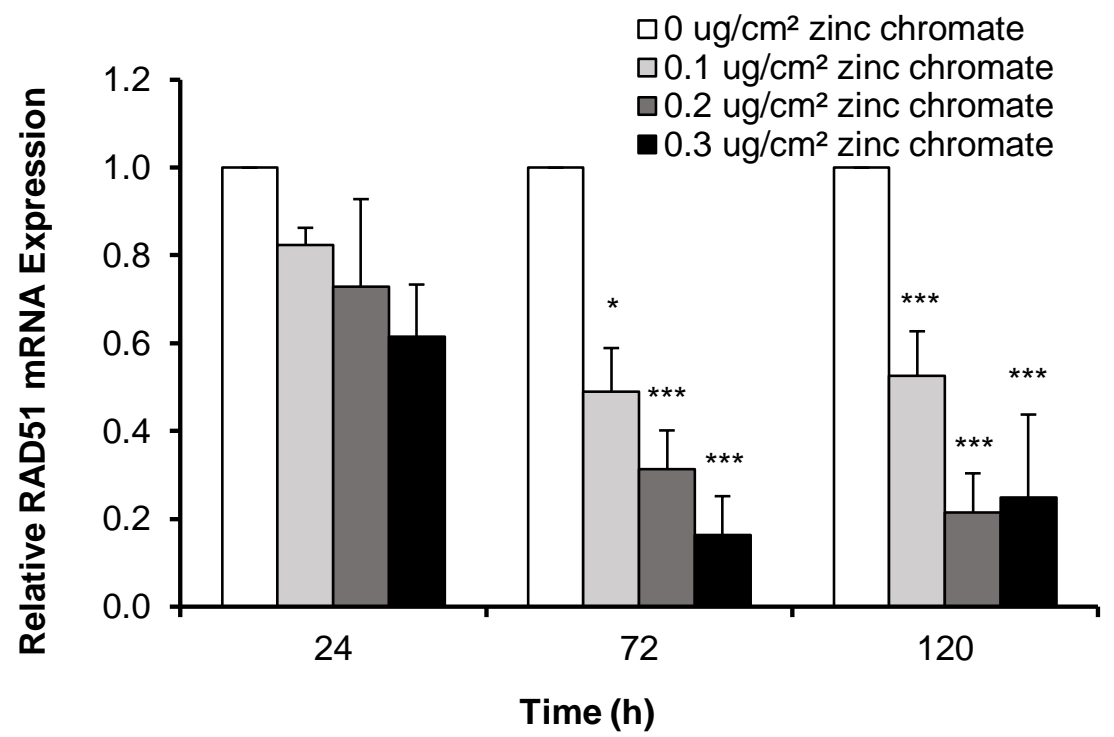

Figure 3.4. Particulate $\mathrm{Cr}(\mathrm{VI})$ inhibits RAD51 mRNA. This figure shows after prolonged 72 and $120 \mathrm{~h}$ exposure zinc chromate inhibits RAD51 mRNA levels. GAPD was used to normalize RAD51 mRNA levels. RAD51 mRNA level was significantly reduced at all concentrations after 72 and $120 \mathrm{~h}$ exposure compared to control $\left({ }^{*} \mathrm{p}<0.05 ;{ }^{* *} \mathrm{p}<0.0001\right)$. RAD51 mRNA at all zinc chromate-treated concentrations was significantly decreased after 72 and $120 \mathrm{~h}$ compared to the respective concentration at $24 \mathrm{~h}$ exposure. Data represent the mean of three experiments. Error bars = standard error of the mean. 


\section{Objective 2: Particulate $\mathrm{Cr}(\mathrm{VI})$ inhibits E2F1 expression}

The combination of protein half-life and qPCR data suggests the reduction of RAD51 protein following particulate $\mathrm{Cr}(\mathrm{VI})$ exposure is primarily a result of inhibited transcription. We sought to further investigate how $\mathrm{Cr}(\mathrm{VI})$ inhibits RAD51 expression. We chose to focus on E2F1, the predominant transcription factor for RAD51, to assess how particulate $\mathrm{Cr}(\mathrm{VI})$ exposure affects E2F1 expression.

Figure 3.5A shows representative E2F1 whole cell western blots. Similar to the effects on RAD51, particulate $\mathrm{Cr}(\mathrm{VI})$ did not affect E2F1 whole cell protein levels after $24 \mathrm{~h}$ exposure (84, 103 and $88 \%$ of control), but decreased levels to 57,48 , and $41 \%$ and 43,47 , and $55 \%$ after 72 and 120 h $0.1,0.2$, and $0.3 \mathrm{ug} / \mathrm{cm}^{2}$ zinc chromate exposure, respectively (Figure 3.5B). E2F1 whole cell protein was decreased significantly compared to the control after $72 \mathrm{~h} 0.3 \mathrm{ug} / \mathrm{cm}^{2}$ and $120 \mathrm{~h}$ $0.1 \mathrm{ug} / \mathrm{cm}^{2}$ zinc chromate, however all zinc chromate treated concentrations are clearly repressed compared to control at these time points.

E2F1 self-regulates its own transcription and we found prolonged particulate $\mathrm{Cr}(\mathrm{VI})$ exposure inhibits E2F1 protein expression (Johnson et al., 1994). We tested if particulate $\mathrm{Cr}(\mathrm{VI})$ inhibits E2F1 mRNA levels using qPCR following particulate $\mathrm{Cr}(\mathrm{VI})$ exposure. Particulate $\mathrm{Cr}(\mathrm{VI})$ inhibited E2F1 mRNA levels after 24, 72, and $120 \mathrm{~h}$ exposure (Figure 3.6). After $24 \mathrm{~h} \mathrm{E2F1} \mathrm{mRNA} \mathrm{was} \mathrm{reduced} \mathrm{to}$ 82,55 , and $56 \%$ of control following $0.1,0.2$, and $0.3 \mathrm{ug} / \mathrm{cm}^{2}$ zinc chromate, and further decreased to 45,28 , and $18 \%$ of control after 72 and h. E2F1 mRNA remained low after $120 \mathrm{~h}$ decreasing to 55,26 , and $36 \%$ of control. At all time points each concentration was significantly decreased compared to control except $24 \mathrm{~h} 0.1 \mathrm{ug} / \mathrm{cm}^{2}$ zinc chromate. All concentrations after prolonged exposure of 72 
and $120 \mathrm{~h}$ were significantly decreased compared to the respective acute $24 \mathrm{~h}$ concentration. 
A. Zinc chromate

conc. (ug/ $\left./ \mathrm{cm}^{2}\right)$


Figure 3.5. Prolonged particulate $\mathrm{Cr}(\mathrm{VI})$ inhibits E2F1 whole cell protein. This figure shows E2F1 whole cell protein is reduces after prolonged 72 and $120 \mathrm{~h}$ exposure to zinc chromate. Data represent the mean of three experiments. Error bars $=$ standard error of the mean. (A) Representative images of E2F1 whole cell protein western blots. GAPDH was used as a loading control. (B) E2F1 whole cell protein (relative to control). Statistically significant compared to control: ${ }^{*} \mathrm{p}<0.05$. 


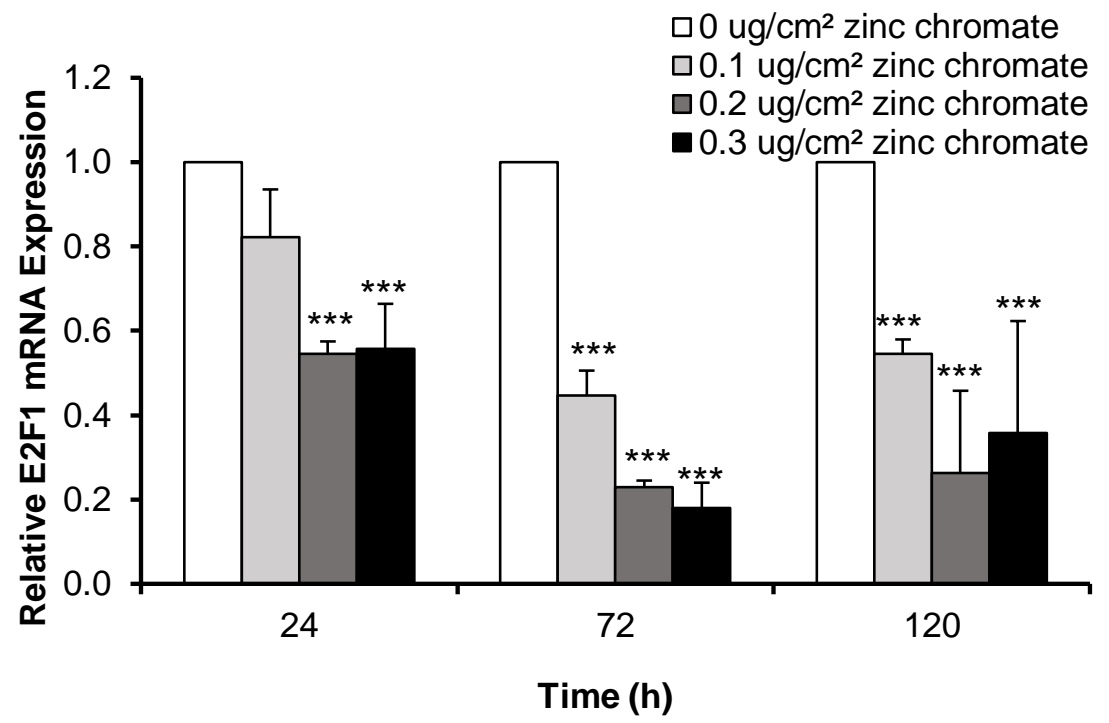

Figure 3.6. Particulate $\mathrm{Cr}(\mathrm{VI})$ inhibits $\mathrm{E} 2 \mathrm{~F} 1 \mathrm{mRNA}$ levels. This figure shows 24, 72 and $120 \mathrm{~h}$ zinc chromate exposure inhibits E2F1 mRNA levels. GAPD was used as to normalize E2F1 mRNA levels. E2F1 mRNA level was significantly reduced at all concentrations compared to control except $24 \mathrm{~h} 0.1 \mathrm{ug} / \mathrm{cm}^{2}$ zinc chromate $\left({ }^{* * *} p<0.0001\right)$. E2F1 mRNA at all zinc chromate-treated concentrations was significantly decreased after 72 and $120 \mathrm{~h}$ compared to the respective concentration at $24 \mathrm{~h}$ exposure. Data represent the mean of three experiments. Error bars = standard error of the mean. 


\section{Objective 3: E2F1 overexpression does not rescue $\mathrm{Cr}(\mathrm{VI})$-induced RAD51}

\section{failure}

Particulate $\mathrm{Cr}(\mathrm{VI})$ induces a normal RAD51 response after acute $24 \mathrm{~h}$ exposure and an abnormal response after $120 \mathrm{~h}$ exposure characterized by inhibited protein expression and RAD51 nuclear foci formation and increased RAD51 cytoplasmic accumulation (Browning et al., 2016; Qin et al., 2014). Here, we show particulate $\mathrm{Cr}(\mathrm{VI})$ inhibits RAD51 mRNA indicating RAD51 expression specifically is impaired following exposure (Figure 3.4). We also showed the expression of the predominant transcription factor for RAD51, E2F1, was also suppressed following particulate $\mathrm{Cr}(\mathrm{VI})$ exposure (Figure 3.6). Therefore, we wanted to connect the correlating data between RAD51 and E2F1 impairment following particulate $\mathrm{Cr}(\mathrm{VI})$ exposure. We sought to determine if overexpression of E2F1 could offset the $\mathrm{Cr}(\mathrm{VI}$-reduced E2E1 protein levels to rescue $\mathrm{Cr}(\mathrm{VI})$-induced RAD51 failure after $120 \mathrm{~h}$ exposure. To test this connection, cells were treated with zinc chromate for $120 \mathrm{~h}$. For the last $48 \mathrm{~h}$ of exposure cells were transfected with either a plasmid vector control (CMV500) or E2F1 overexpression plasmid. At harvest, cells were collected for protein or fixed for immunofluorescence staining. Figure 3.7 shows E2F1 was successfully transfected into WTHBF-6 cells. After $120 \mathrm{~h}$ exposure to 0 and $0.2 \mathrm{ug} / \mathrm{cm}^{2}$ zinc chromate E2F1 protein was 6220 and 5630 percent of the untransfected control. 




Figure 3.7. Transfection with E2F1 overexpression plasmid increases E2F1 whole cell protein. This figure shows E2F1 protein increases following transfection with E2F1 overexpression plasmid compared to untransfected cells and the transfection control plasmid (CMV500). E2F1 protein was normalized to GAPDH as a loading control. Data represent the mean of two experiments. Error bars = standard error of the mean. 
RAD51 cytoplasmic accumulation is a key phenotype observed after prolonged exposure to particulate $\mathrm{Cr}(\mathrm{VI})$, however, the function of RAD51 is in the nucleus. (Browning et al., 2016; Qin et al. ,2014). The mislocalization of RAD51 in the cytoplasm may inhibit RAD51 from participating in homologous recombination repair. We used immunofluorescence staining and confocal microscopy to analyze RAD51 cytoplasmic accumulation following $120 \mathrm{~h}$ particulate chromium exposure and E2F1 overexpression.

Figure 3.8A shows representative images of WTHBF-6 cells exposed to 120 h 0 or $0.2 \mathrm{ug} / \mathrm{cm}^{2}$ zinc chromate with or without transfection. Cells were considered positive for cytoplasmic accumulation if the cytoplasmic intensity was greater than $95 \%$ of control cells. All conditions were compared to the untransfected $0 \mathrm{ug} / \mathrm{cm}^{2}$ zinc chromate control. Following $120 \mathrm{~h}$ exposure to $0.2 \mathrm{ug} / \mathrm{cm}^{2}$ zinc chromate $43 \%$ of cells were positive for RAD51 cytoplasmic accumulation consistent with previously published data (Browning et al., 2016)(Figure 3.8B). If E2F1 rescued particulate $\mathrm{Cr}(\mathrm{VI})$-induced RAD51 cytoplasmic accumulation we would expect to see lower cytoplasmic accumulation levels in the E2F1 overexpression-transfected cells compared to the CMV500 transfection control. However, the percent of cells with RAD51 cytoplasmic accumulation was decreased in both the CMV500 control and E2F1-transfected cells. Additionally, there was no difference between control and $0.2 \mathrm{ug} / \mathrm{cm}^{2}$ zinc chromate treated cells in either transfection condition. This indicates the transfection procedure itself, not E2F1 overexpression caused the reduction in RAD51 cytoplasmic accumulation after $120 \mathrm{~h}$ particulate $\operatorname{Cr}(\mathrm{VI})$ exposure. 

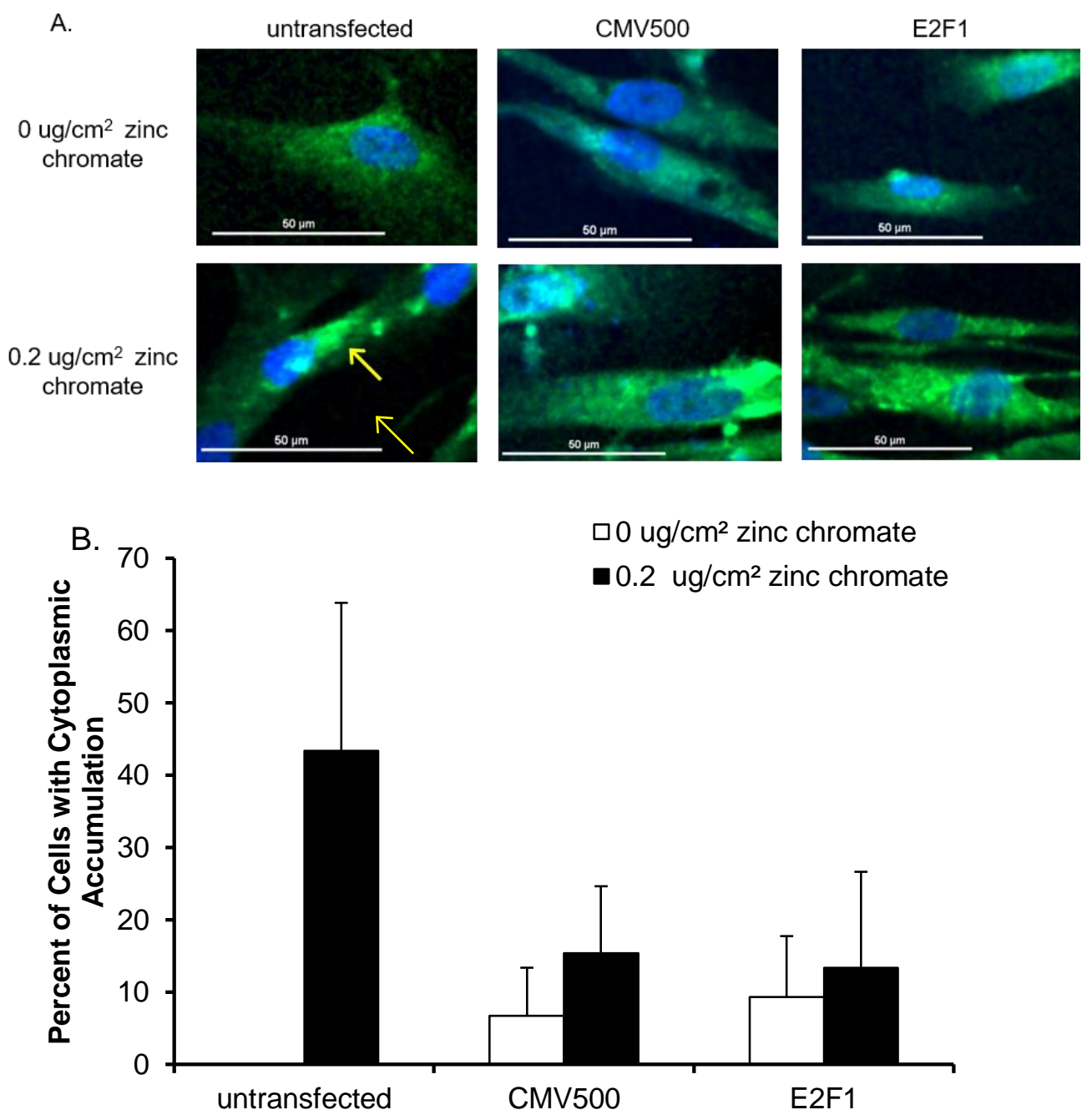

Figure 3.8. E2F1 overexpression does not prevent particulate $\mathrm{Cr}(\mathrm{VI})$ induced RAD51 cytoplasmic accumulation. This figures shows E2F1 does not rescue particulate $\mathrm{Cr}(\mathrm{VI})$-induced RAD51 cytoplasmic accumulation. (A) Representative images of RAD51 subcellular localization. The yellow arrow points to a cytoplasmic RAD51 aggregate. (B) Exposure to $120 \mathrm{~h} 0.2 \mathrm{ug} / \mathrm{cm}^{2}$ zinc chromate induces cytoplasmic accumulation of RAD51 in untransfected cells. However, no cytoplasmic accumulation was observed in the CMV500 transfection control or E2F1 overexpression conditions. Data 
represent the mean of three experiments. Error bars = standard error of the mean. No statistical significance was observed. 
RAD51 foci formation is an indicator of RAD51 function in homologous recombination repair at double strand breaks. Previous studies show RAD51 nuclear foci formation is inhibited following prolonged but not acute exposure to particulate $\operatorname{Cr}(\mathrm{VI})$ (Browning et al., 2016; Qin et al., 2014). We tested if E2F1 overexpression could rescue the loss of RAD51 nuclear foci following $120 \mathrm{~h}$ exposure to particulate $\mathrm{Cr}(\mathrm{VI})$. The baseline level of RAD51 nuclear foci is set at $5 \%$ of cells with more than 10 foci per cell based on previous studies (Browning et al., 2016; Qin et al., 2014). In untransfected cells we saw the expected response finding RAD51 nuclear foci formation is inhibited after $120 \mathrm{~h}$ exposure to $0.2 \mathrm{ug} / \mathrm{cm}^{2}$ zinc chromate consistent with our previous work (Browning et al., 2016; Qin et al., 2014) (Figure 3.9). If E2F1 overexpression rescues particulate $\mathrm{Cr}(\mathrm{VI})$-inhibited RAD51 nuclear foci formation we would expect those levels to increase. However, in both the CMV500 transfection control and E2F1-transfected cells, RAD51 foci remain below baseline level. 


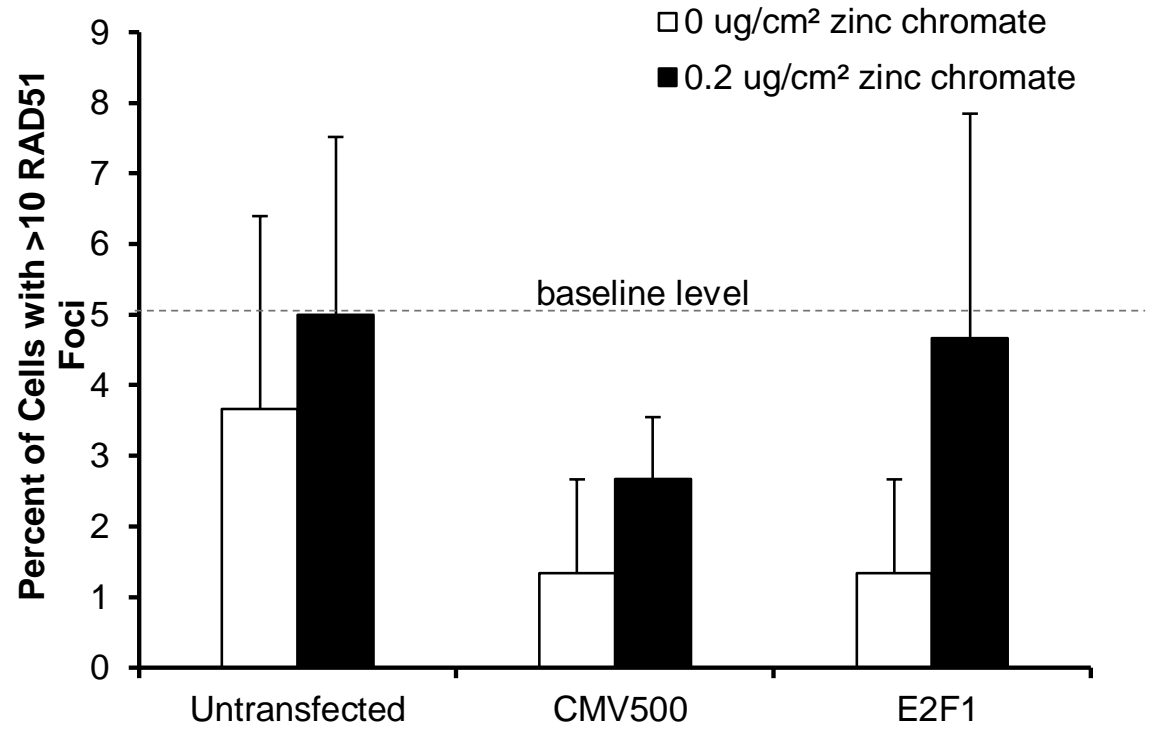

Figure 3.9. Particulate $\mathrm{Cr}(\mathrm{VI})$-inhibited RAD51 nuclear foci is not rescued by E2F1 overexpression. This figure shows after $120 \mathrm{~h}$ particulate $\mathrm{Cr}(\mathrm{VI})$ exposure E2F1 overexpression does not increase RAD51 nuclear foci formation. The untransfected control has inhibited RAD51 nuclear foci formation following exposure to 0.2 $\mathrm{ug} / \mathrm{cm}^{2}$ zinc chromate, and similar levels of RAD51 nuclear foci were observed in the CMV500 transfection control and E2F1-transfected cells. The horizontal dashed grey line at 5 percent of cells with more than 10 RAD51 foci represents baseline levels normally observed in untreated cells. Data represent the mean of three experiments. Error bars $=$ standard error of the mean. No statistical significance was observed. 
The literature suggests the primary role of E2F1 in RAD51 regulation is currently as a transcription factor for RAD51 expression. There may be many mechanisms affecting the localization of RAD51 unrelated to E2F1. Although we did not find E2F1 overexpression rescues $\mathrm{Cr}(\mathrm{VI})$-induced RAD51 mislocalization we wanted to test if RAD51 protein levels could be restored by overexpressing E2F1 after $120 \mathrm{~h}$ particulate $\mathrm{Cr}(\mathrm{VI})$ exposure. Figure 3.10A shows representative western blot images of E2F1 and RAD51 following $120 \mathrm{~h}$ exposure to $0.2 \mathrm{ug} / \mathrm{cm}^{2}$ zinc chromate with or without transfection. In untransfected cells, particulate $\mathrm{Cr}(\mathrm{Vl})$ reduced RAD51 whole cell protein levels to $50 \%$ of control after $120 \mathrm{~h}$ exposure to

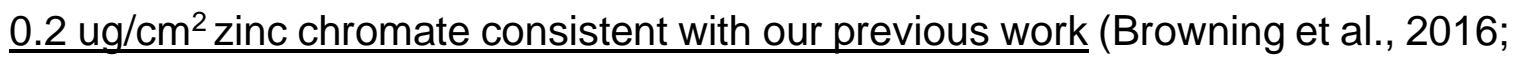
Qin et al., 2014) (Figure 3.10B). However, E2F1 overexpression did not increase RAD51 protein levels following 0 or $0.2 \mathrm{ug} / \mathrm{cm}^{2}$ zinc chromate exposure. RAD51 protein increases slightly in E2F1-transfected cells compared to the CMV500 transfection control ( $40 \%$ to $60 \%$, respectively) in $0 \mathrm{ug} / \mathrm{cm}^{2}$ zinc chromate controls, but there was no difference after exposure to $0.2 \mathrm{ug} / \mathrm{cm}^{2}$ zinc chromate (both $30 \%$ of control). 

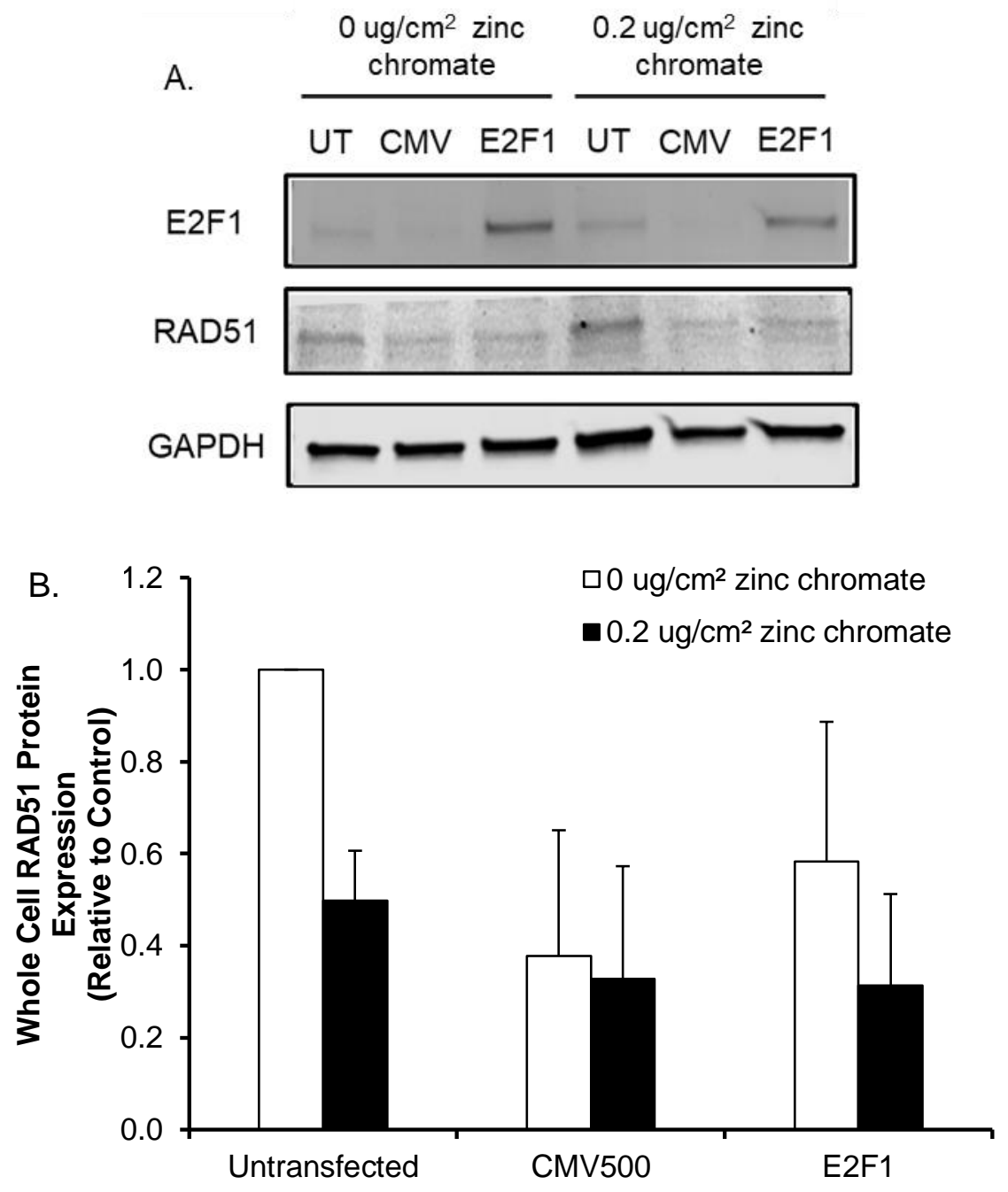

Figure 3.10. E2F1 overexpression does not rescue particulate $\mathrm{Cr}(\mathrm{VI})$-inhibited RAD51 protein expression. This figure shows RAD51 whole cell protein is inhibited following $120 \mathrm{~h}$ exposure to 0.2 $\mathrm{ug} / \mathrm{cm}^{2}$ zinc chromate in untransfected cells and this phenotype is not rescued by E2F1 overexpression. GAPDH was used as a loading control. (A) Representative western blot images. (B) RAD51 whole cell protein expression (all conditions are relative to the untransfected $0 \mathrm{ug} / \mathrm{cm}^{2}$ zinc chromate control). Data represent the mean of two experiments. Error bars $=$ standard error of the mean. 


\section{Objective 4: Loss of E2F1 does not induce RAD51 failure after acute $24 \mathrm{~h}$ particulate $\mathrm{Cr}(\mathrm{VI})$ exposure}

E2F1 overexpression did not rescue RAD51 failure following prolonged 120 h particulate $\mathrm{Cr}(\mathrm{VI})$ exposure. However, we also wanted to test the possible connection by determining if knocking down E2F1 could inhibit RAD51 following acute $24 \mathrm{~h}$ particulate $\mathrm{Cr}(\mathrm{VI})$ exposure to recapitulate the $120 \mathrm{~h}$ exposure outcomes. RAD51 has a normal response following $24 \mathrm{~h}$ particulate $\mathrm{Cr}(\mathrm{VI})$ exposure characterized by unaffected protein expression, and increased nuclear localization, and foci formation at double strand breaks (Browning et al., 2016; Tamblyn et al., 2009; Qin et al., 2014). Studies show loss of E2F1 results in reduced RAD51 protein levels, nuclear foci formation and inhibited homologous recombination repair (Chen et al., 2011; Choi and Kim, 2019; Wu et al., 2014). We transfected cells with E2F1 siRNA for $48 \mathrm{~h}$ and treated with $0.2 \mathrm{ug} / \mathrm{cm}^{2}$ zinc chromate the last $24 \mathrm{~h}$ of the transfection. Cells were harvested for immunofluorescence staining, protein, and RNA.

Figure 3.11 shows E2F1 was successfully knocked down following transfection with four different E2F1 siRNAs after $24 \mathrm{~h}$ exposure to 0 and 0.2 $\mathrm{ug} / \mathrm{cm}^{2}$ zinc chromate. This analysis was performed two ways. The observed effects of the transfection procedure on E2F1 expression, all conditions were normalized to the untransfected $0 \mathrm{ug} / \mathrm{cm}^{2}$ zinc chromate control. The transfection procedure reduced E2F1 protein levels (60\%) compared to the untransfected 0 $\mathrm{ug} / \mathrm{cm}^{2}$ zinc chromate control (Figure 3.11A). However, $0.2 \mathrm{ug} / \mathrm{cm}^{2}$ zinc chromate reduced E2F1 expression to $70 \%$ in both the untransfected and non-targeting siRNA control compared to $0 \mathrm{ug} / \mathrm{cm}^{2}$ zinc chromate, respectively (Figure $3.11 \mathrm{~A}$ - 
B). This reduction is the result we would expect after $24 \mathrm{~h}$ particulate $\operatorname{Cr}(\mathrm{VI})$ exposure. E2F1 protein was decreased significantly in all E2F1 siRNA conditions compared to the untransfected and non-targeting siRNA control. E2F1 was knocked down to $30 \%$ or less compared to the non-targeting control. 

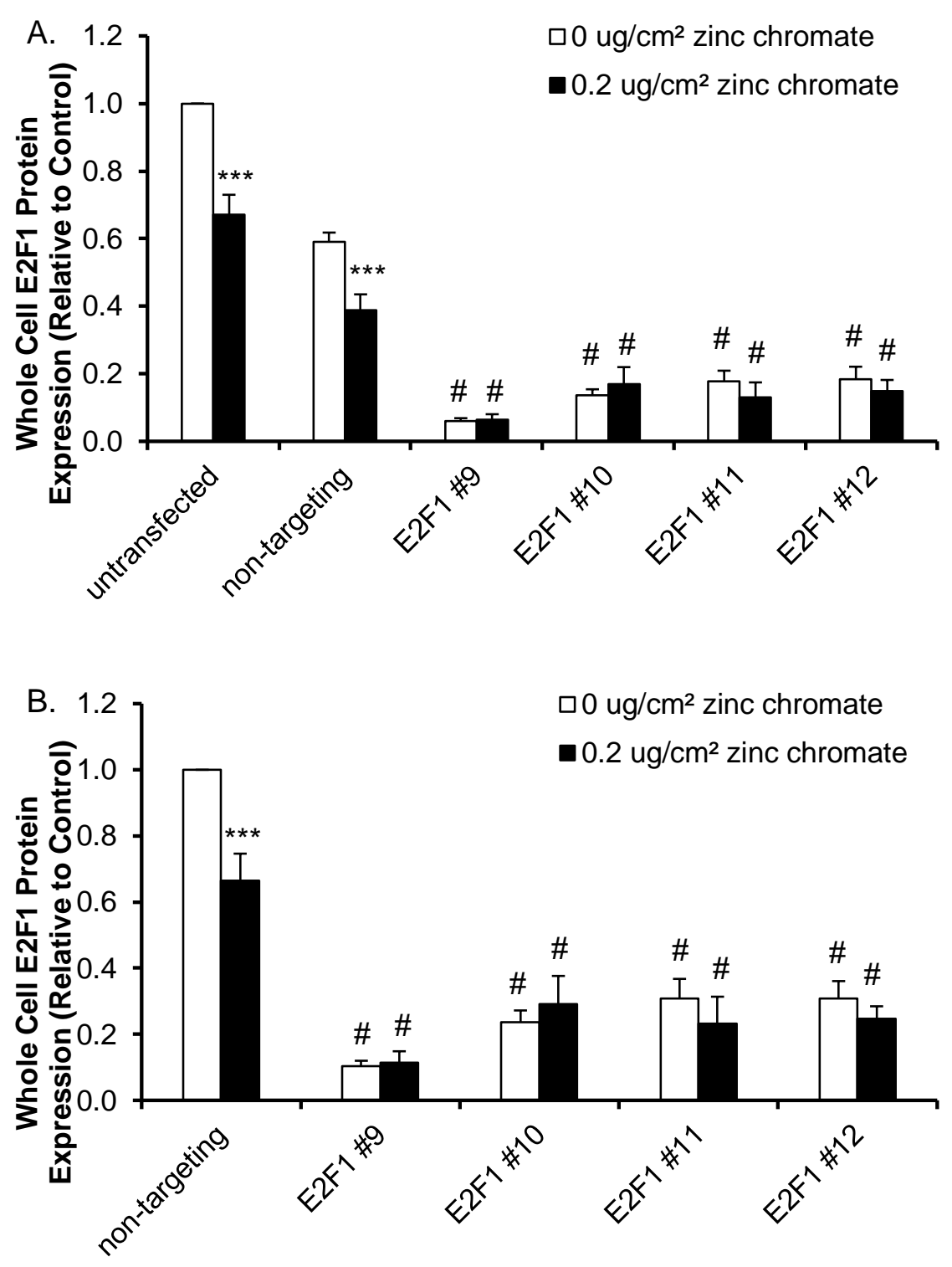

Figure 3.11. Knockdown of E2F1 inhibits E2F1 protein levels. This figure shows E2F1 knockdown for $48 \mathrm{~h}$ leads to reduced E2F1 protein levels. Data represent the mean of at least 5 experiments. Error bars $=$ standard error of the mean. $(\mathrm{A}) \mathrm{E} 2 \mathrm{~F} 1$ whole cell protein levels relative to the $0 \mathrm{ug} / \mathrm{cm}^{2}$ zinc chromate untransfected control. E2F1 decreased significantly after $0.2 \mathrm{ug} / \mathrm{cm}^{2}$ zinc chromate compared to $0 \mathrm{ug} / \mathrm{cm}^{2}$ zinc chromate in both the untransfected and 
non-targeting siRNA conditions $\quad\left({ }^{* * *} \mathrm{p}<0.0001\right)$, however, no difference in this comparison was observed in E2F1 siRNA conditions. E2F1 levels were significantly decreased in all E2F1 siRNA conditions compared to the untransfected and non-targeting siRNA control $(\# p<.0 .0001)$ (B) E2F1 protein levels relative to the 0 $\mathrm{ug} / \mathrm{cm}^{2}$ zinc chromate non-targeting siRNA control. E2F1 decreased in all E2F1 siRNA conditions compared to the non-targeting siRNA control. 
We analyzed RAD51 cytoplasmic accumulation after E2F1 knockdown and $24 \mathrm{~h}$ particulate $\mathrm{Cr}(\mathrm{VI})$ exposure. The same measures used in the E2F1 overexpression experiments for RAD51 cytoplasmic accumulation were applied. After $24 \mathrm{~h}$ particulate $\mathrm{Cr}(\mathrm{VI})$ exposure we would expect a normal RAD51 response and no increase in RAD51 cytoplasmic accumulation in untransfected cells. This outcome is confirmed in the results which show $0.2 \mathrm{ug} / \mathrm{cm}^{2}$ zinc chromate control did not increase RAD51 cytoplasmic accumulation in the untransfected control (Figure 3.12). We also observed no increase in RAD51 cytoplasmic accumulation in the E2F1 knockdown conditions after either $0 \mathrm{ug} / \mathrm{cm}^{2}$ or $0.2 \mathrm{ug} / \mathrm{cm}^{2}$ zinc chromate exposure. The highest level of RAD51 cytoplasmic accumulation in any condition was $12 \%$ compared to $4 \%$ in the control (Figure 3.12 ) and $43 \%$, which was observed in untransfected cells exposed to $120 \mathrm{~h} 0.2 \mathrm{ug} / \mathrm{cm}^{2}$ zinc chromate (Figure 3.8). 


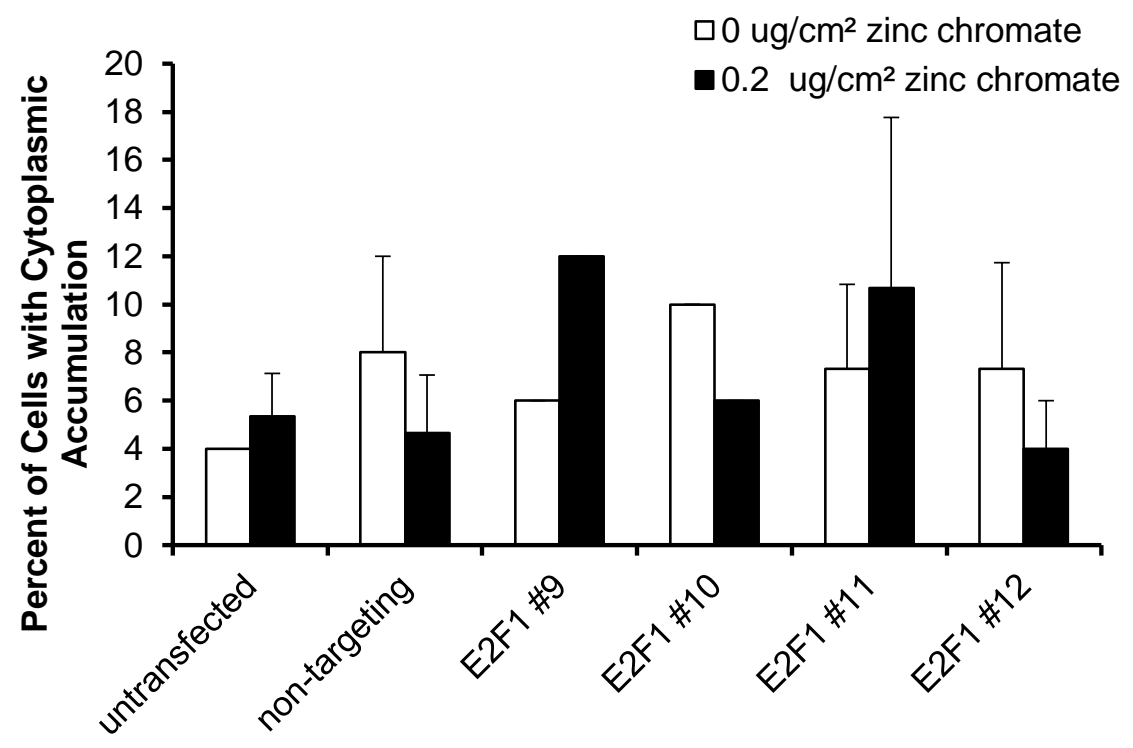

Figure 3.12. E2F1 knockdown does not induce RAD51 cytoplasmic accumulation after $24 \mathrm{~h}$ particulate $\mathrm{Cr}(\mathrm{VI})$ exposure. This figure shows RAD51 cytoplasmic accumulation did not increase following E2F1 knockdown and $24 \mathrm{~h}$ particulate $\mathrm{Cr}(\mathrm{VI})$ exposure. Data represent the mean of three experiments for all conditions (E2F1 \#9 and \#10;n=1). Error bars = standard error of the mean. No statistical significance was observed. 
Since E2F1 knockdown did not induce cytoplasmic accumulation of RAD51, RAD51 protein may still be available in the nucleus to form foci at DNA double strand breaks. We measured RAD51 nuclear foci after E2F1 knockdown and $24 \mathrm{~h}$ particulate $\mathrm{Cr}(\mathrm{VI})$ exposure to test this possibility. Exposure to $24 \mathrm{~h} 0.2 \mathrm{ug} / \mathrm{cm}^{2}$ zinc chromate increased RAD51 foci in all conditions (Figure 3.13). These increases were significant in the untransfected and non-targeting siRNA control (21 and 26\% of cells, respectively), and these results are consistent with our previous work (Browning et al., 2016; Qin et al., 2014). One of the four E2F1 siRNA conditions also had a significant increase in RAD51 foci (E2F1 \#10,15\% of cells). There was no difference in RAD51 foci level in cells with no zinc chromate exposure across all conditions. This outcome is expected because untreated RAD51 foci levels are already below baseline level and without a stimulus to induce RAD51 foci formation no change would be observable. However, when comparing RAD51 foci levels after $0.2 \mathrm{ug} / \mathrm{cm}^{2}$ zinc chromate exposure, the percent of cells with RAD51 foci was significantly decreased in all E2F1 knockdown conditions (except E2F1 \#10) compared to the non-targeting siRNA control. These data indicate loss of E2F1 inhibited RAD51 foci formation after acute $24 \mathrm{~h}$ particulate $\mathrm{Cr}(\mathrm{VI})$ exposure. 


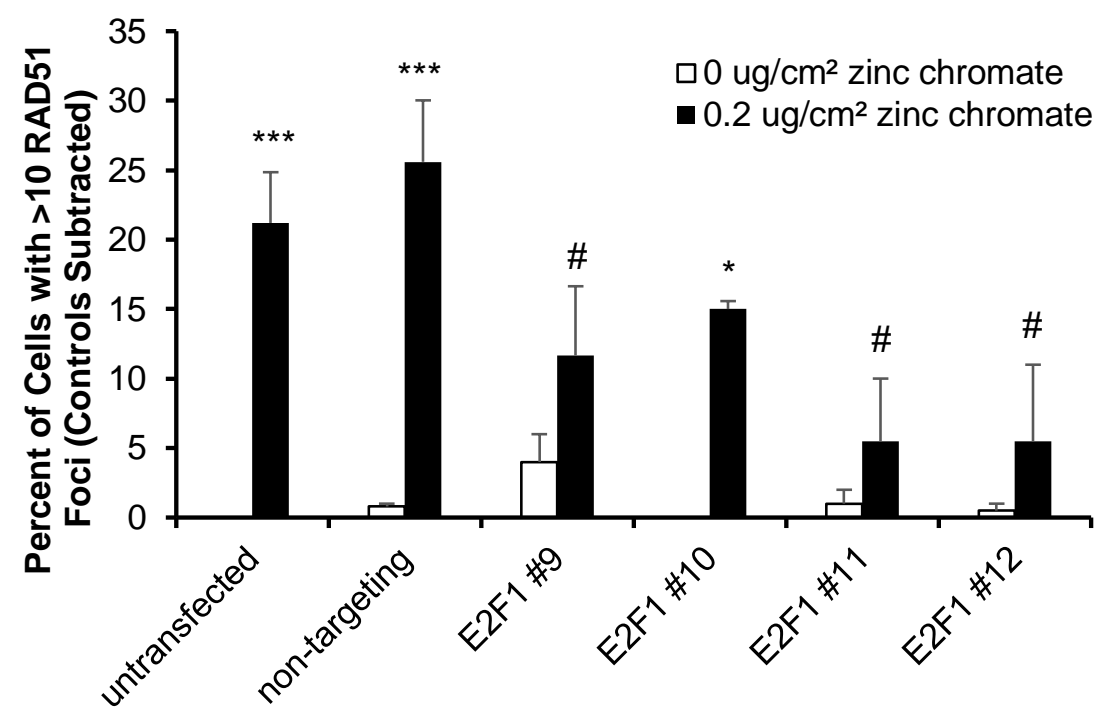

Figure 3.13. E2F1 knockdown decreases RAD51 nuclear foci after acute particulate $\mathrm{Cr}(\mathrm{VI})$ exposure. This figure shows the percent of cells with more than 10 RAD51 foci per cell following $24 \mathrm{~h}$ particulate $\mathrm{Cr}(\mathrm{VI})$ exposure and E2F1 knockdown (untransfected $0 \mathrm{ug} / \mathrm{cm}^{2}$ zinc chromate controls subtracted). Exposure to 24 h $0.2 \mathrm{ug} / \mathrm{cm}^{2}$ zinc chromate significantly increased RAD51 foci in the untransfected and non-targeting siRNA controls and the E2F1 \#10 siRNA condition $\left({ }^{*} \mathrm{p}<0.05 ;{ }^{* *} \mathrm{p}, 0.0001\right)$. RAD51 foci were significantly decreased in all E2F1 siRNA conditions (except E2F1 \#10) after exposure to 0.2 $\mathrm{ug} / \mathrm{cm}^{2}$ zinc chromate compared to the non-targeting siRNA control $(\# p<0.05)$. Data represent the mean of at least 3 experiments (E2F1 \#11 and 12; $n=2)$. Error bars = standard error of the mean. 
We are proposing E2F1's transcription factor function would inhibit RAD51 expression. Less RAD51 protein may also explain the inhibited RAD51 nuclear foci response to acute $24 \mathrm{~h}$ particulate $\mathrm{Cr}(\mathrm{VI})$ exposure after E2F1 knockdown. To determine if RAD51 protein is suppressed following E2F1 knockdown and acute $24 \mathrm{~h}$ particulate $\mathrm{Cr}(\mathrm{VI})$ exposure we measured RAD51 protein. Figure 3.14 shows representative western blot images of E2F1 and RAD51 after E2F1 knockdown and $24 \mathrm{~h}$ exposure to particulate $\mathrm{Cr}(\mathrm{VI})$. We assessed the effect of the transfection on RAD51 protein expression and found while the transfection decreased RAD51 protein to $70 \%$ in the non-targeting siRNA condition compared to the untransfected condition, it was not significant (Figure 3.14B). In the untransfected and nontargeting control we saw the expected result of no difference in RAD51 protein level between 0 and $0.2 \mathrm{ug} / \mathrm{cm}^{2}$ zinc chromate. When we compared the E2F1 knockdown conditions to the non-targeting siRNA control only E2F1 \#9 reduced RAD51 protein levels ( $50 \%$ of control), and only in the $0 \mathrm{ug} / \mathrm{cm}^{2}$ zinc chromate condition. These data indicate E2F1 knockdown does not affect RAD51 protein levels. 

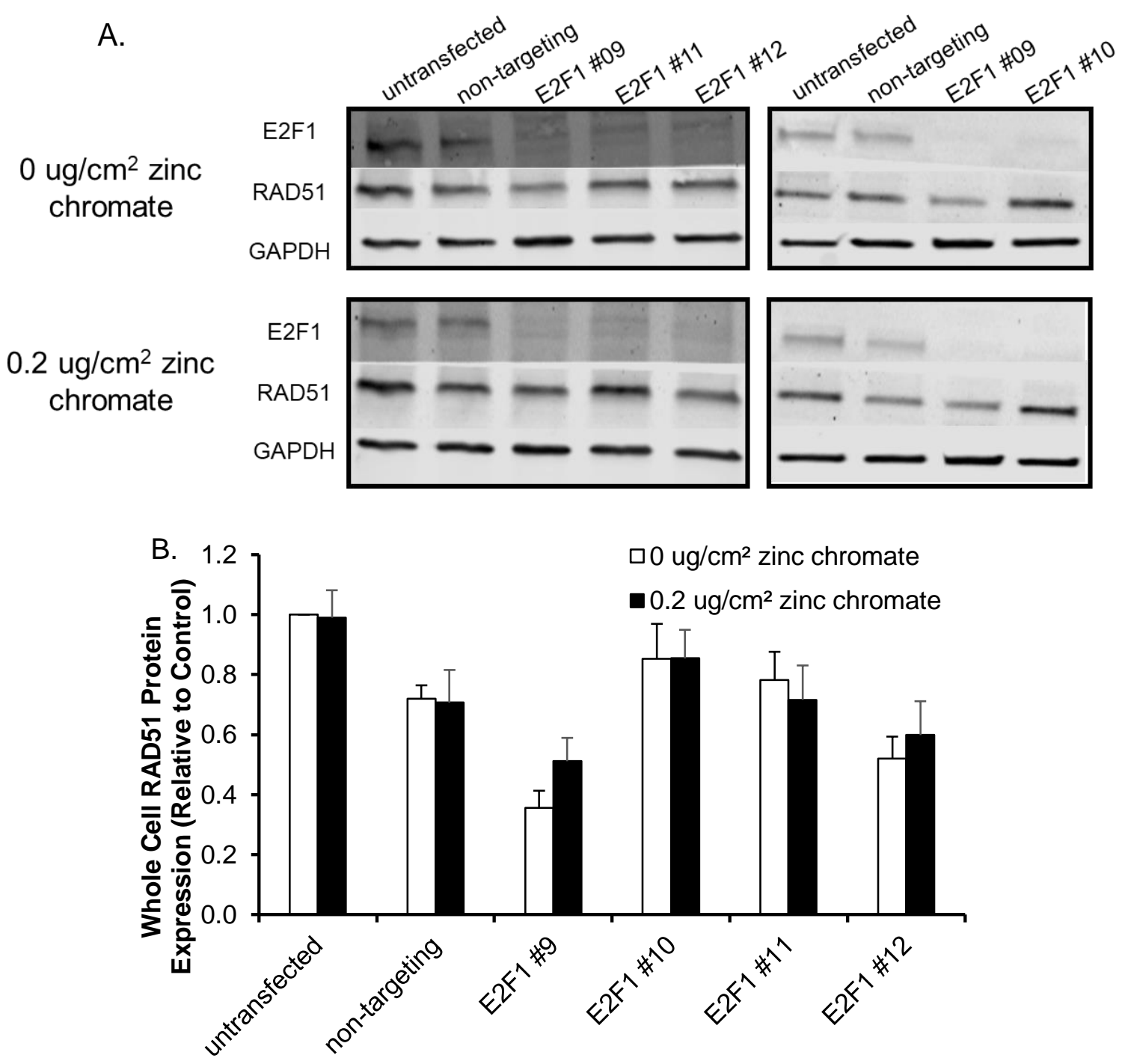

C. $\quad \square 0 \mathrm{ug} / \mathrm{cm}^{2}$ zinc chromate

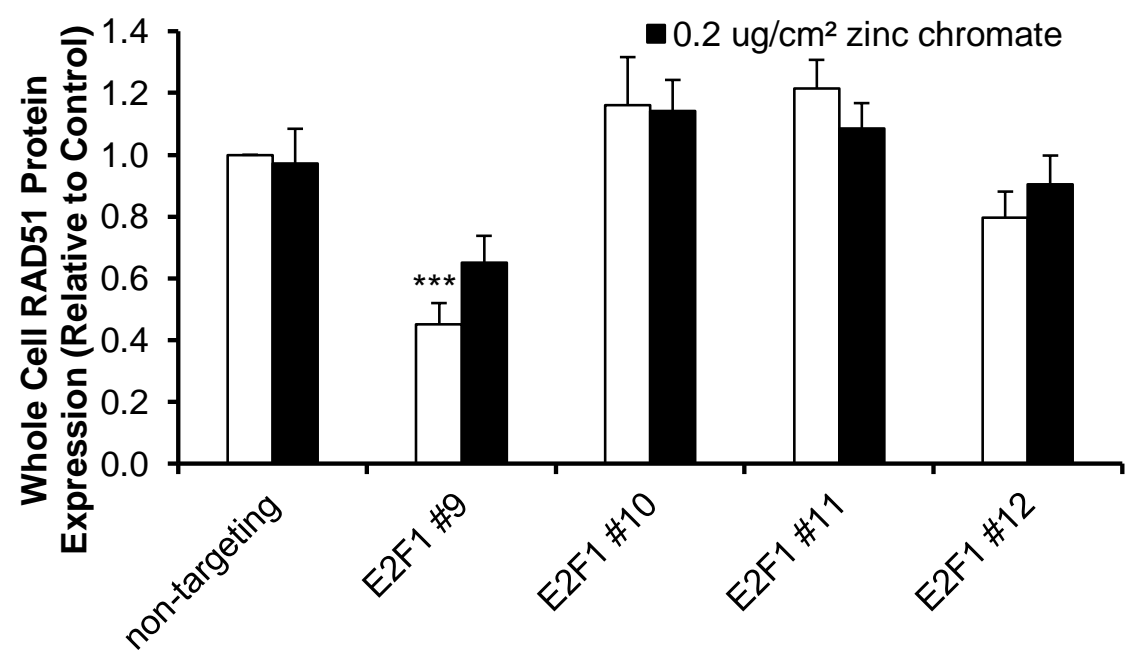


Figure 3.14. E2F1 knockdown does not inhibit RAD51 protein after $24 \mathrm{~h}$ particulate $\mathrm{Cr}(\mathrm{VI})$ exposure. This figure shows E2F1 knockdown for $48 \mathrm{~h}$ does not affect RAD51 protein levels. Data represent the mean of at least 5 experiments. Error bars $=$ standard error of the mean. (A) Representative image of E2F1 and RAD51 western blots. (B) RAD51 whole cell protein levels relative to the $0 \mathrm{ug} / \mathrm{cm}^{2}$ zinc chromate untransfected control. There was no change in RAD51 protein level between 0 and $0.2 \mathrm{ug} / \mathrm{cm}^{2}$ zinc chromate in any of the conditions. RAD51 protein was decreased to $70 \%$ in the nontargeting siRNA control compared to the untransfected control, but this was not significant. (C) RAD51 protein levels relative to the 0 $\mathrm{ug} / \mathrm{cm}^{2}$ zinc chromate non-targeting siRNA control. RAD51 protein level only decreased in one E2F1 siRNA condition (E2F1 \#9; $\left.{ }^{* * *} \mathrm{p}<0.001\right)$ compared to the non-targeting siRNA control, and only in the $0 \mathrm{ug} / \mathrm{cm}^{2}$ zinc chromate condition. 
It is possible E2F1 knockdown inhibits RAD51 transcription, but not protein levels. To test this possibility, we determined the effect of E2F1 knockdown on RAD51 mRNA levels using qPCR. We confirmed E2F1 knockdown inhibits E2F1 mRNA (Figure 3.15A). E2F1 mRNA was significantly inhibited in all E2F1 knockdown conditions compared to the non-targeting siRNA control except E2F1 \#10 after $0.2 \mathrm{ug} / \mathrm{cm}^{2}$ zinc chromate exposure. Exposure to $24 \mathrm{~h} 0.2 \mathrm{ug} / \mathrm{cm}^{2}$ zinc chromate also decreased E2F1 mRNA in all conditions, although only significantly in the untransfected control. The E2F1 mRNA reduction is consistent with our previous results (Figure 3.6).

Next, we evaluated RAD51 mRNA levels following E2F1 knockdown. Figure 3.15B shows RAD51 mRNA is decreased by $24 \mathrm{~h}$ exposure to $0.2 \mathrm{ug} / \mathrm{cm}^{2}$ zinc chromate however, none of the changes in these levels are significant. For example, $0.2 \mathrm{ug} / \mathrm{cm}^{2}$ zinc chromate reduced RAD51 mRNA to $64 \%$ compared to control similar to our previous experiments evaluating RAD51 mRNA after particulate $\mathrm{Cr}(\mathrm{VI})$ exposure (Figure 3.4). RAD51 mRNA was reduced by E2F1 siRNA \#9 compared to the non-targeting control, but this reduction was not significant. E2F1 \#10 increased RAD51 mRNA slightly compared to the nontargeting control. 

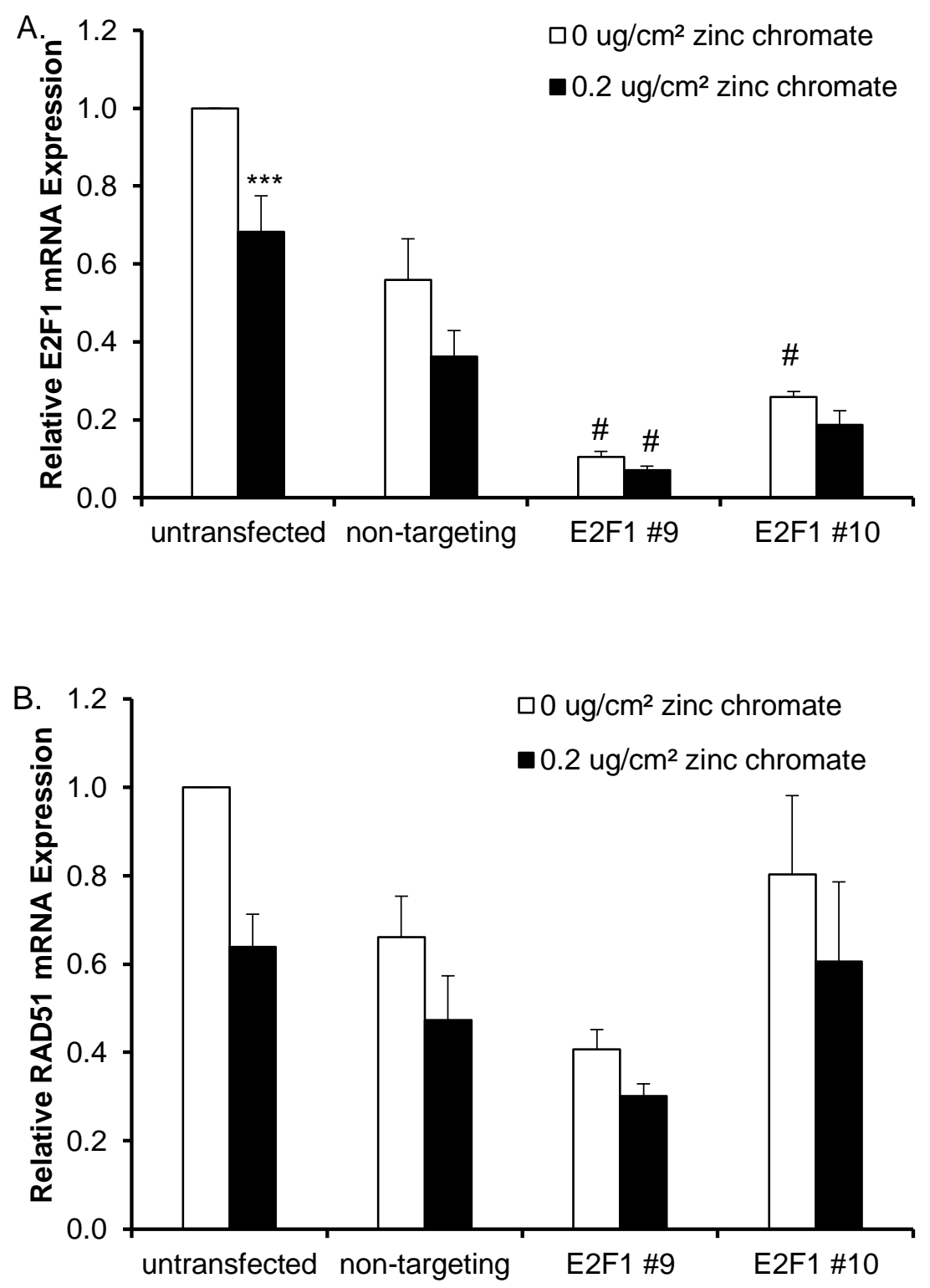

Figure 3.15. E2F1 knockdown does not consistently RAD51 mRNA expression. This figure shows E2F1 knockdown does not inhibit RAD51 mRNA expression after acute $24 \mathrm{~h}$ particulate $\mathrm{Cr}(\mathrm{Vl})$ exposure. Data represent the mean of three experiments. Error bars = standard error of the mean. (A) E2F1 mRNA were successfully reduced following E2F1 knockdown $(\# p<0.05)$. Particulate $\mathrm{Cr}(\mathrm{VI})$ reduced E2F1 mRNA levels in all conditions, but was only significant 
in the untransfected control $\left({ }^{* *} p<0.0001\right)$. (B) RAD51 mRNA was unaffected by $0.2 \mathrm{ug} / \mathrm{cm}^{2}$ zinc chromate exposure or E2F1 knockdown. GAPD was used as to normalize E2F1 and RAD51 mRNA levels. 


\section{Alternative hypotheses for reduced RAD51 expression}

The literature shows loss of E2F1 results in RAD51 impairment after induction of DNA double strand breaks (Chen et al., 2011; Choi and Kim, 2019; Wu et al., 2014). It is well known exposure to particulate $\mathrm{Cr}(\mathrm{VI})$ induces DNA double strand breaks and the canonical repair of those breaks occurs through homologous recombination (Bryant et al., 2006; Gastaldo et al., 2007; Helleday et al., 2000; Stackpole et al., 2007). However, the data in objective 3 and 4 indicate E2F1 does not modulate the RAD51 response to particulate $\mathrm{Cr}(\mathrm{VI})$. We began to develop alternative hypotheses that may explain this outcome. Although we showed E2F1 whole cell protein was significantly inhibited following prolonged exposure to particulate $\mathrm{Cr}(\mathrm{VI})$ it is possible in this case available protein is accumulated in the nucleus in order to preserve critical functions. Therefore, we measured E2F1 nuclear protein levels following particulate $\mathrm{Cr}(\mathrm{VI})$ exposure. Figure 3.16A shows representative western lots of E2F1 nuclear protein. Particulate $\mathrm{Cr}(\mathrm{VI})$ had no effect on $\mathrm{E} 2 \mathrm{~F} 1$ nuclear protein levels after 24,72 , or 120 $\mathrm{h}$ exposure. For example, exposure to $0.2 \mathrm{ug} / \mathrm{cm}^{2}$ zinc chromate resulted in nuclear E2F1 protein levels of 94, 92, and $65 \%$ of control after 24, 72, and $120 \mathrm{~h}$, respectively. E2F1 nuclear protein decreased with concentration after $120 \mathrm{~h}$ exposure resulting in 85,65 , and $55 \%$ of control following $0.1,0.2,0.3 \mathrm{ug} / \mathrm{cm}^{2}$ zinc chromate, however these levels were not significant compared to control or each other. These data suggest although total levels of E2F1 are significantly suppressed following exposure to prolonged particulate $\mathrm{Cr}(\mathrm{VI})$ the levels of E2F1 protein remaining are sequestered in the nucleus. 

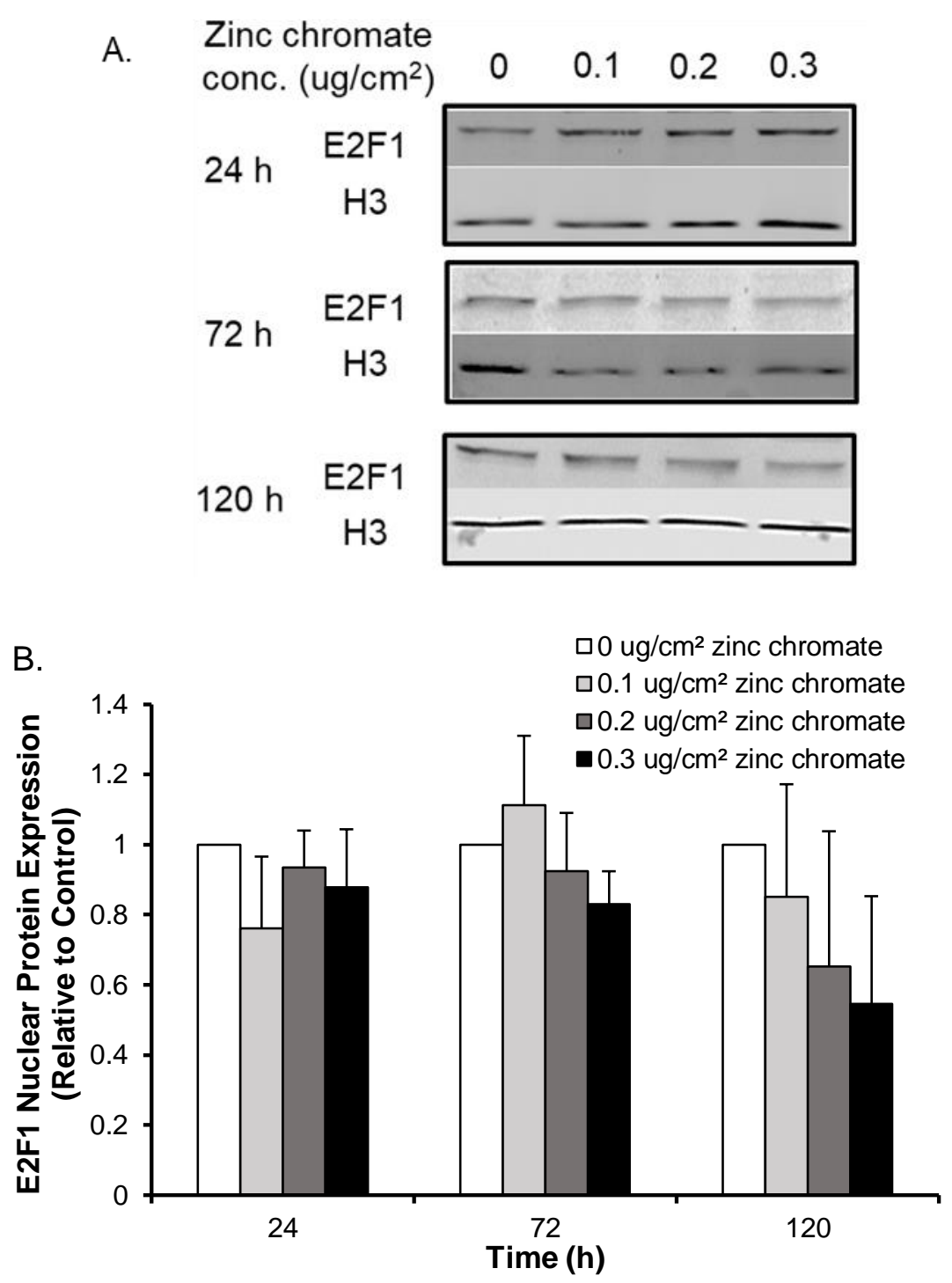

Figure 3.16. Particulate $\mathrm{Cr}(\mathrm{VI})$ does not affect E2F1 nuclear protein levels. This figure shows E2F1 nuclear protein is unaffected by exposure to particulate $\mathrm{Cr}(\mathrm{VI})$. (A) Representative western blots of E2F1 nuclear protein. (B) E2F1 nuclear protein levels (relative to control) are unaffected following exposure to 24,72 , and $120 \mathrm{~h}$ particulate $\mathrm{Cr}(\mathrm{VI})$. H3 was used as loading control. Data represent the mean of three experiments. Error bars $=$ standard error of the mean. No statistical significance was observed. 
RAD51 expression is tightly regulated by a balance of transcriptional activators and repressors. We wanted to investigate if other transcription factors involved in RAD51 expression were affected by particulate $\mathrm{Cr}(\mathrm{VI})$ exposure. We considered another transcriptional activator of RAD51 transcription, EGR1. Figure 3.17A shows representative western blots of whole cell EGR1 protein. EGR1 whole cell protein is unaffected by acute $24 \mathrm{~h}$ exposure to particulate $\mathrm{Cr}(\mathrm{VI})$ but decreases after $120 \mathrm{~h}$ exposure with concentration (Figure 3.17). For example, EGR1 protein is only reduced to $87 \%$ of control after $24 \mathrm{~h}$ exposure to $0.3 \mathrm{ug} / \mathrm{cm}^{2}$ zinc chromate but to $81,76,65 \%$ of control after $120 \mathrm{~h}$ exposure to $0.1,0.2$ and $0.2 \mathrm{ug} / \mathrm{cm}^{2}$ zinc chromate; these levels are not significant. These data indicate another activator of RAD51 expression is suppressed following prolonged particulate $\mathrm{Cr}(\mathrm{VI})$ exposure. 
A. Zinc Chromate Concentration

$\left(\mathrm{ug} / \mathrm{cm}^{2}\right)$

$\begin{array}{llll}0 & 0.1 & 0.2 & 0.3\end{array}$

$24 \mathrm{~h}$

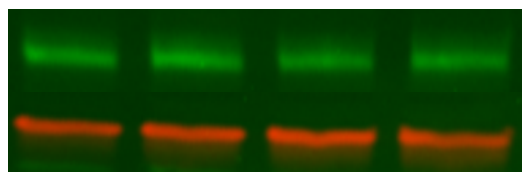

EGR1

GAPDH

$120 \mathrm{~h}$

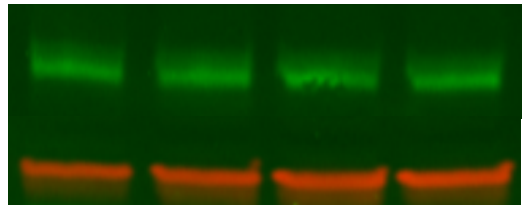

\section{EGR1}

\section{GAPDH}

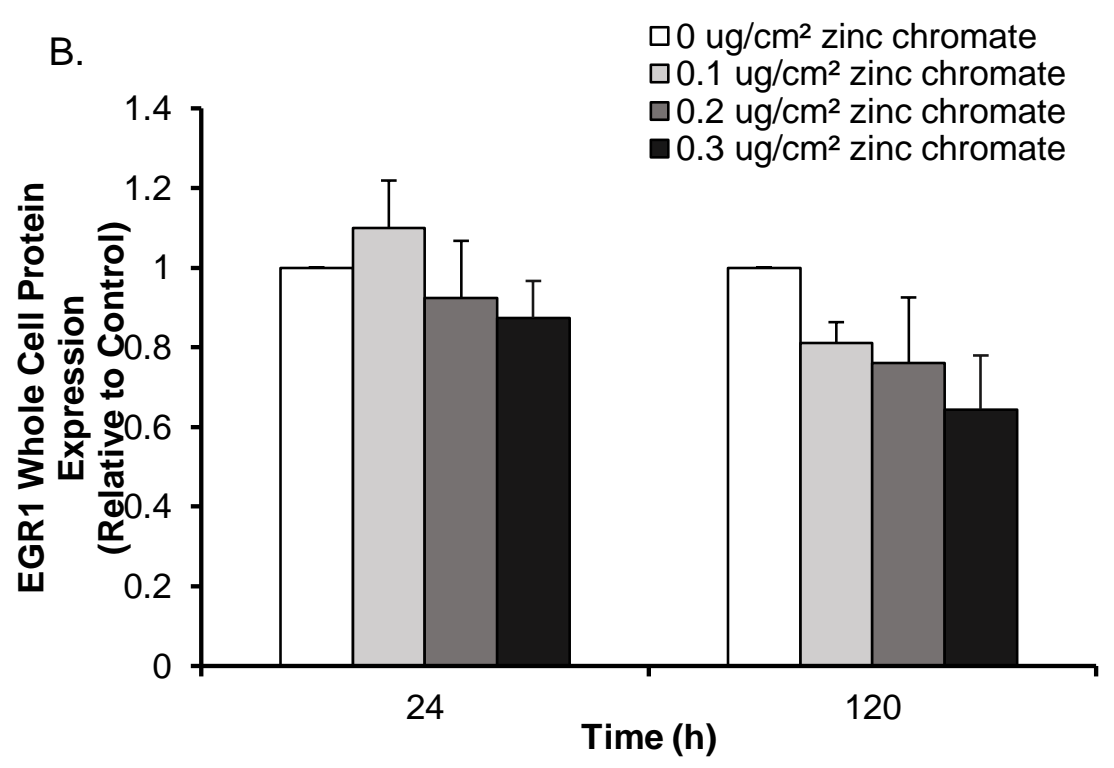

Figure 3.17. Prolonged particulate $\mathrm{Cr}(\mathrm{VI})$ exposure decreases EGR1 whole cell protein expression. This figure shows prolonged $120 \mathrm{~h}$ exposure to particulate $\mathrm{Cr}(\mathrm{VI})$ decreases whole cell EGR1 protein (relative to control). (A) Representative western blot images of whole cell EGR1 protein. (B) EGR1 whole cell protein expression after acute 24 and prolonged $120 \mathrm{~h}$ exposure to particulate $\mathrm{Cr}(\mathrm{VI})$ exposure. GAPDH was used as a loading control. Data represent the 
mean of three experiments. Error bars = standard error of the mean.

No statistical significance was observed. 
Loss of the tumor suppressor p53 is commonly associated with carcinogenic mechanisms (Hamadeh et al., 1999; Shen et al., 2008; Wang, 1999). As previously mentioned p53 suppresses RAD51 transcription through at least two mechanisms. It indirectly suppresses RAD51 through the DREAM complex (Engeland et al., 2018). Second, p53 can directly bind to the RAD51 promoter repressing transcription (Hine et al., 2014; Arias-Lopez et al., 2005; Hannay et al., 2007). We measured total p53 and phospho-p53 (Ser15), which indicates p53 stabilization associated with DNA damage (Canman et al., 1997; Shieh et al., 1997). Figure 3.18A shows representative of p53 western blots. Particulate $\mathrm{Cr}(\mathrm{VI})$ exposure increased total p53 expression after $24 \mathrm{~h}$ exposure and decreased expression after $120 \mathrm{~h}$ exposure (Figure 13.18B). For example, $24 \mathrm{~h}$ exposure to $0.1,0.2$, and $0.3 \mathrm{ug} / \mathrm{cm}^{2}$ zinc chromate increased p53 total protein to 114,139 , and $144 \%$ of control while $120 \mathrm{~h}$ reduced total p53 protein to 92,79 , and $69 \%$ of control. Neither the increase after $24 \mathrm{~h}$ nor the decrease after $120 \mathrm{~h}$ exposure were significant compared to control. Figure $3.18 \mathrm{C}$ shows while particulate $\mathrm{Cr}(\mathrm{VI})$ slightly alters total p53, phospho-p53 (Ser15) is unaffected. For example, 0.2 $\mathrm{ug} / \mathrm{cm}^{2}$ zinc chromate altered p-p53 protein to 107 and 77\% of control after 24 and $120 \mathrm{~h}$, respectively. These data suggest p53 stabilization is unaffected by particulate $\mathrm{Cr}(\mathrm{VI})$ exposure, and the minimal effect of $\mathrm{Cr}(\mathrm{VI})$ on p53 may not be a major contributor to the reduction of RAD51 expression. 
A. Zinc Chromate Concentration $\left(\mathrm{ug} / \mathrm{cm}^{2}\right)$
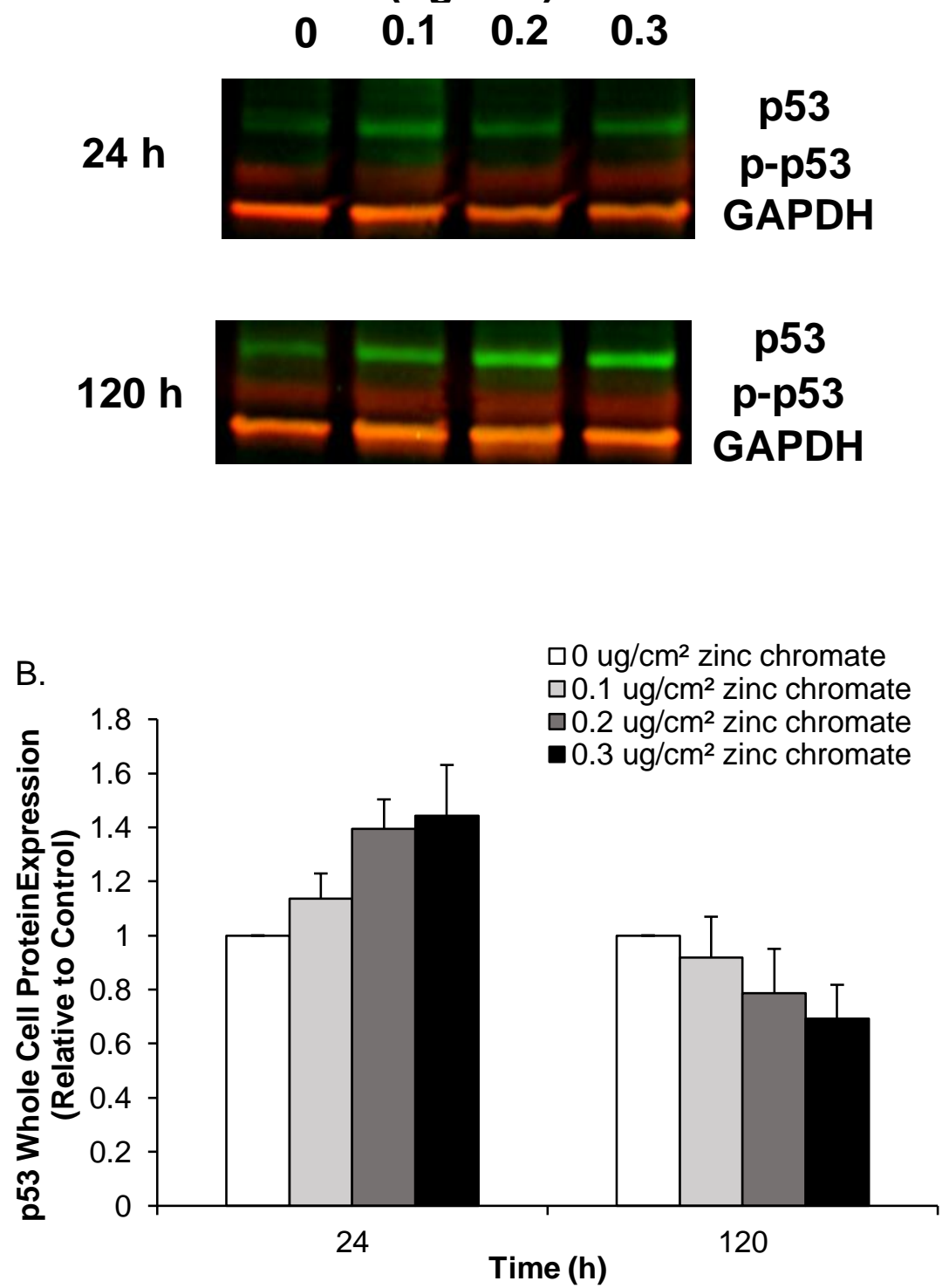


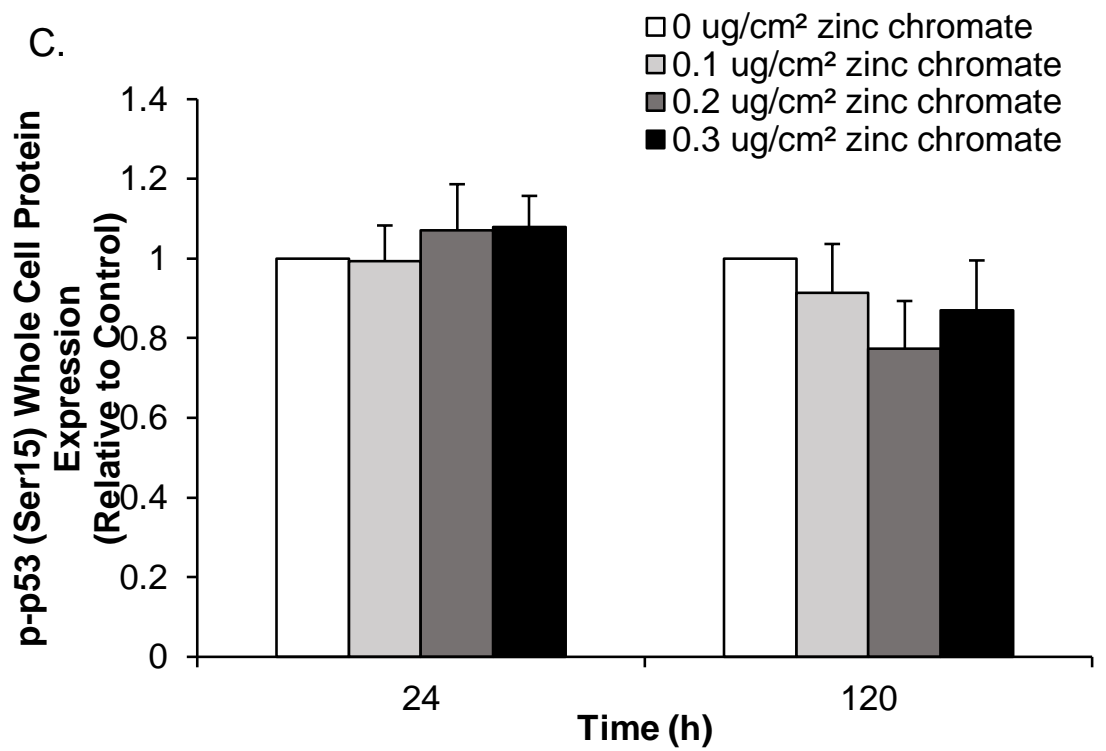

Figure 3.18. Particulate $\mathrm{Cr}(\mathrm{VI})$ does not affect p53. This figure shows particulate $\mathrm{Cr}(\mathrm{VI})$ exposure does not affect p53 or phospho-p53. (A) Representative western blot images of total p53 and phospho-p53 (Ser15). (B) Particulate $\mathrm{Cr}(\mathrm{VI})$ modulates total p53 levels differently after 24 and $120 \mathrm{~h}$ exposure, however no statistical significance was observed. (B) Phospho-p53 (Ser15) was unaffected by exposure to acute $24 \mathrm{~h}$ or prolonged $120 \mathrm{~h}$ exposure to particulate $\mathrm{Cr}(\mathrm{VI})$. No statistical significance was observed. GAPDH was used as a loading control. Data represent the mean of four experiments. Error bars = standard error of the mean. 
One mechanism of p53 repression of RAD51 expression is through the DREAM complex. We found p53 was not inhibited significantly by particulate $\mathrm{Cr}(\mathrm{VI})$ exposure. Downstream of p53 in the DREAM pathway p130 binds with E2F4 resulting in repressed transcription (Engeland et al., 2018). Hypo-phosphorylation of p130 facilitates p130 binding E2F4, and this process is mediated by $\mathrm{p} 53$. We assessed total and phospho-p130 expression following particulate $\mathrm{Cr}(\mathrm{VI})$ exposure.

Figure 3.19 shows representative western blot images of total and phosphop130. Particulate $\mathrm{Cr}(\mathrm{VI})$ decreased total p130 protein levels after $24 \mathrm{~h}$ and further decreases after $120 \mathrm{~h}$ exposure (Figure 3.19B). For example, exposure to 0.2 $\mathrm{ug} / \mathrm{cm}^{2}$ zinc chromate decreased total p130 protein levels to 85 and $51 \%$ of control after 24 and $120 \mathrm{~h}$, respectively. Although total p130 was decreased following exposure to particulate $\mathrm{Cr}(\mathrm{VI})$ the hypo-phosphorylation of $\mathrm{p} 130$ facilitates its binding with the transcriptional repressor E2F4. Therefore, we also measured phospho-p130 levels following exposure to particulate $\mathrm{Cr}(\mathrm{VI})$. Figure $3.19 \mathrm{C}$ shows exposure to particulate $\mathrm{Cr}(\mathrm{VI})$ reduces phospho-p130 after 24 and $120 \mathrm{~h}$. For example, exposure to $0.3 \mathrm{ug} / \mathrm{cm}^{2}$ zinc chromate reduces to 40 and $47 \%$ of control after 24 and $120 \mathrm{~h}$, respectively. These data indicate, of the total p130 available after particulate $\mathrm{Cr}(\mathrm{VI})$ exposure less is phosphorylated. 
A. Zinc Chromate Concentration

\section{(ug/ $/ \mathrm{cm}^{2}$ )}

$\begin{array}{llll}0 & 0.1 & 0.2 & 0.3\end{array}$
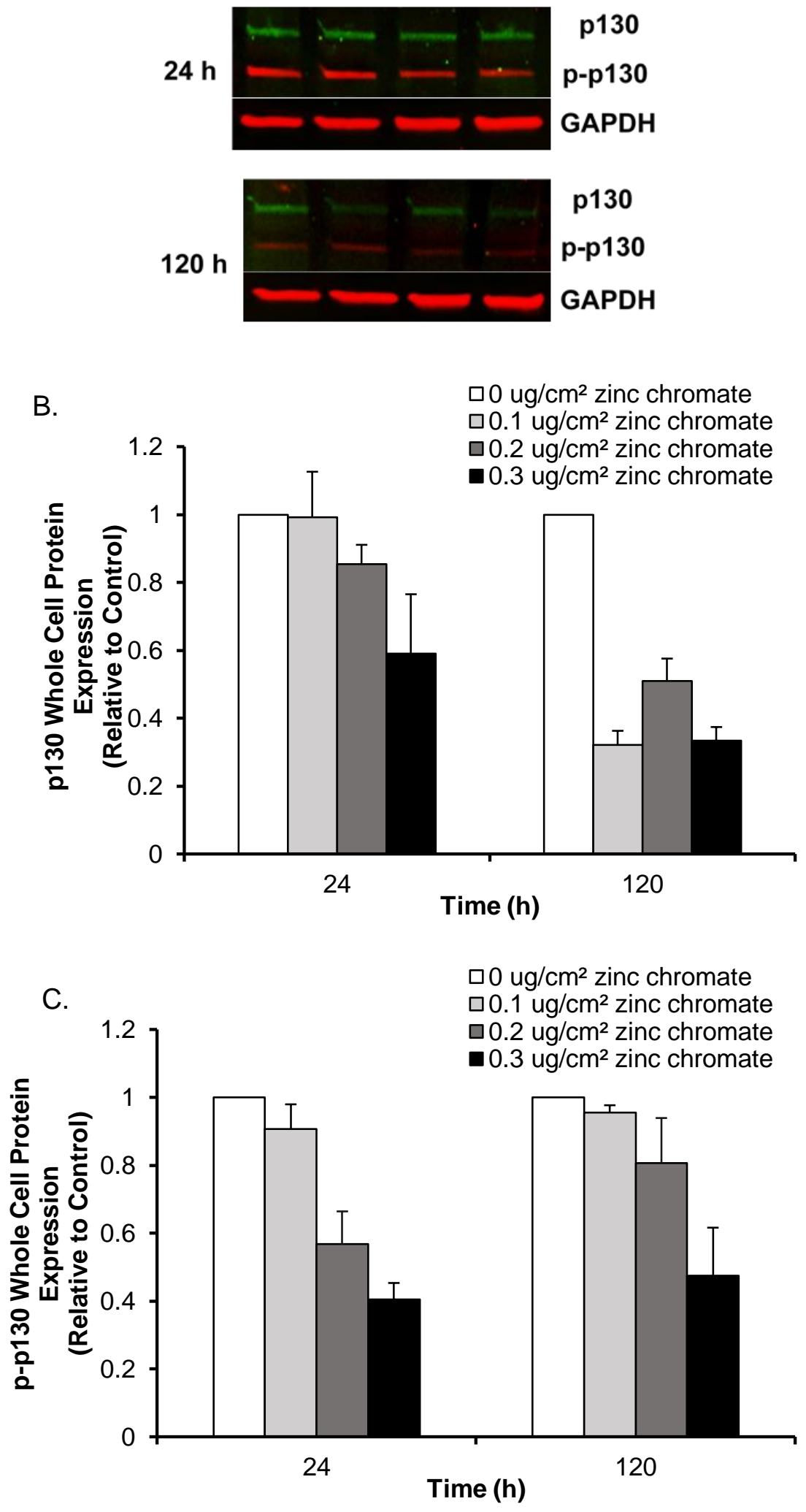
Figure 3.19. Particulate $\mathrm{Cr}(\mathrm{VI})$ decreases total and phospho-p130 protein levels. This figure shows particulate $\mathrm{Cr}(\mathrm{VI})$ inhibits total and phospho-p130 whole cell protein levels. (A) Representative western blot images of total and phospho-p130 whole cell protein. Particulate $\mathrm{Cr}(\mathrm{VI})$ inhibits (B) p130 and (C) phospho-p130 after $24 \mathrm{~h}$ and further after $120 \mathrm{~h}$ exposure. GAPDH was used a loading control. Data represent the mean of two experiments. Error bars = standard error of the mean. 
Less phosphorylation increases the interaction of p130 with E2F4. E2F4 is a repressive transcription factor that directly competes with E2F1 for the same binding site at the RAD51 promoter. To begin to test if E2F4-induced suppression may play a role in the repression of E2F1-mediated transcription we measured E2F4 protein levels following particulate $\mathrm{Cr}(\mathrm{VI})$ exposure. Figure 3.20 shows representative western blots of E2F4 whole cell protein. Particulate $\mathrm{Cr}(\mathrm{VI})$ had no effect on E2F4 protein level after 24 or $120 \mathrm{~h}$ exposure. For example, E2F4 levels after $0.3 \mathrm{ug} / \mathrm{cm}^{2}$ zinc chromate were 104 and $110 \%$ of control (Figure $3.20 \mathrm{~B}$ ). These data show while exposure to particulate $\mathrm{Cr}(\mathrm{VI})$ inhibits $\mathrm{E} 2 \mathrm{~F} 1$ protein after prolonged exposure (Figure 3.5) E2F4 protein levels are unaffected. Engeland et al 2018 suggests the balance of activating E2F1 and repressive E2F4 controls expression. Specifically, Bindra et al., 2007 showed E2F1 and E2F4 compete for the same binding sequence on the RAD51 promoter. We looked at the ratio of E2F4 to E2F1 after acute and prolonged particulate $\mathrm{Cr}(\mathrm{VI})$ exposure. Figure 3.20C shows after $24 \mathrm{~h}$ there is no change in the ratio of E2F4 to E2F1, however, after $120 \mathrm{~h}$ exposure the ratio increases. These data indicate the increase in the ratio of E2F4 to E2F1 after prolonged exposure to particulate $\mathrm{Cr}(\mathrm{VI})$ may inhibit E2F1mediated expression of RAD51. 
A. Zinc Chromate Concentration
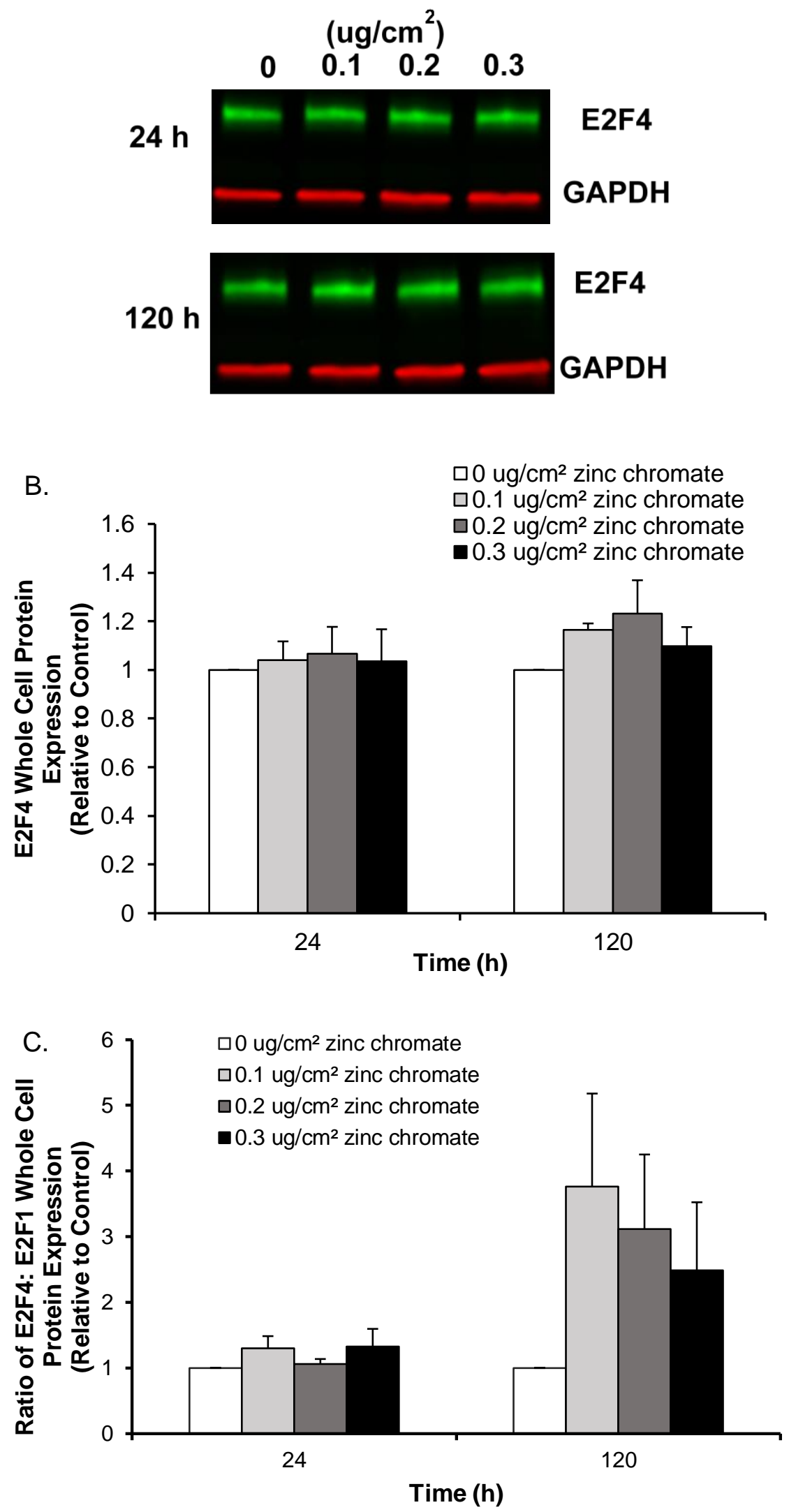
Figure 3.20. Particulate $\mathrm{Cr}(\mathrm{VI})$ increases the ratio of E2F4 to E2F1. This figure shows particulate $\mathrm{Cr}(\mathrm{VI})$ does not affect E2F4 protein levels after particulate $\mathrm{Cr}(\mathrm{VI})$ exposure, but increases the ratio of E2F4 to E2F1 after prolonged exposure. Data represent the mean of three experiments. Error bars $=$ standard error of the mean. $(A)$ Representative western blot images of E2F4. (B) E2F4 whole cell protein levels (relative to control) are unaffected by acute 24 or prolonged $120 \mathrm{~h}$ exposure to particulate $\mathrm{Cr}(\mathrm{VI})$. GAPDH was used as a loading control. No statistical significance was observed. (C) The ratio of E2F4 to E2F1 increases after exposure to $120 \mathrm{~h}$ particulate $\mathrm{Cr}(\mathrm{VI})$. 


\section{Summary}

In this Aim, we show the reduction in RAD51 protein after particulate $\mathrm{Cr}(\mathrm{VI})$ exposure is primarily a result of decreased transcription. We found RAD51 mRNA levels begin to decrease after $24 \mathrm{~h}$ exposure to particulate $\mathrm{Cr}(\mathrm{VI})$ and further decrease after 72 and $120 \mathrm{~h}$. However, we did not find any considerable difference in RAD51 protein half-life after 24 or $120 \mathrm{~h}$ exposure. Considering the reduction of RAD51 protein is due to a transcriptional issue we investigated the effects of particulate $\mathrm{Cr}(\mathrm{VI})$ on E2F1, the predominant transcription factor for RAD51. We found particulate $\mathrm{Cr}(\mathrm{VI})$ decreased $\mathrm{E} 2 \mathrm{~F} 1$ whole cell protein levels after prolonged 72 and $120 \mathrm{~h}$ exposure, and mRNA decreased beginning after $24 \mathrm{~h}$ and continued to decrease after 72 and $120 \mathrm{~h}$.

To connect the loss of E2F1 and RAD51 after particulate $\mathrm{Cr}(\mathrm{VI})$ exposure we tested if overexpressing E2F1 could rescue RAD51 failure induced by prolonged particulate $\mathrm{Cr}(\mathrm{VI})$ exposure. We analyzed three endpoints to assess RAD51 failure: RAD51 cytoplasmic accumulation, nuclear foci formation, and RAD51 whole cell protein expression. We found E2F1 overexpression did not inhibit RAD51 cytoplasmic accumulation or restore RAD51 nuclear foci and protein levels after prolonged particulate $\mathrm{Cr}(\mathrm{VI})$ exposure.

We also tried to confirm the connection by recapitulating 120 exposure outcomes after $24 \mathrm{~h}$ exposure. We knocked down E2F1 after acute particulate $\mathrm{Cr}(\mathrm{VI})$ exposure to test if loss of E2F1 could inhibit the RAD51 response to particulate $\operatorname{Cr}(\mathrm{VI})$ when the RAD51 response is usually normal. We found loss of E2F1 did not induce RAD51 cytoplasmic accumulation and did not reduce RAD51 protein or mRNA levels after acute particulate $\mathrm{Cr}(\mathrm{VI})$ exposure and so E2F1 
inhibition did not recapitulate most $120 \mathrm{~h}$ exposure outcomes. However, we did find loss of E2F1 inhibited RAD51 foci formation after $24 \mathrm{~h}$ particulate $\mathrm{Cr}(\mathrm{VI})$ exposure when foci formation usually increases.

We demonstrated the reduction of RAD51 protein is due to a transcriptional issue, however, RAD51 expression was not modulated by E2F1 in response to particulate $\mathrm{Cr}(\mathrm{VI})$. Therefore, we explored alternative hypotheses. While particulate $\mathrm{Cr}(\mathrm{VI})$ knocked down E2F1 whole cell protein we found nuclear protein was unaffected potentially explaining the results of our E2F1 overexpression and knockdown experiments. We also assessed how other mediators of RAD51 transcription were affected by particulate $\mathrm{Cr}(\mathrm{VI})$ exposure. The transcriptional activator, EGR1, was slightly decreased by particulate $\operatorname{Cr}(\mathrm{VI})$ exposure after $24 \mathrm{~h}$ exposure and further decreased after $120 \mathrm{~h}$ exposure. The transcriptional repressor p53 increased slightly after $24 \mathrm{~h}$ and decreased after $120 \mathrm{~h}$ exposure, however, p53 stability was unaffected. Finally, we assessed the transcriptional repressor, E2F4, and its binding partner p130 and found while p130 levels decreased after particulate $\mathrm{Cr}(\mathrm{VI})$ exposure, phosphorylation also decreased. E2F4 protein was unaffected by particulate $\mathrm{Cr}(\mathrm{VI})$ exposure, and this resulted in an increase in the ratio of E2F4 to E2F1 following prolonged particulate $\mathrm{Cr}(\mathrm{VI})$ exposure. This result, in part, may explain inhibited RAD51 expression following prolonged particulate $\mathrm{Cr}(\mathrm{VI})$ exposure. 


\section{Aim 2: Identify particulate $\mathrm{Cr}(\mathrm{VI})$-altered miRNAs involved in RAD51 regulation and homologous recombination repair}

\section{Background}

$\mathrm{Cr}(\mathrm{VI})$ causes permanent-heritable phenotypes, but induces low rates of mutations in key oncogenes and tumor suppressors (Ewis et al., 2001; Wetterhahn and Hamilton, 1989; Katabami et al., 2000; Kondo et al., 1997; Wise et al., 2018). Additionally, $\operatorname{Cr}(\mathrm{VI})$ is known to alter global gene expression, however, the mechanisms of this effect are unknown (Andrew et al., 2003; Izzotti et al., 2002; Ye and Shi, 2001). The field of $\mathrm{Cr}(\mathrm{VI})$ research is increasingly finding epigenetic modifications may play a significant role in $\mathrm{Cr}(\mathrm{VI})$ carcinogenesis contributing to the permanent-heritable phenotypes and global changes in gene expression following $\operatorname{Cr}(\mathrm{VI})$ exposure (Rager et al., 2019).

Specifically related to our study, $\mathrm{Cr}(\mathrm{VI})$ has been shown to downregulate expression of DNA repair genes (Andrew et al., 2003; Clancy et al., 2012, Wu et al., 2012). Aim 1 shows RAD51 transcription is decreased following particulate $\mathrm{Cr}(\mathrm{VI})$ exposure. Aim 1 also shows the primary transcription factor of RAD51, E2F1, does not modulate RAD51 expression following particulate $\mathrm{Cr}(\mathrm{VI})$ exposure. Additionally, while alternative transcription factors of RAD51 were investigated, they cannot fully explain particulate $\mathrm{Cr}(\mathrm{VI})$-inhibited RAD51 expression. Based on these data and the general consensus from the literature that epigenetic mechanisms play a role in altered gene expression and $\mathrm{Cr}(\mathrm{VI})$ carcinogenesis, we investigated how miRNAs may play a role in inhibited RAD51.

miRNAs are short non-coding RNA sequences with an average 22 base pairs in length. miRNAs are transcribed into primary-miRNA (pri-miRNA) and then 
exported out of the nucleus to the cytoplasm where they are processed to precursor-miRNA (pre-miRNA) before finally being converted into mature miRNA (O'Brien et al., 2018; Perron, 2008). Mature miRNAs target mRNA sequences to regulate expression through the RNA-induced silencing complex (RISC) (MacFarlane and Murphy, 2010). miRNAs usually target to the 3' UTR site of mRNA ( $\mathrm{Ha}$ and Kim, 2014). The binding location on the mRNA transcript and the homology of the sequence of the miRNA to the mRNA transcript play a role in the effectiveness of the miRNA effect on either target degradation or translation inhibition (Finnegan and Matzke, 2003; McGeary et al., 2019). For example, miRNAs with perfect sequence matches in the 3' UTR region of an mRNA transcript leads to mRNA degradation (Rhoades et al., 2002). However, imperfect matches have been shown to only inhibit translation of an mRNA transcript, which may only delay the translation process, or have no effect (Martin et al., 2014; Saxena et al., 2003). These, perfect and imperfect matches mostly refer to the seed region of the 3' UTR of an mRNA target. However, they can also bind to other regions of the mRNA transcript contributing to the complexity of miRNA-mRNA target analysis (Betel et al., 2010; Broughton et al., 2016).

Single miRNAs may target mRNA transcripts from many different genes, and any given mRNA transcript may be regulated by many different miRNAs. It has been challenging to determine how the balance of miRNAs may affect the expression of specific genes. One approach to understanding how the altered balance of miRNAs plays a role in gene expression is using RNAseq analysis. RNAseq analysis provides global analysis of the expression of RNAs. Using 
RNAseq to evaluate miRNAs provides hypothesis-driving data about how miRNAs may contribute to a pathogenic endpoint.

Studies have evaluated the effects of $\mathrm{Cr}(\mathrm{VI})$ exposure on limited miRNAs, but none considered particulate $\mathrm{Cr}(\mathrm{VI})$ (Chandra et al., 2015; He et al., 2013; Li et al., 2014; Li et al., 2016; Pratheeshkumar et al., 2017; Wang et al., 2019, Wang et al., 2020; Zhang et al., 2020). Cr(VI)-altered miRNAs have specifically been linked to DNA damage in cell culture and epidemiology studies (Chandra et al., 2016; Li et al., 2014). For example, Li et al., 2014 found miR-3940-5p was associated with genetic damage in the blood of workers exposed to $\mathrm{Cr}(\mathrm{VI})$.

To date, five studies have evaluated miRNAs in lung cells after $\mathrm{Cr}(\mathrm{VI})$ exposure (He et al., 2013; Li et al., 2016; Pratheeshkumar et al., 2017; Wang et al., 2019; Wang et al., 2020). However, only one evaluated miRNAs in relation to DNA repair (Li et al., 2016). In general, there is very limited data available on the effects of miRNAs on pathways of $\mathrm{Cr}(\mathrm{VI})$ carcinogenesis. This is partly due to the fact only one genome-wide study has been done to evaluate $\operatorname{Cr}(\mathrm{VI})$-altered miRNA expression, and this was done in the radish plant (Raphanus sativus L.) (Liu et al., 2015). No global expression data is available to evaluate $\mathrm{Cr}(\mathrm{VI})$ altered miRNAs in humans, let alone in the lung, which is the primary target of $\mathrm{Cr}(\mathrm{VI})$ exposure.

In Aim 2 we performed a global analysis of miRNA expression using RNAseq in human lung cells following particulate $\mathrm{Cr}(\mathrm{VI})$ exposure. We characterized particulate $\mathrm{Cr}(\mathrm{VI})$-altered miRNA expression patterns to assess how particulate $\mathrm{Cr}(\mathrm{VI})$ up- or down-regulates miRNA expression (Objective 1). We are specifically interested in how miRNAs affect pathways of $\mathrm{Cr}(\mathrm{VI})$ carcinogenesis. We applied the RNAseq analysis of differentially expressed miRNAs to identify 
$\mathrm{Cr}(\mathrm{VI})$-altered miRNAs involved in pathways of $\mathrm{Cr}(\mathrm{VI})$ carcinogenesis (Objective 2). To focus more closely on homologous recombination repair and RAD51 we identified $\operatorname{Cr}(\mathrm{VI})$-altered miRNAs that specifically regulate targets in the homologous recombination pathway and RAD51 (Objective 3).

\section{Results}

\section{Objective 1: Particulate $\mathrm{Cr}(\mathrm{VI})$ alters global expression of miRNAs}

This is the first study to evaluate global miRNA expression after $\operatorname{Cr}(\mathrm{VI})$ exposure in human cells. The primary target of particulate $\mathrm{Cr}(\mathrm{VI})$ exposure is the lung. We evaluated how particulate $\mathrm{Cr}(\mathrm{VI})$ altered miRNA expression in human lung cells after acute and prolonged exposures. Our first goal was to assess changes in miRNA expression patters after particulate $\mathrm{Cr}(\mathrm{VI})$ exposure. In our analysis, 956 unique miRNAs were identified across all conditions. Of these, table 3.4 shows the total number of significantly altered (adjusted $p$-value $<0.01$ ) miRNAs affected by particulate $\mathrm{Cr}(\mathrm{VI})$ exposure. In Table 3.3 the numbers of upregulated and downregulated miRNAs are included. In some conditions, a miRNA was only expressed in a treated condition indicating that miRNA was 'turned on', or alternatively a miRNA may only have been expressed in the control and therefore, 'turned off'. miRNAs that were turned off or on are listed distinctly from the up- or down-regulated miRNAs in Table 3.4 and combined together as another measure. 
Table 3.3 Distribution of significantly altered miRNAs by particulate $\mathrm{Cr}(\mathrm{VI})$ exposure.

\begin{tabular}{|c|c|c|c|c|c|c|c|c|c|}
\hline & \multicolumn{3}{|c|}{$24 \mathrm{~h}$} & \multicolumn{3}{|c|}{$72 \mathrm{~h}$} & \multicolumn{3}{|c|}{$120 \mathrm{~h}$} \\
\hline $\begin{array}{c}\text { Zinc Chromate } \\
\text { Concentration }\left(\mathrm{ug} / \mathrm{cm}^{2}\right)\end{array}$ & 0.1 & 0.2 & 0.3 & 0.1 & 0.2 & 0.3 & 0.1 & 0.2 & 0.3 \\
\hline Upregulated & 20 & 146 & 63 & 17 & 17 & 51 & 33 & 48 & 47 \\
\hline Downregulated & 12 & 46 & 46 & 69 & 99 & 105 & 110 & 122 & 136 \\
\hline Turned on & 3 & 8 & 2 & 2 & 2 & 4 & 2 & 4 & 7 \\
\hline Turned off & 3 & 9 & 1 & 1 & 1 & 2 & 0 & 1 & 2 \\
\hline Total upregulated & 23 & 154 & 65 & 19 & 19 & 55 & 35 & 52 & 54 \\
\hline Total downregulated & 15 & 55 & 47 & 70 & 100 & 107 & 110 & 123 & 138 \\
\hline Total altered & 38 & 209 & 112 & 89 & 119 & 162 & 145 & 175 & 192 \\
\hline
\end{tabular}

Table 3.3 shows the number of significantly (adjusted $p$-value $<0.01$ ) up- or down-regulated miRNAs, the number of miRNAs turned on or off, and the total for each (Total Upregulated $=$ upregulated + turned on; total downregulated $=$ downregulated + turned off). For each condition the total number of miRNAs significantly altered by particulate $\mathrm{Cr}(\mathrm{VI})$ exposure is listed as the "Total altered" for each column. Data represent the mean of three independent experiments and four technical replicates. 
To determine trends in expression changes after particulate $\operatorname{Cr}(\mathrm{VI})$ exposure we visualized the data in Table 3.3 as bar graphs in Figure 3.21. Figure 3.21A shows higher concentrations of particulate $\mathrm{Cr}(\mathrm{VI})$ increase the number of upregulated miRNAs at all time points. However, there is a spike in upregulated miRNA after $24 \mathrm{~h}$ exposure to $0.2 \mathrm{ug} / \mathrm{cm}^{2}$ zinc chromate. Figure 3.14B shows the number of downregulated miRNAs increase with time and concentration after exposure to particulate $\mathrm{Cr}(\mathrm{VI})$. For example, exposure to $0.2 \mathrm{ug} / \mathrm{cm}^{2}$ zinc chromate resulted in a total of 55, 100, and 138 miRNAs downregulated after 24, 72 and 120 h exposure, respectively. It is also notable more miRNAs were downregulated compared to those that were upregulated. For example, after $120 \mathrm{~h}$ exposure to $0.3 \mathrm{ug} / \mathrm{cm}^{2}$ zinc chromate only 54 miRNAs were upregulated while 138 miRNAs were downregulated. Downregulation of protein-coding gene expression is associated with $\mathrm{Cr}(\mathrm{VI})$ exposure. These data show for the first time $\mathrm{Cr}(\mathrm{VI})$ also downregulates global miRNA expression. 

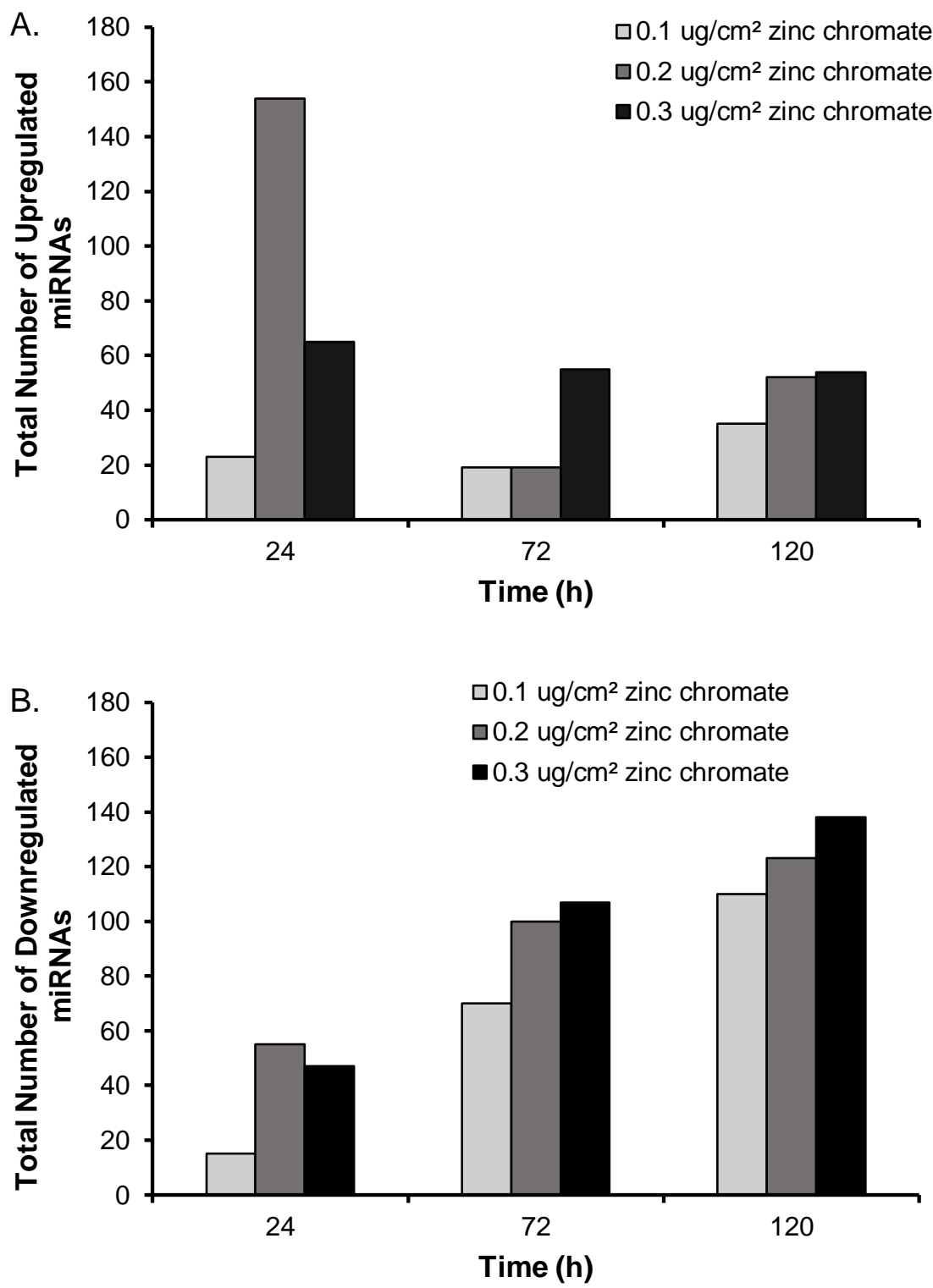

Figure 3.21. Particulate $\mathrm{Cr}(\mathrm{VI})$ exposure increases global downregulation of miRNAs. This figure shows particulate $\mathrm{Cr}(\mathrm{VI})$ significantly (adjusted $p$-value $<0.01$ ) upregulated or downregulated miRNAs compared to control. Data represent the mean of three independent experiments and four technical replicates. (A) Particulate $\operatorname{Cr}(\mathrm{VI})$ significantly upregulated miRNAs at all zinc chromate concentrations compared to the control, though there was 
a spike after $24 \mathrm{~h}$ exposure to $0.2 \mathrm{ug} / \mathrm{cm}^{2}$ zinc chromate. (B) Particulate $\mathrm{Cr}(\mathrm{VI})$ significantly downregulated miRNAs in a time-and concentration-associated manner. 
We visualized these data using volcano plots to assess the distribution and scattering of miRNAs according to two measures: significance and fold change. All 956 miRNAs were included in each analysis. The volcano plots visualize the distribution of up- or -downregulated miRNAs, their significance, and whether the fold change was greater than two (Figure 3.22). The fold change parameter was set to provide some biological relevance to the changes in expression in this global analysis. It is notable that under each condition there are miRNAs with a fold change greater than 2 that did not reach our significance cut-off of an adjusted $p$ value $<0.01$. In addition, there were also changes is expression that were significant, but were less than 2-fold that are also not included. From these data we can see the number of significantly up- or -downregulated miRNAs with a fold change greater than two for each condition. These values are listed in table 3.4. For example, $0.3 \mathrm{ug} / \mathrm{cm}^{2}$ zinc chromate resulted in 12, 18 and 45 miRNAs downregulated and 14, 30 and 19 miRNAs upregulated after 24, 72, and $120 \mathrm{~h}$ exposure, respectively.

These data are presented as bar graphs in Figure 3.23 to assess trends across concentrations and time. There is a spike in significantly upregulated miRNAs (fold change >2) after $24 \mathrm{~h}$ exposure to $0.2 \mathrm{ug} / \mathrm{cm}^{2}$ zinc chromate, which reflects the spike seen in all upregulated miRNAs under this condition (Figure 3.21). There is also a large increase in upregulated miRNAs after $72 \mathrm{~h}$ exposure to $0.3 \mathrm{ug} / \mathrm{cm}^{2}$ zinc chromate ( $30 \mathrm{miRNAs}$ ) compared to 0.1 and $0.2 \mathrm{ug} / \mathrm{cm}^{2}$ zinc chromate, which only had 7 significantly upregulated miRNAs with a fold change greater than 2 each. After $120 \mathrm{~h}$ the number of significantly upregulated miRNAs with a fold change greater than 2 increases with concentration. For example, after 
$0.1,0.2$ and $0.3 \mathrm{ug} / \mathrm{cm}^{2}$ zinc chromate 8,17 , and 19 miRNAs were upregulated, respectively. Figure 3.21B shows particulate $\mathrm{Cr}(\mathrm{VI})$ increased the number of downregulated miRNAs in a concentration and time-associated manner after prolonged exposure (72 and $120 \mathrm{~h}$ ) For example, $120 \mathrm{~h}$ exposure to $0.1,0.2$ and $0.3 \mathrm{ug} / \mathrm{cm}^{2}$ zinc chromate resulted in 15, 37 and 45 significantly downregulated miRNAs (fold change $>2$ ), respectively. Notably, after $24 \mathrm{~h}$ exposure there was a spike in significantly downregulated miRNAs (fold change $>2$ ) after $0.2 \mathrm{ug} / \mathrm{cm}^{2}$ zinc chromate (29 miRNAs) compared to 0.1 and $0.2 \mathrm{ug} / \mathrm{cm}^{2}$ zinc chromate (11 and 12 miRNAs, respectively). 
A. $\quad \begin{aligned} & 24 \mathrm{~h} \\ & 0 \text { vs. } 0.1\end{aligned}$

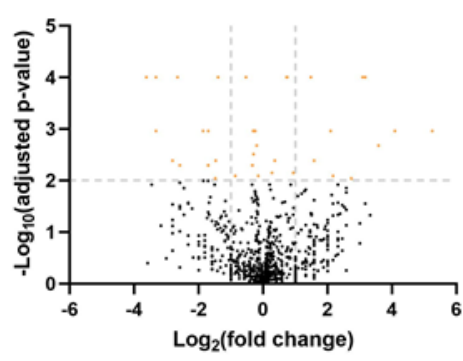

D.

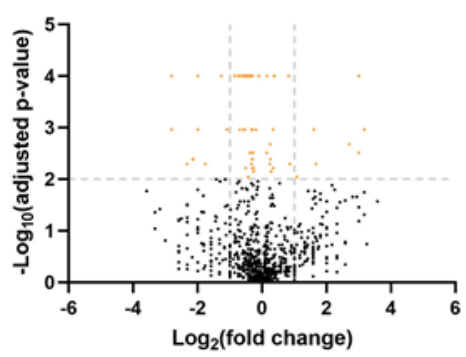

G.
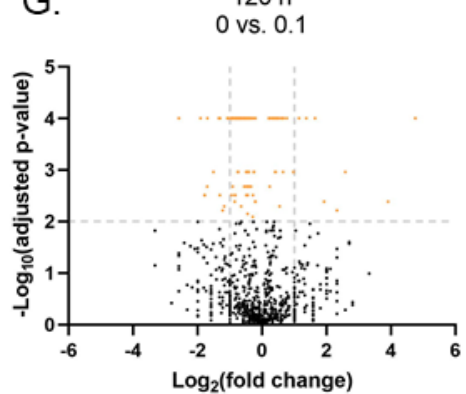

B.



E.

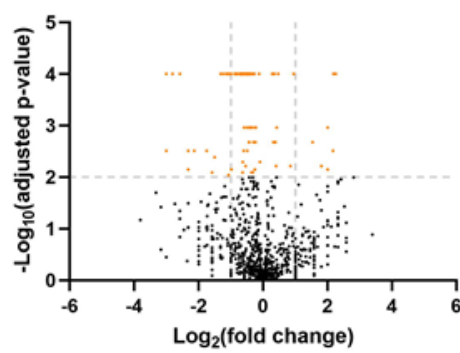

$\mathrm{H}$



C. $24 \mathrm{~h}$
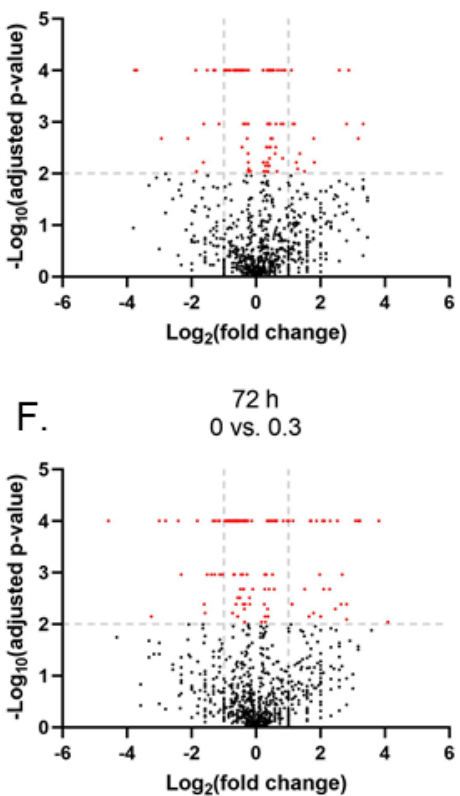

$120 \mathrm{~h}$
0 vs. 0.3



Figure 3.22. Particulate $\mathrm{Cr}(\mathrm{VI})$ alters the expression of miRNAs. This figure shows the $-\log _{10}$ (adjusted $p$-value) and $\log _{2}$ (fold change) of all miRNAs identified in the RNAseq analysis after $24 \mathrm{~h}(\mathrm{~A}, \mathrm{~B}, \mathrm{C}-0.1$, 0.2, and $0.3 \mathrm{ug} / \mathrm{cm}^{2}$ zinc chromate compared to control), respectively, $72 \mathrm{~h}\left(\mathrm{D}, \mathrm{E}, \mathrm{F}-0.1,0.2\right.$, and $0.3 \mathrm{ug} / \mathrm{cm}^{2}$ zinc chromate compared to control, respectively), and $120 \mathrm{~h}(\mathrm{G}, \mathrm{H}, \mathrm{I}-0.1,0.2$, and $0.3 \mathrm{ug} / \mathrm{cm}^{2}$ zinc chromate compared to control, respectively). All miRNAs above the grey horizontal grey dashed line were significantly affected by particulate $\mathrm{Cr}(\mathrm{VI})$ exposure (adjusted $\mathrm{p}$ - 
value $<0.01$ ). These miRNAs are signified by orange or red dots. All miRNAs to the right of the vertical grey dashed line on the $x$-axis set at 1 were upregulated with a fold change greater than 2. All miRNA to the left of the vertical grey dashed line set at -1 were downregulated with a fold change greater than 2. Data represent the mean of three independent experiments and four technical replicates. 
Table 3.4 Number of significantly up- or down-regulated miRNAs with a fold change greater than 2 after particulate $\mathrm{Cr}(\mathrm{VI})$ exposure.

\begin{tabular}{|c|c|c|c|}
\hline $\begin{array}{l}\text { Time point } \\
\text { (h) }\end{array}$ & $\begin{array}{l}\text { Zinc chromate } \\
\text { conc. }\left(\mathrm{ug} / \mathrm{cm}^{2}\right)\end{array}$ & $\begin{array}{c}\text { Significantly } \\
\text { Downregulated } \\
\text { miRNAs } \\
\text { (Fold change >2) }\end{array}$ & $\begin{array}{c}\text { Significantly } \\
\text { Upregulated miRNAs } \\
\text { (Fold change }>\mathbf{2} \text { ) }\end{array}$ \\
\hline \multirow{3}{*}{24} & 0.1 & 11 & 10 \\
\hline & 0.2 & 29 & 70 \\
\hline & 0.3 & 12 & 14 \\
\hline \multirow{3}{*}{72} & 0.1 & 10 & 7 \\
\hline & 0.2 & 17 & 7 \\
\hline & 0.3 & 18 & 30 \\
\hline \multirow{3}{*}{120} & 0.1 & 15 & 8 \\
\hline & 0.2 & 37 & 17 \\
\hline & 0.3 & 45 & 19 \\
\hline
\end{tabular}



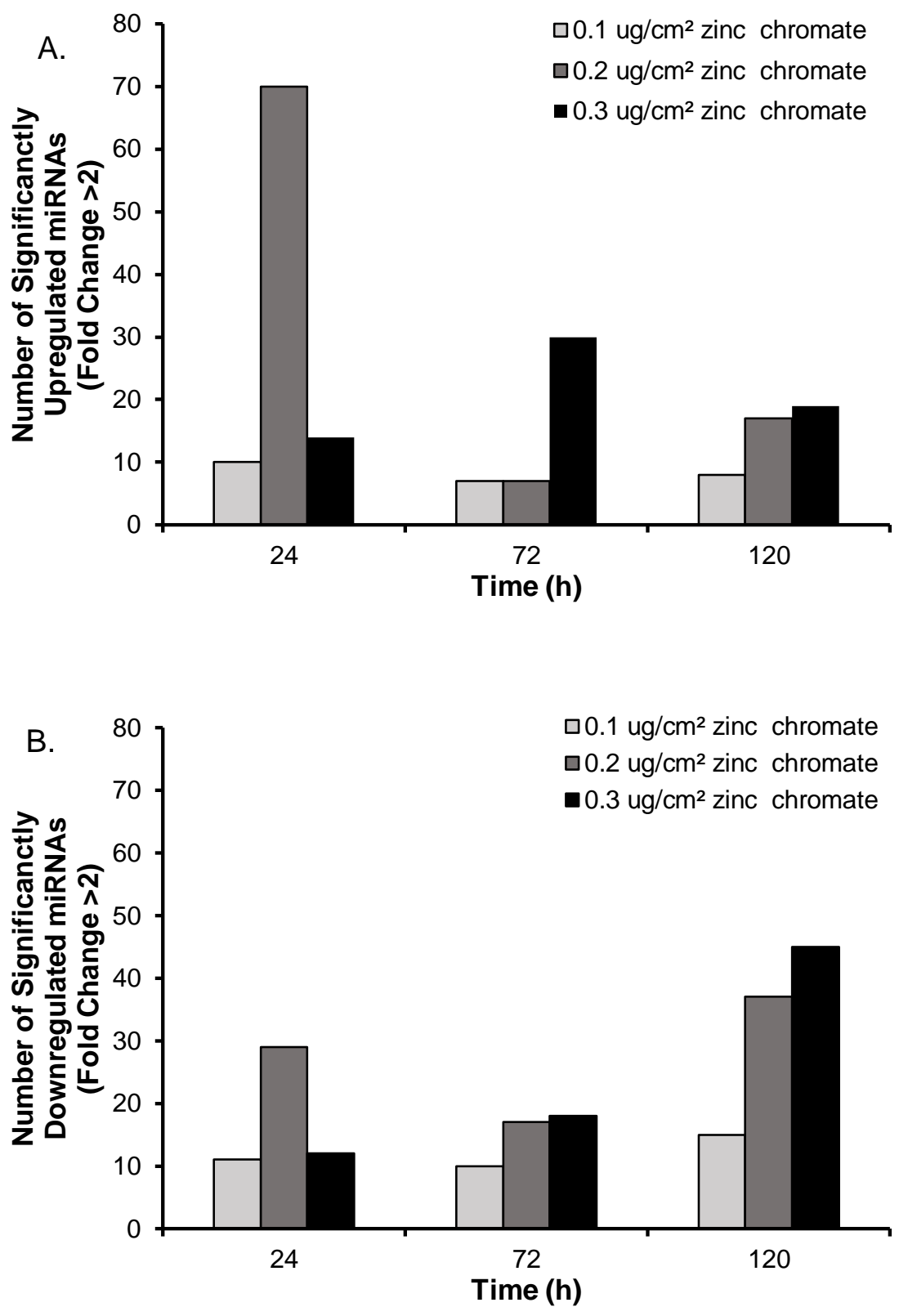

Figure 3.23. miRNAs significantly altered by particulate $\mathrm{Cr}(\mathrm{VI})$ with a fold change greater than 2. This figure shows particulate $\mathrm{Cr}(\mathrm{VI})$ increases the number of miRNAs significantly up- or down-regulated (adjusted $p$-value $<0.01$ ) with a fold change greater than 2 compared to control. Data represent the mean of three independent experiments and four technical replicates. (A) miRNAs upregulated 
by particulate $\mathrm{Cr}(\mathrm{VI})$ exposure relative to control. (B) miRNAs downregulated by particulate $\mathrm{Cr}(\mathrm{VI})$ exposure relative to control. 
This broad general view of particulate $\mathrm{Cr}(\mathrm{VI})$ altered miRNAs in Table 3.5 and Figure 3.23 does not indicate how many of the same miRNAs were affected between conditions. To better understand the number of miRNAs upregulated or downregulated by particulate $\mathrm{Cr}(\mathrm{VI})$ exposure across concentrations we visualized the data using Venn diagrams. Each Venn diagram shows the crossover of miRNAs significantly affected (either up- or down-regulated) by particulate $\mathrm{Cr}(\mathrm{VI})$ within a time point (Figure 3.22). Very few of the same miRNAs were significantly upregulated (fold change $>2$ ) in both the 0.1 and $0.3 \mathrm{ug} / \mathrm{cm}^{2}$ zinc chromate conditions at all time points. For example, no significantly upregulated miRNAs were the same between 0.1 and $0.3 \mathrm{ug} / \mathrm{cm}^{2}$ zinc chromate after 24 and $72 \mathrm{~h}$, respectively, and only 0 and 1 downregulated miRNAs were shared between these two time points. However, after $120 \mathrm{~h}$ exposure there were 5 downregulated and 21 upregulated miRNAs shared between 0.2 and $0.3 \mathrm{ug} / \mathrm{cm}^{2}$ zinc chromate, respectively. 
A.



D.



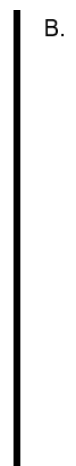

E.
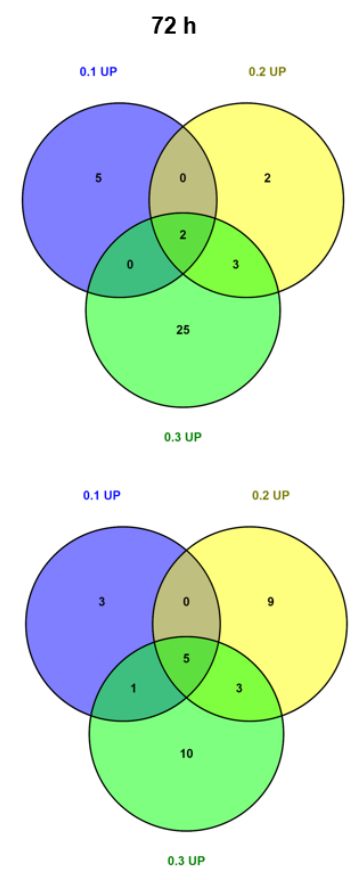

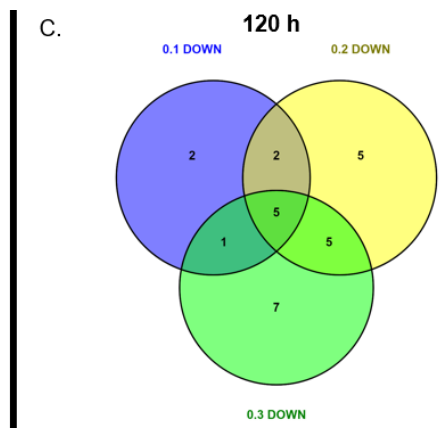

F.

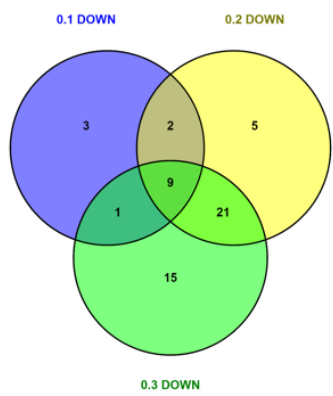

Figure 3.24. Venn diagrams of up- and down-regulated miRNAs across particulate $\operatorname{Cr}(\mathrm{VI})$ concentrations. This figure shows how many miRNAs were significantly up- or down-regulated (fold change >2) after particulate $\mathrm{Cr}(\mathrm{VI})$ exposure between concentrations compared to control. Data represent the mean of three independent experiments and four technical replicates. A, B, and C show Venn diagrams of miRNAs upregulated by $0.1,0.2$ and $0.3 \mathrm{ug} / \mathrm{cm}^{2}$ zinc chromate after 24, 72, and $120 \mathrm{~h}$ exposure, respectively. D, E, and F show Venn diagrams of miRNAs downregulated by $0.1,0.2$ and $0.3 \mathrm{ug} / \mathrm{cm}^{2}$ zinc chromate after 24,72 , and $120 \mathrm{~h}$, respectively compared to control. 
To better understand how particulate $\mathrm{Cr}(\mathrm{VI})$ affected expression across different miRNAs we generated heatmaps using fold change data. Figure 3.25 shows Euclidean hierarchical clustering of miRNAs after 24 (A), 72 (B), and $120 \mathrm{~h}$ (C) exposure to particulate $\mathrm{Cr}(\mathrm{VI})$. These heatmaps cluster together miRNAs using the Euclidean hierarchical model, which clusters units based on direct lines of relatedness. In this case, the closer in color of the unit, the more similar the fold change of the miRNA compared to the control. For example, after $120 \mathrm{~h}$ exposure miR-200A, miR-194-1 and miR-194-2 clustered closely to one another and were all significantly upregulated. We can see distinct clustering of up- or downregulated miRNAs in these heatmaps, but this clustering is especially prominent after prolonged 72 and $120 \mathrm{~h}$ exposure where the top halves of the heatmaps are almost exclusively orange (upregulated) and the bottom halves are almost exclusively blue (downregulated). This distinction is less obvious after $24 \mathrm{~h}$ exposure to particulate $\mathrm{Cr}(\mathrm{VI})$. The difference between the $24 \mathrm{~h}$ and 72 or $120 \mathrm{~h}$ distinctions in clustering reflects our other data that show the $24 \mathrm{~h}$ response to particulate $\mathrm{Cr}(\mathrm{VI})$ is different than the 72 and $120 \mathrm{~h}$ responses. Additionally, the larger number of miRNAs in the $24 \mathrm{~h}$ heatmap shows more miRNAs were significantly affected (fold change $>2$ ) than after 72 or $120 \mathrm{~h}$ exposure. However, this likely reflects the spike of upregulated miRNAs after $24 \mathrm{~h}$ exposure to 0.2 $\mathrm{ug} / \mathrm{cm}^{2}$ zinc chromate presented earlier (Figure 3.23). It is noteworthy that of the large number of miRNAs in the $24 \mathrm{~h}$ heatmap many of them have light-colored units (white correlating to a fold change of 0 ) indicating a low fold change in expression. The heatmaps were also clustered using k-clustering to show relatedness between miRNA expression changes. Figure 3.26 shows heatmaps of 
the miRNAs using Euclidean k-clustering. A k-cluster $\mathrm{n}=3$ was used in the analysis, and clearly clusters the miRNAs by expression patterns. In Figure 3.26A we can clearly see the distinction between miRNAs with higher fold change patterns and those with low fold change. There is also a stronger distinction across all the time points between the clusters of up- and down-regulated miRNAs. Similar to the hierarchical clustering, the 72 and $120 \mathrm{~h}$ heatmaps are more distinct than the $24 \mathrm{~h}$ heatmap. 
A.

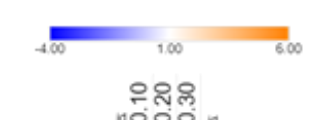
100\%

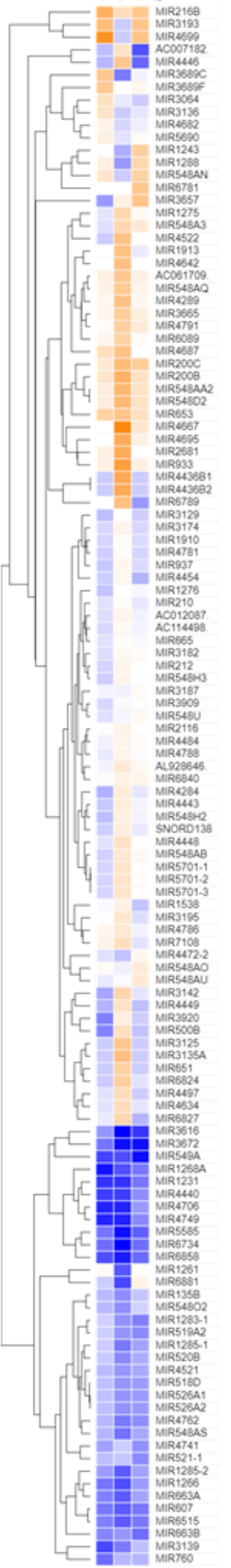

B.



c.

Figure 3.25. Euclidean hierarchical clustering of miRNAs altered by particulate $\mathrm{Cr}(\mathrm{VI})$ exposure. This figure shows hierarchical clustering of significantly altered miRNAs after particulate $\mathrm{Cr}(\mathrm{VI})$ exposure compared to control. Data represent the mean of three independent experiments and four technical replicates. Clustering of miRNAs was performed after $24(\mathrm{~A}), 72(\mathrm{~B})$, and $120 \mathrm{~h}(\mathrm{C})$ exposure to particulate $\mathrm{Cr}(\mathrm{VI})$. The average linkage method was applied. Data are represented as fold change relative to control. miRNAs were included if they were significantly affected (adjusted $p$-value $<0.01$, fold change $>2$ ) in at least one condition for each individual time point compared to control. Upregulated miRNAs are coded orange while downregulated miRNAs are coded blue. 
A.

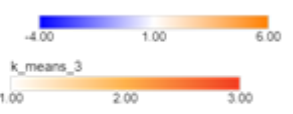

웅중용.

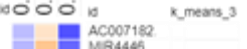

He Ma445

Marsis

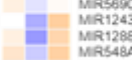

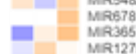

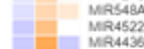





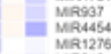

ACC10 2009
AC 11449

MASSE



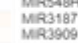

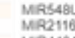

MRA484

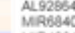

MAS20
MA44
MAS4
MAS4

SNORO 130

MA44AB

MAS501

MR1500

$M R 7108$
$M R 4422$

MAS48A

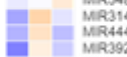

MRSO06
MR3125
MaP125

MAO51

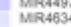

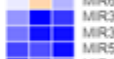

级

\begin{tabular}{l} 
MaA \\
$-\quad$ MRAT \\
\hline
\end{tabular}

B.

MAR698
$-\quad$ MR 1355
-


MRA521

- Marat

M MRS21.

\begin{tabular}{l} 
MA6634 \\
MAR507 \\
\hline
\end{tabular}

Mas635

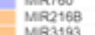

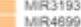

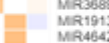

ACC6170

M 1942.29

MASA79

\begin{tabular}{l} 
MAR4689 \\
MPR2000 \\
\hline
\end{tabular}

MP2000

MARSS4002
MARS3



MRA4695
MR261
MRR933
B.



을ํ요

wO 0 1

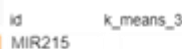

id
MIR215
MiR375
MiR302D

MIR1908

MIR3195

MIR194.1

MIR2008

MIR670
MIR4676

MIR4700

MiR551A

MIR7846

MIIF549X

MiR549X
MiR0078

MIR3655

MIRA740

MiR6797

MRR4429

M.r.

MiR1293

MIR184

MIR6638

MIR 4746

MIR3658

MiR 1283-1

MIR4451

MIR519A2

MIR573

MIRS12.2
MIR7974

MIR2278

MIR663A

MIR3133
MIR5579

MIR6607

MIR6B26

MiR4 4802

MiR4723

MiR57

MIR8052

MIR2276

MIR141

MiR3159

MIR4284

MIR210

Al 925845

MIR5701.

MiR5701

AL 358013

MIR5004
C.

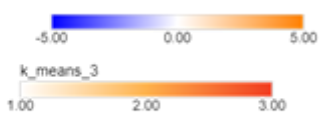

융융유

do 0 '0 is knmeans_3

MRESO1
MiR3157
AC021590
$M 123516$

MiRS4SH4

MiR 1305
MiRs $54+11$

MiR55841-1
MRR218-2

MiR1276

MiR4765

MR448

MIRR21303

MiR378

MiR158

MIR520E

MiR520F

MiRS16A1

MiR518B

MiR378A

Mir37ec

MRR51442

MiR 4521

MiR445

MRP 42

MiR11323

MRR54SY

MIRS4 $5 F$

MRR $M$ M 12522

MRT MRA

MiR129.2

MRSASAM

MiR 129.1

MRR518F

MiRR 194.1

MRE

MiRE 508

MR 4479

MR3118.2

MiR3118-3

MiR4653

MiR 4705

MiR195

MRRES12

MRR625

MiR190B

MiR670

MiR2215

MR210

MiR6716

MiRR1249

MiREs

SNORD 139 MIR 4 S5-1

MiR205

MRA694

MiR6733

MRESS

MIRST3

MiR7974

MiR366

MiR625
MiRg44

MRE732

MiR 1532 
Figure 3.26. K-clustering of miRNAs altered by particulate $\mathrm{Cr}(\mathrm{VI})$ exposure. This figure shows the k-clustering of miRNAs significantly affected by particulate $\mathrm{Cr}(\mathrm{VI})$ exposure compared to control. Data represent the mean of three independent experiments and four technical replicates. K-clustering of miRNAs was performed after 24 (A), $72(B)$, and $120 \mathrm{~h}(\mathrm{C})$ exposure to particulate $\mathrm{Cr}(\mathrm{VI})$. The average linkage method was applied. Data are represented as fold change relative to control. miRNAs were included if they were significantly affected (adjusted $p$-value $<0.01$, fold change $>2$ ) in at least one condition for each individual time point. Upregulated miRNAs are coded orange while downregulated miRNAs are coded blue. A kcluster of 3 was applied and grouped the miRNAs by red, orange, or white for each distinct cluster. 
Objective 2: Particulate $\mathrm{Cr}(\mathrm{VI})$ alters miRNAs involved in pathways of $\mathrm{Cr}(\mathrm{VI})$ carcinogenesis

The data in Objective 1 provide the first analysis of global miRNA expression after $\mathrm{Cr}(\mathrm{VI})$ exposure in human cells. We found particulate $\mathrm{Cr}(\mathrm{VI})$ increased the number of miRNAs significantly up- or down-regulated and identified trends in the analyses. We are specifically interested in the role of miRNAs in $\mathrm{Cr}(\mathrm{VI})$ carcinogenesis. While the global analysis is informative about trends of $\mathrm{Cr}(\mathrm{VI})$-altered miRNAs we wanted to know how they may be involved in the mechanisms of $\mathrm{Cr}(\mathrm{VI})$ carcinogenesis. We performed a literature search for recent review papers on $\mathrm{Cr}(\mathrm{VI})$ to identify pathways proposed to be involved in $\mathrm{Cr}(\mathrm{VI})$ carcinogenesis. We identified 9 recent articles (Table 3.5) for this purpose. 
Table 3.5. Articles used to populate pathways of $\mathrm{Cr}(\mathrm{VI})$ carcinogenesis.

\begin{tabular}{|c|c|}
\hline Paper Title & Citation \\
\hline $\begin{array}{c}\text { Molecular and epigenetic mechanisms of Cr(VI)-induced } \\
\text { carcinogenesis }\end{array}$ & Chen et al., 2019 \\
\hline $\begin{array}{c}\text { Oxidative stress and metabolic reprogramming in Cr(VI) } \\
\text { Mechanisms of chromium-induced toxicity }\end{array}$ & Clementino et al., 2018 \\
\hline $\begin{array}{c}\text { chromium(VI)-induced toxic effects } \\
\text { chroviance of oxidative and reductive species involved in } \\
\text { chromium exposure in lung cells supports a role of } \\
\text { epigenetic mediators in carcinogenesis }\end{array}$ & Hu et al., 2017 2019 \\
\hline $\begin{array}{c}\text { Current status on chromium research and its implications } \\
\text { for health and risk assessment }\end{array}$ & Speer and Wise, 2018 \\
\hline $\begin{array}{c}\text { Metal carcinogen exposure induces cancer stem cell-like } \\
\text { property through epigenetic reprograming: A novel } \\
\text { mechanism of metal carcinogenesis }\end{array}$ & Wang and Yang, 2019 \\
\hline $\begin{array}{c}\text { Carcinogenicity of chromium and chemoprevention: a brief } \\
\text { update }\end{array}$ & Wang et al., 2017 \\
\hline $\begin{array}{c}\text { Metal carcinogenesis and DNA damage: A case study } \\
\text { using hexavalent chromium }\end{array}$ & Wise and Wise, 2018 \\
\hline
\end{tabular}


We correlated the pathways of $\mathrm{Cr}(\mathrm{VI})$ carcinogenesis identified in the literature with pathways in the KEGG database. We identified 5 networks and 13 sub-networks that pathways of $\mathrm{Cr}(\mathrm{VI})$ carcinogenesis applied to (Table 3.6). The 5 networks include 4 involved in cell mechanisms, and 1 related to human disease. All the human disease sub-networks are related to cancer. Of those networks related to cellular mechanisms, 3 are related to environmental information processing, genetic information processing, and metabolism while one is related to cellular processes. Upon looking at the sub-networks many are expectedly associated with carcinogenesis including signaling transduction, energy metabolism, and replication and repair. Thirty-six distinct KEGG pathways were identified within these networks to be involved in $\mathrm{Cr}(\mathrm{VI})$ carcinogenesis. These are presented in the data below. 
Table 3.6. KEGG networks of $\mathrm{Cr}(\mathrm{VI})$ carcinogenesis.

\begin{tabular}{|l|l|}
\hline \multicolumn{1}{|c|}{ Network } & \multicolumn{1}{|c|}{ Sub-Network } \\
\hline Cellular Processes & Cell growth and death \\
\hline Environmental information processing & Transport and catabolism \\
\hline Environmental information processing & Signal transduction \\
\hline Environmental information processing & Signaling molecules and interactions \\
\hline Genetic information processing & Folding, sorting, degradation \\
\hline Genetic information processing & Replication and repair \\
\hline Genetic information processing & Transcription \\
\hline Metabolism & Carbohydrate metabolism \\
\hline Metabolism & Energy Metabolism \\
\hline Metabolism & Xenobiotics biodegradation and metabolism \\
\hline Human disease & Cancer: overview \\
\hline Human disease & Cancer: specific types \\
\hline Human disease & Drug resistance: antineoplastic \\
\hline
\end{tabular}


We populated lists of significantly up-or down-regulated miRNAs (fold change >2) for each condition and uploaded them to the web-based analysis system mirPath, which identified KEGG pathways affected by sets of miRNAs (Vlachos et al .,2015). These pathways were then cross-referenced with the KEGG pathways identified through our $\mathrm{Cr}(\mathrm{VI})$ literature search to determine how many genes within a pathway was affected by particualte $\mathrm{Cr}(\mathrm{VI})$-upregulated miRNAs and how many miRNAs targeted each pathway. We focused on upregulated miRNAs because upregulation of miRNAs leads to the downregulation of gene expression. We partitioned the pathways by their relevance to one another resulting in 4 groupings: Cancer related (Table 3.7A-B), signaling (Table 3.8A-B), cellular processes (Table 3.9A-B), and DNA repair (Table 3.10A-B). We can see the number of particulate $\mathrm{Cr}(\mathrm{VI})$-upregulated miRNAs predicted to target pathways of $\mathrm{Cr}(\mathrm{VI})$ carcinogenesis and the number of genes targeted increase with time or concentration. For example, the number of predicted genes targeted by particulate $\mathrm{Cr}(\mathrm{VI})$-upregulated miRNAs in the pathways in cancer pathway are 64, 87, and 93 after 24,72 , and $120 \mathrm{~h}$. In all these tables, we can see an increase after $24 \mathrm{~h} 0.2$ $\mathrm{ug} / \mathrm{cm}^{2}$ zinc chromate consistent with the earlier data showing a spike at under this condition (Figure 3.23). Of all of the pathways involved in signaling the PI3K-AKT pathway had the most predicted genes targeted by $\operatorname{Cr}(\mathrm{VI})$-upregulated miRNAs. Of the 'cellular processes' pathways, apoptosis, cell cycle, and ubiquitin-mediated proteolysis were the most targeted. For example, 10, 20 and 23 genes in the cell cycle pathway were predicted to be targeted by particulate $\mathrm{Cr}(\mathrm{VI})$-upregulated miRNAs after $0.3 \mathrm{ug} / \mathrm{cm}^{2}$ zinc chromate after 24,72 , and $120 \mathrm{~h}$, respectively. The DNA repair pathways had similar numbers of genes predicted to be targeted by 
particulate $\mathrm{Cr}(\mathrm{VI})$-upregulated miRNAs and the number of miRNAs that targeted those pathways. For example, the fanconi anemia pathway, nucleotide excision repair, and homologous recombination had 8,7 , and 5 genes predicted to be targeted by particulate $\mathrm{Cr}(\mathrm{VI})$-upregulated miRNAs, after 24,72 , and $120 \mathrm{~h}$ exposure to $0.3 \mathrm{ug} / \mathrm{cm}^{2}$ zinc chromate, respectively. 
Table 3.7A. Number of genes targeted by $\mathrm{Cr}(\mathrm{VI})$-upregulated miRNAs in cancer related pathways.

\begin{tabular}{|l|c|c|c|c|c|c|c|c|c|}
\hline \multicolumn{1}{|c|}{ Time point } & \multicolumn{3}{c|}{$\mathbf{2 4} \mathbf{~}$} & \multicolumn{3}{c|}{$\mathbf{7 2} \mathbf{~}$} & \multicolumn{3}{c|}{$\mathbf{1 2 0} \mathbf{~}$} \\
\hline \multicolumn{1}{|c}{ Zinc chromate conc. $\left(\mathbf{u g} / \mathbf{c m}^{2}\right.$ ) } & $\mathbf{0 . 1}$ & $\mathbf{0 . 2}$ & $\mathbf{0 . 3}$ & $\mathbf{0 . 1}$ & $\mathbf{0 . 2}$ & $\mathbf{0 . 3}$ & $\mathbf{0 . 1}$ & $\mathbf{0 . 2}$ & $\mathbf{0 . 3}$ \\
\hline Pathways in cancer & 41 & 174 & 64 & 33 & 15 & 87 & 30 & 62 & 93 \\
\hline $\begin{array}{l}\text { Transcriptional misregulation in } \\
\text { cancer }\end{array}$ & 18 & 74 & 30 & 13 & 9 & 34 & 13 & 25 & 39 \\
\hline MicroRNAs in cancer & 22 & 78 & 29 & 14 & 8 & 40 & 15 & 27 & 43 \\
\hline Non-small cell lung cancer & 5 & 29 & 11 & 7 & 1 & 16 & 3 & 11 & 15 \\
\hline Small cell lung cancer & 3 & 34 & 15 & 9 & 1 & 15 & 3 & 14 & 19 \\
\hline Total: & 89 & 389 & 149 & 76 & 34 & 192 & 64 & 139 & 209 \\
\hline
\end{tabular}

Table 3.7B. Number of $\mathrm{Cr}(\mathrm{VI})$-upreguated miRNAs targeting genes in cancer related pathways.

\begin{tabular}{|l|c|c|c|c|c|c|c|c|c|}
\hline \multicolumn{1}{|c|}{ Time point } & \multicolumn{3}{c|}{$\mathbf{2 4} \mathbf{h}$} & \multicolumn{3}{c|}{$\mathbf{7 2} \mathbf{~}$} & \multicolumn{3}{c|}{$120 \mathrm{~h}$} \\
\hline \multicolumn{1}{|c}{ Zinc chromate conc. $\left(\mathbf{u g} / \mathbf{c m}^{2}\right.$ ) } & 0.1 & 0.2 & 0.3 & 0.1 & 0.2 & 0.3 & 0.1 & 0.2 & 0.3 \\
\hline Pathways in cancer & 10 & 65 & 14 & 10 & 8 & 29 & 11 & 20 & 20 \\
\hline $\begin{array}{l}\text { Transcriptional misregulation in } \\
\text { cancer }\end{array}$ & 10 & 45 & 11 & 9 & 4 & 18 & 5 & 14 & 16 \\
\hline MicroRNAs in cancer & 7 & 50 & 11 & 7 & 4 & 18 & 6 & 13 & 14 \\
\hline Non-small cell lung cancer & 4 & 27 & 6 & 5 & 1 & 12 & 3 & 8 & 10 \\
\hline Small cell lung cancer & 3 & 30 & 8 & 5 & 1 & 10 & 3 & 8 & 9 \\
\hline Total: & 34 & 217 & 50 & 36 & 18 & 87 & 28 & 63 & 69 \\
\hline
\end{tabular}

Table 3.8A. Number of genes targeted by $\mathrm{Cr}(\mathrm{VI})$-upregulated miRNAs in signaling pathways.

\begin{tabular}{|c|c|c|c|c|c|c|c|c|c|}
\hline Time point & \multicolumn{3}{|c|}{$24 \mathrm{~h}$} & \multicolumn{3}{|c|}{$72 \mathrm{~h}$} & \multicolumn{3}{|c|}{$120 \mathrm{~h}$} \\
\hline Zinc chromate conc. (ug/cm $\left.{ }^{2}\right)$ & 0.1 & 0.2 & 0.3 & 0.1 & 0.2 & 0.3 & 0.1 & 0.2 & 0.3 \\
\hline PI3K-Akt signaling pathway & 9 & 55 & 13 & 9 & 6 & 20 & 7 & 15 & 18 \\
\hline MAPK & 6 & 48 & 12 & 6 & 5 & 19 & 7 & 16 & 17 \\
\hline HIPPO signaling pathway & 8 & 47 & 11 & 7 & 6 & 20 & 8 & 16 & 17 \\
\hline AMPK signaling pathway & 7 & 39 & 9 & 7 & 5 & 14 & 3 & 13 & 15 \\
\hline Ras signaling pathway & 8 & 56 & 13 & 6 & 4 & 20 & 8 & 14 & 14 \\
\hline HIF-1 signaling pathway & 6 & 37 & 5 & 5 & 3 & 14 & 4 & 12 & 13 \\
\hline \begin{tabular}{|l} 
TNF signaling pathway \\
\end{tabular} & 3 & 41 & 6 & 4 & 4 & 14 & 5 & 5 & 13 \\
\hline NF-kappa B signaling pathway & 7 & 32 & 7 & 4 & 4 & 12 & 4 & 13 & 12 \\
\hline p53 signaling pathway & 3 & 34 & 9 & 4 & 2 & 13 & 5 & 9 & 12 \\
\hline Wnt signaling pathway & 8 & 40 & 11 & 6 & 4 & 18 & 7 & 11 & 12 \\
\hline VEGF signaling pathway & 2 & 23 & 6 & 4 & 0 & 13 & 1 & 7 & 6 \\
\hline Cell adhesion molecules (CAMs) & 5 & 41 & 7 & 4 & 6 & 14 & 6 & 12 & 12 \\
\hline ECM-receptor interaction & 4 & 32 & 9 & 5 & 3 & 10 & 5 & 8 & 11 \\
\hline Total: & 76 & 525 & 118 & 71 & 52 & 201 & 70 & 151 & 172 \\
\hline
\end{tabular}


Table 3.8B. Number of $\mathrm{Cr}(\mathrm{VI})$-upreguated miRNAs targeting genes in signaling.

\begin{tabular}{|l|c|c|c|c|c|c|c|c|c|}
\hline \multicolumn{1}{|c|}{ Time point } & \multicolumn{3}{c|}{$\mathbf{2 4} \mathbf{~ h}$} & \multicolumn{3}{c|}{$\mathbf{7 2} \mathbf{~ h}$} & \multicolumn{3}{c|}{$\mathbf{1 2 0} \mathbf{~ h}$} \\
\hline \multicolumn{1}{|c|}{ Zinc chromate conc. (ug/cm $\mathbf{2})$} & $\mathbf{0 . 1}$ & $\mathbf{0 . 2}$ & $\mathbf{0 . 3}$ & $\mathbf{0 . 1}$ & $\mathbf{0 . 2}$ & $\mathbf{0 . 3}$ & $\mathbf{0 . 1}$ & $\mathbf{0 . 2}$ & $\mathbf{0 . 3}$ \\
\hline PI3K-Akt signaling pathway & 34 & 140 & 52 & 31 & 11 & 65 & 23 & 57 & 77 \\
\hline MAPK & 16 & 114 & 37 & 23 & 8 & 59 & 20 & 44 & 70 \\
\hline HIPPO signaling pathway & 17 & 72 & 27 & 17 & 9 & 30 & 12 & 21 & 44 \\
\hline AMPK signaling pathway & 10 & 58 & 24 & 10 & 6 & 26 & 7 & 22 & 31 \\
\hline Ras signaling pathway & 26 & 99 & 42 & 18 & 11 & 61 & 22 & 45 & 57 \\
\hline HIF-1 signaling pathway & 9 & 45 & 7 & 8 & 4 & 28 & 10 & 23 & 27 \\
\hline TNF signaling pathway & 3 & 58 & 12 & 5 & 5 & 22 & 9 & 6 & 25 \\
\hline NF-kappa B signaling pathway & 8 & 38 & 11 & 5 & 4 & 18 & 7 & 18 & 24 \\
\hline p53 signaling pathway & 5 & 34 & 14 & 6 & 2 & 17 & 5 & 10 & 19 \\
\hline Wnt signaling pathway & 12 & 61 & 26 & 13 & 6 & 29 & 12 & 23 & 43 \\
\hline VEGF signaling pathway & 2 & 30 & 8 & 5 & 0 & 18 & 2 & 10 & 12 \\
\hline Cell adhesion molecules (CAMs) & 9 & 61 & 23 & 11 & 10 & 37 & 12 & 23 & 37 \\
\hline ECM-receptor interaction & 7 & 35 & 13 & 11 & 4 & 15 & 8 & 15 & 25 \\
\hline Total: & 158 & 845 & 296 & 163 & 80 & 425 & 149 & 317 & 491 \\
\hline
\end{tabular}

Table 3.9A. Number of genes targeted by $\mathrm{Cr}(\mathrm{VI})$-upregulated miRNAs in cellular

processes pathways.

\begin{tabular}{|l|c|c|c|c|c|c|c|c|c|c|}
\hline \multicolumn{1}{|c|}{ Time point } & \multicolumn{3}{c|}{$\mathbf{2 4} \mathbf{~ h}$} & \multicolumn{3}{c|}{$\mathbf{7 2} \mathbf{~ h} \mathbf{~ h}$} \\
\hline \multicolumn{1}{|c|}{ Zinc chromate conc. $\mathbf{( u g / \mathbf { c m } ^ { 2 } )}$} & $\mathbf{0 . 1}$ & $\mathbf{0 . 2}$ & $\mathbf{0 . 3}$ & $\mathbf{0 . 1}$ & $\mathbf{0 . 2}$ & $\mathbf{0 . 3}$ & $\mathbf{0 . 1}$ & $\mathbf{0 . 2}$ & $\mathbf{0 . 3}$ \\
\hline Apoptosis & 3 & 41 & 13 & 6 & 3 & 19 & 7 & 15 & 22 \\
\hline Cell cycle & 8 & 41 & 10 & 9 & 5 & 20 & 4 & 9 & 23 \\
\hline Regulation of autophagy & 2 & 12 & 5 & 2 & 1 & 4 & 1 & 5 & 4 \\
\hline Glycolysis/gluconeogenesis & 11 & 22 & 13 & 2 & 3 & 13 & 6 & 10 & 11 \\
\hline Pentose phosphate pathway & 6 & 8 & 3 & 1 & 1 & 4 & 2 & 3 & 5 \\
\hline Oxidative phosphorylation & 7 & 39 & 11 & 5 & 5 & 15 & 0 & 7 & 15 \\
\hline Metabolism of xenobiotics by cytochrome P450 & 12 & 26 & 9 & 4 & 1 & 10 & 5 & 12 & 9 \\
\hline Basal transcription factors & 3 & 14 & 8 & 4 & 3 & 10 & 3 & 7 & 8 \\
\hline Ubiquitin mediated proteolysis & 13 & 59 & 20 & 13 & 5 & 17 & 5 & 17 & 23 \\
\hline Total: & 65 & 262 & 92 & 46 & 27 & 112 & 33 & 100 & 120 \\
\hline
\end{tabular}

Table 3.9B. Number of $\mathrm{Cr}(\mathrm{VI})$-upreguated miRNAs targeting genes in cellular processes pathways.

\begin{tabular}{|l|c|c|c|c|c|c|c|c|c|}
\hline \multicolumn{1}{|c|}{ Time point } & \multicolumn{3}{c|}{$\mathbf{2 4} \mathbf{h}$} & \multicolumn{3}{c|}{$\mathbf{7 2} \mathbf{~ h}$} & \multicolumn{3}{c|}{$\mathbf{1 2 0} \mathbf{~}$} \\
\hline \multicolumn{1}{|c|}{ Zinc chromate conc. (ug/cm $\mathbf{2})$} & $\mathbf{0 . 1}$ & $\mathbf{0 . 2}$ & $\mathbf{0 . 3}$ & $\mathbf{0 . 1}$ & $\mathbf{0 . 2}$ & $\mathbf{0 . 3}$ & $\mathbf{0 . 1}$ & $\mathbf{0 . 2}$ & $\mathbf{0 . 3}$ \\
\hline Apoptosis & 1 & 32 & 6 & 5 & 3 & 14 & 4 & 10 & 12 \\
\hline Cell cycle & 5 & 41 & 11 & 7 & 3 & 13 & 4 & 9 & 10 \\
\hline Regulation of autophagy & 2 & 13 & 5 & 2 & 1 & 3 & 1 & 5 & 4 \\
\hline Glycolysis/gluconeogenesis & 5 & 25 & 8 & 2 & 3 & 11 & 6 & 10 & 9 \\
\hline Pentose phosphate pathway & 2 & 10 & 3 & 1 & 1 & 4 & 2 & 3 & 3 \\
\hline Oxidative phosphorylation & 4 & 27 & 6 & 4 & 1 & 8 & 0 & 5 & 7 \\
\hline Metabolism of xenobiotics by cytochrome P450 & 6 & 30 & 8 & 2 & 1 & 7 & 3 & 7 & 7 \\
\hline Basal transcription factors & 2 & 18 & 7 & 4 & 3 & 7 & 3 & 7 & 7 \\
\hline Ubiquitin mediated proteolysis & 7 & 47 & 12 & 5 & 3 & 14 & 5 & 9 & 9 \\
\hline Total: & 34 & 243 & 66 & 32 & 19 & 81 & 28 & 75 & 68 \\
\hline
\end{tabular}


Table 3.10A. Number of genes targeted by $\mathrm{Cr}(\mathrm{VI})$-upregulated miRNAs in DNA repair pathways.

\begin{tabular}{|l|c|c|c|c|c|c|c|c|c|}
\hline \multicolumn{1}{|c|}{ Time point } & \multicolumn{3}{c|}{$\mathbf{2 4} \mathbf{~}$} & \multicolumn{3}{c|}{$\mathbf{7 2} \mathbf{~ h}$} & \multicolumn{3}{c|}{$\mathbf{1 2 0} \mathbf{~}$} \\
\hline $\begin{array}{c}\text { Zinc chromate conc. } \\
\text { (ug/cm } \text { ) }^{2}\end{array}$ & $\mathbf{0 . 1}$ & $\mathbf{0 . 2}$ & $\mathbf{0 . 3}$ & $\mathbf{0 . 1}$ & $\mathbf{0 . 2}$ & $\mathbf{0 . 3}$ & $\mathbf{0 . 1}$ & $\mathbf{0 . 2}$ & $\mathbf{0 . 3}$ \\
\hline Fanconi anemia pathway & 7 & 20 & 8 & 4 & 3 & 12 & 4 & 6 & 8 \\
\hline Nucleotide excision repair & 3 & 19 & 5 & 8 & 2 & 9 & 3 & 12 & 7 \\
\hline Homologous recombination & 4 & 16 & 6 & 3 & 0 & 6 & 2 & 5 & 5 \\
\hline DNA replication & 4 & 17 & 3 & 4 & 1 & 7 & 2 & 8 & 8 \\
\hline Mismatch repair & 2 & 7 & 3 & 3 & 0 & 3 & 2 & 5 & 4 \\
\hline $\begin{array}{l}\text { Non-homologous end- } \\
\text { joining }\end{array}$ & 1 & 4 & 4 & 0 & 1 & 4 & 1 & 1 & 4 \\
\hline Base excision repair & 2 & 13 & 0 & 2 & 1 & 2 & 0 & 3 & 5 \\
\hline Total: & 23 & 96 & 29 & 24 & 8 & 43 & 14 & 40 & 41 \\
\hline
\end{tabular}

Table 3.10B. Number of $\mathrm{Cr}(\mathrm{VI})$-upreguated miRNAs targeting genes in DNA repair pathways.

\begin{tabular}{|c|c|c|c|c|c|c|c|c|c|}
\hline Time point & \multicolumn{3}{|c|}{$24 \mathrm{~h}$} & \multicolumn{3}{|c|}{$72 \mathrm{~h}$} & \multicolumn{3}{|c|}{$120 \mathrm{~h}$} \\
\hline $\begin{array}{c}\text { Zinc chromate conc. } \\
\left(\mathrm{ug} / \mathrm{cm}^{2}\right)\end{array}$ & 0.1 & 0.2 & 0.3 & 0.1 & 0.2 & 0.3 & 0.1 & 0.2 & 0.3 \\
\hline Fanconi anemia pathway & 6 & 24 & 6 & 4 & 3 & 12 & 4 & 6 & 8 \\
\hline Nucleotide excision repair & 3 & 20 & 5 & 4 & 2 & 7 & 2 & 7 & 4 \\
\hline Homologous recombination & 4 & 19 & 5 & 3 & 0 & 7 & 2 & 5 & 4 \\
\hline DNA replication & 4 & 18 & 3 & 2 & 1 & 5 & 1 & 5 & 3 \\
\hline Mismatch repair & 2 & 7 & 3 & 2 & 0 & 2 & 1 & 3 & 3 \\
\hline $\begin{array}{l}\text { Non-homologous end- } \\
\text { joining }\end{array}$ & 1 & 4 & 4 & 0 & 1 & 4 & 1 & 1 & 3 \\
\hline Base excision repair & 2 & 13 & 0 & 2 & 1 & 2 & 0 & 3 & 2 \\
\hline Total: & 22 & 105 & 26 & 17 & 8 & 39 & 11 & 30 & 27 \\
\hline
\end{tabular}


We compared how many genes were predicted to be targeted by particulate $\mathrm{Cr}(\mathrm{VI})$ up- or down-regulated miRNAs using $0.3 \mathrm{ug} / \mathrm{cm}^{2}$ zinc chromate as a representative concentration (Figure 3.27). For most pathways the number of genes predicted to be targeted by downregulated miRNAs was lower than the number of genes predicted to be targeted by upregulated miRNAs (24h: 9 out of 29, $72 \mathrm{~h}$ : 6 out of 29, $120 \mathrm{~h}: 18$ out of 29). The increase of genes predicted to be targeted by particulate $\mathrm{Cr}(\mathrm{VI})$-downregulated miRNAs after $120 \mathrm{~h}$ reflects the global downregulation of miRNA expression induced by particulate $\operatorname{Cr}(\mathrm{VI})$ exposure. It is noteworthy, although particulate $\mathrm{Cr}(\mathrm{VI})$ induces downregulation of more miRNAs than those that are upregulated, genes in more pathways of $\mathrm{Cr}(\mathrm{VI})$ carcinogenesis are targeted by particulate $\mathrm{Cr}(\mathrm{VI})$-upregulated miRNAs. 
A.




B.

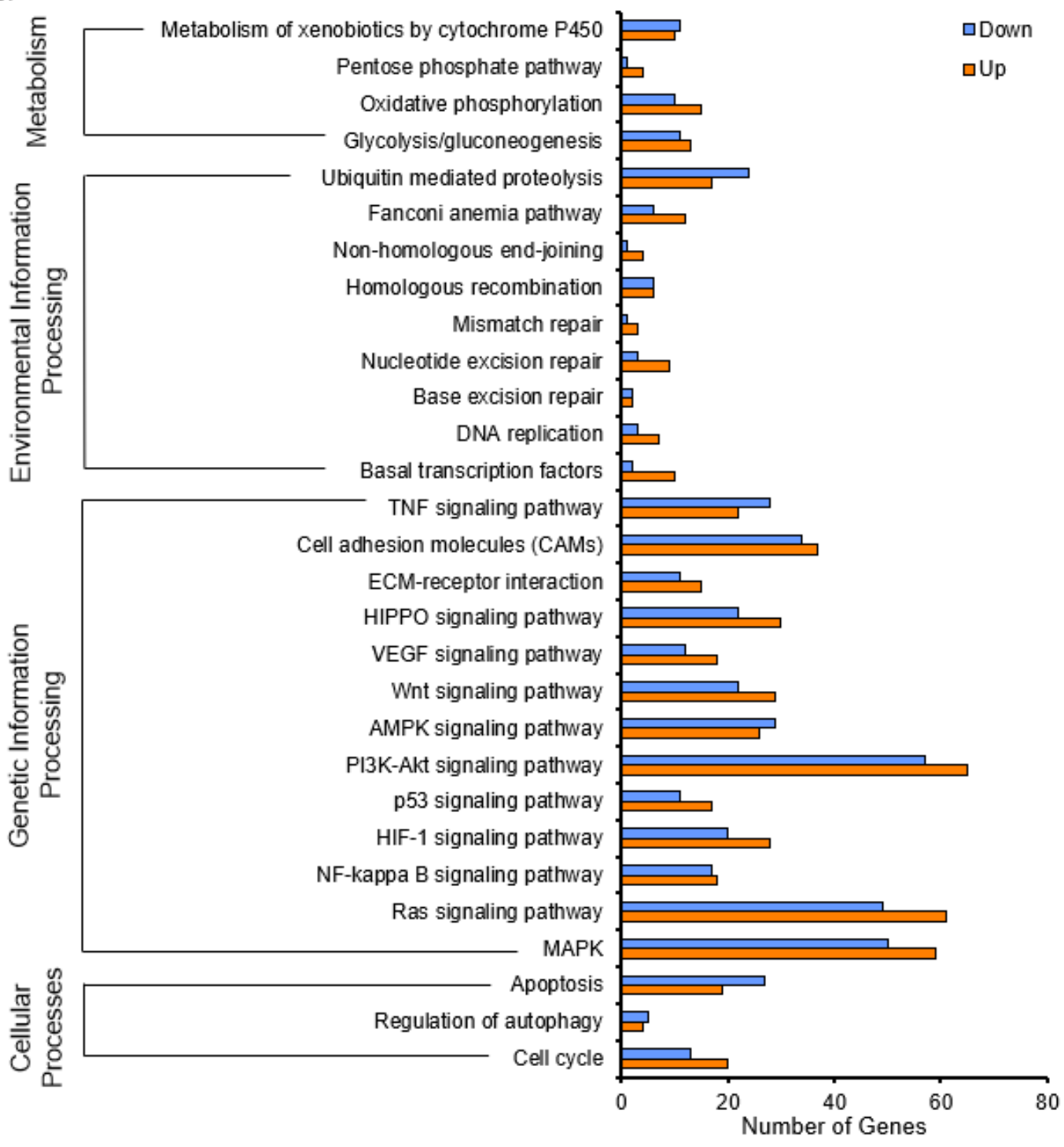






Figure 3.27. Comparison of the number of genes targeted by particulate $\mathrm{Cr}(\mathrm{VI})$-up or down-regulated miRNAs in pathways of $\mathrm{Cr}(\mathrm{VI})$ carcinogenesis. This figure shows the number genes targeted by up- or down-regulated miRNAs in pathways of $\mathrm{Cr}(\mathrm{VI})$ carcinogenesis after exposure to $0.3 \mathrm{ug} / \mathrm{cm}^{2}$ zinc chromate compared to control (adjusted $p$-value $<0.01$, fold change $>2$ ). Data represent the mean of three independent experiments and four 
technical replicates. Genes targeted after $24(A), 72(h)$, and $120 \mathrm{~h}$ (C) exposure to particulate $\mathrm{Cr}(\mathrm{VI})$ exposure are shown. 
Similarly, in Figure 3.28 we show the numbers of particulate $\mathrm{Cr}(\mathrm{VI})$ up- and down-regulated miRNAs predicted to target genes in pathways of $\mathrm{Cr}(\mathrm{VI})$ carcinogenesis. We found for most pathways the number of downregulated miRNAs affected by particulate $\mathrm{Cr}(\mathrm{VI})$ exposure was relatively low after $24 \mathrm{~h}$ (10 out of 29 pathways) and 72 h (5 out of 29). However, after 120 h 24 out of 29 pathways had more miRNAs downregulated by particulate $\mathrm{Cr}(\mathrm{VI})$ exposure than those that were upregulated. This accurately reflects the global downregulation of miRNAs by particulate $\mathrm{Cr}(\mathrm{VI})$ exposure we showed earlier (Figure 3.23). After 120 $\mathrm{h}$ exposure to particulate $\mathrm{Cr}(\mathrm{VI})$ only the apoptosis, non-homologous end joining, mismatch repair, and oxidative phosphorylation pathways had more miRNAs upregulated than downregulated. It is notable after 24 and $72 \mathrm{~h}$ exposure the number of upregulated miRNAs in the ubiquitin mediated proteolysis pathway is 6 and 7 times higher than the number of downregulated miRNAs in that pathway, respectively (Figure 3.28A-B). 
A.

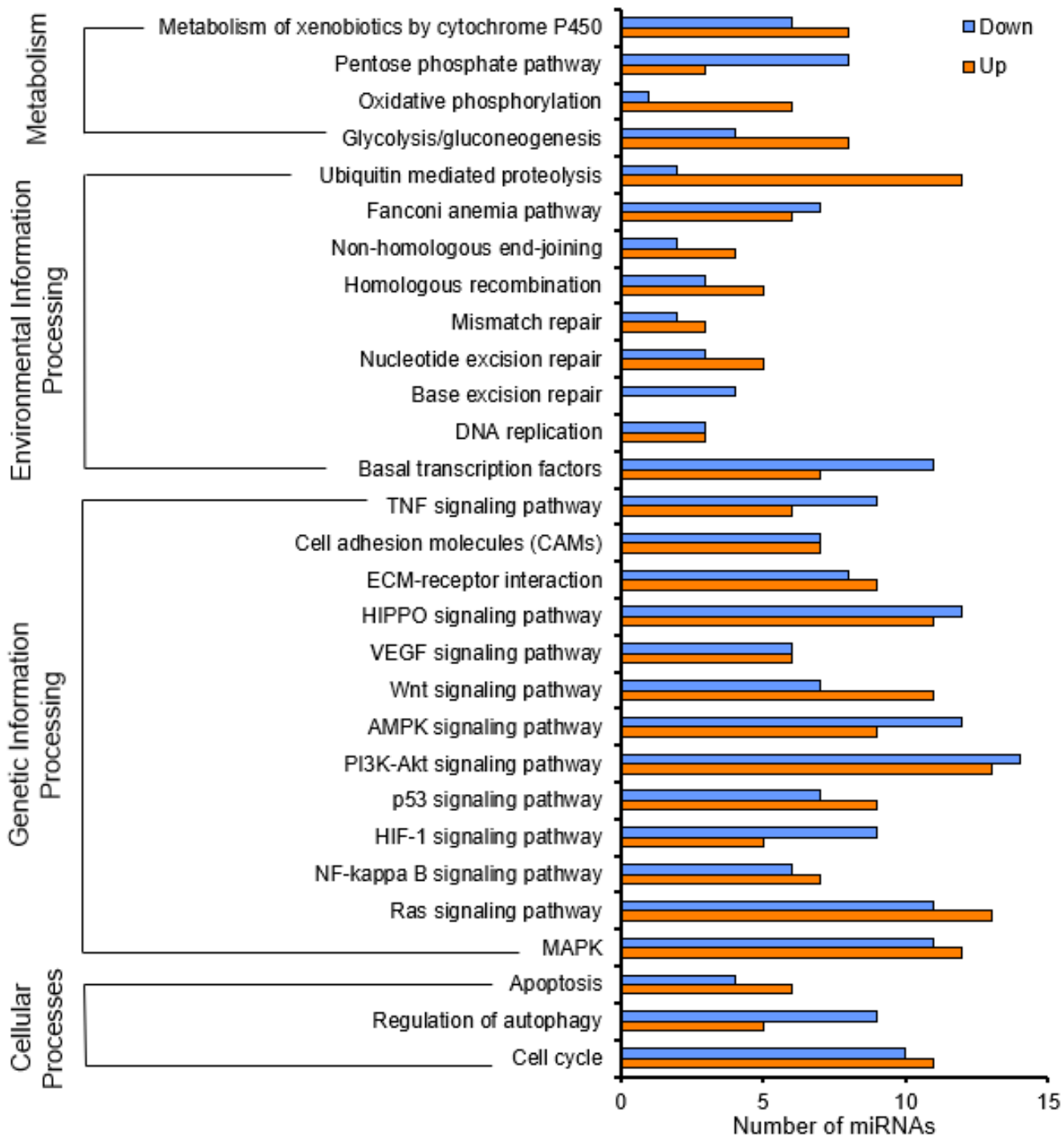


B.

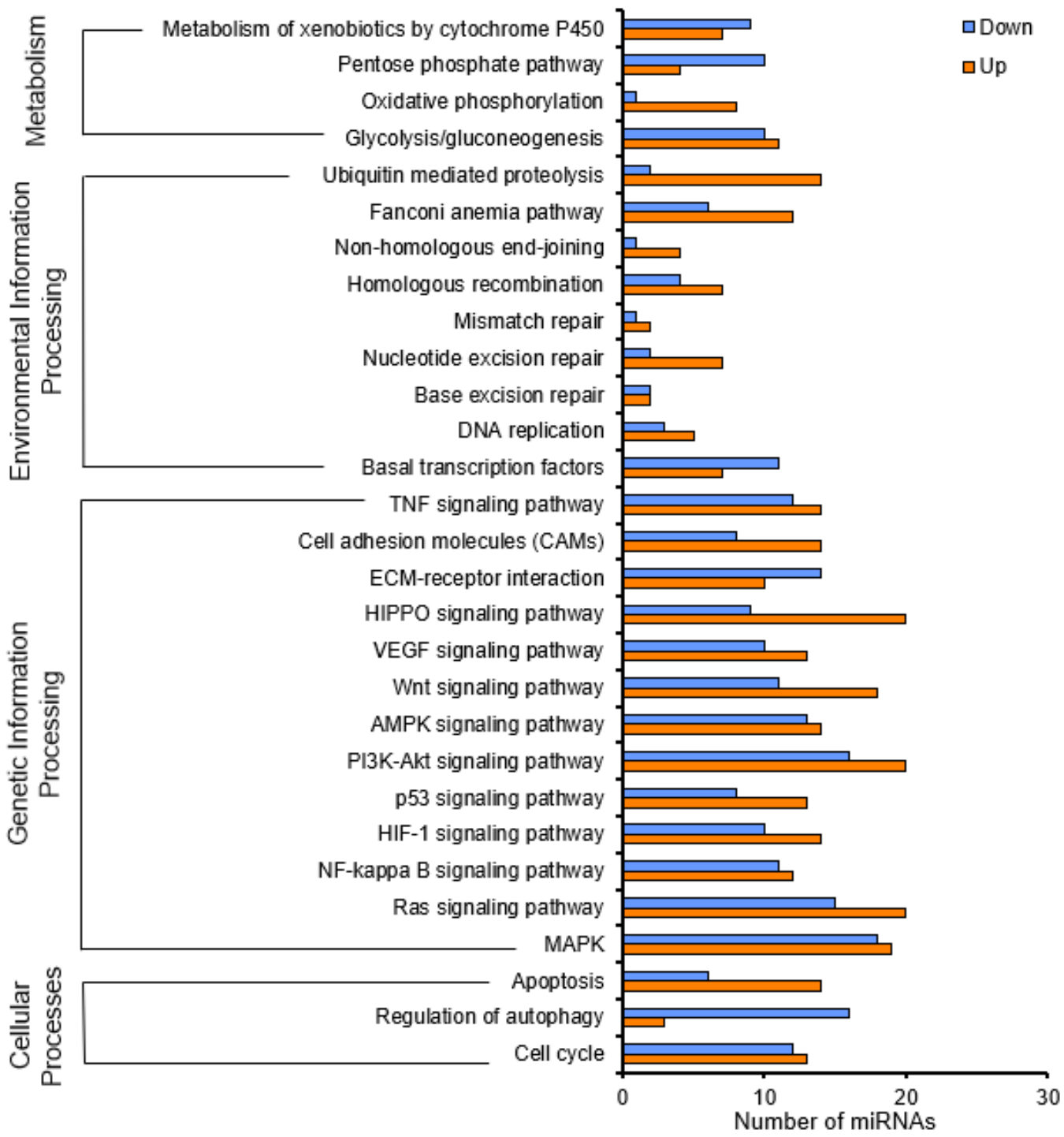


C.

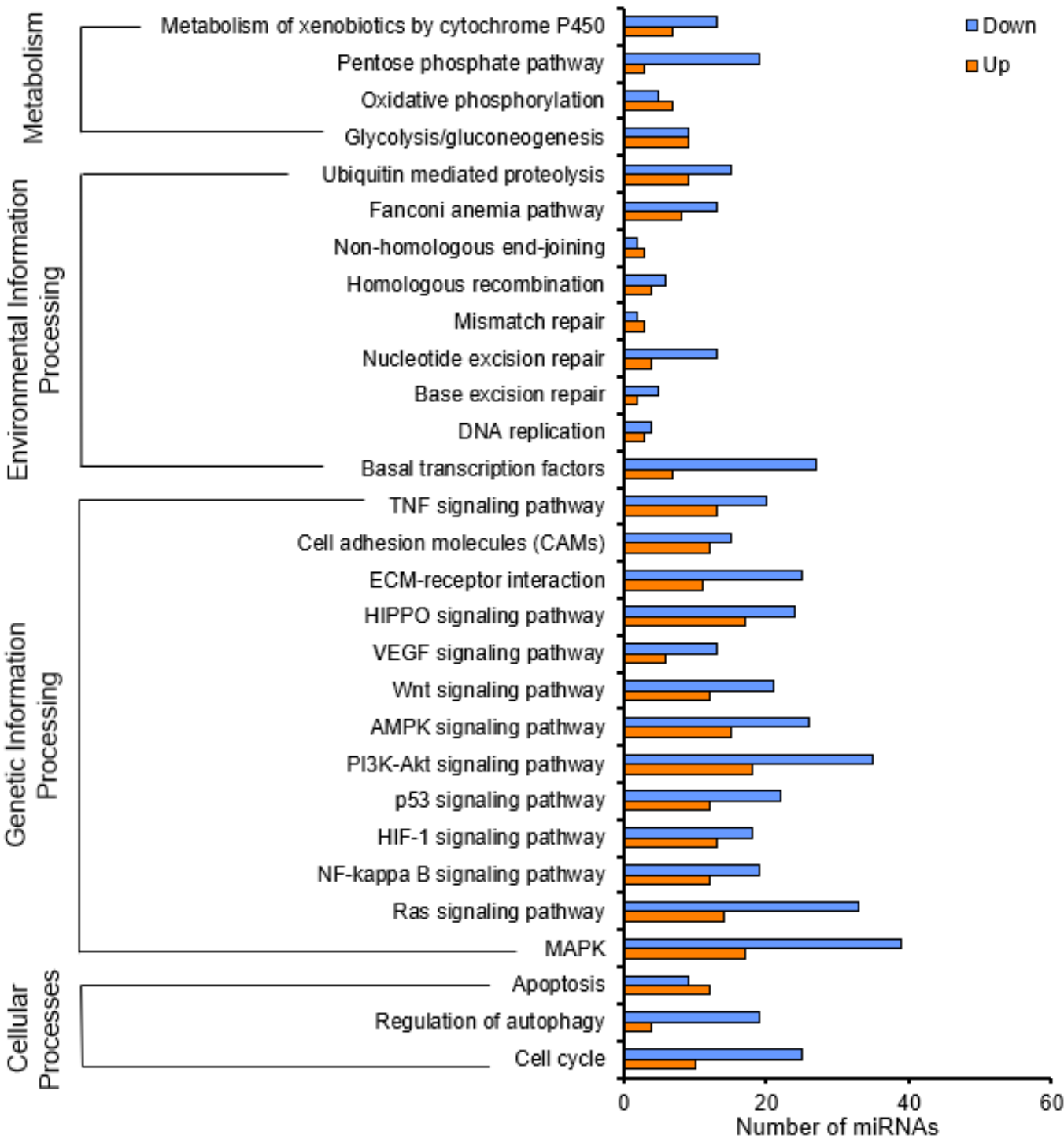

Figure 3.28. Comparison of the number of particulate $\mathrm{Cr}(\mathrm{VI})$-up or down-regulated miRNAs targeting genes in pathways of $\mathrm{Cr}(\mathrm{VI})$ carcinogenesis. This figure shows the number of up- or downregulated miRNAs targeting genes in pathways of $\mathrm{Cr}(\mathrm{VI})$ carcinogenesis after exposure to $0.3 \mathrm{ug} / \mathrm{cm}^{2}$ zinc chromate compared to control (adjusted $p$-value $<0.01$, fold change $>2$ ). Data represent the mean of three independent experiments and four 
technical replicates. miRNAs altered after $24(A), 72(\mathrm{~h})$, and $120 \mathrm{~h}$ (C) exposure to particulate $\mathrm{Cr}(\mathrm{VI})$ exposure are shown. 


\section{Objective 3: Particulate $\mathrm{Cr}(\mathrm{VI})$ alters miRNAs that target homologous recombination and regulate RAD51 expression}

In Objective 2 of Aim 2 we began to investigate $\mathrm{Cr}(\mathrm{VI})$-altered miRNAs involved in pathways of $\mathrm{Cr}(\mathrm{VI})$ carcinogenesis. To further narrow down the focus, we wanted to look closer at how miRNAs significantly induced by particulate $\mathrm{Cr}(\mathrm{VI})$ affect the homologous recombination pathway, and ultimately, RAD51. We further analyzed the mirPath data correlating significantly particulate $\mathrm{Cr}(\mathrm{VI})$-upregulated miRNAs (fold change >2) with the KEGG pathway of homologous recombination. For each particulate $\mathrm{Cr}(\mathrm{VI})$-upregulated miRNA at each condition we identified gene targets in the homologous recombination pathway. Table 3.11 shows the specific particulate $\mathrm{Cr}(\mathrm{VI})$-upregulated miRNAs and their predicted targets in the homologous recombination pathway. Comparing across time points miRNAs targeting RPA2 and RPA1 are upregulated. After $24 \mathrm{~h}$ exposure miRNAs predicted to target XRCC3 were upregulated at all concentrations. Similarly, after $72 \mathrm{~h}$ miRNAs predicted to target RPA1 and RPA2 were upregulated after 0.1 and 0.3 $\mathrm{ug} / \mathrm{cm}^{2}$ zinc chromate (none were observed after $0.2 \mathrm{ug} / \mathrm{cm}^{2}$ zinc chromate). After $120 \mathrm{~h}$ exposure miRNAs predicted to target RPA2 and RAD52 were upregulated at all concentrations.

This breakdown also allows us to see which miRNAs were significantly upregulated under all 9 of the conditions ( 3 time points and 3 concentrations). After 24 and $72 \mathrm{~h}$ no miRNAs were upregulated at all concentrations. However, after $120 \mathrm{~h}$ exposure miR-210-5p and miR-210-3p were upregulated at all concentrations. miR-210-3p is also upregulated after $72 \mathrm{~h}$ exposure to $0.3 \mathrm{ug} / \mathrm{cm}^{2}$ 
zinc chromate, and miR-210-3p and miR-210-5p were upregulated after $24 \mathrm{~h}$ exposure to $0.2 \mathrm{ug} / \mathrm{cm}^{2}$ zinc chromate. 
Table 3.11. Particulate $\mathrm{Cr}(\mathrm{VI})$-upregulated miRNAs and their targets in the homologous recombination pathway.

\begin{tabular}{|l|l|}
\hline \multicolumn{2}{|l|}{$24 \mathbf{~}$} \\
\hline \multicolumn{2}{|c|}{$\mathbf{0 . 1}$ ZC } \\
\hline $\begin{array}{c}\text { miRNAs found to } \\
\text { target pathway }\end{array}$ & \multicolumn{1}{c|}{ Gene Targeted } \\
\hline miR-3064-5p & XRCC3 \\
\hline miR-3136-3p & RPA3 \\
\hline miR-3193 & MUS81 \\
\hline miR-3689c & RAD51B \\
\hline & $\mathbf{0 . 2 ~ Z C ~}$ \\
\hline miR-4695-5p & XRCC2 \\
\hline miR-6824-5p & RPA1 \\
\hline miR-6827-5p & POLD4 \\
\hline miR-210-5p & RPA2 \\
\hline miR-6789-3p & TOP3A \\
\hline miR-7108-3p & POLD1, XRCC3 \\
\hline miR-4786-3p & POLD3 \\
\hline miR-6840-3p & MRE11A \\
\hline miR-210-3p & RAD52 \\
\hline miR-4642 & BLM \\
\hline miR-1913 & RPA1, EME1, RPA2 \\
\hline miR-3665 & TOP3A, TOP3B \\
\hline miR-6089 & TOP3A \\
\hline miR-1275 & MUS81 \\
\hline miR-4497 & RAD51C \\
\hline miR-4634 & XRCC2 \\
\hline miR-3195 & RAD51D \\
\hline miR-1538 & TOP3A, TOP3B, XRCC3 \\
\hline miR-665 & EME1, RAD51D \\
\hline & $\mathbf{0 . 3 ~ Z C ~}$ \\
\hline miR-3187-5p & TOP3A \\
\hline miR-3657 & XRCC3, MRE11A \\
\hline miR-4472 & RPA1 \\
\hline miR-6087 & RAD51C \\
\hline miR-6881 & BLM \\
\hline & \\
\hline
\end{tabular}

\begin{tabular}{|l|l|}
\hline \multicolumn{2}{|c|}{$\mathbf{7 2} \mathbf{~ h}$} \\
\hline \multicolumn{2}{|c|}{$\mathbf{0 . 1}$ ZC } \\
\hline $\begin{array}{c}\text { miRNAs found to } \\
\text { target pathway }\end{array}$ & \multicolumn{1}{|c|}{$\begin{array}{c}\text { Gene } \\
\text { Targeted }\end{array}$} \\
\hline miR-6797-5p & RPA1 \\
\hline miR-2276-5p & RPA2 \\
\hline miR-6882-3p & RAD54B \\
\hline \multicolumn{2}{|c|}{ 0.2 ZC } \\
\hline \multicolumn{2}{|c|}{ None } \\
\hline miR-7109-5p & RPA1 \\
\hline miR-210-5p & RPA2 \\
\hline miR-7846-3p & RAD52 \\
\hline miR-210-3p & RAD52 \\
\hline miR-6089 & TOP3A \\
\hline miR-3195 & RAD51D \\
\hline miR-6087 & RAD51C \\
\hline
\end{tabular}

\begin{tabular}{|l|l|}
\hline \multicolumn{2}{|c|}{120 h } \\
\hline \multicolumn{2}{|c|}{$\mathbf{0 . 1}$ ZC } \\
\hline $\begin{array}{c}\text { miRNAs found to } \\
\text { target pathway }\end{array}$ & Gene Targeted \\
\hline miR-210-5p & RPA2 \\
\hline miR-210-3p & RAD52 \\
\hline \multicolumn{2}{|c|}{$\mathbf{0 . 2}$ ZC } \\
\hline miR-6880-5p & POLD3 \\
\hline miR-6880-3p & TOP3A \\
\hline miR-210-5p & RPA2 \\
\hline miR-210-3p & RAD52 \\
\hline miR-1249-5p & RPA1 \\
\hline \multicolumn{2}{|c|}{0.3 ZC } \\
\hline miR-6825-5p & RAD51B, SSBP1 \\
\hline miR-486-3p & POLD1 \\
\hline miR-210-5p & RPA2 \\
\hline miR-210-3p & RAD52 \\
\hline
\end{tabular}


Regulators of RAD51 and RAD51 homologs were predicted to be targeted by miRNAs significantly upregulated by particulate $\mathrm{Cr}(\mathrm{VI})$ exposure (fold change >2). However, we did not want to overlook particulate $\mathrm{Cr}(\mathrm{VI})$-upregulated miRNAs predicted to target RAD51. In our next analysis we included all miRNAs significantly upregulated by particulate $\mathrm{Cr}(\mathrm{VI})$ exposure (adjusted $p$-value $<0.01$ ). We used an online database called mirSystem to identify miRNAs predicted to target RAD51 (Lu et al., 2012). Using this platform, 126 miRNAs were identified that target RAD51. Then we cross-referenced RAD51 targeting miRNAs with significantly upregulated miRNAs in our RNAseq dataset. We found particulate $\mathrm{Cr}(\mathrm{VI})$ upregulated 37 unique miRNAs out of the 126 that target RAD51. Figure 3.29 shows the total number of particulate $\mathrm{Cr}(\mathrm{VI})$ upregulated miRNAs that target RAD51. We can see the number of particulate $\mathrm{Cr}(\mathrm{VI})$ upregulated miRNAs increased to 24 and 14 after $24 \mathrm{~h}$ exposure after 0.2 and $0.3 \mathrm{ug} / \mathrm{cm}^{2}$ zinc chromate, respectively. After $72 \mathrm{~h}$ exposure to $0.3 \mathrm{ug} / \mathrm{cm}^{2}$ zinc chromate there were 11 upregulated miRNAs that target RAD51 and this level remained elevated after 120 h exposure. 


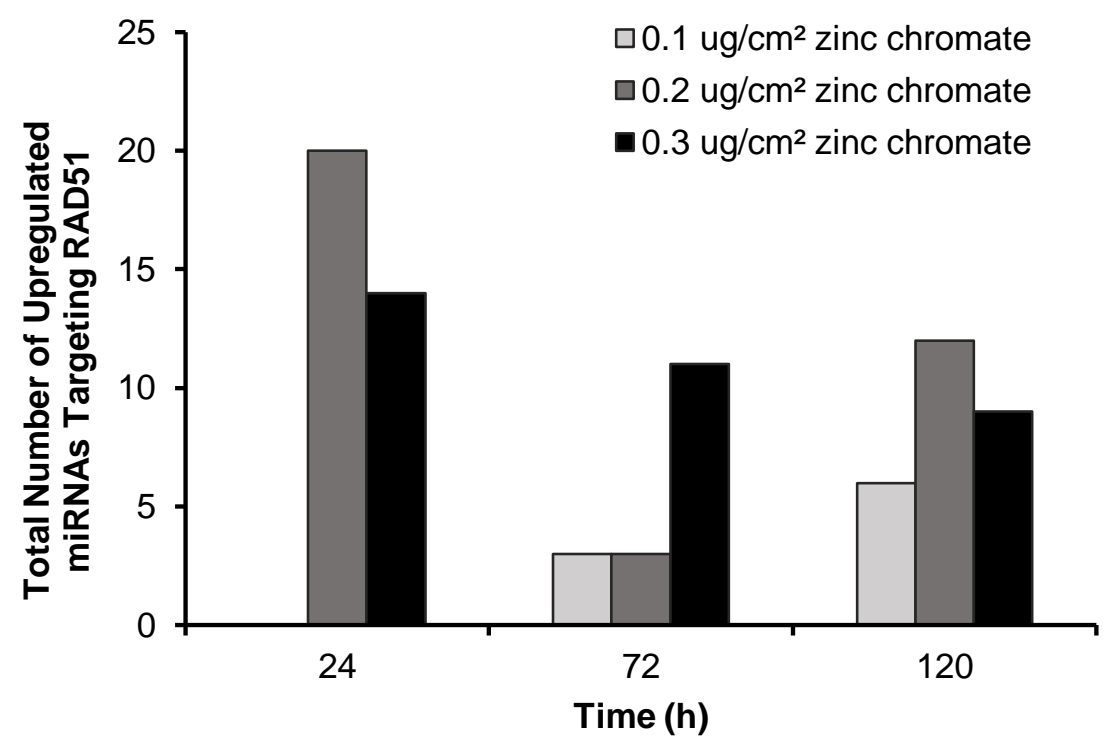

Figure 3.29. Particulate $\mathrm{Cr}(\mathrm{VI})$ upregulates miRNAs that target RAD51. This figure shows the number of significantly (adjusted pvalue $<0.01$ ) upregulated miRNAs that target RAD51 after particulate $\mathrm{Cr}(\mathrm{VI})$ exposure compared to control. Upregulated miRNA targeting RAD51 increase after 24, 72 and $120 \mathrm{~h}$ exposure. Data represent the mean of three independent experiments and four technical replicates. 
We considered each miRNA that targets RAD51 to see if there were any trends in the upregulation across concentration or time. Figure 3.30 shows the RAD51-targeting miRNAs and under each condition they were significantly upregulated. Several miRNAs were significantly upregulated after $24 \mathrm{~h}$ exposure to 0.2 and $0.3 \mathrm{ug} / \mathrm{cm}^{2}$ zinc chromate including miR-320a, miR-134-5p, miR-136$5 p$, and miR-432-5p. miR-134-5p was also upregulated at all concentrations after 72 and 120 h exposure. miR432-5p and miR-194-5p were significantly upregulated after $72 \mathrm{~h}$ exposure to 0.2 and $0.3 \mathrm{ug} / \mathrm{cm}^{2}$ zinc chromate and at all concentrations after $120 \mathrm{~h}$ exposure. miR-26b-5p was significantly upregulated after $72 \mathrm{~h}$ exposure to the highest concentration and the two highest concentrations after 120 h exposure. miR-411-5p and miR-30b-5p were significantly upregulated after both 72 and $120 \mathrm{~h}$ at the highest concentration. All these miRNAs show either a trend in concentration or time and should be further considered in the regulation of RAD51 expression after particulate $\mathrm{Cr}(\mathrm{VI})$ exposure. 




Figure 3.30. This figure shows trends in the fold change of expression of miRNAs predicted to target RAD51 altered by particulate $\mathrm{Cr}(\mathrm{VI})$ exposure. miRNAs were included if at least one miRNA was significantly upregulated at any condition. The color 
scheme represents the $\log _{2}$ (fold change). Units with black boarders represent conditions with significantly upregulated miRNAs. 
We find particulate $\mathrm{Cr}(\mathrm{VI})$ significantly upregulates miRNAs predicted to target the RAD51 mRNA transcript. However, studies show the quality of the binding between a miRNA and its target mRNA plays a role in the efficacy and fate of these interactions (Martin et al., 2014; Rhoades et al., 2002; Saxena et al., 2003). We evaluated the binding characteristics of the miRNAs predicted to target RAD51 significantly upregulated by particulate $\mathrm{Cr}(\mathrm{VI})$ exposure. This analysis was done using microRNA.org which is an online database that allows you to search for an mRNA target and view the binding location, mirSVR score, and exact nucleotide pairing of each miRNA that binds it. Table 3.13 shows the total number of binding sites for each miRNA on the mRNA transcript, their mirSVR score, and the number of nucleotides in the 3' UTR region the miRNA had a perfect match to on the RAD51 mRNA transcript. The mirSVR score is assigned based on a regression model to determine the likelihood of mRNA target downregulation and the lower the score, the more likely it is the miRNA will result in the downregulation of a target (Betel et al., 2010). All the miRNAs on the list have mirSVR scores less than -1 except 2 indicating the likelihood of binding is high. However, we found several miRNAs have more than one predicted binding site to RAD51 mRNA. For example, miR-130b-3p has 2 predicted binding sites, while miR-148b-5p has 4 predicted binding sites.

For those miRNAs with more than one prediced binding site, one is preferable over the others. For example, the first binding site of miR-130b-3p has a mirSVR score of -0.005 and has 6 mer binding compared to the second binding site with a mirSVR of -0.0933 which has 8 mer binding. A 6 mer is a perfect 6 nucleotide match in the seed region and is considered the strongest followed by 
7mer and 8mer binding (Grimson et al., 2007). We can see all the miRNA binding sites with the lowest mirSVR scores are 6mers. For example, the 6mers miR-532$3 p$ and miR-30b-5p have mirSVR score of -0.0007 and -0.0015 , respectively while 8mers miR-130a-3p and miR-320a have mirSVR scores of -0.1015 and -1.0068 , respectively. The miRNAs with perfect 6 mer binding and low mirSVR scores are the best candidates for targeting RAD51 mRNA for degradation. We found 17 of the 37 miRNAs significantly upregulated by particulate $\mathrm{Cr}(\mathrm{VI})$ exposure have a 6 mer binding site. These data suggest RAD51 targeting miRNAs significantly upregulated by particulate $\mathrm{Cr}(\mathrm{VI})$ exposure are likely to bind the RAD51 mRNA transcript interfering with expression. 
Table 3.12. RAD51 mRNA binding site information of significantly upregulated miRNAs by particulate $\mathrm{Cr}(\mathrm{VI})$ exposure.

\begin{tabular}{|c|c|c|c|c|c|c|c|c|c|}
\hline \multirow[b]{2}{*}{ microRNA } & \multirow{2}{*}{$\begin{array}{l}\text { Total } \\
\text { binding } \\
\text { sites }\end{array}$} & \multicolumn{2}{|c|}{ Binding site 1} & \multicolumn{2}{|c|}{ Binding site 2} & \multicolumn{2}{|c|}{ Binding site 3} & \multicolumn{2}{|c|}{ Binding site 4} \\
\hline & & $\underset{\text { score }}{\operatorname{mirSVR}}$ & $\begin{array}{l}\text { 3' UTR } \\
\text { Match }\end{array}$ & $\begin{array}{c}\text { mirSVR } \\
\text { score }\end{array}$ & $\begin{array}{l}\text { 3' UTR } \\
\text { Match }\end{array}$ & $\underset{\text { score }}{\operatorname{mirSVR}}$ & $\begin{array}{l}\text { 3' UTR } \\
\text { Match }\end{array}$ & $\underset{\text { score }}{\text { mirSVR }}$ & $\begin{array}{l}\text { 3' UTR } \\
\text { Match }\end{array}$ \\
\hline hsa-miR-130a-3p & 2 & -0.0942 & 6 & -0.1015 & 8 & & & & \\
\hline hsa-miR-130b-3p & 2 & -0.005 & 6 & -0.0933 & 8 & & & & \\
\hline hsa-miR-132-3p & 1 & -0.0181 & 6 & & & & & & \\
\hline hsa-miR-193a-3p & 1 & -0.2825 & 8 & & & & & & \\
\hline hsa-miR-212-3p & 1 & -0.0185 & 6 & & & & & & \\
\hline hsa-miR-222-3p & 1 & -0.4198 & 7 & & & & & & \\
\hline hsa-miR-370-3p & 2 & -0.038 & 6 & -0.0096 & 8 & & & & \\
\hline \multicolumn{10}{|l|}{ hsa-miR-431-5p } \\
\hline hsa-miR-532-3p & 2 & -0.0007 & 6 & -0.2985 & 7 & & & & \\
\hline hsa-miR-543 & 1 & -0.0975 & 6 & & & & & & \\
\hline hsa-miR-548d-3p & 2 & -0.9201 & 7 & -0.2152 & 7 & & & & \\
\hline hsa-miR-767-5p & 1 & -0.2126 & 8 & & & & & & \\
\hline hsa-miR-193b-3p & 1 & -0.2641 & 7 & & & & & & \\
\hline hsa-miR-197-3p & 1 & -0.3494 & 10 & & & & & & \\
\hline hsa-miR-320b & 1 & -1.0068 & $8(1)$ & & & & & & \\
\hline hsa-miR-320a & 1 & -1.0068 & $8(1)$ & & & & & & \\
\hline hsa-miR-134-5p & 1 & -0.0572 & 7 (1) & & & & & & \\
\hline hsa-miR-136-5p & 1 & -0.0064 & 6 & & & & & & \\
\hline hsa-miR-432-5p & 1 & -0.027 & $7(1)$ & & & & & & \\
\hline hsa-miR-589-5p & 1 & -0.1943 & 7 & & & & & & \\
\hline hsa-miR-148b-3p & 4 & -0.1015 & 7 & -0.0343 & 6 & 0.6801 & $8(1)$ & -0.1418 & 7 \\
\hline hsa-miR-186-5p & 3 & -0.0184 & 6 & -0.1761 & $8(1)$ & -0.0649 & 7 & & \\
\hline hsa-miR-221-3p & 3 & -0.2693 & 7 & -0.4166 & 7 & -0.0026 & 6 & & \\
\hline hsa-miR-376c-3p & 1 & -0.0248 & 6 & & & & & & \\
\hline hsa-miR-454-3p & 2 & -0.0923 & 8 & -0.0049 & 6 & & & & \\
\hline hsa-miR-655-3p & 1 & -1.012 & $8(1)$ & & & & & & \\
\hline hsa-miR-152-3p & 2 & -0.1015 & $8(1)$ & -0.1315 & 7 & & & & \\
\hline hsa-miR-194-5p & 1 & -0.5015 & 7 & & & & & & \\
\hline \multicolumn{10}{|l|}{ hsa-miR-26b-5p } \\
\hline hsa-miR-301a-3p & 2 & -0.0049 & 6 & -0.0923 & 8 & & & & \\
\hline hsa-miR-301b-3p & 2 & -0.0049 & 6 & -0.0923 & 8 & & & & \\
\hline hsa-miR-302d-3p & 2 & -0.0175 & 6 & -0.0178 & 7 & & & & \\
\hline hsa-miR-570-3p & 1 & -0.4501 & 7 & & & & & & \\
\hline hsa-miR-211-5p & 1 & -0.3681 & $9(1)$ & & & & & & \\
\hline hsa-miR-494-3p & 2 & -0.5774 & 8 & -0.3735 & 7 & & & & \\
\hline hsa-miR-411-5p & 1 & -0.3139 & 7 & & & & & & \\
\hline hsa-miR-30b-5p & 1 & -0.0015 & 6 & & & & & & \\
\hline
\end{tabular}

Table 3.12 shows significantly upregulated (adjusted $p$-value<0.01) miRNAs by particulate $\mathrm{Cr}(\mathrm{VI})$ exposure that target RAD51. The total binding sites are shown as well as the mirSVR score and number of nucleotides that match perfectly to the 
3' UTR of RAD51 for all binding sites for each miRNA. Numbers in parenthesis

(i.e. 7 (1)) indicate a mis-match in the 3' UTR binding sequence. 


\section{Summary}

In Aim 2 we present the first study to evaluate global expression of miRNAs after $\mathrm{Cr}(\mathrm{VI})$ exposure in human cells. We show particulate $\mathrm{Cr}(\mathrm{VI})$ significantly alters the expression of miRNAs. The number of significantly increased miRNAs increased with particulate $\mathrm{Cr}(\mathrm{VI})$ exposure at all time points, and these levels were higher at higher concentrations of zinc chromate. We also observed when comparing the number of significantly upregulated miRNAs to the number of downregulated miRNAs at each condition, more miRNAs were downregulated by particulate $\mathrm{Cr}(\mathrm{VI})$ exposure. These are the first data to show $\mathrm{Cr}(\mathrm{VI})$ alters global miRNA expression, and more miRNAs are downregulated.

We also compared the altered expression of miRNAs after particulate $\mathrm{Cr}(\mathrm{VI})$ expression by narrowing the parameters by evaluating significantly altered miRNAs with a fold change greater than 2. Such a large dataset allowed us to focus on miRNAs that may have the largest biological relevance for global effect analysis. We visualized the scattering of miRNAs based on these criteria using volcano plots and found not all miRNAs with a fold change greater than 2 were significant (adjusted $p$-value $<2$ ). We also found the number of significantly upregulated miRNAs (fold change $>2$ ) increased almost 7-fold after 24 h exposure to $0.2 \mathrm{ug} / \mathrm{cm}^{2}$ zinc chromate compared to $0.10 \mathrm{r} 0.3 \mathrm{ug} / \mathrm{cm}^{2}$ zinc chromate at this this time point. After 72 and $120 \mathrm{~h}$ more miRNAs were significantly upregulated at higher zinc chromate concentrations. The number of significantly downregulated miRNAs (fold change $>2$ ) also increased with concentration and time, although there was a spike in the $24 \mathrm{~h} 0.2 \mathrm{ug} / \mathrm{cm}^{2}$ zinc chromate condition. We also included analysis of the overlap of miRNAs significantly expressed across zinc chromate 
concentration. This analysis was also used to generate heat maps showing the clustering of miRNAs based on their fold change values to better understand how patterns of miRNA expression altered by particulate $\mathrm{Cr}(\mathrm{VI})$ exposure.

In Objective 2 we focused the analysis on particulate $\mathrm{Cr}(\mathrm{VI})$-altered miRNAs that target genes in pathways of $\mathrm{Cr}(\mathrm{VI})$ carcinogenesis. We generated a list of KEGG pathways involved in $\mathrm{Cr}(\mathrm{VI})$ carcinogenesis and performed analysis comparing the KEGG pathways list with KEGG pathways targeted by particulate $\mathrm{Cr}(\mathrm{VI})$-altered miRNAs at each of our conditions. We found particulate $\mathrm{Cr}(\mathrm{VI})$ altered miRNAs target pathways of $\mathrm{Cr}(\mathrm{VI})$ carcinogenesis. We further analyzed these data to compared the number of up- or down-regulated miRNAs that target each pathway of $\mathrm{Cr}(\mathrm{VI})$ carcinogenesis and the number of genes targeted by miRNAs up- or down-regulated by particulate $\mathrm{Cr}(\mathrm{VI})$ exposure.

In Objective 3 we focused in on how particulate $\mathrm{Cr}(\mathrm{VI})$-upregulated miRNAs affect the homologous recombination pathway and specifically RAD51. We identified miRNAs at each time point and particulate $\operatorname{Cr}(\mathrm{VI})$ concentration that target specific proteins in the homologous recombination pathway. We found trends in predicted target genes and the miRNAs that affect their expression. Finally, we analyzed all significantly up-regulated miRNAs from the RNAseq analysis that predicted to target RAD51. Using an online database 126 miRNAs were predicted to target the RAD51 mRNA transcript. Of those 37 unique miRNAs were upregulated by particulate $\mathrm{Cr}(\mathrm{VI})$ exposure. We evaluated each of these 37 miRNAs under each treatment condition and identified trends in expression associated with time and concentration. Lastly, we assessed the quality of each predicted binding site of these miRNAs to determine the likeliness that they would 
result in a biological effect. We found all but two of the $\mathrm{Cr}(\mathrm{VI})$-upregulated miRNAs have a high likelihood of binding and 17 out of the 37 had perfect match binding in the seed region.

\section{Aim 3: Characterize the effects of particulate $\mathrm{Cr}(\mathrm{VI})$ on homologous recombination in leatherback sea turtle lung cells.}

\section{Background}

$\mathrm{Cr}(\mathrm{VI})$ is a global environmental pollutant and can affect both humans and wildlife. The One Environmental Health approach is a research perspective that incorporates human, wildlife, and ecosystem health to better understand how toxicants affect the overall health of the environment (Perez and Wise, 2018). We are investigating the effects of particulate $\mathrm{Cr}(\mathrm{VI})$ cells from both human and wildlife species. We showed particulate $\mathrm{Cr}(\mathrm{VI})$ does not induce the same response to particulate $\mathrm{Cr}(\mathrm{VI})$ in whale cells that is observed in human cells (Browning et al., 2017; Li Chen et al., 2009a; Li Chen et al., 2009b; Li Chen et al., 2012; Wise et al. 2015). In this study we focus on another marine species, leatherback sea turtles.

Leatherback sea turtles are a large (up to $1200 \mathrm{lbs}$ ) and long-lived ( 45 years) marine reptile that spend the entirety of their lives in the ocean. The extended amount of time leatherbacks spend in the ocean exposes them to pollutants and contaminants in the water, air, or food sources (Godley et al., 1999; Guirlet et al., 2008; Perrault et al., 2013; Storelli and Marcotrigiano, 2003). These exposures may lead to detrimental health impacts including immune and reproductive failure (Guirlet et al., 2010; Stewart et al., 2011a). Furthermore, leatherbacks may bioaccumulate environmental contaminants exacerbating health issues caused by even low levels of exposure. 
Several studies have investigated metal levels in leatherback sea turtles around the world and found their tissues may accumulate metals such as mercury, cadmium, lead, and arsenic (Guirlet et al., 2010; Kunito et al., 2008; Stewart et al., 2011b). To our knowledge only one study has investigated $\mathrm{Cr}$ levels in leatherbacks but did not measure Cr levels in lung tissue (Poppi et al., 2012). However, one study showed in tissues of adult and young loggerhead sea turtles (Caretta caretta) $\mathrm{Cr}$ accumulated in the highest concentrations in the lung (Storelli et al., 1998). These studies demonstrate leatherbacks are exposed to $\mathrm{Cr}(\mathrm{VI})$ in the environment.

It is important to study the potential effects of environmental contaminants such as $\mathrm{Cr}(\mathrm{VI})$ in leatherbacks to understand the potential impact on the health of their population, the health of the environment, and to gain insight into human health. Previously, we have shown particulate and soluble $\mathrm{Cr}(\mathrm{VI})$ is cytotoxic and genotoxic in leatherback sea turtle lung cells (Speer et al., 2017). Additionally, we found human and leatherback lung cells has similar levels of cytotoxicity and genotoxicity although there were some observable differences between the two species (Speer et al., 2018). No studies have investigated DNA damage or repair in leatherbacks, and it is unknown how $\mathrm{Cr}(\mathrm{VI})$ causes genotoxicity in leatherback cells.

In Aims 1 and 2 of this dissertation we investigated mechanisms of particulate $\mathrm{Cr}(\mathrm{VI})$ induced loss of homologous recombination repair in human lung cells. In Aim 3 we investigate key endpoints of particulate $\mathrm{Cr}(\mathrm{VI})$ exposure in leatherback lung cells to begin to understand the mechanisms of particulate $\mathrm{Cr}(\mathrm{VI})$ toxicity in this species. We hypothesize particulate $\mathrm{Cr}(\mathrm{VI})$ will induce DNA damage 
in leatherback cells and impair DNA repair based on our previous studies of $\mathrm{Cr}(\mathrm{VI})$ in leatherback lung cells. We tested this hypothesis my measuring DNA double strand breaks and homologous recombination repair in primary leatherback lung cells.

\section{Results}

Objective 1: Particulate Cr(VI) induces DNA damage in leatherback lung cells.

We observed particulate $\mathrm{Cr}(\mathrm{VI})$ induced genotoxicity in leatherback lung cells after acute and prolonged exposure as a measure of structural chromosome instability (Speer et al., 2017; Speer et al., 2018). Induction of DNA double strand breaks is a primary driver of structural chromosome instability. We measured DNA double strand breaks in leatherback lung cells using two measures. We used the neutral comet assay to measure of DNA double strand breaks in leatherback lung cells. We found particulate $\mathrm{Cr}(\mathrm{VI})$ did not increase comet tail intensity in leatherback lung cells after 24 or $120 \mathrm{~h}$ exposure (Figure 3.31). For example, $24 \mathrm{~h}$ exposure to 0.1 or $0.4 \mathrm{ug} / \mathrm{cm}^{2}$ zinc chromate resulted in a tail intensity of 1 and 1.2 relative to control, respectively, while $120 \mathrm{~h}$ exposure resulted in a tail intensity of 0.9 and 1.4 relative to control, respectively. 



Figure 3.31. Particulate $\mathrm{Cr}(\mathrm{VI})$ does not increase DNA damage. This figure shows tail intensity as a measure of DNA double strand breaks does not increase after 24 or $120 \mathrm{~h}$ exposure to particulate $\mathrm{Cr}(\mathrm{VI})$. Data represent the mean of at least 3 independent experiments. Error bars $=$ standard error of the mean. No statistical significance was observed. (A) Representative images of comets after exposure to particulate $\mathrm{Cr}(\mathrm{VI})$ in leatherback lung cells. (B) Particulate $\mathrm{Cr}(\mathrm{VI})$ does not increase comet tail intensity in leatherback lung cells after 24 or $120 \mathrm{~h}$ exposure. 
We also measured DNA double strand breaks using gamma-H2AX nuclear foci. The histone variant, $\mathrm{H} 2 \mathrm{AX}$ is phosphorylated (gamma-H2AX) in response to DNA double strand breaks as a signaling method to initiate repair (Khanna and Jackson, 2001).

Figure 3.32A shows representative images of gamma-H2AX foci in leatherback lung cells. We found particulate $\mathrm{Cr}(\mathrm{VI})$ increased the percent of cells with $>10$ foci after 24 and $120 \mathrm{~h}$ exposure (Figure 3.32B). For example, $24 \mathrm{~h}$ exposure to 0.1 or $0.4 \mathrm{ug} / \mathrm{cm}^{2}$ zinc chromate resulted in 8.7 and 27.3 percent of cell with $>10$ gamma$\mathrm{H} 2 \mathrm{AX}$ foci, respectively, while $120 \mathrm{~h}$ exposure resulted in 11.3 and 24.7 percent of cells with >10 gamma-H2AX foci, respectively. Only $24 \mathrm{~h}$ exposure to $0.4 \mathrm{ug} / \mathrm{cm}^{2}$ zinc chromate was significant from control $\left({ }^{*} p<0.05\right)$, but there is a clear increasing trend in the percent of cells with $>10$ gamma-H2AX foci after $24 \mathrm{~h}$ exposure. We observed similar levels of gamma-H2AX foci after both 24 and $120 \mathrm{~h}$ exposure. 


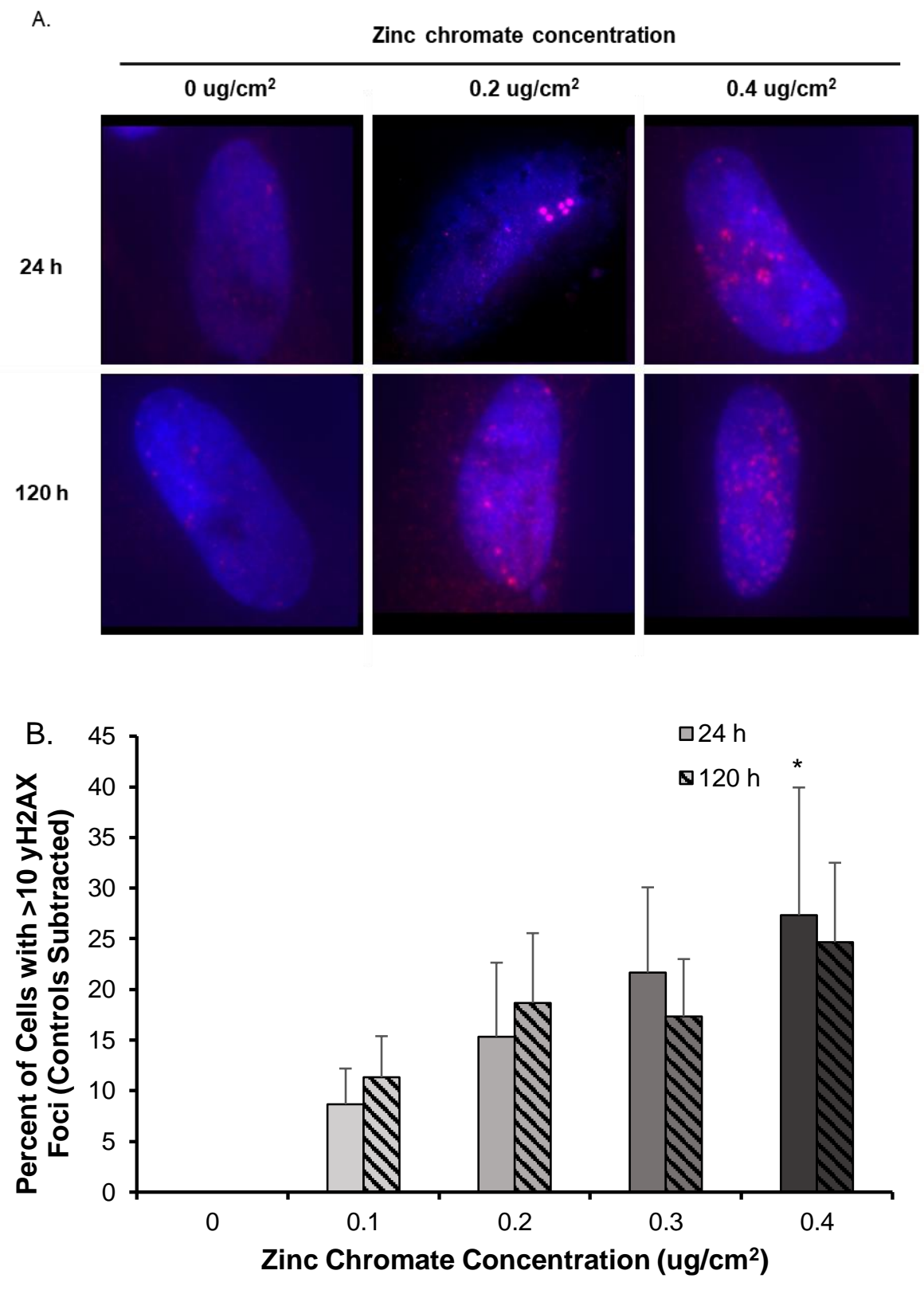

Figure 3.32. Particulate $\mathrm{Cr}(\mathrm{VI})$ increases gamma-H2AX foci in leatherback lung cells. This figure shows the percent of leatherback lung cells with $>10$ gamma-H2AX foci increases with concentration after 24 and $120 \mathrm{~h}$ exposure. Data represent the mean of three independent experiments. Error bars $=$ standard error of the mean. (A) Representative images of gamma-H2AX foci in leatherback lung 
cells. The nucleus is stained blue with DAPI. gamma-H2AX foci are stained pink. (B) The percent of cells with $>10$ gamma-H2AX foci after 24 and $120 \mathrm{~h}$ exposure increased with increasing zinc chromate concentrations. The percent of cells with $>10$ gamma-H2AX foci was significantly higher after $24 \mathrm{~h}$ exposure to $0.4 \mathrm{ug} / \mathrm{cm}^{2}$ zinc chromate compared to control $\left({ }^{*} p<0.05\right)$. The percent of cells with $>10$ gamma$\mathrm{H} 2 \mathrm{AX}$ foci increased after $120 \mathrm{~h}$ exposure to $0.1,0.3$, and $0.4 \mathrm{ug} / \mathrm{cm}^{2}$ zinc chromate compared to control. 
Objective 2: RAD51 but not homologous recombination is impaired after prolonged particulate $\mathrm{Cr}(\mathrm{VI})$ exposure

In Objective 1 we found induction of DNA double strand breaks increased after particulate $\mathrm{Cr}(\mathrm{VI})$ exposure in leatherback lung cells using gamma-H2AX as a measure. However, there appeared to be no increase in DNA double strand breaks in the comet assay analysis. To better understand this result and to determine if particulate $\mathrm{Cr}(\mathrm{VI})$ affects DNA repair in leatherback lung cells we first assessed homologous recombination repair by measuring RAD51 nuclear foci. Figure 3.33A shows representative images of RAD51 foci in leatherback lung cells. We found RAD51 nuclear foci increase after $24 \mathrm{~h}$ exposure to particulate $\mathrm{Cr}(\mathrm{VI})$ (Figure 3.33B). For example, exposure to $0.1,0.2,0.3$, and $0.4 \mathrm{ug} / \mathrm{cm}^{2}$ zinc chromate resulted in $9.315 .3,18$, and $18.3 \%$ of cells with $>10$ RAD51 foci. The 0.2, 0.3 and $0.4 \mathrm{ug} / \mathrm{cm}^{2}$ concentrations were significant compared to control $\left({ }^{*} \mathrm{p}<0.05\right.$ and $\left.{ }^{* *} \mathrm{p}<0.01\right)$. However, after $120 \mathrm{~h}$ exposure to particulate $\operatorname{Cr}(\mathrm{Vl})$ RAD51 nuclear foci increase at lower concentrations and then decreased at the higher concentrations. For example, 0.1 and $0.2 \mathrm{ug} / \mathrm{cm}^{2}$ zinc chromate increase the percent of cells with $>10$ RAD51 foci to 8 and 11 , respectively, while after 0.3 and $0.4 \mathrm{ug} / \mathrm{cm}^{2}$ zinc chromate the percent of cells with $>10$ RAD51 foci is only 2.8 and 1.5 , respectively. The increase was only significant after $0.2 \mathrm{ug} / \mathrm{cm}^{2}$ zinc chromate $\left({ }^{*} p<0.5\right)$. The percent of cells with $>10$ RAD51 foci was significantly lower after $120 \mathrm{~h}$ exposure to 0.3 and $0.4 \mathrm{ug} / \mathrm{cm}^{2}$ zinc chromate compared to $24 \mathrm{~h}$ $\left({ }^{\#} \mathrm{p}<0.05 ;{ }^{\#} \mathrm{p}<0.01\right)$. 
A.

Zinc chromate concentration


Figure 3.33. RAD51 nuclear foci increase after acute but not prolonged particulate $\mathrm{Cr}(\mathrm{VI})$ exposure in leatherback lung cells. Data represent the mean of at least three independent experiments. Error bars $=$ standard error of the mean. (A) Representative images of RAD51 foci in leatherback lung cells. The nucleus is stained blue with DAPI. $y H 2 A X$ foci are stained red. (B) The percent of cells with $>10$ RAD51 foci (controls subtracted) in leatherback lung cells. Particulate $\mathrm{Cr}(\mathrm{VI})$ increases the percent of cells with >10 RAD51 foci 
after $24 \mathrm{~h}$ in leatherback lung cells compared to control $\left({ }^{*} \mathrm{p}<0.05\right.$, ${ }^{* *} \mathrm{p}<0.01$ ). While the percent of cells with $>10$ RAD51 foci increases after $120 \mathrm{~h}$ exposure to 0.1 and $0.2 \mathrm{ug} / \mathrm{cm}^{2}$ zinc chromate $\left({ }^{*} \mathrm{p}<0.05\right)$ it decreases after 0.3 and $0.4 \mathrm{ug} / \mathrm{cm}^{2}$ zinc chromate. The percent of cells with $>10$ RAD51 foci is significantly lower after $120 \mathrm{~h}$ compared to $24 \mathrm{~h}$ at 0.3 and $0.4 \mathrm{ug} / \mathrm{cm}^{2}$ zinc chromate $\left({ }^{\#} \mathrm{p}<0.05\right.$; $\left({ }^{\# \#} \mathrm{p}<0.01\right)$. 
RAD51 nuclear foci were decreased after $120 \mathrm{~h}$ exposure to particulate $\mathrm{Cr}(\mathrm{VI})$ compared to $24 \mathrm{~h}$. Sister chromatid exchanges were used as a measure of homologous recombination repair in leatherback lung cells. Figure 3.34A shows representative images of leatherback lung cells metaphases with sister chromatid exchanges. We found the ratio of sister chromatid exchanges to chromosome number increased significantly after 24 and $120 \mathrm{~h}$ exposure to all concentrations of particulate $\mathrm{Cr}(\mathrm{VI})\left({ }^{* *} \mathrm{p}<0.01 ;{ }^{* * *} \mathrm{p}<0.001\right)$. For example, $24 \mathrm{~h}$ exposure to 0.1 and $0.3 \mathrm{ug} / \mathrm{cm}^{2}$ zinc chromate increased the ratio of sister chromatid exchanges to chromosome number to 0.1 and 0.2 , respectively. This ratio was higher after 120 $\mathrm{h}$ exposure resulting in a ratio of 0.2 and 0.4 after exposure to 0.1 and $0.4 \mathrm{ug} / \mathrm{cm}^{2}$ zinc chromate, respectively. The ratio of sister chromatid exchanges to chromosome number was significantly higher after $120 \mathrm{~h}$ exposure to $0.15,0.2$, and $0.3 \mathrm{ug} / \mathrm{cm}^{2}$ zinc chromate compared to $24 \mathrm{~h}\left({ }^{\# \#} \mathrm{p}<0.001\right)$. No metaphases were observed after $120 \mathrm{~h}$ exposure to $0.4 \mathrm{ug} / \mathrm{cm}^{2}$ zinc chromate consistent with previous data (Speer et al., 2019). 
A.
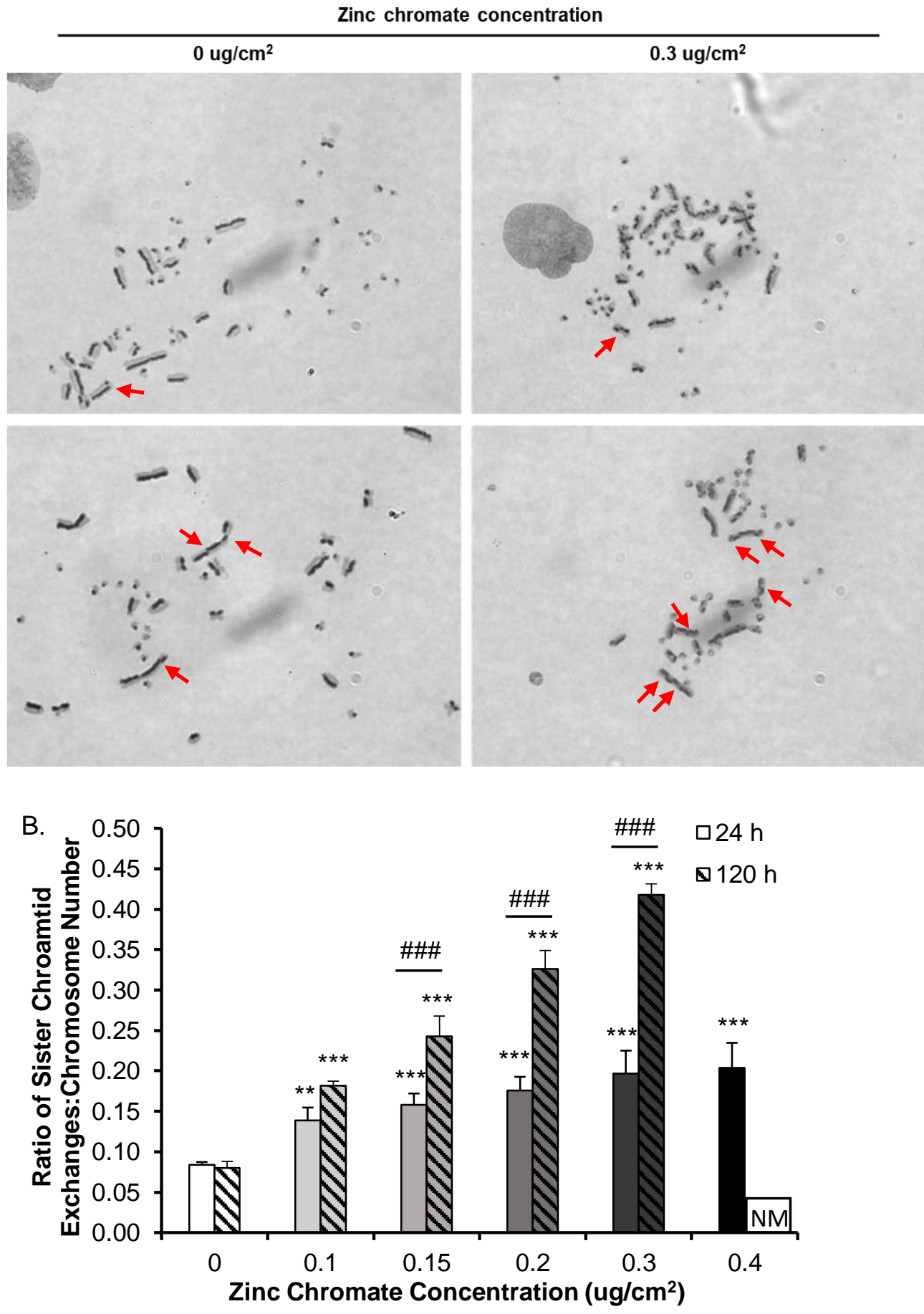

Figure 3.34. Particulate $\mathrm{Cr}(\mathrm{VI})$ induces sister chromatid exchanges in leatherback lung cells. This figure shows after 24 and $120 \mathrm{~h}$ exposure sister chromatid exchanges increase with particulate $\mathrm{Cr}(\mathrm{VI})$ concentration. (A) Representative images of sister chromatid 
exchanges in leatherback lung cells. (B) Ratio of sister chromatid exchanges to chromosome number. Sister chromatid exchanges were increased in each zinc chromate concentration $\left({ }^{* *} p<0.01\right.$; $\left.{ }^{* * *} \mathrm{p}<0.001\right)$. Sister chromatid exchanges were significantly higher after $120 \mathrm{~h}$ exposure to $0.15,0.2$, and $0.3 \mathrm{ug} / \mathrm{cm}^{2}$ zinc chromate

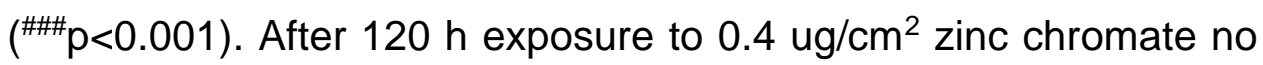
metaphases (NM) were observed. Results represent the mean of at least three independent experiments. Error bars $=$ standard error of the mean. 


\section{Summary}

In objective 2 we investigated DNA damage and repair in leatherback lung cells after acute and prolonged exposure to particulate $\mathrm{Cr}(\mathrm{VI})$. We found DNA double strand breaks did not increase with particulate $\mathrm{Cr}(\mathrm{VI})$ concentration after 24 or $120 \mathrm{~h}$ exposure using the comet assay. However, gamma-H2AX foci increased with concentration to similar levels after both 24 and $120 \mathrm{~h}$ particulate $\mathrm{Cr}(\mathrm{VI})$ exposure. The difference between the comet assay and gamma-H2AX foci analysis could be the result of differences in the two measurements or signify double strand breaks are being partially repaired in leatherback lung cells after exposure to particulate $\mathrm{Cr}(\mathrm{VI})$.

After measuring DNA repair in leatherback lung cells we saw prolonged exposure to particulate $\mathrm{Cr}(\mathrm{VI})$ inhibited RAD51 foci at higher concentrations of particulate $\mathrm{Cr}(\mathrm{VI})$, but homologous recombination repair was not inhibited. These data indicate while RAD51 may be inhibited after prolonged exposure, homologous recombination is still available to leatherback lung cells and may be partially protective. 


\section{CHAPTER 4: DISCUSSION}

\section{Overview}

Homologous recombination is a high-fidelity DNA repair mechanism critical in maintaining genomic stability (Bryant et al., 2006; Stackpole et al., 2007). Studies show the homologous recombination pathway is involved in the repair of DNA double strand breaks induced by several metals including $\mathrm{Cr}(\mathrm{VI})$, arsenic, cadmium, lead, and nickel (Bryant et al., 2006; Gastaldo et al., 2007; Helleday et al., 2000; Stackpole et al., 2007). When homologous recombination repair is unavailable the cell must resort to low-fidelity repair mechanisms increasing the rate of chromosome instability. Indeed, we have shown $\mathrm{Cr}(\mathrm{VI})$ induces DNA double strand breaks while inhibiting homologous recombination repair resulting in chromosome instability (Browning et al., 2016, Qin et al., 2014; Wise et al., 2003; Wise et al., 2002; Xie et al., 2009)

A critical factor in homologous recombination repair is the protein RAD51, which is involved in carrying out the effector step in this pathway. RAD51 is inhibited after prolonged exposure to particulate $\mathrm{Cr}(\mathrm{VI})$ illustrated by inhibited RAD51 monofilament formation and nuclear foci, cytoplasmic accumulation of RAD51 protein, and inhibited RAD51 protein expression (Browning et al., 2016; Qin et al., 2014). Decreased RAD51 protein is a key event that may underlie the other RAD51 phenotypes observed after prolonged $\mathrm{Cr}(\mathrm{VI})$ exposure. The transcription factor, E2F1, is predominantly responsible for RAD51 expression, 
and studies show loss of E2F1 inhibits RAD51 expression and foci formation as well as homologous recombination repair (Chen et al., 2011; Choi and Kim, 2019; Wu et al., 2014). However, there are no studies investigating RAD51 expression and the mechanisms controlling RAD51 expression after $\mathrm{Cr}(\mathrm{VI})$ exposure.

In Aim 1 we tested if E2F1 mediates the RAD51 response to particulate $\mathrm{Cr}(\mathrm{VI})$ exposure. We demonstrated the decrease in RAD51 protein is likely due to inhibited expression and not protein degradation. We focused on the predominant transcription factor for RAD51, E2F1, to determine if E2F1 was critical for expression of RAD51 after particulate $\mathrm{Cr}(\mathrm{VI})$ exposure. We found E2F1 overexpression does not rescue RAD51 failure induced by prolonged particulate $\mathrm{Cr}(\mathrm{VI})$ exposure. This result indicates E2F1 alone does not modulate the RAD51 response to particulate $\mathrm{Cr}(\mathrm{VI})$. This conclusion was supported by our data that shows knocking down E2F1 does not inhibit RAD51 expression. While we began to investigate the potential role of alternative transcription factors in particulate $\mathrm{Cr}(\mathrm{VI})$-inhibited RAD51 expression, these results could not fully explain the decrease of RAD51 expression.

In Aim 2 we performed a global RNAseq analysis to investigate how particulate $\mathrm{Cr}(\mathrm{VI})$ alters the expression of miRNAs. miRNAs are key regulators of gene expression, and studies show $\mathrm{Cr}(\mathrm{VI})$ causes global changes in gene expression. However, limited studies have evaluated changes in miRNA expression following $\mathrm{Cr}(\mathrm{VI})$ exposure, and none focused on homologous recombination repair or RAD51. We investigated the effects of acute and prolonged exposure to particulate $\mathrm{Cr}(\mathrm{VI})$ on miRNAs and characterized their expression profiles. We found particulate $\mathrm{Cr}(\mathrm{VI})$ significantly altered miRNA 
expression and caused global down regulation of miRNAs. Additionally, we found miRNAs altered by particulate $\mathrm{Cr}(\mathrm{VI})$ target genes in pathways of $\mathrm{Cr}(\mathrm{VI})$ carcinogenesis. RAD51 expression is a focus of this study and we characterized which particulate $\mathrm{Cr}(\mathrm{VI})$-altered miRNAs predicted to target RAD51 and the likelihood of their potential to bind to the RAD51 mRNA transcript. Together these data provide insight into how particulate $\mathrm{Cr}(\mathrm{VI})$ alters global expression of miRNAs and how they may play a role in pathways of $\mathrm{Cr}(\mathrm{VI})$ carcinogenesis.

To complement our investigation in the mechanisms of particulate $\mathrm{Cr}(\mathrm{VI})$ induced homologous recombination failure we applied the One Environmental Health approach by evaluating key endpoints in leatherback sea turtle lung cells. Previous studies using this approach have identified differences in the response to $\mathrm{Cr}(\mathrm{VI})$ exposure that may serve as protective mechanisms in one species over another (Browning et al., 2017a; Li Chen et al., 2009a; Li Chen et al., 2009b; Li Chen et al., 2012; Wise et al. 2015). Therefore, in aim 3 we investigated DNA damage and repair in leatherback lung cells. Using the comet assay we found particulate $\mathrm{Cr}(\mathrm{VI})$ did not induce DNA damage. However, when we measured gamma-H2AX foci, there was an increase after acute and prolonged particulate $\mathrm{Cr}(\mathrm{VI})$ exposure. When we investigated repair, we found RAD51 foci increased after $24 \mathrm{~h}$, but was inhibited after $120 \mathrm{~h}$ exposure indicating RAD51 is impaired. Alternatively, the breaks could be resolved. Even though RAD51 was decreased, homologous recombination repair was active indicated by the increase of sister chromatid exchanges. These data indicate homologous recombination repair is available in leatherback lung cells to repair double strand breaks. 
The conclusions of these aims are supported by the data in this dissertation. Below, we discuss the results in detail.

\section{Particulate $\mathrm{Cr}(\mathrm{VI})$ inhibits expression of RAD51 and E2F1}

RAD51, the key protein in the effector step of homologous recombination, is impaired after prolonged exposure to particulate $\mathrm{Cr}(\mathrm{VI})$ while earlier steps in the pathway remain functional (Qin et al., 2014). Loss of RAD51 was characterized by inhibited nuclear foci and monofilament formation, increased cytoplasmic accumulation, and inhibited protein expression (Browning et al., 2016; Qin et al., 2014). Browning et al., 2017a further investigated mechanisms of cytoplasmic accumulation of RAD51 after prolonged $\mathrm{Cr}(\mathrm{VI})$ exposure, however how particulate $\mathrm{Cr}(\mathrm{VI})$ inhibits RAD51 protein expression is unknown and was a major focus of this investigation.

We confirmed RAD51 protein expression decreased following prolonged, but not acute particulate $\operatorname{Cr}(\mathrm{VI})$ exposure consistent with previous studies (Browning et al., 2014, Qin et al., 2014). Decreased levels of protein could result from either increased protein degradation or decreased production of the protein. Bruno et al., 2016 characterized ubiquitin-mediated protein degradation as an important pathway of $\mathrm{Cr}(\mathrm{VI})$ exposure leading to deleterious cellular effects. However, our data show particulate $\mathrm{Cr}(\mathrm{VI})$ exposure had minimal effect on RAD51 protein half-life indicating protein degradation likely plays a minor role in the decrease of RAD51 protein levels. We did not apply additional methods to investigate RAD51 protein degradation in our analysis, however, it is unlikely to be

a major contributor based on our protein half-life results. Thus, degradation may 
be an overall important pathway for $\mathrm{Cr}(\mathrm{VI})$, but it does not appear to have a major contribution to this specific protein.

By contrast, we did find a reduction in processes underlying protein production, specifically RAD51 transcription. RAD51 mRNA expression decreased slightly after $24 \mathrm{~h}$ (not significant) but notably, and significantly decreased after 72 and remained low after $120 \mathrm{~h}$ exposure to particulate $\mathrm{Cr}(\mathrm{VI})$. While Bruno et al., 2016, suggests protein degradation is increased following $\mathrm{Cr}(\mathrm{VI})$ exposure our mRNA expression data suggest inhibited transcription is the primary mechanism responsible for the decrease of RAD51 protein, specifically. This result is supported by Manning and Patierno, 1992 who demonstrated $\operatorname{Cr}(\mathrm{VI})$ inhibits transcription. Our data are the first to describe RAD51 mRNA expression following $\mathrm{Cr}(\mathrm{VI})$ exposure, for both particulate and soluble $\mathrm{Cr}(\mathrm{VI})$ compounds. These results are consistent with studies showing $\mathrm{Cr}(\mathrm{VI})$ downregulates expression of DNA repair genes and correlate with the trend in RAD51 protein levels previously reported after acute and prolonged $\mathrm{Cr}(\mathrm{VI})$ exposure (Browning et al., 2016; Hodges et al., 2002; Hu et al., 2018; Pritchard et al., 2007; Qin e al., 2014; Takahashi et al., 2004).

Although we found decreased levels of RAD51 mRNA it is possible RAD51 protein reduction after prolonged particulate $\mathrm{Cr}(\mathrm{VI})$ exposure is also due to inhibited translation. Several studies have shown $\mathrm{Cr}(\mathrm{VI})$ inhibits protein translation (Blankenship et al., 1994; Gunaratnam and Grant, 2008; Shumilla and Barchowsky, 1999) Gunaratnam and Grant, 2008 showed $\mathrm{Cr}(\mathrm{VI})$ inhibited DNA, RNA, and protein synthesis, but the most significant effect was on protein synthesis. It is possible the decreased protein synthesis caused by $\operatorname{Cr}(\mathrm{VI})$ is the 
result of several mechanisms including inhibited transcription, RNA degradation, and inhibited translation as the end product of gene expression. Specific mechanisms of inhibited protein translation involving transcriptional machinery after $\operatorname{Cr}(\mathrm{VI})$ exposure have not been investigated. However, one emerging mechanism is the involvement of miRNAs in mRNA degradation and inhibited translation. We will discuss this possibility further below.

RAD51 is a key protein in homologous recombination repair and thus its transcriptional control has been investigated. Control of RAD51 expression is tightly regulated. E2F1 is the predominant transcription factor for RAD51 and loss of E2F1 inhibits RAD51 protein and nuclear foci formation (Chen et al., 2011; Choi and Kim, 2019; Wu et al., 2014). These results correlate with the RAD51 response after prolonged particulate $\mathrm{Cr}(\mathrm{VI})$ exposure. Studies show E2F1 is inhibited following exposure to other metals including arsenic and cadmium (Lam et al., 2014; Lam et al., 2015; Li et al., 2008; Wu et al., 2013). However, only one study investigated E2F1 after $\mathrm{Cr}(\mathrm{VI})$ exposure and found $24 \mathrm{~h}$ exposure increased $\mathrm{E} 2 \mathrm{~F} 1$ expression (Permenter et al., 2011). Prolonged exposures have not been investigated. We investigated the effects of particulate $\mathrm{Cr}(\mathrm{VI})$ on $\mathrm{E} 2 \mathrm{~F} 1$ to determine if particulate $\mathrm{Cr}(\mathrm{VI})$-induced loss of E2F1 may underlie reduced RAD51 expression. Our data show E2F1 protein expression is unaffected after 24 exposure but decreases after 72 and $120 \mathrm{~h}$ exposure. We observe significant decrease of RAD51 mRNA after prolonged exposures correlating with prolonged $\mathrm{Cr}(\mathrm{VI})$-inhibited E2F1 protein expression. E2F1 mRNA also decreased after $24 \mathrm{~h}$ and further decreased after 72 and $120 \mathrm{~h}$ exposure to particulate $\mathrm{Cr}(\mathrm{VI})$ consistent with the E2F1 protein levels. E2F1 self regulates its own transcription. Therefore, 
the loss of E2F1 protein after prolonged exposure may explain reduced E2F1 mRNA. RAD51 and E2F1 mRNA begin to decrease after $24 \mathrm{~h}$ suggesting transcription may be inhibited earlier than the decrease in protein is detected and indicates there may more than one mechanism for decreased mRNA levels at this time point. The mechanism underlying the loss of mRNA is currently unknown. One possible mechanism that may explain our results is miRNAs target the mRNA for degradation, and we will address this possibility below. miRNA-induced loss of mRNA does not explain why RAD51 and E2F1 protein levels are not affected after $24 \mathrm{~h}$ particulate $\mathrm{Cr}(\mathrm{VI})$ exposure. One explanation is the cell recognizes the need for RAD51 and E2F1 protein after acute particulate $\mathrm{Cr}(\mathrm{VI})$-induced DNA damage and protects available protein. Indeed, studies show E2F1 protein is stabilized following DNA damage (Biwas and Johnson, 2012; lanari et al., 2004; Lin et al., 2001).

\section{E2F1 does not mediate the RAD51 response to particulate $\mathrm{Cr}(\mathrm{VI})$}

We observed particulate $\mathrm{Cr}(\mathrm{VI})$ affected RAD51 and E2F1 mRNA and protein expression in a similar temporal manner suggesting loss of E2F1 after prolonged particulate $\mathrm{Cr}(\mathrm{VI})$ exposure may be responsible for loss of RAD51. To confirm this connection, we attempted to rescue the RAD51 response by overexpressing E2F1 after prolonged particulate $\mathrm{Cr}(\mathrm{VI})$ exposure. We found overexpression of E2F1 did not rescue RAD51 as the reduced protein levels, inhibited foci formation and aberrant cytoplasmic accumulation remained despite elevated E2F1 levels. RAD51 protein levels were inhibited in our untransfected control after $120 \mathrm{~h}$ exposure to particulate $\mathrm{Cr}(\mathrm{VI})$ consistent with previous data (Browning et al., 2016; Qin et al., 2014). However, while RAD51 protein levels 
increased after E2F1 overexpression in the cells untreated with particulate $\mathrm{Cr}(\mathrm{VI})$, after $120 \mathrm{~h}$ exposure to $0.2 \mathrm{ug} . \mathrm{cm}^{2}$ zinc chromate RAD51 protein did not increase compared to the transfection control. These data show that while E2F1 overexpression may increase RAD51 protein levels, it does not rescue prolonged particulate $\mathrm{Cr}(\mathrm{VI})$-induced reduction in RAD51 protein. When we examined RAD51 nuclear foci we did not find E2F1 rescued prolonged particulate $\mathrm{Cr}(\mathrm{VI})$-inhibited RAD51 foci formation observed in our untransfected control. This result indicates E2F1 may not directly affect RAD51 nuclear foci formation. One explanation for this result may be E2F1 overexpression does not abrogate prolonged particulate $\mathrm{Cr}(\mathrm{VI})$-induced RAD51 cytoplasmic accumulation and RAD51 is not available in the nucleus. However, when we examined RAD51 cytoplasmic accumulation after E2F1 overexpression we did not find RAD51 cytoplasmic accumulation was inhibited after prolonged particulate $\mathrm{Cr}(\mathrm{VI})$ exposure. These data suggest E2F1 is not involved in RAD51 nuclear localization.

The regulation of RAD51 expression and localization in the cell are controlled by complex mechanisms. Our data showing E2F1 increased RAD51 protein expression in cells untreated with particulate $\mathrm{Cr}(\mathrm{VI})$ is consistent with the literature. However, RAD51 protein levels were not modulated by E2F1 after particulate $\mathrm{Cr}(\mathrm{VI})$ exposure. Alternative repressive mechanisms may prevent the excess amount of E2F1 in the cells from expressing RAD51 explaining this result. Failure of E2F1 overexpression to rescue particulate $\mathrm{Cr}(\mathrm{VI})$-inhibited RAD51 foci formation may be explained by the fact that RAD51 protein was not restored. Alternatively, RAD51 nuclear foci are formed as a result of RAD51 loading onto single-stranded DNA at sites of DNA double strand breaks in part by BRCA2 and 
RAD51C, and this process may be unaffected by E2F1 (Amunugama et al., 2013; Forget and Kowalczykowski, 2010; Jensen et al., 2010).

Inhibited RAD51 nuclear foci may also be attributed to our result showing E2F1 overexpression did not abrogate particulate $\operatorname{Cr}(\mathrm{IV})$-induced RAD51 cytoplasmic accumulation rendering RAD51 unavailable in the nucleus. This outcome was unexpected as Ketchap et al., 2010 found histone deacetylase inhibitors affected RAD51 through E2F1-mediated mechanisms. One endpoint they confirmed was the induction of RAD51 cytoplasmic accumulation. The difference in our results may be due to the histone deacetylase inhibitors themselves used in Katchap et al., 2010 and not the loss of E2F1 directly. Katchap et al., 2010 used a histone deacetylase inhibitor that targets both class I and class II histone deacetylases, which can target non-histone proteins (Glozak et al., 2005). It is possible the inhibitor in this study affected post-translational modifications on proteins important for RAD51 localization.

RAD51 has no nuclear localization signal and thus must bind to other proteins, BRCA2 and RAD51C, to be transported into the nucleus (Gildemeister et al., 2009; Jeyasekharan et al., 2013). These proteins interact with nuclear pore complexes to mediate transport of RAD51 into the nucleus (Christie et al., 2016). Indeed, Browning et al., 2017a showed RAD51 nuclear transport mediated by BRCA2 and RAD51C was inhibited. It is possible E2F1 does not affect these mechanisms and that is why we did not see E2F1 overexpression rescue RAD51 cytoplasmic accumulation of RAD51 after prolonged particulate $\mathrm{Cr}(\mathrm{VI})$ exposure. It is notable that RAD51 cytoplasmic accumulation was decreased to low levels in the transfection control of our experiment. This result makes it difficult compare 
any observable effect of E2F1 overexpression and may have artifactually masked the result. This result indicates the transfection procedure itself affected RAD51 cytoplasmic accumulation, although the mechanisms underlying this possibility have not been investigated.

An alternative explanation for why E2F1 overexpression did not rescue any particulate $\mathrm{Cr}(\mathrm{VI})$-induced RAD51 phenotypes is due to off-target effects directly related to E2F1 overexpression. Previously, overexpression of E2F1 was found to lead to activation of cell death pathways in fibroblasts (Kowalik et al., 1995). Therefore, it is possible E2F1 overexpression induced off-target effects that interfered with normal DNA repair mechanisms. Although we did not measure cell death, if cell death pathways were activated after E2F1 overexpression, it is likely less resources would be allocated to DNA repair mechanisms. This points to the delicate balance of factors in the cell and how they respond to genotoxic insult.

It may be that complications of the E2F1 overexpression paradigm prevented us from determining if E2F1 mediates the RAD51 response to particulate $\mathrm{Cr}(\mathrm{VI})$. Therefore, we tried to connect E2F1 with the RAD51 response by knocking down E2F1 after acute exposure to particulate $\mathrm{Cr}(\mathrm{VI})$ when RAD51 is normally active to try an recapitulate the prolonged exposure response. Previous studies were successful showing loss of E2F1 inhibits RAD51 (Chen et al., 2011; Choi and Kim, 2019; Wu et al., 2014). We found knockdown of E2F1 did not inhibit RAD51 mRNA or protein expression or induce RAD51 cytoplasmic accumulation but did inhibit RAD51 nuclear foci formation. RAD51 protein levels were unaffected by E2F1 knockdown in three out of the four E2F1 siRNAs tested after exposure to acute $24 \mathrm{~h}$ particulate $\mathrm{Cr}(\mathrm{VI})$. Although one E2F1 siRNA inhibited RAD51 protein 
levels, it is possible this siRNA has an off-target effect on RAD51 expression inconsistent with the other siRNAs. These data indicate E2F1 does not modulate RAD51 protein levels in WTHBF-6 cells in response to particulate $\mathrm{Cr}(\mathrm{VI})$ consistent with our E2F1 overexpression data. Similarly, when we investigated RAD51 mRNA after E2F1 knockdown we found RAD51 mRNA were not consistently affected. While RAD51 mRNA was decreased slightly after E2F1 knockdown with one siRNA, it was slightly increased by another siRNA correlating with the RAD51 protein data after E2F1 knockdown. When we examined RAD51 localization, we found E2F1 knockdown did not induce RAD51 cytoplasmic accumulation observed after prolonged particulate $\mathrm{Cr}(\mathrm{VI})$ exposure indicating E2F1 does is not involved in mechanisms regulated RAD51 nuclear localization. These data are consistent with our E2F1 overexpression analysis. The cytoplasmic accumulation result is contrary to our finding that E2F1 knockdown inhibited RAD51 nuclear foci formation after only acute $24 \mathrm{~h}$ exposure to particulate $\mathrm{Cr}(\mathrm{VI})$. This result suggests E2F1 may affect RAD51 localization or stability at DNA double strand breaks but not nuclear localization.

The results of our E2F1 knockdown experiments may be explained by the complex nature of the involvement of E2F1 in RAD51 expression and function. Only one of the four E2F1 siRNA transfection resulted in decreased RAD51 protein expression and was only significant in the condition with no particulate $\operatorname{Cr}(\mathrm{VI})$ exposure. An explanation for this result may be that in this condition E2F1 was knocked down to $10 \%$ while the other E2F1 knockdowns E2F1 was only knocked down to between $20-30 \%$. This difference could explain why we do not observe the decrease of RAD51 reported by others in the literature. However, within our 
study mechanism, particulate $\mathrm{Cr}(\mathrm{VI})$ does not reduce $\mathrm{E} 2 \mathrm{~F} 1$ protein to these levels. In fact, the largest effect on E2F1 protein loss is after $72 \mathrm{~h}$ exposure to $0.3 \mathrm{ug} / \mathrm{cm}^{2}$ zinc chromate resulting in $41 \%$ E2F1 protein levels relative to control. Therefore, it may be possible E2F1 knockdown inhibits RAD51, but only at levels not reached after particulate $\mathrm{Cr}(\mathrm{VI})$ exposure.

E2F1 is responsible for the transcription of RAD51. However, we found E2F1 knockdown did not inhibit RAD51 mRNA expression consistently after acute particulate $\mathrm{Cr}(\mathrm{VI})$ exposure. Other studies have found E2F1 knockdown inhibits RAD51 mRNA expression (Choi and Kim, 2019; Wu et al., 2014). These papers are inconsistent with our results showing E2F1 knockdown did not significantly impact RAD51 mRNA. The levels of E2F1 in our study may not low enough to induce the RAD51 effect observed in other studies. Similar to the RAD51 protein expression results the E2F1 siRNA condition where E2F1 was knocked down to $10 \%$ reduced RAD51 mRNA, while in the other E2F1 siRNA condition E2F1 was knocked down to $20-30 \%$ and slightly increased RAD51 mRNA. An alternative explanation is we found nuclear E2F1 protein levels only decreased after $120 \mathrm{~h}$ exposure. Although total E2F1 protein is significantly decreased after 72 and 120 h particulate $\mathrm{Cr}(\mathrm{VI})$ exposure, it appears what $\mathrm{E} 2 \mathrm{~F} 1$ protein is available is shuttled into the nucleus. Another explanation is alternative transcription factors may be compensating for the loss of E2F1 in the expression of RAD51. Consistent with these results and our E2F1 overexpression data we found E2F1 knockdown did not induce RAD51 cytoplasmic accumulation after only acute exposure to particulate $\mathrm{Cr}(\mathrm{VI})$. This result may be because E2F1 simply is not involved in the nuclear localization of RAD51 as discussed above. 
It is also possible the timing of the experiment did not allow for the development of RAD51 cytoplasmic accumulation or the reduction in RAD51 mRNA and protein. For example, we knocked down E2F1 for a total of $48 \mathrm{~h}$ and treated with particulate $\mathrm{Cr}(\mathrm{VI})$ the last $24 \mathrm{~h}$ of the transfection. In initial testing, we found WTHBF-6 cells did not tolerate longer E2F1 knockdown transfection times well. This timing issue may have inhibited our ability to detect the RAD51 phenotypes investigated that may require longer to develop. It is also possible knocking down E2F1 had off-target effects in the cells that affected these endpoints.

Although RAD51 protein and mRNA expression and cytoplasmic accumulation were unaffected by E2F1 knockdown, we did find RAD51 nuclear foci were inhibited. This result is consistent with studies showing loss of E2F1 reduces RAD51 nuclear foci at double strand breaks and inhibits DNA repair. For example, Chen et al., 2011 showed E2F1 knockout cells had increased DNA damage and inhibited repair indicated by the comet assay and gamma-H2AX foci while also reducing RAD51 nuclear foci. RAD51 nuclear foci normally increase in response to acute particulate $\mathrm{Cr}(\mathrm{VI})$ exposure (Browning et al., 2014; Qin et al., 2014). Our data show loss of E2F1 inhibited RAD51 nuclear foci formation after acute particulate $\mathrm{Cr}(\mathrm{VI})$ exposure. These data indicate $\mathrm{E} 2 \mathrm{~F} 1$ may play a role in RAD51 loading onto single-stranded DNA at double strand breaks, or affect proteins involved in this process. E2F1 can localize to DNA double strand breaks and plays a role in the signaling and stability of DNA repair proteins (Chen et al., 2011; Choi and Kim, 2019; Liao et al., 2010; Lin et al., 2001). It is possible E2F1 facilitates RAD51 nuclear foci formation directly or through the regulation of 
mediator proteins. This direct involvement at DNA double strand breaks may explain why E2F1 knockdown affected RAD51 nuclear foci but not the other endpoints we assessed. This result does not explain why we did not see E2F1 overexpression rescue prolonged particulate $\mathrm{Cr}(\mathrm{VI})$-inhibited RAD51 nuclear foci formation. However, as previously discussed the overexpression procedure may have had off-target effects affecting the result. Further work is required to determine the role of E2F1 in RAD51 foci formation after particulate $\mathrm{Cr}(\mathrm{VI})$ exposure.

\section{Alternative RAD51 transcription factors may play a role in RAD51 expression after particulate $\mathrm{Cr}(\mathrm{VI})$ exposure}

While we found E2F1 may affect RAD51 nuclear foci formation, RAD51 expression was unaffected by modulating E2F1. We explored alternative mechanisms that may explain these results focusing on alternate proteins involved in RAD51 transcription however there is little data on the regulation of RAD51 by other transcription factors. EGR1 is a proposed transcriptional activator of RAD51 (Hine et al., 2014). We found EGR1 was unaffected after $24 \mathrm{~h}$ but had a modest decrease after $120 \mathrm{~h}$ exposure. For example, $120 \mathrm{~h}$ exposure to $0.1,0.2$, and 0.3 $\mathrm{ug} / \mathrm{cm}^{2}$ zinc chromate decreased EGR 1 to 81,76 , and $64 \%$ of control, respectively, although these results were not significant. We have not investigated the modest decrease in EGR1 after prolonged particulate $\mathrm{Cr}(\mathrm{VI})$ exposure thus far and how it may contribute to loss of RAD51 expression.

We considered the opposite scenario, that rather than RAD51 activators being decreases, perhaps transcription was low because inhibitors were increased. It is possible transcriptional repressors modulate RAD51 expression 
after particulate $\mathrm{Cr}(\mathrm{VI})$ exposure. Indeed, Engeland, 2018 suggests the balance of activating and repressive complexes are important in gene expression. P53 is a direct and indirect transcriptional repressor of RAD51 (Buchop, 1997; Toledo, 1998). However, we found p53 protein increased after $24 \mathrm{~h}$ and decreased slightly after $120 \mathrm{~h}$ exposure to particulate $\mathrm{Cr}(\mathrm{VI})$, which does not support a conclusion that p53 was repressing RAD51 transcription. We further found p53 stabilization was not altered. These data suggest p53 may not play a significant direct role in the expression of RAD51 after particulate $\mathrm{Cr}(\mathrm{VI})$ exposure. Our observations that stability is unaffected would allow p53 to participate in indirect regulation of RAD51 expression. For example, p53 facilitates hypo-phosphorylation of p130, and hypop130 binds to E2F4 facilitation the formation of the repressive DREAM complex (Engeland, 2018).

The DREAM complex is thought to displace activating complexes containing E2F1. Indeed, Bindra et al., 2007 showed E2F1 and E2F4 compete for the same binding location at the RAD51 promoter. We found while p130 protein decreased after particulate $\mathrm{Cr}(\mathrm{VI})$ exposure, phospho-p130 was further deceased. These data indicate of the $\mathrm{p} 130$ available after particulate $\mathrm{Cr}(\mathrm{VI})$ exposure, more is in the hypo-phosphorylated form, which may then complex with E2F4. We found E2F4 protein to be slightly elevated level after acute and prolonged exposure to particulate $\mathrm{Cr}(\mathrm{VI})$. This outcome indicates while E2F1 is inhibited following particulate $\mathrm{Cr}(\mathrm{VI})$ exposure E2F4 is unaffected, which would shift the balance of the two transcription factors towards the repressive E2F4. Based on the literature this imbalance may be responsible for the repressed RAD51 expression (Bindra et al., 2007; Schwentner et al., 2015). Our data showing E2F1 overexpression 
might initially seem to contradict the hypothesis that the balance of E2F1 to E2F4 is responsible for RAD51 repression after particulate $\mathrm{Cr}(\mathrm{VI})$ exposure. However, the complexity of this process may need to be further investigated to better delineate the mechanism. Indeed, there is not much known about how the repressive DREAM complex displaces the transcriptional activating complex containing E2F1.

\section{Particulate $\mathrm{Cr}(\mathrm{VI})$ upregulates miRNAs targeting RAD51 expression}

Our data exploring transcriptional control of RAD51 do not fully explain loss of RAD51 mRNA and protein after particulate $\mathrm{Cr}(\mathrm{VI})$ exposure. miRNAs play a significant role in regulating gene expression by targeting mRNA for degradation or inhibition of translation. Only a few studies have evaluated changes in miRNAs after $\mathrm{Cr}(\mathrm{VI})$ expression, however, these only focused on a few miRNAs each, and none in connection to RAD51 (Chandra et al., 2015; Li et al., 2014; Li et al., 2016). We performed a global analysis of miRNAs using RNAseq after exposure to acute and prolonged particulate $\mathrm{Cr}(\mathrm{VI})$ exposure in human lung cells and identified miRNAs upregulated by particulate $\mathrm{Cr}(\mathrm{VI})$ that target RAD51.

We found particulate $\mathrm{Cr}(\mathrm{VI})$ upregulated miRNAs targeting RAD51 mRNA. Of the 126 miRNAs predicted to target RAD51, we found 37 to be significantly upregulated by particulate $\mathrm{Cr}(\mathrm{VI})$ exposure. Thirty-five of these miRNAs targeted RAD51 with high likelihood of binding according to their mirSVR scores. Seventeen out of the 37 total miRNA targeting RAD51 had perfect 6 mer binding, which indicates many of the particulate $\mathrm{Cr}(\mathrm{VI})$ upregulated miRNAs targeting RAD51 have a high likelihood of binding and having an effect on RAD51 expression. 
We observed trends in concentration and time associated with several miRNAs. For example, miR-432-5p and miR-194-5p were upregulated after 72 and $120 \mathrm{~h}$ exposure at all concentrations of particulate $\mathrm{Cr}(\mathrm{VI})$. These miRNAs have 7mer binding to the RAD51 mRNA transcript. miR-30b was significantly upregulated after $120 \mathrm{~h}$ exposure at the highest concentration and has perfect 6 mer binding to the RAD51 mRNA transcript. We observed significant upregulation of RAD51-targeting miR-186 after $24 \mathrm{~h}$ exposure to particulate $\mathrm{Cr}(\mathrm{VI})$ with 3 predicted binding sites on the RAD51 mRNA transcript (one with a perfect 6mer match). This miRNA was also found to induce chromosome instability following arsenic exposure although this study did not consider the implications of miR-186 targeting RAD51 in their analysis (Wu et al., 2019). miR-186 and those RAD51targeting miRNAs upregulated after prolonged exposure would be excellent candidates for further evaluation of their effect on RAD51 expression and chromosome instability after particulate $\mathrm{Cr}(\mathrm{IV})$ exposure.

No previous studies evaluated miRNAs altered by $\mathrm{Cr}(\mathrm{VI})$ in relation to RAD51. However, RAD51 itself has been the target of therapeutic studies for interference by miRNAs. For example, Huang et al., targeted RAD51 using miR103 and miR-107 although we did not see these miRNAs affected by particulate $\mathrm{Cr}(\mathrm{VI})$ exposure. Several other studies also identified RAD51-targeting miRNAs in relation to cancers or therapeutic use, but none overlapped with particulate $\mathrm{Cr}(\mathrm{VI})$ upregulated miRNAs targeting RAD51 in our results (Lai et al., 2016; Gasparini et al., 2014; Li et al., 2016). 


\section{Particulate $\mathrm{Cr}(\mathrm{VI})$ upregulates miRNAs that target homologous}

recombination genes

RAD51 is a key protein in the homologous recombination pathway and we found particulate $\mathrm{Cr}(\mathrm{VI})$ upregulated miRNAs predicted to target RAD51. However, $\mathrm{Cr}(\mathrm{VI})$ may upregulate miRNAs targeting additional proteins in the homologous recombination pathway affecting RAD51. We identified individual miRNAs significantly upregulated (fold change $>2$ ) by particulate $\mathrm{Cr}(\mathrm{VI})$ under each experimental condition and their gene targets in the homologous recombination pathway. It is notable RAD51 was not included in this list. This is because of our stringent cut-off of a fold change $>2$ for this specific analysis. However, the analysis shows many of the genes targeted are RAD51 homologs or involved in loading RAD51 onto the single-stranded DNA at double strand breaks. For example, XRCC2, RAD52, RAD51D, RAD51C, and RAD51B were all targeted by particulate $\mathrm{Cr}(\mathrm{VI})$-upregulated miRNAs. Specifically, we observed several trends across concentration and time including miR-210 (which targets RAD52), which was upregulated at all time points. RAD52 is involved in loading RAD51 onto the singlestranded DNA at double strand breaks. Few genes in the earlier steps of homologous recombination repair were affected consistent with our previous reports showing it is the downstream steps in homologous recombination affected by particulate $\mathrm{Cr}(\mathrm{VI})$ exposure (Browning et al., 2016; Browning et al., 2017a; Qin et al., 2014). For example, early proteins in the homologous recombination pathway RAD50, ATM, and NBS1 were not predicted to be targeted by particulate $\mathrm{Cr}(\mathrm{VI})$-upregulated miRNAs. We have not investigated the effect of $\mathrm{Cr}(\mathrm{VI})$ on NBS1 specifically, however, MRE11 which is a part of the sensing DNA double strand 
breaks with NBS1 (MRN complex) was unaffected by prolonged $\mathrm{Cr}(\mathrm{VI})$ exposure (Qin et al., 2014). The MRN complex is important for signaling of DNA double strand breaks, and our previous study also shows downstream signaling by ATM remains functional after prolonged $\mathrm{Cr}(\mathrm{VI})$ exposure (Qin et al., 2014). This is consistent with the RNAseq data showing ATM was not a predicted target by particulate $\mathrm{Cr}(\mathrm{VI})$ upregulated miRNAs. In contrast, RPA proteins, which coat single-stranded DNA were targeted under all particulate $\mathrm{Cr}(\mathrm{VI})$ conditions. RPA nuclear foci levels are decreased after prolonged particulate $\mathrm{Cr}(\mathrm{VI})$ exposure compared to acute exposure indicating a possible inhibitory effect correlating with our RNAseq data (data not published, Cynthia Browning). However, RPA expression has not been measured. RPA is involved in many processes including cell cycle, DNA damage checkpoints, DNA replication, and most DNA repair pathways (Zou et al., 2006). Further work is needed to understand if the miRNAs predicted to target RPA in our analysis have a significant impact on homologous recombination repair.

\section{Particulate $\mathrm{Cr}(\mathrm{VI})$ alters miRNAs that target pathways of $\mathrm{Cr}(\mathrm{VI})$ carcinogenesis}

We identified particulate $\mathrm{Cr}(\mathrm{VI})$-upregulated miRNAs that target RAD51 and other proteins involved in homologous recombination repair, which is known to be an important in the mechanism of $\mathrm{Cr}(\mathrm{VI})$ carcinogenesis. Carcinogenesis is a complex process and involves many different pathways, and it is unknown how $\mathrm{Cr}(\mathrm{VI})$-altered miRNAs affect other pathways of $\mathrm{Cr}(\mathrm{VI})$ carcinogenesis. To date this is the only study to evaluate global changes in miRNAs after $\mathrm{Cr}(\mathrm{VI})$ exposure. Therefore, we considered the broader implications of particulate $\mathrm{Cr}(\mathrm{VI})$-altered 
miRNAs. To address this gap in the literature, we identified up- or down-regulated miRNAs significantly affected by particulate $\mathrm{Cr}(\mathrm{VI})$ exposure then assessed them in the context of pathways of $\mathrm{Cr}(\mathrm{VI})$ carcinogenesis.

Particulate $\mathrm{Cr}(\mathrm{VI})$ increased the number of significantly (adjusted $\mathrm{p}$ value $<0.01)$ up- and down-regulated miRNAs compared to the control in all conditions. Increased expression of miRNAs is often associated with decreased translation of their mRNA targets. Therefore the upregulation of miRNAs by particulate $\mathrm{Cr}(\mathrm{VI})$ may increase the chance of those miRNAs binding to their target mRNA transcripts resulting in downregulation of translation. Conversely, the downregulation of miRNAs by particulate $\mathrm{Cr}(\mathrm{VI})$ may result in increased translation of their target mRNAs. The balance of up-and down-regulated miRNAs is a complex process. For example, the upregulation of a miRNA targeting an activator of a pathway may decrease activity in that pathway. Alternatively, the downregulation of a miRNA targeting a repressor may result in increased activity of that repressor's target.

In our analysis we observed a significantly higher number of miRNAs upregulated after $24 \mathrm{~h}$ exposure to $0.2 \mathrm{ug} / \mathrm{cm}^{2}$ zinc chromate compared to all other particulate $\mathrm{Cr}(\mathrm{VI})$ concentrations at any time point. In our previous studies on particulate $\mathrm{Cr}(\mathrm{VI})$ exposure we have found a different response after $24 \mathrm{~h}$ compared to prolonged 72 or $120 \mathrm{~h}$ exposure (Browning et al., 2016; Browning et al., 2017a; Holmes et al., 2006; Martino et al., 2015; Qin et al., 2014). However, the reason for the specific concentration effect after $24 \mathrm{~h}$ exposure to $0.2 \mathrm{ug} / \mathrm{cm}^{2}$ zinc chromate is unknown. Apart from this anomaly, we found the total number of downregulated miRNAs under each condition was greater than the number of 
upregulated miRNAs. For example, after $120 \mathrm{~h}$ exposure particulate $\mathrm{Cr}(\mathrm{VI})$ downregulated more than twice the number of miRNAs that were upregulated. This result suggests $\mathrm{Cr}(\mathrm{VI})$ causes more downregulation than upregulation of miRNAs and is the first assessment to show global expression of non-coding RNAs affected by $\mathrm{Cr}(\mathrm{VI})$ exposure. Indeed, studies show exposure to $\mathrm{Cr}(\mathrm{VI})$ alters global gene expression (Andrew et al., 2003; Izzotti et al., 2002; Wetterhahn and Hamilton, 1989; Ye and Shi, 2001). One explanation for how $\mathrm{Cr}(\mathrm{VI})$ alters global expression may be $\mathrm{Cr}(\mathrm{VI})$ affects miRNAs targeting the transcriptional machinery in cells, however, further investigation of this possibility is required.

Due to the large dataset we characterized the miRNAs significantly (adjusted $p$-value $<0.01$ ) affected by particulate $\mathrm{Cr}(\mathrm{VI})$ exposure. A stringent foldchange cut-off of 2 was applied to focus on miRNAs that may have a more impactful biological responses in the cell. Analysis of miRNAs shared between treatment concentrations of up- or down-regulated revealed not many miRNAs were shared between the lowest and highest particulate $\mathrm{Cr}(\mathrm{VI})$ concentrations tested. This result indicates different concentrations of particulate $\mathrm{Cr}(\mathrm{VI})$ modulate expression of different sets of miRNAs. There are no studies addressing the impact of this effect. However, this result could have implications in the mixture of miRNAs available at any given concentration of particulate $\mathrm{Cr}(\mathrm{VI})$ exposure and affect how cells respond.

Using Euclidean clustering to create heatmaps, we determined which miRNAs were up- or down-regulated with similar patterns across particulate $\mathrm{Cr}(\mathrm{VI})$ exposure conditions. We found strong clustering between miRNAs similarly affected by particulate $\mathrm{Cr}(\mathrm{VI})$ exposure. One endpoint considered was how the 
miRNAs clustered after acute or prolonged particulate $\operatorname{Cr}(\mathrm{VI})$ exposure. When comparing the $24 \mathrm{~h}$ clustering to the 72 or $120 \mathrm{~h}$ clustering the $24 \mathrm{~h}$ clustering looks less similar to the 72 and $120 \mathrm{~h}$ clustering. This difference seems to be in part due to a large number of miRNAs with low fold change values in the $24 \mathrm{~h}$ data indicating they may not have a significant impact. It is also notable in the $24 \mathrm{~h}$ data there are more miRNAs included in the heatmap than 72 or $120 \mathrm{~h}$, however, this likely reflects the spike in the total number of upregulated miRNAs after $24 \mathrm{~h}$ exposure to $0.2 \mathrm{ug} / \mathrm{cm}^{2}$ zinc chromate previously discussed. We also observed miRNAs in the $24 \mathrm{~h}$ data with a switch in expression patterns that was only observed in one miRNA in the $72 \mathrm{~h}$ dataset and not at all in the $120 \mathrm{~h}$ data set. For example, miRNAs went from being upregulated at $0.1 \mathrm{ug} / \mathrm{cm}^{2}$ zinc chromate to downregulated at $0.2 \mathrm{ug} / \mathrm{cm}^{2}$ zinc chromate, and then upregulated again at 0.3 $\mathrm{ug} / \mathrm{cm}^{2}$ zinc chromate or vice versa. These data indicate the trends in concentration-response were stronger after prolonged 72 and $120 \mathrm{~h}$ exposure than after $24 \mathrm{~h}$ exposure to particulate $\mathrm{Cr}(\mathrm{VI})$. This difference in the analysis at $24 \mathrm{~h}$ compared to prolonged 72 or $120 \mathrm{~h}$ exposure is consistent with trends in our previous data and highlights the different effects of acute verses prolonged $\operatorname{Cr}(\mathrm{VI})$ exposure (Browning et al., 2016; Browning et al., 2017a; Holmes et al., 2006; Martino et al., 2015; Qin et al., 2014).

When we used this analysis to look closer at specific miRNA effects we found miR-194-1 was significantly upregulated after $72 \mathrm{~h}$ and after $120 \mathrm{~h}$ exposure had the highest fold change increase at that time point. Upregulation of miR-1941 was also reported in the liver of rats treated with arsenic although gene targets may differ between species (Ren et al., 2015). In general metals are known to 
share similar mechanisms of carcinogenesis (Chen et al., 2019). Studies have begun to investigate how carcinogenic metals such as cadmium and arsenic alter global miRNA expression, but none have been done following $\mathrm{Cr}(\mathrm{VI})$ exposure (Liu et al., 2015; Ren et al., 2015). Hou et al., 2011 summarized a set of studies evaluating the effect of environmental chemicals including cadmium, arsenic, cigarette smoke, and metal-rich particulate matter on miRNA expression and found miR-210 was downregulated by arsenic trioxide (Cao et al., 2011). We also found miR-210 was downregulated after $24 \mathrm{~h}$ exposure to $0.3 \mathrm{ug} / \mathrm{cm}^{2}$ zinc chromate in our study. Additional studies comparing how metals alter miRNA expression may be insightful to their role in carcinogenesis.

We used this differential miRNA expression data to identify and characterize pathways of $\mathrm{Cr}(\mathrm{VI})$ carcinogenesis targeted by particulate $\mathrm{Cr}(\mathrm{VI})$-altered miRNAs. Pathways of $\mathrm{Cr}(\mathrm{VI})$ carcinogenesis were identified through a literature search of recent papers on this topic and aligning those pathways with pathways in the KEGG database. We noted trends in the number of genes predicted to be targeted by $\operatorname{Cr}(\mathrm{VI})$-altered miRNAs in each pathway and identified which pathways were targeted by the most $\mathrm{Cr}(\mathrm{VI})$-altered miRNAs. Of the cellular processes pathways cell cycle and apoptosis were two of the pathways predicted to have the most targeted genes. $\mathrm{Cr}(\mathrm{VI})$ is known to alter cell cycle and cell death mechanisms contributing to carcinogenesis (Gavin et al., 2007; O'Brien et al., 2002; Russo et al., 2005; Wise et al., 2006b). For example, Wise et al., 2006b showed prolonged exposure to particulate lead chromate induced spindle assembly checkpoint bypass altering cell cycle in WTHBF-6 cells. These cells also exhibited numerical chromosome instability, a hallmark of lung cancers. Russo et al., 2005 showed 
$\mathrm{Cr}(\mathrm{VI})$ increased pro-apoptotic genes, however, this was only after acute $24 \mathrm{~h}$ exposure to high concentrations of soluble $\mathrm{Cr}(\mathrm{VI})$. It is currently unclear how subsets of $\mathrm{Cr}(\mathrm{VI})$-exposure cells evade apoptosis to develop into malignant cells. Our miRNA analysis may provide insight into this mechanism.

The pathway analysis also shows which pathways have bigger differences in the number of genes per pathway targeted by up- or down-regulated miRNAs and the total number of up- or down-regulated miRNAs predicted to target each pathway. For example, in the ubiquitin mediated proteolysis pathway after $24 \mathrm{~h}$ exposure to $0.3 \mathrm{ug} / \mathrm{cm}^{2}$ zinc chromate 16 genes were predicted to be targeted by downregulated miRNAs and 20 genes were targeted by upregulated miRNAs while only 2 downregulated miRNAs targeted genes in this pathway and 12 upregulated miRNAs targeted genes in this pathway. One consideration is that the number of predicted targets identified in any given KEGG pathways may play a role in our analysis. For example, we observed the PI3K-AKT pathway had the most genes targeted my $\operatorname{Cr}(\mathrm{VI})$-upregulated miRNAs (13, 20, and 18 after 24, 72, and $120 \mathrm{~h}$ exposure to $0.3 \mathrm{ug} / \mathrm{cm}^{2}$ zinc chromate, respectively). While the PI3K-AKT pathway is extensive (354 genes), it is still worth noting this result to investigate further. This analysis demonstrates the complex dynamics of the relationship between miRNAs and their targets and highlights the need to better understand how miRNAregulated gene expression is controlled.

Pathway analysis revealed correlations between these results and those of several studies that have investigated smaller sets of miRNAs. For example, Li et al., 2014 identified miR-3940-5p was altered by $\mathrm{Cr}(\mathrm{VI})$ exposure in human plasma and associated it with regulation of a gene in involved in homologous 
recombination repair, a pathway targeted by $\mathrm{Cr}(\mathrm{VI})$-altered miRNAs. However, we found miR-3940 was significantly increased, but only after $24 \mathrm{~h}$ exposure. Similarly, miR-4741 and miR-590 were reported as significantly down- and upregulated, respectively, in the $\mathrm{Cr}(\mathrm{VI})$ plasma study. In our RNAseq results we found miR-4741 was also downregulated after $24 \mathrm{~h}$ exposure to particulate $\mathrm{Cr}(\mathrm{VI})$ consistent with the plasma miRNA report. However, miR-590 was upregulated after $120 \mathrm{~h}$ exposure in our RNAseq data set contrary to being upregulated by $\mathrm{Cr}(\mathrm{VI})$ exposure in the blood. These results may be due to many factors including the source of the miRNAs (human plasma of people exposed to potassium chromate vs. cultured lung cells exposed to zinc chromate) and different study methods (microarray vs. RNAseq). In future studies these analyses can be used to further investigate miRNAs involved in pathways of $\mathrm{Cr}(\mathrm{VI})$ carcinogenesis providing a road map of affected targets.

Our data support a recent analysis of pathways of $\mathrm{Cr}(\mathrm{VI})$ carcinogenesis suggesting $\mathrm{Cr}(\mathrm{VI})$-altered epigenetic mechanisms lead to genomic instability as a key driver of $\operatorname{Cr}(\mathrm{VI})$ carcinogenesis (Rager et al., 2019). This hypothesis is supported by data showing $\operatorname{Cr}(\mathrm{VI})$ induces low-rates of point mutations while causing inheritable phenotypes (Ewis et al., 2001; DeFlora and Wetterhahn, 1989; Katabami et al., 2000; Kondo et al., 1997; Wise et al., 2018). Specifically, Cr(VI)altered miRNAs have been proposed to downregulate DNA repair factors ultimately leading to genomic instability. Our data support this hypothesis and it will be important to investigate how miRNAs contribute to the multiple mechanisms of genomic instability. 


\section{Leatherback lung cells are resistant to particulate $\mathrm{Cr}(\mathrm{VI})$-inhibited homologous recombination repair}

Leatherback sea turtles are an excellent candidate for the One Environmental Health approach. Leatherbacks are a large marine reptile with a long lifespan and may be exposed to environmental contaminants throughout their life. Few studies have evaluated Cr levels in tissues of leatherback (Guzman et al,. 2020; Perrault et al., 2019; Poppi et al., 2012). However, Guzman et al., 2020 found $\mathrm{Cr}$ levels in leatherback eggs considered unsafe for humans. $\mathrm{Cr}$ was measured in another marine species, sperm whales (Physeter macrocephalus) and their tissues had Cr levels as high as levels found in human lung tissue from workers who died of chromate-induced lung cancer (Wise et al., 2009). These studies confirm $\mathrm{Cr}$ is a threat to marine species.

While $\operatorname{Cr}(\mathrm{VI})$ induces chromosome instability in whale cells, the levels are far lower than those observed in human cells demonstrating a difference in response (Li Chen et al., 2009a; Li Chen et al., 2009b). We used this same approach to show $\mathrm{Cr}(\mathrm{VI})$ induces chromosome instability in leatherback sea turtle lung cells at similar levels to those observed in human lung cells although some differences in response were observed (Speer et al., 2018; Speer et al., 2019). Browning et al., 2017b began to investigate the mechanisms of chromosome instability in whale cells and showed RAD51 increases after both acute and prolonged $\mathrm{Cr}(\mathrm{VI})$ exposure in whale cells, but these levels were higher after acute $\mathrm{Cr}(\mathrm{VI})$ exposure. RAD51 and homologous recombination repair have not been investigated in leatherbacks. 
We measured RAD51 foci after acute and prolonged exposure to particulate $\mathrm{Cr}(\mathrm{VI})$ in leatherback lung cells. We found RAD51 nuclear foci increased after acute $24 \mathrm{~h}$ exposure to particulate $\mathrm{Cr}(\mathrm{VI})$. However, after prolonged $120 \mathrm{~h}$ exposure RAD51 nuclear foci increased at lower concentrations slightly, then decreased to baseline levels at the higher concentrations. These data suggest RAD51 is inhibited after prolonged exposure to particulate $\mathrm{Cr}(\mathrm{VI})$ in leatherback lung cells and are consistent with results in human data (Browning et al., 2016; Qin et al., 2014).

Homologous recombination repair is protective against $\mathrm{Cr}(\mathrm{VI})$-induced genomic instability in human cells (Bryant et al., 2006; Stackpole et al., 2007). As we found RAD51 foci were decreased after prolonged particulate $\mathrm{Cr}(\mathrm{VI})$ exposure, we also assessed homologous recombination repair using the sister chromatid exchange assay. We found sister chromatid exchanges increase after $24 \mathrm{~h}$ with increasing particulate $\mathrm{Cr}(\mathrm{VI})$ concentration and increase further after prolonged $120 \mathrm{~h}$ exposure. This result suggests homologous recombination repair is available to repair DNA double strand breaks after both acute and prolonged particulate $\mathrm{Cr}(\mathrm{VI})$ exposure.

This result initially seems contradictory to our RAD51 outcomes we observed in turtle cells. It is tempting to suggest that $\mathrm{Cr}(\mathrm{VI})$ might be inducing sister chromatid exchanges not by inducing homologous recombination repair, but instead by inhibiting topoisomerase II. Historically, some data in the literature suggest topoisomerase II inhibitors can increase sister chromatid exchanges (Dillehay et al., 1989; Pommier et al., 1988). However, this possibility seems is unlikely to be a major contributor to our effect. First, the hypothesis that 
topoisomerase inhibitors induce sister chromatid exchanges is controversial many reports show they do not increase sister chromatid exchanges (Fantini et al., 1998; Lim et al., 1986). Secondly, topoisomerase II inhibitors ultimately cause DNA double strand breaks and these breaks can be repaired by homologous recombination repair. Thus, the most likely explanation for topoisomerase II inhibitinduced sister chromatid exchanges is the induction of homologous recombination repair and not some homologous recombination repair-independent mechanism. Furthermore, the breaks after topoisomerase II inhibitors are predominately repaired by non-homologous recombination repair (Adachi et al., 2003, Kantidze and Razin, 2006; Terasawa et al., 2014). If $\mathrm{Cr}(\mathrm{VI})$ was inhibiting topoisomerase II, one would expect the breaks to be repaired by non-homologous end joining resulting in reduced sister chromatid exchanges and reduced RAD51 foci, but we did not find this outcome. Therefore, it seems unlikely that topoisomerase II inhibitions would explain this outcome.

Another explanation for the difference between the RAD51 foci and sister chromatid exchange data is that homologous recombination repair in leatherbacks may differ than that in human cells where RAD51 is necessary for successful repair. RAD51 is highly conserved across species (Khoo et al., 2009). However, it is possible slight differences in the RAD51 protein may have affected the sensitivity of human RAD51 antibodies in the leatherback cells. Browning et al., 2017b also found RAD51 nuclear foci increased to lower levels after prolonged exposure then was observed after acute exposure, however, sister chromatid exchanges increased). This is consistent with the pattern of our result in leatherback lung cells. 
Structural chromosome instability increases with $\mathrm{Cr}(\mathrm{VI})$ exposure in leatherback lung cells (Speer et al., 2018; Speer et al., 2019). Induction of DNA double strand breaks is a key event of structural chromosome instability, however, we found homologous recombination repair was active after prolonged particulate $\mathrm{Cr}(\mathrm{VI})$ exposure in leatherback lung cells. When we investigated DNA damage in leatherback lung cells we found no increase in DNA double strand breaks after 24 or $120 \mathrm{~h}$ exposure to particulate $\mathrm{Cr}(\mathrm{VI})$ using the neutral comet assay in leatherback lung cells. However, we did observe an increase in gamma-H2AX foci after both 24 and $120 \mathrm{~h}$ exposure to particulate $\mathrm{Cr}(\mathrm{VI})$. The gamma-H2AX data indicate particulate $\mathrm{Cr}(\mathrm{VI})$ induces DNA double strand breaks after both acute and prolonged exposure, but these data do not correlate with our sister chromatid exchange data showing an increase in homologous recombination repair after acute and prolonged exposure to particulate $\mathrm{Cr}(\mathrm{VI})$. In contrast, our comet analysis does support the sister chromatid exchange data. There are several explanations that may explain the difference between the comet assay analysis and gammaH2AX data. One explanation may be due to assay sensitivity. The sensitivity of the comet analysis may not have been high enough to detect a significant change in DNA double strand breaks after particulate $\mathrm{Cr}(\mathrm{VI})$ exposure. In contrast, at least $25 \%$ of cells had elevated levels of gamma-H2AX foci after the highest concentration of particulate $\mathrm{Cr}(\mathrm{VI})$ at both time points. Alternatively, the timing of the detection of gamma-H2AX compared to the detection of double strand breaks by comet assay may play a role in the different response. Future investigation is necessary to assess DNA repair dynamics in leatherbacks to determine how the timing of repair in leatherbacks may affect our results. 
These data do not fully explain the increase in chromosome damage seen after prolonged particulate $\mathrm{Cr}$ exposure in leatherback lung cells (Speer et al., 2019). Chromosome breakage during mitosis can induce structural chromosome instability contributing to higher levels of chromosome damage however, this mechanism has not been investigated after $\mathrm{Cr}(\mathrm{VI})$ exposure (Bayani et al., 2007). In conclusion, we have shown RAD51 was inhibited after prolonged exposure, however homologous recombination repair is uninhibited by prolonged particulate $\mathrm{Cr}(\mathrm{VI})$ exposure demonstrated by our sister chromatid exchange data. These results provide the first mechanistic data on how $\operatorname{Cr}(\mathrm{VI})$ causes chromosome instability in leatherback sea turtle cells. 


\section{FUTURE DIRECTIONS}

This study provides data contributing to the mechanistic insight of $\mathrm{Cr}(\mathrm{VI})$ induced carcinogenesis. It provides the first analysis of transcriptional regulation of RAD51 following $\mathrm{Cr}(\mathrm{VI})$ exposure and the role of E2F1 in this process. We also present the first global analysis of miRNAs after $\mathrm{Cr}(\mathrm{VI})$ exposure in human cells using RNAseq analysis. These data were applied to identify miRNAs targeting pathways of $\mathrm{Cr}(\mathrm{VI})$ carcinogenesis, and specifically homologous recombination and RAD51. We also demonstrated for the first-time mechanisms involved in DNA repair in leatherback cells. However, these data generated many new ideas and hypotheses to investigate in the future.

First, while we showed E2F1 did not modulate RAD51 expression after particulate $\mathrm{Cr}(\mathrm{VI})$ exposure directly it would be important to test $\mathrm{E} 2 \mathrm{~F} 1$ binding the RAD51 promotor and its ability to transcribe the RAD51 gene. Investigating this possibility could be accomplished using the ChIP assay and a gene reporter system. It is possible other proteins involved in E2F1-mediated transcription are affected by $\mathrm{Cr}(\mathrm{VI})$ exposure, and thus, are required for successful expression of RAD51. Specifically, the release of E2F1 from the retinoblastoma protein is required for E2F1 to perform its transcriptional function. E2F1 must also associate

with its dimerization protein to enhance transcription. These functions could be tested using proximity ligation assay as well as the ChIP assay. In lung cells E2F1 
may be more important for RAD51 localization at double strand breaks than transcription. This hypothesis could be tested using immunofluorescence assays. Knocking down E2F1 in a direct repeat green fluorescent protein (DR-GFP) reporter system for homologous recombination repair may elucidate if E2F1 is essential for homologous recombination repair after $\mathrm{Cr}(\mathrm{VI})$ exposure. Additionally, we showed E2F4 may play a role in RAD51 repression. It would be interesting to pursue this hypothesis by overexpressing E2F4 or knocking it down to test the effect on RAD51 and homologous recombination repair. Using the ChIP assay to investigate if $\mathrm{Cr}(\mathrm{VI})$ displaces $\mathrm{E} 2 \mathrm{~F} 1$ with $\mathrm{E} 2 \mathrm{~F} 4$ would provide insight into regulation of RAD51 transcription specifically.

In Aim 2, we provided extensive hypothesis-driving data. It will be interesting to compare the results of $\mathrm{Cr}(\mathrm{VI})$-altered miRNAs with miRNAs altered by other metals to better understand mechanisms of metal carcinogenesis. Additionally, looking closer at the miRNAs with the highest fold-change in expression and their targets in more detail warrant further investigation. Validation of some of the differentially expressed miRNAs identified in the RNAseq analysis using qPCR would confirm their change in expression after particulate $\mathrm{Cr}(\mathrm{VI})$ exposure. Additionally, using miRNA mimics of specific miRNAs from the analysis can be used to confirm effects on targets of select miRNAs, and specifically of RAD51. While we investigated specific genes in the homologous recombination pathway predicted to be targeted by $\mathrm{Cr}(\mathrm{VI})$-upregulated miRNAs this type of analysis would be insightful for other pathways in $\mathrm{Cr}(\mathrm{VI})$ carcinogenesis as well.

Finally, further investigation into the mechanisms of genotoxicity in leatherback lung cells warrant further investigation to elucidate differences in DNA 
damage and repair. It will be important to perform cell cycle analysis to determine if $\mathrm{Cr}(\mathrm{VI})$ induces cell cycle arrest. Additionally, measuring RAD51 using western blot analysis may provide a more clear image of how $\operatorname{Cr}(\mathrm{VI})$ affects RAD51 in leatherback lung cells. Additionally, performing time course analysis of DNA repair to characterize the time it takes for leatherback lung cells to repair double strand breaks would be insightful to the dynamics of repair. These data might also explain the results of this study in better detail. 


\section{REFERENCES}

Adachi, Noritaka, Hiromi Suzuki, Susumu liizumi, and Hideki Koyama. "Hypersensitivity of Nonhomologous DNA End-Joining Mutants to VP-16 and ICRF-193 IMPLICATIONS FOR THE REPAIR OF TOPOISOMERASE II-MEDIATED DNA DAMAGE." Journal of Biological Chemistry 278, no. 38 (September 19, 2003): 35897-902. https://doi.org/10.1074/jbc.M306500200.

Agency for Toxic Substances and Disease Registry (ATSDR). Case studies in environmental medicine: Chromium toxicity. U.S. Department of Health and Human Services; Course SS3048 (July 2000).

Agency for Toxic Substances and Disease Registry (ATSDR). A Toxicological Profile for Chromium. U.S. Department of Health and Human Services (September 2012).

Ali, H. Raza, Sarah-Jane Dawson, Fiona M. Blows, Elena Provenzano, Paul D. Pharoah, and Carlos Caldas. "Cancer Stem Cell Markers in Breast Cancer: Pathological, Clinical and Prognostic Significance." Breast Cancer Research 13, no. 6 (November 23, 2011): R118. https://doi.org/10.1186/bcr3061.

Allen, William L., Sally E. Street, and Isabella Capellini. "Fast Life History Traits Promote Invasion Success in Amphibians and Reptiles." Ecology Letters 20, no. 2 (2017): 222-30. https://doi.org/10.1111/ele.12728.

Amunugama, Ravindra, Joanna Groden, and Richard Fishel. "The HsRAD51BHsRAD51C Stabilizes the HsRAD51 Nucleoprotein Filament." DNA Repair 12, no. 9 (September 1, 2013): 723-32. https://doi.org/10.1016/j.dnarep.2013.05.005.

Andrew Angeline S, Warren Amy J, Barchowsky Aaron, Temple Kaili A, Klei Linda, Soucy Nicole V, O'Hara Kimberley A, and Hamilton Joshua W. "Genomic and Proteomic Profiling of Responses to Toxic Metals in Human Lung Cells." Environmental Health Perspectives 111, no. 6 (May 1, 2003): 825-35. https://doi.org/10.1289/ehp.111-1241504.

Anna L. Rowbotham, Linda K. Shuker, Leonard S. Levy. "Chromium in the Environment: An Evaluation of Exposure of the Uk General Population and Possible Adverse Health Effects." Journal of Toxicology and Environmental Health, Part B 3, no. 3 (July 1, 2000): 145-78. https://doi.org/10.1080/10937400050045255.

Arias-Lopez, Carmen, Iciar Lazaro-Trueba, Peter Kerr, Christopher J Lord, Tim Dexter, Marjan Iravani, Alan Ashworth, and Augusto Silva. "P53 Modulates Homologous 
Recombination by Transcriptional Regulation of the RAD51 Gene." EMBO Reports 7, no. 2 (February 1, 2006): 219-24. https://doi.org/10.1038/sj.embor.7400587.

Azad, Neelam, Anand Krishnan V. Iyer, Liying Wang, Yongju Lu, Djordje Medan, Vincent Castranova, and Yon Rojanasakul. "Nitric Oxide-Mediated Bcl-2 Stabilization Potentiates Malignant Transformation of Human Lung Epithelial Cells." American Journal of Respiratory Cell and Molecular Biology 42, no. 5 (May 1, 2010): 578-85. https://doi.org/10.1165/rcmb.2009-00940C.

Bagchi, D., E.A. Hassoun, M. Bagchi, and S.J. Stohs. "Chromium-Induced Excretion of Urinary Lipid Metabolites, DNA Damage, Nitric Oxide Production, and Generation of Reactive Oxygen Species in Sprague-Dawley Rats." Comparative Biochemistry and Physiology Part C: Pharmacology, Toxicology and Endocrinology 110, no. 2 (February 1, 1995): 177-87. https://doi.org/10.1016/0742-8413(94)00093-P.

Barbour, Leslie, and Wei Xiao. "Regulation of Alternative Replication Bypass Pathways at Stalled Replication Forks and Its Effects on Genome Stability: A Yeast Model." Mutation Research/Fundamental and Molecular Mechanisms of Mutagenesis, DNA Replication, the Cell Cycle and Genome Stability, 532, no. 1 (November 27, 2003): 137-55. https://doi.org/10.1016/..mrfmmm.2003.08.014.

Barnhart, Joel. "Occurrences, Uses, and Properties of Chromium." Regulatory Toxicology and Pharmacology 26, no. 1 (August 1, 1997): S3-7. https://doi.org/10.1006/rtph.1997.1132.

Baumann, Peter, Fiona E Benson, and Stephen C West. "Human Rad51 Protein Promotes ATP-Dependent Homologous Pairing and Strand Transfer Reactions In Vitro." Cell 87, no. 4 (November 15, 1996): 757-66. https://doi.org/10.1016/S00928674(00)81394-X.

Bayani, Jane, Shamini Selvarajah, Georges Maire, Bisera Vukovic, Khaldoun AlRomaih, Maria Zielenska, and Jeremy A. Squire. "Genomic Mechanisms and Measurement of Structural and Numerical Instability in Cancer Cells." Seminars in Cancer Biology, Non-random genomic instability in cancer: A fact, not an illusion, 17, no. 11 (February $1, \quad$ 2007): https://doi.org/10.1016/j.semcancer.2006.10.006.

Berkovich, Eli, and Doron Ginsberg. "ATM Is a Target for Positive Regulation by E2F1." Oncogene 22, no. 2 (January 2003): 161-67. https://doi.org/10.1038/sj.onc. 1206144 .

Betel, Doron, Manda Wilson, Aaron Gabow, Debora S. Marks, and Chris Sander. "The MicroRNA.Org Resource: Targets and Expression." Nucleic Acids Research 36, no. suppl_1 (January 1, 2008): D149-53. https://doi.org/10.1093/nar/gkm995.

Betel, Doron, Anjali Koppal, Phaedra Agius, Chris Sander, and Christina Leslie. "Comprehensive Modeling of MicroRNA Targets Predicts Functional NonConserved and Non-Canonical Sites." Genome Biology 11, no. 8 (August 27, 2010): R90. https://doi.org/10.1186/gb-2010-11-8-r90. 
Bindra, R. S., and P. M. Glazer. "Repression of RAD51 Gene Expression by E2F4/P130 Complexes in Hypoxia." Oncogene 26, no. 14 (March 2007): 2048-57. https://doi.org/10.1038/sj.onc.1210001.

Biswas, Anup K., and David G. Johnson. "Transcriptional and Nontranscriptional Functions of E2F1 in Response to DNA Damage." Cancer Research 72, no. 1 (January 1, 2012): 13-17. https://doi.org/10.1158/0008-5472.CAN-11-2196.

Borges, Kim M., John S. Boswell, Robert H. Liebross, and Karen E. Wetterhahn. "Activation of Chromium(VI) by Thiols Results in Chromium(V) Formation, Chromium Binding to DNA and Altered DNA Conformation." Carcinogenesis 12, no. 4 (April 1, 1991): 551-61. https://doi.org/10.1093/carcin/12.4.551.

Blankenship, L. J., F. C. R. Manning, J. M. Orenstein, and S. R. Patierno. "Apoptosis Is the Mode of Cell Death Caused by Carcinogenic Chromium." Toxicology and Applied Pharmacology 126, no. 1 (May 1, 1994): 75-83. https://doi.org/10.1006/taap.1994.1092.

Bowen, H. J. M. "Environmental Chemistry of the Elements." Environmental Chemistry of the Elements., 1979. https://www.cabdirect.org/cabdirect/abstract/19800700395.

Broughton, James P., Michael T. Lovci, Jessica L. Huang, Gene W. Yeo, and Amy E. Pasquinelli. "Pairing beyond the Seed Supports MicroRNA Targeting Specificity." Molecular Cell 64, no. 2 (October 20, 2016): 320-33. https://doi.org/10.1016/i.molcel.2016.09.004.

Browning, Cynthia L., Qin Qin, Deborah F. Kelly, Rohit Prakash, Fabio Vanoli, Maria Jasin, and John Pierce Wise. "Prolonged Particulate Hexavalent Chromium Exposure Suppresses Homologous Recombination Repair in Human Lung Cells." Toxicological Sciences 153, no. 1 (September 1, 2016): 70-78. https://doi.org/10.1093/toxsci/kfw103.

Browning, Cynthia L., Rachel M. Speer, and John Pierce Wise. "Molecular Mechanisms of Chromium-Induced Carcinogenesis." In Essential and Non-Essential Metals: Carcinogenesis, Prevention and Cancer Therapeutics, edited by Anuradha Mudipalli and Judith T. Zelikoff, 143-80. Molecular and Integrative Toxicology. Cham: Springer International Publishing, 2017a. https://doi.org/10.1007/978-3319-55448-8 7.

Browning, Cynthia L., Catherine F. Wise, and John Pierce Wise. "Prolonged Particulate Chromate Exposure Does Not Inhibit Homologous Recombination Repair in North Atlantic Right Whale (Eubalaena Glacialis) Lung Cells." Toxicology and Applied Pharmacology, Recent advances in metal toxicity and carcinogenesis research, 331 (September 15, 2017b): 18-23. https://doi.org/10.1016/j.taap.2017.04.006.

Bruno, Maribel, Jeffrey Ross, and Yue Ge. "Proteomic Responses of BEAS-2B Cells to Nontoxic and Toxic Chromium: Protein Indicators of Cytotoxicity Conversion." Toxicology Letters 264 (December 15, 2016): 59-70. https://doi.org/10.1016/j.toxlet.2016.08.025. 
Bryant, Helen E., Songmin Ying, and Thomas Helleday. "Homologous Recombination Is Involved in Repair of Chromium-Induced DNA Damage in Mammalian Cells." Mutation Research/Fundamental and Molecular Mechanisms of Mutagenesis 599, no. 1 (July 25, 2006): 116-23. https://doi.org/10.1016/j.mrfmmm.2006.02.001.

Buchhop, Sabine, Michael K. Gibson, Xin W. Wang, Peter Wagner, Horst-Werner Stürzbecher, and Curtis C. Harris. "Interaction of P53 with the Human Rad51 Protein." Nucleic Acids Research 25, no. 19 (October 1, 1997): 3868-74. https://doi.org/10.1093/nar/25.19.3868.

Caglieri Andrea, Goldoni Matteo, Acampa Olga, Andreoli Roberta, Vettori Maria Vittoria, Corradi Massimo, Apostoli Pietro, and Mutti Antonio. "The Effect of Inhaled Chromium on Different Exhaled Breath Condensate Biomarkers among ChromePlating Workers." Environmental Health Perspectives 114, no. 4 (April 1, 2006): 542-46. https://doi.org/10.1289/ehp.8506.

Cai, Qinhong, Tsz-Wai Ng, Kin-Hang Wong, Po-Keung Wong, Ya Xiong, Yonghua Wang, and Ying Zhang. "Speciation of $\operatorname{Cr}(\mathrm{III})$ and $\mathrm{Cr}(\mathrm{VI})$ in the Presence of Chromium Azo Dye Acid Yellow 99 by Column Solid Phase Extraction." In 2012 International Conference on Biomedical Engineering and Biotechnology, 1684-87, 2012. https://doi.org/10.1109/iCBEB.2012.360.

Camyre, Eric, Sandra S. Wise, Peter Milligan, Nancy Gordon, Britton Goodale, Megan Stackpole, Natalie Patzlaff, AbouEl-Makarim Aboueissa, and John Pierce Wise. "Ku80 Deficiency Does Not Affect Particulate Chromate-Induced Chromosome Damage and Cytotoxicity in Chinese Hamster Ovary Cells." Toxicological Sciences 97, no. 2 (June 1, 2007): 348-54. https://doi.org/10.1093/toxsci/kfm045.

Canman, Christine E., and Michael B. Kastan. "Role of P53 in Apoptosis." In Advances in Pharmacology, edited by Scott H. Kaufmann, 41:429-60. Apoptosls. Academic Press, 1997. https://doi.org/10.1016/S1054-3589(08)61068-6.

Cao, Yan, Shi-Liang Yu, Yan Wang, Gui-Ying Guo, Qiang Ding, and Rui-Hua An. "MicroRNA-Dependent Regulation of PTEN after Arsenic Trioxide Treatment in Bladder Cancer Cell Line T24." Tumor Biology 32, no. 1 (February 1, 2011): 179_ 88. https://doi.org/10.1007/s13277-010-0111-z.

Caulin, Aleah F., and Carlo C. Maley. "Peto's Paradox: Evolution's Prescription for Cancer Prevention." Trends in Ecology \& Evolution 26, no. 4 (April 1, 2011): 17582. https://doi.org/10.1016/j.tree.2011.01.002.

Cespón-Romero, R.M., M.C. Yebra-Biurrun, and M.P. Bermejo-Barrera. "Preconcentration and Speciation of Chromium by the Determination of Total Chromium and Chromium(III) in Natural Waters by Flame Atomic Absorption Spectrometry with a Chelating lon-Exchange Flow Injection System." Analytica Chimica Acta 327, no. 1 (June 20, 1996): 37-45. https://doi.org/10.1016/00032670(96)00062-1.

Chandra, Swati, Ashutosh Pandey, and Debapratim Kar Chowdhuri. "MiRNA Profiling Provides Insights on Adverse Effects of $\mathrm{Cr}(\mathrm{VI})$ in the Midgut Tissues of Drosophila 
Melanogaster." Journal of Hazardous Materials 283 (February 11, 2015): 558-67. https://doi.org/10.1016/j.jhazmat.2014.09.054.

"Characterisation of the Promoter Region of the Human DNA-Repair Gene Rad51. Abstract - Europe PMC." Accessed June 5, 2020. https://europepmc.org/article/med/16398215.

Chen, Danqi, Thomas Kluz, Lei Fang, Xiaoru Zhang, Hong Sun, Chunyuan Jin, and Max Costa. "Hexavalent Chromium $(\mathrm{Cr}(\mathrm{VI}))$ Down-Regulates Acetylation of Histone H4 at Lysine 16 through Induction of Stressor Protein Nupr1." PLOS ONE 11, no. 6 (June 10, 2016). https://doi.org/10.1371/journal.pone.0157317.

Chen, Jie, Feng Zhu, Regina L. Weaks, Anup K. Biswas, Ruifeng Guo, Yanjie Li, and David G. Johnson. "E2F1 Promotes the Recruitment of DNA Repair Factors to Sites of DNA Double-Strand Breaks." Cell Cycle 10, no. 8 (April 15, 2011): 128794. https://doi.org/10.4161/cc.10.8.15341.

Chen, Qiao Yi, Thomas DesMarais, and Max Costa. "Metals and Mechanisms of Carcinogenesis." Annual Review of Pharmacology and Toxicology 59, no. 1 (2019): 537-54. https://doi.org/10.1146/annurev-pharmtox-010818-021031.

Cheng, Hongguang, Tan Zhou, Qian Li, Lu Lu, and Chunye Lin. "Anthropogenic Chromium Emissions in China from 1990 to 2009." PloS One 9, no. 2 (February 5, 2014): e87753-e87753. https://doi.org/10.1371/journal.pone.0087753.

Chiari, Ylenia, Scott Glaberman, and Vincent J. Lynch. "Insights on Cancer Resistance in Vertebrates: Reptiles as a Parallel System to Mammals." Nature Reviews Cancer 18, no. 8 (August 2018): 525-525. https://doi.org/10.1038/s41568-0180033-4.

Choi, Eui-Hwan, and Keun Pil Kim. "E2F1 Facilitates DNA Break Repair by Localizing to Break Sites and Enhancing the Expression of Homologous Recombination Factors." Experimental \& Molecular Medicine 51, no. 9 (September 2019): 1-12. https://doi.org/10.1038/s12276-019-0307-2.

Christie, Mary, Chiung-Wen Chang, Gergely Róna, Kate M. Smith, Alastair G. Stewart, Agnes A. S. Takeda, Marcos R. M. Fontes, et al. "Structural Biology and Regulation of Protein Import into the Nucleus." Journal of Molecular Biology, Functional and Mechanistic Landscape of the Nuclear Pore Complex, 428, no. 10, Part A (May 22, 2016): 2060-90. https://doi.org/10.1016/j.jmb.2015.10.023.

Clancy, Hailey A., Hong Sun, Lisa Passantino, Thomas Kluz, Alexandra Muñoz, Jiri Zavadil, and Max Costa. "Gene Expression Changes in Human Lung Cells Exposed to Arsenic, Chromium, Nickel or Vanadium Indicate the First Steps in Cancer." Metallomics 4, no. 8 (July 25, 2012): 784-93. https://doi.org/10.1039/C2MT20074K.

Clementino, Marco, Xianglin Shi, and Zhuo Zhang. "Oxidative Stress and Metabolic Reprogramming in $\mathrm{Cr}(\mathrm{VI})$ Carcinogenesis." Current Opinion in Toxicology, Mechanistic Toxicology: Metabolic Disruption in Environmental Diseases, 8 (April 1, 2018): 20-27. https://doi.org/10.1016/..cotox.2017.11.015. 
Constantinou, Angelos, Adelina A Davies, and Stephen C West. "Branch Migration and Holliday Junction Resolution Catalyzed by Activities from Mammalian Cells." Cell 104, no. 2 (January 26, 2001): 259-68. https://doi.org/10.1016/S00928674(01)00210-0.

Cupo, D. Y., and K. E. Wetterhahn. "Modification of Chromium(VI)-Induced DNA Damage by Glutathione and Cytochromes P-450 in Chicken Embryo Hepatocytes." Proceedings of the National Academy of Sciences 82, no. 20 (October 1, 1985): 6755-59. https://doi.org/10.1073/pnas.82.20.6755.

D'Amours, Damien, and Stephen P. Jackson. "The MRE11 Complex: At the Crossroads of DNA Repair and Checkpoint Signalling." Nature Reviews Molecular Cell Biology 3, no. 5 (May 2002): 317-27. https://doi.org/10.1038/nrm805.

Danadevi, K., Roya Rozati, B. Saleha Banu, and Paramjit Grover. "Genotoxic Evaluation of Welders Occupationally Exposed to Chromium and Nickel Using the Comet and Micronucleus Assays." Mutagenesis 19, no. 1 (January 1, 2004): 3541. https://doi.org/10.1093/mutage/geh001.

Davies, J M. "Lung Cancer Mortality among Workers Making Lead Chromate and Zinc Chromate Pigments at Three English Factories." British Journal of Industrial Medicine 41, no. 2 (May 1, 1984): 158. https://doi.org/10.1136/oem.41.2.158.

Davies, J M, D F Easton, and P L Bidstrup. "Mortality from Respiratory Cancer and Other Causes in United Kingdom Chromate Production Workers." British Journal of Industrial Medicine 48, no. 5 (May 1, 1991): 299. https://doi.org/10.1136/oem.48.5.299.

De Flora, S., A. Camoirano, M. Bagnasco, C. Bennicelli, G. E. Corbett, and B. D. Kerger. "Estimates of the Chromium(VI) Reducing Capacity in Human Body Compartments as a Mechanism for Attenuating Its Potential Toxicity and Carcinogenicity." Carcinogenesis 18, no. 3 (March 1, 1997): 531-37. https://doi.org/10.1093/carcin/18.3.531.

De Flora, Silvio, Alberto Izzotti, Kurt Randerath, Erika Randerath, Helmut Bartsch, Jagadeesan Nair, Roumen Balansky, et al. "DNA Adducts and Chronic Degenerative Diseases. Pathogenetic Relevance and Implications in Preventive Medicine." Mutation Research/Reviews in Genetic Toxicology 366, no. 3 (December 27, 1996): 197-238. https://doi.org/10.1016/S0165-1110(96)00043-7.

"Deciphering the Retinoblastoma Protein Phosphorylation Code." Trends in Biochemical Sciences 38, no. 1 (January 1, 2013): 12-19. https://doi.org/10.1016/j.tibs.2012.10.007.

DeLoughery, Zachary, Michal W. Luczak, Sara Ortega-Atienza, and Anatoly Zhitkovich. "DNA Double-Strand Breaks by $\mathrm{Cr}(\mathrm{VI})$ Are Targeted to Euchromatin and Cause ATR-Dependent Phosphorylation of Histone H2AX and Its Ubiquitination." Toxicological Sciences 143, no. 1 (January 1, 2015): 54-63. https://doi.org/10.1093/toxsci/kfu207. 
DesMarias, Thomas Liborio, and Max Costa. "Mechanisms of Chromium-Induced Toxicity." Current Opinion in Toxicology, Mechanistic Toxicology, 14 (April 1, 2019): $1-7$. https://doi.org/10.1016/i.cotox.2019.05.003.

Devoy, Jérôme, Antoine Géhin, Samuel Müller, Mathieu Melczer, Aurélie Remy, Guillaume Antoine, and Isabelle Sponne. "Evaluation of Chromium in Red Blood Cells as an Indicator of Exposure to Hexavalent Chromium: An in Vitro Study." Toxicology Letters 255 (July 25, 2016): 63-70. https://doi.org/10.1016/.jtoxlet.2016.05.008.

Dillehay, Larry E., David Jacobson-Kram, and Jerry R. Williams. "DNA Topoisomerases and Models of Sister-Chromatid Exchange." Mutation Research/Fundamental and Molecular Mechanisms of Mutagenesis 215, no. 1 (November 1, 1989): 15-23. https://doi.org/10.1016/0027-5107(89)90213-3.

Donaldson, Robert M., and Robert F. Barreras. "Intestinal Absorption of Trace Quantities of Chromium." The Journal of Laboratory and Clinical Medicine 68, no. 3 (September 1, 1966): 484-93. https://doi.org/10.5555/uri:pii:0022214366901028.

Engeland, Kurt. "Cell Cycle Arrest through Indirect Transcriptional Repression by P53: I Have a DREAM." Cell Death \& Differentiation 25, no. 1 (January 2018): 114-32. https://doi.org/10.1038/cdd.2017.172.

Enright, Anton J., Bino John, Ulrike Gaul, Thomas Tuschl, Chris Sander, and Debora S. Marks. "MicroRNA Targets in Drosophila." Genome Biology 5, no. 1 (December 12, 2003): R1. https://doi.org/10.1186/gb-2003-5-1-r1.

Ewis, Ashraf A., Kazuya Kondo, Fuquan Dang, Yutaka Nakahori, Yasuo Shinohara, Mitsuru Ishikawa, and Yoshinobu Baba. "Surfactant Protein B Gene Variations and Susceptibility to Lung Cancer in Chromate Workers." American Journal of Industrial Medicine 49, no. 5 (2006): 367-73. https://doi.org/10.1002/ajim.20283.

Ewis, Ashraf A., Kazuya Kondo, Juwon Lee, Masaru Tsuyuguchi, Masato Hashimoto, Tomoyuki Yokose, Kiyoshi Mukai, et al. "Occupational Cancer Genetics: Infrequent Ras Oncogenes Point Mutations in Lung Cancer Samples from Chromate Workers." American Journal of Industrial Medicine 40, no. 1 (2001): 92 97. https://doi.org/10.1002/ajim.1075.

Falcone, Lauryn M., Aaron Erdely, Terence G. Meighan, Lori A. Battelli, Rebecca Salmen, Walter McKinney, Samuel Stone, et al. "Inhalation of Gas Metal ArcStainless Steel Welding Fume Promotes Lung Tumorigenesis in A/J Mice." Archives of Toxicology 91, no. 8 (August 1, 2017): 2953-62. https://doi.org/10.1007/s00204-016-1909-2.

Fantini, Cristina, Patrizia Vernole, Bruna Tedeschi, and Daniela Caporossi. "Sister Chromatid Exchanges and DNA Topoisomerase II Inhibitors: Effect of Low Concentrations of Etoposide (VP-16) in Ataxia Telangiectasia Lymphoblastoid Cell Lines." Mutation Research/Genetic Toxicology and Environmental Mutagenesis 
412, no. 1 (January 13, 1998): 1-7. https://doi.org/10.1016/S1383-5718(97)00143$\underline{5}$.

Finnegan, E. Jean, and Marjori A. Matzke. "The Small RNA World." Journal of Cell Science 116, no. 23 (December 1, 2003): 4689-93. https://doi.org/10.1242/jcs.00838.

Fischer, Martin, Lydia Steiner, and Kurt Engeland. "The Transcription Factor P53: Not a Repressor, Solely an Activator." Cell Cycle 13, no. 19 (October 1, 2014): 303758. https://doi.org/10.4161/15384101.2014.949083.

Fishbein, Lawrence. "Environmental Metallic Carcinogens: An Overview of Exposure Levels." Journal of Toxicology and Environmental Health 2, no. 1 (September 1, 1976): 77-109. https://doi.org/10.1080/15287397609529419.

Forget, Anthony L., and Stephen C. Kowalczykowski. "Single-Molecule Imaging Brings Rad51 Nucleoprotein Filaments into Focus." Trends in Cell Biology 20, no. 5 (May 1, 2010): 269-76. https://doi.org/10.1016/j.tcb.2010.02.004.

Friedman, Jeffrey M., and Peter A. Jones. "MicroRNAs: Critical Mediators of Differentiation, Development and Disease." Swiss Medical Weekly 139, no. 33-34 (August 22, 2009): 466-72.

Gasparini, Pierluigi, Francesca Lovat, Matteo Fassan, Lucia Casadei, Luciano Cascione, Naduparambil K. Jacob, Stefania Carasi, et al. "Protective Role of MiR155 in Breast Cancer through RAD51 Targeting Impairs Homologous Recombination after Irradiation." Proceedings of the National Academy of Sciences 111, no. 12 (March 25, 2014): 4536-41. https://doi.org/10.1073/pnas.1402604111.

Gastaldo, Jérôme, Muriel Viau, Zuzana Bencokova, Aurélie Joubert, Anne-Marie Charvet, Jacques Balosso, and Nicolas Foray. "Lead Contamination Results in Late and Slowly Repairable DNA Double-Strand Breaks and Impacts upon the ATM-Dependent Signaling Pathways." Toxicology Letters 173, no. 3 (September 28, 2007): 201-14. https://doi.org/10.1016/j.toxlet.2007.08.003.

Gavin, Igor M., Bruce Gillis, Zarema Arbieva, and Bellur S. Prabhakar. "Identification of Human Cell Responses to Hexavalent Chromium." Environmental and Molecular Mutagenesis 48, no. 8 (2007): 650-57. https://doi.org/10.1002/em.20331.

Gibb, Herman J., Peter S. J. Lees, Paul F. Pinsky, and Brian C. Rooney. "Lung Cancer among Workers in Chromium Chemical Production." American Journal of Industrial Medicine 38, no. 2 (August 1, 2000): 115-26. https://doi.org/10.1002/10970274(200008)38:2<115::AID-AJIM1>3.0.CO;2-Y.

Gibb, Herman Jones, Peter St. John Lees, Jing Wang, and Keri Grace O'Leary. "Extended Followup of a Cohort of Chromium Production Workers." American Journal of Industrial Medicine 58, no. 8 (August 1, 2015): 905-13. https://doi.org/10.1002/ajim.22479. 
Gibbs, E. Paul J. "The Evolution of One Health: A Decade of Progress and Challenges for the Future." Veterinary Record 174, no. 4 (January 25, 2014): 85-91. https://doi.org/10.1136/vr.g143.

Gildemeister, Otto S., Jay M. Sage, and Kendall L. Knight. "Cellular Redistribution of Rad51 in Response to DNA Damage NOVEL ROLE FOR Rad51C." Journal of Biological Chemistry 284, no. 46 (November 13, 2009): 31945-52. https://doi.org/10.1074/jbc.M109.024646.

Glorian, Valérie, Jennifer Allègre, Jean Berthelet, Baptiste Dumetier, Pierre-Marie Boutanquoi, Nathalie Droin, Cémile Kayaci, et al. "DNA Damage and S PhaseDependent E2F1 Stabilization Requires the CIAP1 E3-Ubiquitin Ligase and Is Associated with K63-Poly-Ubiquitination on Lysine 161/164 Residues." Cell Death \& Disease 8, no. 5 (May 2017): e2816-e2816. https://doi.org/10.1038/cddis.2017.222.

Glozak, Michele A., Nilanjan Sengupta, Xiaohong Zhang, and Edward Seto. "Acetylation and Deacetylation of Non-Histone Proteins." Gene 363 (December 19, 2005): 15-23. https://doi.org/10.1016/i.gene.2005.09.010.

Godley, Brendan J., David R. Thompson, and Robert W. Furness. "Do Heavy Metal Concentrations Pose a Threat to Marine Turtles from the Mediterranean Sea?" Marine Pollution Bulletin 38, no. 6 (June 1, 1999): 497-502. https://doi.org/10.1016/S0025-326X(98)00184-2.

Goldoni, Matteo, Andrea Caglieri, Giuseppe De Palma, Olga Acampa, Petra Gergelova, Massimo Corradi, Pietro Apostoli, and Antonio Mutti. "Chromium in Exhaled Breath Condensate (EBC), Erythrocytes, Plasma and Urine in the Biomonitoring of Chrome-Plating Workers Exposed to Soluble $\mathrm{Cr}(\mathrm{VI})$." Journal of Environmental Monitoring 12, no. 2 (February 10, 2010): 442-47. https://doi.org/10.1039/B914673C.

Goldoni, Matteo, Andrea Caglieri, Diana Poli, Maria Vittoria Vettori, Massimo Corradi, Pietro Apostoli, and Antonio Mutti. "Determination of Hexavalent Chromium in Exhaled Breath Condensate and Environmental Air among Chrome Plating Workers." Analytica Chimica Acta 562, no. 2 (March 15, 2006): 229-35. https://doi.org/10.1016/j.aca.2006.01.065.

Grimson, Andrew, Kyle Kai-How Farh, Wendy K. Johnston, Philip Garrett-Engele, Lee P. Lim, and David P. Bartel. "MicroRNA Targeting Specificity in Mammals: Determinants beyond Seed Pairing." Molecular Cell 27, no. 1 (July 6, 2007): 91 105. https://doi.org/10.1016/j.molcel.2007.06.017.

Güerci, A., A. Seoane, and F. N. Dulout. "Aneugenic Effects of Some Metal Compounds Assessed by Chromosome Counting in MRC-5 Human Cells." Mutation Research/Genetic Toxicology and Environmental Mutagenesis 469, no. 1 (August 21, 2000): 35-40. https://doi.org/10.1016/S1383-5718(00)00057-7.

Guirlet, Elodie, Krishna Das, and Marc Girondot. "Maternal Transfer of Trace Elements in Leatherback Turtles (Dermochelys Coriacea) of French Guiana." Aquatic 
Toxicology 88, no. 4 (July 30, 2008): 267-76. https://doi.org/10.1016/j.aquatox.2008.05.004.

Guirlet, Elodie, Krishna Das, Jean-Pierre Thomé, and Marc Girondot. "Maternal Transfer of Chlorinated Contaminants in the Leatherback Turtles, Dermochelys Coriacea, Nesting in French Guiana." Chemosphere 79, no. 7 (April 1, 2010): 720 26. https://doi.org/10.1016/i.chemosphere.2010.02.047.

Gunaratnam, Mekala, and M. Helen Grant. " $\mathrm{Cr}$ (VI) Inhibits DNA, RNA and Protein Syntheses in Hepatocytes: Involvement of Glutathione Reductase, Reduced Glutathione and DT-Diaphorase." Toxicology in Vitro 22, no. 4 (June 1, 2008): 879-86. https://doi.org/10.1016/.tiv.2008.01.005.

Guzman, Hector M., Stefanie Kaiser, and Vincent J. van Hinsberg. "Accumulation of Trace Elements in Leatherback Turtle (Dermochelys Coriacea) Eggs from the South-Western Caribbean Indicates Potential Health Risks to Consumers." $\begin{array}{llll}\text { Chemosphere } 243 \quad \text { (March } 1, & 2020):\end{array}$ https://doi.org/10.1016/j.chemosphere.2019.125424.

Ha, Linan, Susan Ceryak, and Steven R. Patierno. "Generation of S Phase-Dependent DNA Double-Strand Breaks by $\mathrm{Cr}(\mathrm{VI})$ Exposure: Involvement of ATM in $\mathrm{Cr}(\mathrm{VI})$ Induction of $\mathrm{y}-\mathrm{H} 2 \mathrm{AX}$." Carcinogenesis 25, no. 11 (November 1, 2004): 2265-74. https://doi.org/10.1093/carcin/bgh242.

$\mathrm{Ha}$, Minju, and V. Narry Kim. "Regulation of MicroRNA Biogenesis." Nature Reviews Molecular Cell Biology 15, no. 8 (August 2014): 509-24. https://doi.org/10.1038/nrm3838.

Halasova, E., M. Adamkov, T. Matakova, E. Kavcova, I. Poliacek, and A. Singliar. "Lung Cancer Incidence and Survival in Chromium Exposed Individuals with Respect to Expression of Anti-Apoptotic Protein Survivin and Tumor Suppressor P53 Protein." European Journal of Medical Research 15, no. 2 (November 4, 2010): 55. https://doi.org/10.1186/2047-783X-15-S2-55.

Hannay, Jonathan A. F., Juehui Liu, Quan-Sheng Zhu, Svetlana V. Bolshakov, Lan Li, Peter W. T. Pisters, Alexander J. F. Lazar, Dihua Yu, Raphael E. Pollock, and Dina Lev. "Rad51 Overexpression Contributes to Chemoresistance in Human Soft Tissue Sarcoma Cells: A Role for P53/Activator Protein 2 Transcriptional Regulation." Molecular Cancer Therapeutics 6, no. 5 (May 1, 2007): 1650-60. https://doi.org/10.1158/1535-7163.MCT-06-0636.

Hannon, G.J. (2010) FASTX-Toolkit. http://hannonlab.cshl.edu/fastx_toolkit.

Harris, Valerie K., Joshua D. Schiffman, and Amy M. Boddy. "Chapter 7 - Evolution of Cancer Defense Mechanisms Across Species." In Ecology and Evolution of Cancer, edited by Beata Ujvari, Benjamin Roche, and Frédéric Thomas, 99-110. Academic Press, 2017. https://doi.org/10.1016/B978-0-12-804310-3.00007-7.

Hawley, Dana M., Erik E. Osnas, Andrew P. Dobson, Wesley M. Hochachka, David H. Ley, and André A. Dhondt. "Parallel Patterns of Increased Virulence in a Recently 
Emerged Wildlife Pathogen." PLoS Biology 11, no. 5 (May 28, 2013). https://doi.org/10.1371/journal.pbio.1001570.

He, Jun, Xu Qian, Richard Carpenter, Qing Xu, Lin Wang, Yanting Qi, Zi-Xuan Wang, Ling-Zhi Liu, and Bing-Hua Jiang. "Repression of MiR-143 Mediates Cr (VI)Induced Tumor Angiogenesis via IGF-IR/IRS1/ERK/IL-8 Pathway." Toxicological Sciences 134, no. 1 (July 1, 2013): 26-38. https://doi.org/10.1093/toxsci/kft101.

Hegan, Denise Campisi, Yuhong Lu, Gregory C. Stachelek, Meredith E. Crosby, Ranjit S. Bindra, and Peter M. Glazer. "Inhibition of Poly(ADP-Ribose) Polymerase downRegulates BRCA1 and RAD51 in a Pathway Mediated by E2F4 and P130." Proceedings of the National Academy of Sciences 107, no. 5 (February 2, 2010): 2201-6. https://doi.org/10.1073/pnas.0904783107.

Helleday, Thomas, Robert Nilsson, and Dag Jenssen. "Arsenic[III] and Heavy Metal Ions Induce Intrachromosomal Homologous Recombination in the Hprt Gene of V79 Chinese Hamster Cells." Environmental and Molecular Mutagenesis 35, no. 2 (2000): 114-22. https://doi.org/10.1002/(SICI)1098-2280(2000)35:2<114::AIDEM6>3.0.CO;2-Q.

Hine, Christopher M., Hongjie Li, Li Xie, Zhiyong Mao, Andrei Seluanov, and Vera Gorbunova. "Regulation of Rad51 Promoter." Cell Cycle 13, no. 13 (July 1, 2014): 2038-45. https://doi.org/10.4161/cc.29016.

Hirose, Toshiyuki, Kazuya Kondo, Yuji Takahashi, Hisashi Ishikura, Haruhiko Fujino, Masaru Tsuyuguchi, Masato Hashimoto, et al. "Frequent Microsatellite Instability in Lung Cancer from Chromate-Exposed Workers." Molecular Carcinogenesis 33, no. 3 (2002): 172-80. https://doi.org/10.1002/mc.10035.

Hodges, N. J., and J. K. Chipman. "Down-Regulation of the DNA-Repair Endonuclease 8-Oxo-Guanine DNA Glycosylase 1 ( HOGG1) by Sodium Dichromate in Cultured Human A549 Lung Carcinoma Cells." Carcinogenesis 23, no. 1 (January 1, 2002): 55-60. https://doi.org/10.1093/carcin/23.1.55.

Holmes, Amie, S. Wise, and John Wise. "Carcinogenicity of Hexavalent Chromium." Indian Journal Of Medical Research, October 1, 2008. https://digitalcommons.usm.maine.edu/appmedsci/3.

$\mathrm{Hu}$, Guiping, Ping Li, Xiaoxing Cui, Yang Li, Ji Zhang, Xinxiao Zhai, Shanfa Yu, et al. "Cr(VI)-Induced Methylation and down-Regulation of DNA Repair Genes and Its Association with Markers of Genetic Damage in Workers and 16HBE Cells." Environmental Pollution 238 (July 1, 2018): 833-43. https://doi.org/10.1016/j.envpol.2018.03.046.

$\mathrm{Hu}$, Guiping, Ping Li, Yang Li, Tiancheng Wang, Xin Gao, Wenxiao Zhang, and Guang Jia. "Methylation Levels of P16 and TP53 That Are Involved in DNA Strand Breakage of 16HBE Cells Treated by Hexavalent Chromium." Toxicology Letters 249 (May 13, 2016): 15-21. https://doi.org/10.1016/j.toxlet.2016.03.003. 
Hu, Guiping, Pai Zheng, Huimin Feng, and Guang Jia. "Imbalance of Oxidative and Reductive Species Involved in Chromium(VI)-Induced Toxic Effects." Reactive Oxygen Species, 2017. https://doi.org/10.20455/ros.2017.803.

Huang, Jen-Wei, Yemin Wang, Kiranjit K. Dhillon, Philamer Calses, Emily Villegas, Patrick S. Mitchell, Muneesh Tewari, Christopher J. Kemp, and Toshiyasu Taniguchi. "Systematic Screen Identifies MiRNAs That Target RAD51 and RAD51D to Enhance Chemosensitivity." Molecular Cancer Research 11, no. 12 (December 1, 2013): 1564-73. https://doi.org/10.1158/1541-7786.MCR-13-0292.

Hubbard, G. B., R. E. Schmidt, and K. C. Fletcher. "Neoplasia in Zoo Animals." The Journal of Zoo Animal Medicine 14, no. 1 (1983): 33-40. https://doi.org/10.2307/20094627.

Hunt, Sarah E., William McLaren, Laurent Gil, Anja Thormann, Helen Schuilenburg, Dan Sheppard, Andrew Parton, et al. "Ensembl Variation Resources." Database 2018 (January 1, 2018). https://doi.org/10.1093/database/bay119.

Hwang, Sung Ho, Jae Bum Park, and Kyung Jong Lee. "Exposure Assessment of Particulate Matter and Blood Chromium Levels in People Living near a Cement Plant." Environmental Geochemistry and Health 40, no. 4 (August 1, 2018): 123746. https://doi.org/10.1007/s10653-017-0039-y.

Ianari, Alessandra, Rita Gallo, Marzia Palma, Edoardo Alesse, and Alberto Gulino. "Specific Role for P300/CREB-Binding Protein-Associated Factor Activity in E2F1 Stabilization in Response to DNA Damage." Journal of Biological Chemistry 279, no. 29 (July 16, 2004): 30830-35. https://doi.org/10.1074/jbc.M402403200.

International Agency for Research on Cancer. IARC monographs on the evaluation of carcinogenic risks to humans: chromium, nickel and welding Volume 49 (1990).

International Agency for Research on Cancer. Chromium and chromium compounds. In Some Metals and Metallic Compounds. IARC Monographs on the Evaluation of Carcinogenic Risk of Chemicals to Humans, vol. 23. Lyon, France: International Agency for Research on Cancer. pp. 205-323 (1980).

Ishikawa, Y., K. Nakagawa, Y. Satoh, T. Kitagawa, H. Sugano, T. Hirano, and E. Tsuchiya. "Characteristics of Chromate Workers' Cancers, Chromium Lung Deposition and Precancerous Bronchial Lesions: An Autopsy Study." British Journal of Cancer 70, no. 1 (July 1994): 160-66. https://doi.org/10.1038/bjc.1994.268.

Ishikawa, Yuichi, Ken Nakagawa, Yukitoshi Satoh, Tomoyuki Kitagawa, Haruo Sugano, Toshio Hirano, and Eiju Tsuchiya. "'Hot Spots' of Chromium Accumulation at Bifurcations of Chromate Workers' Bronchi." Cancer Research 54, no. 9 (May 1, 1994): 2342-46.

Izzotti, Alberto, Cristina Cartiglia, Roumen Balansky, Francesco D'Agostini, Mariagrazia Longobardi, and Silvio De Flora. "Selective Induction of Gene Expression in Rat Lung by Hexavalent Chromium." Molecular Carcinogenesis 35, no. 2 (2002): 75-84. https://doi.org/10.1002/mc.10077. 
Jaber, Sara, Eléonore Toufektchan, Vincent Lejour, Boris Bardot, and Franck Toledo. "P53 Downregulates the Fanconi Anaemia DNA Repair Pathway." Nature Communications 7, no. 1 (April 1, 2016): 11091. https://doi.org/10.1038/ncomms11091.

Jensen, Ryan B., Aura Carreira, and Stephen C. Kowalczykowski. "Purified Human BRCA2 Stimulates RAD51-Mediated Recombination." Nature 467, no. 7316 (October 2010): 678-83. https://doi.org/10.1038/nature09399.

Jeyasekharan, Anand D., Yang Liu, Hiroyoshi Hattori, Venkat Pisupati, Asta Bjork Jonsdottir, Eeson Rajendra, Miyoung Lee, et al. "A Cancer-Associated BRCA2 Mutation Reveals Masked Nuclear Export Signals Controlling Localization." Nature Structural \& Molecular Biology 20, no. 10 (October 2013): 1191-98. https://doi.org/10.1038/nsmb.2666.

Johnson, D. G., K. Ohtani, and J. R. Nevins. "Autoregulatory Control of E2F1 Expression in Response to Positive and Negative Regulators of Cell Cycle Progression." Genes \& Development 8, no. 13 (July 1, 1994): 1514-25. https://doi.org/10.1101/gad.8.13.1514.

Kachhap, Sushant K., Nadine Rosmus, Spencer J. Collis, Madeleine S. Q. Kortenhorst, Michel D. Wissing, Mohammad Hedayati, Shabana Shabbeer, et al. "Downregulation of Homologous Recombination DNA Repair Genes by HDAC Inhibition in Prostate Cancer Is Mediated through the E2F1 Transcription Factor." PLoS ONE 5, no. 6 (June 18, 2010). https://doi.org/10.1371/journal.pone.0011208.

Kano, Katsumi, Mayumi Horikawa, Tadao Utsunomiya, Masatomo Tati, Kunihiro Satoh, and Seiya Yamaguchi. "Lung Cancer Mortality among a Cohort of Male Chromate Pigment Workers in Japan." International Journal of Epidemiology 22, no. 1 (February 1, 1993): 16-22. https://doi.org/10.1093/ije/22.1.16.

Kantidze, Omar L., and Sergey V. Razin. "Chemotherapy-Related Secondary Leukemias: A Role for DNA Repair by Error-Prone Non-Homologous End Joining in Topoisomerase II - Induced Chromosomal Rearrangements." Gene 391, no. 1 (April 15, 2007): 76-79. https://doi.org/10.1016/i.gene.2006.12.006.

Katabami, Motoo, Hirotoshi Dosaka-Akita, Koichi Honma, Yoshiaki Saitoh, Kiyonobu Kimura, Yoshikazu Uchida, Hiroshi Mikami, Yutaka Ohsaki, Yoshikazu Kawakami, and Kokichi Kikuchi. "Pneumoconiosis-Related Lung Cancers." American Journal of Respiratory and Critical Care Medicine 162, no. 1 (July 1, 2000): 295-300. https://doi.org/10.1164/airccm.162.1.9906138.

Khlystov, Andrey, and Yilin Ma. "An On-Line Instrument for Mobile Measurements of the Spatial Variability of Hexavalent and Trivalent Chromium in Urban Air." Atmospheric Environment 40, no. 40 (December 1, 2006): 8088-93. https://doi.org/10.1016/..atmosenv.2006.09.030.

Khoo, Kelvin H. P., Hayley R. Jolly, and Jason A. Able. "The RAD51 Gene Family in Bread Wheat Is Highly Conserved across Eukaryotes, with RAD51A Upregulated 
during Early Meiosis." Functional Plant Biology 35, no. 12 (January 19, 2009): 1267-77. https://doi.org/10.1071/FP08203.

Kim, Daehwan, Geo Pertea, Cole Trapnell, Harold Pimentel, Ryan Kelley, and Steven L. Salzberg. "TopHat2: Accurate Alignment of Transcriptomes in the Presence of Insertions, Deletions and Gene Fusions." Genome Biology 14, no. 4 (April 25, 2013): R36. https://doi.org/10.1186/gb-2013-14-4-r36.

Kim, Hyeon-yeong, Sung-bae Lee, and Beom-su Jang. "Subchronic Inhalation Toxicity of Soluble Hexavalent Chromium Trioxide in Rats." Archives of Toxicology 78, no. 7 (July 1, 2004): 363-68. https://doi.org/10.1007/s00204-004-0553-4.

Kinner, Andrea, Wenqi Wu, Christian Staudt, and George lliakis. " $\mathrm{H}-\mathrm{H} 2 \mathrm{AX}$ in Recognition and Signaling of DNA Double-Strand Breaks in the Context of Chromatin." Nucleic Acids Research 36, no. 17 (October 1, 2008): 5678-94. https://doi.org/10.1093/nar/gkn550.

Kondo, Kazuya, Naoki Hino, Mitsunori Sasa, Yoshitaka Kamamura, Syoji Sakiyama, Masaru Tsuyuguchi, Masato Hashimoto, Tadashi Uyama, and Yasumasa Monden. "Mutations of the P53 Gene in Human Lung Cancer from ChromateExposed Workers." Biochemical and Biophysical Research Communications 239, no. 1 (October 9, 1997): 95-100. https://doi.org/10.1006/bbrc.1997.7425.

Kondo, Kazuya, Yuji Takahashi, Yukiko Hirose, Taeko Nagao, Masaru Tsuyuguchi, Masato Hashimoto, Atsushi Ochiai, Yasumasa Monden, and Akira Tangoku. "The Reduced Expression and Aberrant Methylation of P16INK4a in Chromate Workers with Lung Cancer." Lung Cancer 53, no. 3 (September 1, 2006): 295-302. https://doi.org/10.1016/j.lungcan.2006.05.022.

Kondo, Kazuya, Yuji Takahashi, Sumiyo Ishikawa, Hiroshi Uchihara, Yukiko Hirose, Kiyoshi Yoshizawa, Masaru Tsuyuguchi, et al. "Microscopic Analysis of Chromium Accumulation in the Bronchi and Lung of Chromate Workers." Cancer 98, no. 11 (December 1, 2003): 2420-29. https://doi.org/10.1002/cncr.11818.

Kotaś, J., and Z. Stasicka. "Chromium Occurrence in the Environment and Methods of Its Speciation." Environmental Pollution 107, no. 3 (March 1, 2000): 263-83. https://doi.org/10.1016/S0269-7491(99)00168-2.

Kowalik, T. F., J. DeGregori, J. K. Schwarz, and J. R. Nevins. "E2F1 Overexpression in Quiescent Fibroblasts Leads to Induction of Cellular DNA Synthesis and Apoptosis." Journal of Virology 69, no. 4 (April 1, 1995): 2491-2500.

Krek, W., M. E. Ewen, S. Shirodkar, Z. Arany, W. G. Kaelin, and D. M. Livingston. "Negative Regulation of the Growth-Promoting Transcription Factor E2F-1 by a Stably Bound Cyclin A-Dependent Protein Kinase." Cell 78, no. 1 (July 15, 1994): 161-72. https://doi.org/10.1016/0092-8674(94)90582-7.

Kunito, Takashi, Reiji Kubota, Junko Fujihara, Tetsuro Agusa, and Shinsuke Tanabe. "Arsenic in Marine Mammals, Seabirds, and Sea Turtles." In Reviews of Environmental Contamination and Toxicology, edited by David M. Whitacre, 31- 
69. Reviews of Environmental Contamination and Toxicology. New York, NY: Springer, 2008. https://doi.org/10.1007/978-0-387-77030-7 2.

Lai, Tsung-Huei, Brett Ewald, Alma Zecevic, Chaomei Liu, Melanie Sulda, Dimitrios Papaioannou, Ramiro Garzon, James S. Blachly, William Plunkett, and Deepa Sampath. "HDAC Inhibition Induces MicroRNA-182, Which Targets RAD51 and Impairs HR Repair to Sensitize Cells to Sapacitabine in Acute Myelogenous Leukemia." Clinical Cancer Research 22, no. 14 (July 15, 2016): 3537-49. https://doi.org/10.1158/1078-0432.CCR-15-1063.

Langård, S, and T Norseth. "A Cohort Study of Bronchial Carcinomas in Workers Producing Chromate Pigments." British Journal of Industrial Medicine 32, no. 1 (February 1, 1975): 62. https://doi.org/10.1136/oem.32.1.62.

Langård, S, and T Vigander. "Occurrence of Lung Cancer in Workers Producing Chromium Pigments." British Journal of Industrial Medicine 40, no. 1 (February 1, 1983): 71. https://doi.org/10.1136/oem.40.1.71.

Lee, Pyeong-Koo, Soonyoung Yu, Hye Jung Chang, Hye Young Cho, Min-Ju Kang, and Byung-Gon Chae. "Lead Chromate Detected as a Source of Atmospheric $\mathrm{Pb}$ and $\mathrm{Cr}$ (VI) Pollution." Scientific Reports 6, no. 1 (October 25, 2016): 36088. https://doi.org/10.1038/srep36088.

Leese, Elizabeth, Jackie Morton, Philip H. E. Gardiner, and Vikki A. Carolan. "Development of a Method for the Simultaneous Detection of $\mathrm{Cr}$ ( lii ) and $\mathrm{Cr}(\mathrm{vi})$ in Exhaled Breath Condensate Samples Using MLC-ICP-MS." Journal of Analytical Atomic Spectrometry 31, no. 4 (2016): 924-33. https://doi.org/10.1039/C5JA00436E.

Leese, Elizabeth, Jackie Morton, Philip H.E. Gardiner, and Vikki A. Carolan. "The Simultaneous Detection of Trivalent \& Hexavalent Chromium in Exhaled Breath Condensate: A Feasibility Study Comparing Workers and Controls." International Journal of Hygiene and Environmental Health 220, no. 2, Part B (April 1, 2017): 415-23. https://doi.org/10.1016/j.ijheh.2016.12.003.

Leonard, Stephen S., Jacquelyn J. Bower, and Xianglin Shi. "Metal-Induced Toxicity, Carcinogenesis, Mechanisms and Cellular Responses." Molecular and Cellular Biochemistry 255, no. 1 (January 1, 2004): 3-10. https://doi.org/10.1023/B:MCBI.0000007255.72746.a6.

Leroi, Armand M., Vassiliki Koufopanou, and Austin Burt. "Cancer Selection." Nature Reviews Cancer 3, no. 3 (March 2003): 226-31. https://doi.org/10.1038/nrc1016.

Levy, L. S., and S. Venitt. "Carcinogenicity and Mutagenicity of Chromium Compounds: The Association between Bronchial Metaplasia and Neoplasia." Carcinogenesis 7, no. 5 (May 1, 1986): 831-35. https://doi.org/10.1093/carcin/7.5.831.

Li Chen, Tânia, Sandra S. Wise, Scott Kraus, Fariba Shaffiey, Kaitlynn M. Levine, W. Douglas Thompson, Tracy Romano, Todd O'Hara, and John Pierce Wise. "Particulate Hexavalent Chromium Is Cytotoxic and Genotoxic to the North Atlantic Right Whale (Eubalaena Glacialis) Lung and Skin Fibroblasts." Environmental and 
Molecular Mutagenesis 50, no. 5 (2009a): 387-93. https://doi.org/10.1002/em.20471.

Li Chen, Tânia, Sandra S. Wise, Amie Holmes, Fariba Shaffiey, John Pierce Wise, W. Douglas Thompson, Scott Kraus, and John Pierce Wise. "Cytotoxicity and Genotoxicity of Hexavalent Chromium in Human and North Atlantic Right Whale (Eubalaena Glacialis) Lung Cells." Comparative Biochemistry and Physiology Part C: Toxicology \& Pharmacology 150, no. 4 (November 1, 2009b): 487-94. https://doi.org/10.1016/..cbpc.2009.07.004.

Li Chen, Tânia, Carolyne LaCerte, Sandra S. Wise, Amie Holmes, Julieta Martino, Wise John Pierce, W. Douglas Thompson, and John Pierce Wise. "Comparative Cytotoxicity and Genotoxicity of Particulate and Soluble Hexavalent Chromium in Human and Sperm Whale (Physeter Macrocephalus) Skin Cells." Comparative Biochemistry and Physiology Part C: Toxicology \& Pharmacology, Special Issue dedicated to 5th Aquatic Animal Models of Human Disease meeting: Corvallis, OR, USA, September 20-22, 2010, 155, no. 1 (January 1, 2012): 143-50. https://doi.org/10.1016/..cbpc.2011.03.011.

Li, Heng, and Richard Durbin. "Fast and Accurate Short Read Alignment with BurrowsWheeler Transform." Bioinformatics (Oxford, England) 25, no. 14 (July 15, 2009): 1754-60. https://doi.org/10.1093/bioinformatics/btp324.

Li, Heng, Bob Handsaker, Alec Wysoker, Tim Fennell, Jue Ruan, Nils Homer, Gabor Marth, Goncalo Abecasis, Richard Durbin, and 1000 Genome Project Data Processing Subgroup. "The Sequence Alignment/Map Format and SAMtools." Bioinformatics (Oxford, England) 25, no. 16 (August 15, 2009): 2078-79. https://doi.org/10.1093/bioinformatics/btp352.

$\mathrm{Li}$, Xuan, and Wolf-Dietrich Heyer. "Homologous Recombination in DNA Repair and DNA Damage Tolerance." Cell Research 18, no. 1 (January 2008): 99-113. https://doi.org/10.1038/cr.2008.1.

Li, Yang, Guiping Hu, Ping Li, Shichuan Tang, Ji Zhang, and Guang Jia. "MiR-3940-5p Enhances Homologous Recombination after DSB in $\mathrm{Cr}(\mathrm{VI})$ Exposed 16HBE Cell." Toxicology 344-346 (February 17, 2016): 1-6. https://doi.org/10.1016/.t.tox.2016.02.003.

Li, Yang, Ping Li, Shanfa Yu, Ji Zhang, Tiancheng Wang, and Guang Jia. "MiR-3940$5 p$ Associated with Genetic Damage in Workers Exposed to Hexavalent Chromium." Toxicology Letters 229, no. 1 (August 17, 2014): 319-26. https://doi.org/10.1016/.j.toxlet.2014.06.033.

Lim, Meesun, Leroy F. Liu, David Jacobson-Kram, and Jerry R. Williams. "Induction of Sister Chromatid Exchanges by Inhibitors of Topoisomerases." Cell Biology and Toxicology 2, no. 4 (December 1, 1986): 485-94. https://doi.org/10.1007/BF00117850.

Liao, Ching-Chun, Connie Y. Tsai, Wen-Chang Chang, Wen-Hwa Lee, and Ju-Ming Wang. "RB·E2F1 Complex Mediates DNA Damage Responses through 
Transcriptional Regulation of ZBRK1." Journal of Biological Chemistry 285, no. 43 (October 22, 2010): 33134-43. https://doi.org/10.1074/jbc.M110.143461.

Lindberg, Erik, and Olof Vesterberg. "Urinary Excretion of Chromium in Chromeplaters after Discontinued Exposure." American Journal of Industrial Medicine 16, no. 5 (1989): 485-92. https://doi.org/10.1002/ajim.4700160502.

Linqing, Yang, Xia Bo, Yang Xueqin, Ding Hong, Wu Desheng, Zhang Huimin, Jiang Gaofeng, Liu Jianjun, and Zhuang Zhixiong. "Mitochondrial DNA Hypomethylation in Chrome Plating Workers." Toxicology Letters 243 (January 22, 2016): 1-6. https://doi.org/10.1016/..toxlet.2015.11.031.

Lin, Weei-Chin, Fang-Tsyr Lin, and Joseph R. Nevins. "Selective Induction of E2F1 in Response to DNA Damage, Mediated by ATM-Dependent Phosphorylation." Genes \& Development 15, no. 14 (July 15, 2001): 1833-44.

Liu, Jie, Tammy Doty, Bryan Gibson, and Wolf-Dietrich Heyer. "Human BRCA2 Protein Promotes RAD51 Filament Formation on RPA-Covered Single-Stranded DNA." Nature Structural \& Molecular Biology 17, no. 10 (October 2010): 1260-62. https://doi.org/10.1038/nsmb.1904.

Liu, Wei, Liang Xu, Yan Wang, Hong Shen, Xianwen Zhu, Keyun Zhang, Yinglong Chen, Rugang Yu, Cecilia Limera, and Liwang Liu. "Transcriptome-Wide Analysis of Chromium-Stress Responsive MicroRNAs to Explore MiRNA-Mediated Regulatory Networks in Radish ( Raphanus Sativus L.)." Scientific Reports 5, no. 1 (September 11, 2015): 14024. https://doi.org/10.1038/srep14024.

Lou, Jianlin, Yu Wang, Junqiang Chen, Li Ju, Min Yu, Zhaoqiang Jiang, Lingfang Feng, Lingzhi Jin, and Xing Zhang. "Effects of Soluble and Particulate $\mathrm{Cr}(\mathrm{VI})$ on GenomeWide DNA Methylation in Human B Lymphoblastoid Cells." Mutation Research/Genetic Toxicology and Environmental Mutagenesis 792 (October 1, 2015): 12-18. https://doi.org/10.1016/j.mrgentox.2015.08.004.

Lu, Tzu-Pin, Chien-Yueh Lee, Mong-Hsun Tsai, Yu-Chiao Chiu, Chuhsing Kate Hsiao, Liang-Chuan Lai, Eric Y. Chuang. miRSystem: An Integrated System for Characterizing Enriched Functions and Pathways of MicroRNA Targets. PLoS ONE 7(8): e42390. https://doi:10.1371/journal.pone.0042390 (2012).

Lu, Yuan, Mikki Boswell, William Boswell, Susanne Kneitz, Barbara Klotz, Markita Savage, Raquel Salinas, et al. "Gene Expression Variation and Parental Allele Inheritance in a Xiphophorus Interspecies Hybridization Model." Edited by Xu Wang. PLOS Genetics 14, no. 12 (December 26, 2018): e1007875. https://doi.org/10.1371/journal.pgen.1007875.

Lu, Yuan, Mikki Boswell, William Boswell, Susanne Kneitz, Michael Hausmann, Barbara Klotz, Janine Regneri, et al. "Molecular Genetic Analysis of the Melanoma Regulatory Locus in Xiphophorus Interspecies Hybrids." Molecular Carcinogenesis 56, no. 8 (2017): 1935-44. https://doi.org/10.1002/mc.22651.

Luczak Michal W., Green Samantha E., and Zhitkovich Anatoly. "Different ATM Signaling in Response to Chromium(VI) Metabolism via Ascorbate and 
Nonascorbate Reduction: Implications for in Vitro Models and Toxicogenomics." Environmental Health Perspectives 124, no. 1 (January 1, 2016): 61-66. https://doi.org/10.1289/ehp.1409434.

MacFarlane, Leigh-Ann, and Paul R. Murphy. "MicroRNA: Biogenesis, Function and Role in Cancer." Current Genomics 11, no. 7 (November 1, 2010): 537-61. https://doi.org/10.2174/138920210793175895.

Madhusudanan, K. P., S. B. Katti, R. Vijayalakshmi, and B. U. Nair. "Chromium(III) Interactions with Nucleosides and Nucleotides: A Mass Spectrometric Study." Journal of Mass Spectrometry 34, no. 8 (1999): 880-84. https://doi.org/10.1002/(SICI)1096-9888(199908)34:8<880::AIDJMS844>3.0.CO;2-E.

Maeng, S. H., H. W. Chung, K. J. Kim, B. M. Lee, Y. C. Shin, S. J. Kim, and I. J. Yu. "Chromosome Aberration and Lipid Peroxidation in Chromium-Exposed Workers." Biomarkers 9, no. 6 (January 1, 2004): 418-34. https://doi.org/10.1080/13547500400022200.

Mancuso, T. F., and W. C. Hueper. "Occupational Cancer and other Health Hazards in a Chromate Plant : a Medical Appraisal. 1. Lung Cancers in Chromate Workers." Industrial Medicine and Surgery 20, no. 8 (1951): 358-63.

Manning, Francis C. R., Jian Xu, and Steven R. Patierno. "Transcriptional Inhibition by Carcinogenic Chromate: Relationship to DNA Damage." Molecular Carcinogenesis 6, no. 4 (1992): 270-79. https://doi.org/10.1002/mc.2940060409.

Martin, Hilary C., Shivangi Wani, Anita L. Steptoe, Keerthana Krishnan, Katia Nones, Ehsan Nourbakhsh, Alexander Vlassov, Sean M. Grimmond, and Nicole Cloonan. "Imperfect Centered MiRNA Binding Sites Are Common and Can Mediate Repression of Target MRNAs." Genome Biology 15, no. 3 (March 14, 2014): R51. https://doi.org/10.1186/gb-2014-15-3-r51.

Martino, Julieta, Amie L. Holmes, Hong Xie, Sandra S. Wise, and John Pierce Wise. "Chronic Exposure to Particulate Chromate Induces Premature Centrosome Separation and Centriole Disengagement in Human Lung Cells." Toxicological Sciences 147, no. 2 (October 1, 2015): 490-99. https://doi.org/10.1093/toxsci/kfv146.

McGeary, Sean E., Kathy S. Lin, Charlie Y. Shi, Thy M. Pham, Namita Bisaria, Gina M. Kelley, and David P. Bartel. "The Biochemical Basis of MicroRNA Targeting Efficacy." Science 366, no. 6472 (December 20, 2019). https://doi.org/10.1126/science.aav1741.

Minoia, Claudio, and Alessandro Cavalleri. "Chromium in Urine, Serum and Red Blood Cells in the Biological Monitoring of Workers Exposed to Different Chromium Valency States." Lead, Chromium and Thallium: Toxicity, Environmental and Health Impact, and Regulation 71, no. 3 (June 1, 1988): 323-27. https://doi.org/10.1016/0048-9697(88)90204-5. 
Mwacalimba, Kennedy Kapala, and Judith Green. 'OOne Health' and Development Priorities in Resource-Constrained Countries: Policy Lessons from Avian and Pandemic Influenza Preparedness in Zambia." Health Policy and Planning 30, no. 2 (March 1, 2015): 215-22. https://doi.org/10.1093/heapol/czu001.

Nagy, John D., Erin M. Victor, and Jenese H. Cropper. "Why Don't All Whales Have Cancer? A Novel Hypothesis Resolving Peto's Paradox." Integrative and Comparative Biology 47, no. 2 (August 1, 2007): 317-28. https://doi.org/10.1093/icb/icm062.

Newman D. A case of adeno-carcinoma of the left inferior turbinated body, and perforation of the nasal septum, in the person of a worker in chrome pigments. Glasg Med J, 33: 469-470 (1890).

Nisse, Catherine, Romuald Tagne-Fotso, Mike Howsam, Camille Richeval, Laurence Labat, and Ariane Leroyer. "Blood and Urinary Levels of Metals and Metalloids in the General Adult Population of Northern France: The IMEPOGE Study, 20082010." International Journal of Hygiene and Environmental Health 220, no. 2, Part B (April 1, 2017): 341-63. https://doi.org/10.1016/j.ijheh.2016.09.020.

O'Brien, Jacob, Heyam Hayder, Yara Zayed, and Chun Peng. "Overview of MicroRNA Biogenesis, Mechanisms of Actions, and Circulation." Frontiers in Endocrinology 9 (2018). https://doi.org/10.3389/fendo.2018.00402.

Oliveros, J.C. (2007-2015) Venny. An interactive tool for comparing lists with Venn's diagrams. https://bioinfogp.cnb.csic.es/tools/venny/index.html

OSHA. Hexavalent Chromium. U.S. Department of Labor Occupational Safety and Health Administration 3373-10 (2009).

Papp, John F. "Mineral Yearbook 2015: Chromium". United States Geological Survey.

Park, Soyoung, Cen Li, Hong Zhao, Zbigniew Darzynkiewicz, and Dazhong Xu. "Gene 33/Mig6 Inhibits Hexavalent Chromium-Induced DNA Damage and Cell Transformation in Human Lung Epithelial Cells." Oncotarget 7, no. 8 (January 9, 2016): 8916-30. https://doi.org/10.18632/oncotarget.6866.

Park, Soyoung, Xiaowen Zhang, Cen Li, Changhong Yin, Jiangwei Li, John T. Fallon, Weihua Huang, and Dazhong Xu. "Single-Cell RNA Sequencing Reveals an Altered Gene Expression Pattern as a Result of CRISPR/Cas9-Mediated Deletion of Gene 33/Mig6 and Chronic Exposure to Hexavalent Chromium in Human Lung Epithelial Cells." Toxicology and Applied Pharmacology 330 (September 1, 2017): 30-39. https://doi.org/10.1016/j.taap.2017.07.003.

Patierno, Steven R., Dan Banh, and Joseph R. Landolph. "Transformation of $\mathrm{C} 3 \mathrm{H} / 10 \mathrm{~T}^{1} 12$ Mouse Embryo Cells to Focus Formation and Anchorage Independence by Insoluble Lead Chromate but Not Soluble Calcium Chromate: Relationship to Mutagenesis and Internalization of Lead Chromate Particles." Cancer Research 48, no. 18 (September 15, 1988): 5280-88. 
Pérez, Adam, and John Pierce Wise Sr. "One Environmental Health: An Emerging Perspective in Toxicology." F1000Research 7 (June 27, 2018). https://doi.org/10.12688/f1000research.14233.1.

Permenter, Matthew G., John A. Lewis, and David A. Jackson. "Exposure to Nickel, Chromium, or Cadmium Causes Distinct Changes in the Gene Expression Patterns of a Rat Liver Derived Cell Line." PLOS ONE 6, no. 11 (November 16, 2011). https://doi.org/10.1371/journal.pone.0027730.

Perrault, Justin R., Debra L. Miller, Jeanne Garner, and Jeanette Wyneken. "Mercury and Selenium Concentrations in Leatherback Sea Turtles (Dermochelys Coriacea): Population Comparisons, Implications for Reproductive Success, Hazard Quotients and Directions for Future Research." Science of The Total Environment 463-464 (October 1, 2013): 61-71. https://doi.org/10.1016/j.scitotenv.2013.05.067.

Perron, Marjorie P., and Patrick Provost. "Protein Interactions and Complexes in Human MicroRNA Biogenesis and Function." Frontiers in Bioscience : A Journal and Virtual Library 13 (January 1, 2008): 2537-47.

Pesch, Beate, Martin Lehnert, Tobias Weiss, Benjamin Kendzia, Eleonore Menne, Anne Lotz, Evelyn Heinze, et al. "Exposure to Hexavalent Chromium in Welders: Results of the WELDOX II Field Study." Annals of Work Exposures and Health 62, no. 3 (February 12, 2018): 351-61. https://doi.org/10.1093/annweh/wxy004.

Peto, R., F. J. Roe, P. N. Lee, L. Levy, and J. Clack. "Cancer and Ageing in Mice and Men." British Journal of Cancer 32, no. 4 (October 1975): 411-26. https://doi.org/10.1038/bjc.1975.242.

Petrilli, F L, G A Rossi, A Camoirano, M Romano, D Serra, C Bennicelli, A De Flora, and S De Flora. "Metabolic Reduction of Chromium by Alveolar Macrophages and Its Relationships to Cigarette Smoke." The Journal of Clinical Investigation 77, no. 6 (June 1, 1986): 1917-24. https://doi.org/10.1172/JCl112520.

Pettine, M., and Frank J. Millero. "Chromium Speciation in Seawater: The Probable Role of Hydrogen Peroxide." Limnology and Oceanography 35, no. 3 (May 1, 1990): 730-36. https://doi.org/10.4319/lo.1990.35.3.0730.

Podust, Vladimir N., Anthi Georgaki, Bettina Strack, and Ulrich Hübscher. "Calf Thymus RF-C as an Essential Component for DNA Polymerase $\delta$ and $\varepsilon$ Holoenzymes Function." Nucleic Acids Research 20, no. 16 (August 25, 1992): 4159-65. https://doi.org/10.1093/nar/20.16.4159.

Pommier, Yves, Donna Kerrigan, Joseph M. Covey, Chien-Song Kao-Shan, and Jacqueline Whang-Peng. "Sister Chromatid Exchanges, Chromosomal Aberrations, and Cytotoxicity Produced by Antitumor Topoisomerase II Inhibitors in Sensitive (DC3F) and Resistant (DC3F/9-OHE) Chinese Hamster Cells." Cancer Research 48, no. 3 (February 1, 1988): 512-16.

Poppi, Lisa, Annalisa Zaccaroni, Daniela Pasotto, Giorgia Dotto, Federica Marcer, Dino Scaravelli, and Sandro Mazzariol. "Post-Mortem Investigations on a Leatherback Turtle Dermochelys Coriacea Stranded along the Northern Adriatic Coastline." 
Diseases of Aquatic Organisms 100, no. 1 (August 13, 2012): 71-76. https://doi.org/10.3354/dao02479.

Pratheeshkumar, Poyil, Young-Ok Son, Sasidharan Padmaja Divya, Lei Wang, Lilia Turcios, Ram Vinod Roy, John Andrew Hitron, et al. "Quercetin Inhibits $\mathrm{Cr}(\mathrm{VI})$ Induced Malignant Cell Transformation by Targeting MiR-21-PDCD4 Signaling Pathway." Oncotarget 8, no. 32 (June 17, 2016): 52118-31. https://doi.org/10.18632/oncotarget.10130.

Pritchard, Daryl E., Susan Ceryak, Keri E. Ramsey, Travis J. O’Brien, Linan Ha, Jamie L. Fornsaglio, Dietrich A. Stephan, and Steven R. Patierno. "Resistance to Apoptosis, Increased Growth Potential, and Altered Gene Expression in Cells That Survived Genotoxic Hexavalent Chromium [ $\mathrm{Cr}(\mathrm{VI})]$ Exposure." Molecular and Cellular Biochemistry 279, no. 1-2 (November 2005): 169-81. https://doi.org/10.1007/s11010-005-8292-2.

Qin, Qin, Hong Xie, Sandra S. Wise, Cynthia L. Browning, Kelsey N. Thompson, Amie L. Holmes, and John Pierce Wise. "Homologous Recombination Repair Signaling in Chemical Carcinogenesis: Prolonged Particulate Hexavalent Chromium Exposure Suppresses the Rad51 Response in Human Lung Cells." Toxicological Sciences 142, no. 1 (November 1, 2014): 117-25. https://doi.org/10.1093/toxsci/kfu175.

Quievryn, George, Joseph Messer, and Anatoly Zhitkovich. "Lower Mutagenicity but Higher Stability of $\mathrm{Cr}$-DNA Adducts Formed during Gradual Chromate Activation with Ascorbate." Carcinogenesis 27, no. 11 (November 1, 2006): 2316-21. https://doi.org/10.1093/carcin/bgl076.

Quievryn, George, Elizabeth Peterson, Joseph Messer, and Anatoly Zhitkovich. "Genotoxicity and Mutagenicity of Chromium(VI)/Ascorbate-Generated DNA Adducts in Human and Bacterial Cells." Biochemistry 42, no. 4 (February 1, 2003): 1062-70. https://doi.org/10.1021/bi0271547.

Raderschall, Elke, Alex Bazarov, Jiangping Cao, Rudi Lurz, Avril Smith, Wolfgang Mann, Hans-Hilger Ropers, et al. "Formation of Higher-Order Nuclear Rad51 Structures Is Functionally Linked to P21 Expression and Protection from DNA Damage-Induced Apoptosis." Journal of Cell Science 115, no. 1 (January 1, 2002): $153-64$.

Rager, Julia E., Mina Suh, Grace A. Chappell, Chad M. Thompson, and Deborah M. Proctor. "Review of Transcriptomic Responses to Hexavalent Chromium Exposure in Lung Cells Supports a Role of Epigenetic Mediators in Carcinogenesis." Toxicology Letters 305 (May 1, 2019): 40-50. https://doi.org/10.1016/.j.toxlet.2019.01.011.

R Core Team (2013). R: A language and environment for statistical computing. $R$ Foundation for Statistical Computing, Vienna, Austria. URL http://www.Rproject.org/.

Ren, Xuefeng, Daniel P. Gaile, Zhihong Gong, Wenting Qiu, Yichen Ge, Chuanwu Zhang, Chenping Huang, et al. "Arsenic Responsive MicroRNAs in Vivo and Their 
Potential Involvement in Arsenic-Induced Oxidative Stress." Toxicology and Applied Pharmacology 283, no. 3 (March 15, 2015): 198-209. https://doi.org/10.1016/j.taap.2015.01.014.

Reynolds, Mindy, Elizabeth Peterson, George Quievryn, and Anatoly Zhitkovich. "Human Nucleotide Excision Repair Efficiently Removes Chromium-DNA Phosphate Adducts and Protects Cells against Chromate Toxicity." Journal of Biological Chemistry 279, no. 29 (July 16, 2004): 30419-24. https://doi.org/10.1074/ibc.M402486200.

Rhoades, Matthew W., Brenda J. Reinhart, Lee P. Lim, Christopher B. Burge, Bonnie Bartel, and David P. Bartel. "Prediction of Plant MicroRNA Targets." Cell 110, no. 4 (August 23, 2002): 513-20. https://doi.org/10.1016/S0092-8674(02)00863-2.

Rishi, Vikas, Jozsef Gal, Dmitry Krylov, Jakob Fridriksson, Maria Sandberg Boysen, Susanne Mandrup, and Charles Vinson. "SREBP-1 Dimerization Specificity Maps to Both the Helix-Loop-Helix and Leucine Zipper Domains: Use of a Dominant Negative." The Journal of Biological Chemistry 279, no. 12 (March 19, 2004): 11863-74. https://doi.org/10.1074/jbc.M308000200.

Rodrigues, C. F. D., A. M. Urbano, E. Matoso, I. Carreira, A. Almeida, P. Santos, F. Botelho, et al. "Human Bronchial Epithelial Cells Malignantly Transformed by Hexavalent Chromium Exhibit an Aneuploid Phenotype but No Microsatellite Instability." Mutation Research/Fundamental and Molecular Mechanisms of Mutagenesis 670, no. 1 (November 2, 2009): 42-52. https://doi.org/10.1016/j.mrfmmm.2009.07.004.

Russo, Patrizia, Alessia Catassi, Alfredo Cesario, Andrea Imperatori, Nicola Rotolo, Massimo Fini, Pierluigi Granone, and Lorenzo Dominioni. "Molecular Mechanisms of Hexavalent Chromium-Induced Apoptosis in Human Bronchoalveolar Cells." American Journal of Respiratory Cell and Molecular Biology 33, no. 6 (December 1, 2005): 589-600. https://doi.org/10.1165/rcmb.2005-02130C.

Saner, G, V Yüzbasiyan, and S Cigdem. "Hair Chromium Concentration and Chromium Excretion in Tannery Workers." British Journal of Industrial Medicine 41, no. 2 (May 1, 1984): 263. https://doi.org/10.1136/oem.41.2.263.

Saxena, Sandeep, Zophonías O. Jónsson, and Anindya Dutta. "Small RNAs with Imperfect Match to Endogenous MRNA Repress Translation IMPLICATIONS FOR OFF-TARGET ACTIVITY OF SMALL INHIBITORY RNA IN MAMMALIAN CELLS." Journal of Biological Chemistry 278, no. 45 (November 7, 2003): 44312-19. https://doi.org/10.1074/ibc.M307089200.

Schwentner, Raphaela, Theodore Papamarkou, Maximilian O. Kauer, Vassilios Stathopoulos, Fan Yang, Sven Bilke, Paul S. Meltzer, Mark Girolami, and Heinrich Kovar. "EWS-FLI1 Employs an E2F Switch to Drive Target Gene Expression." Nucleic Acids Research 43, no. 5 (March 11, 2015): 2780-89. https://doi.org/10.1093/nar/gkv123.

Seoane, A. I., A. M. Güerci, and F. N. Dulout. "Malsegregation as a Possible Mechanism of Aneuploidy Induction by Metal Salts in MRC-5 Human Cells." 
Environmental and Molecular Mutagenesis 40, no. 3 (2002): 200-206. https://doi.org/10.1002/em.10110.

Sharma, Shikhar, Theresa K. Kelly, and Peter A. Jones. "Epigenetics in Cancer." Carcinogenesis 31, no. 1 (January 1, 2010): 27-36. https://doi.org/10.1093/carcin/bgp220.

Shieh, Sheau-Yann, Yoichi Taya, and Carol Prives. "DNA Damage-inducible Phosphorylation of P53 at N-terminal Sites Including a Novel Site, Ser20, Requires Tetramerization." The EMBO Journal 18, no. 7 (April 1, 1999): 1815-23. https://doi.org/10.1093/emboj/18.7.1815.

Shumilla, Jennifer A., and Aaron Barchowsky. "Inhibition of Protein Synthesis by Chromium(VI) Differentially Affects Expression of Urokinase and Its Receptor in Human Type II Pneumocytes." Toxicology and Applied Pharmacology 158, no. 3 (August 1, 1999): 288-95. https://doi.org/10.1006/taap.1999.8704.

Sigurdsson, Stefan, Stephen Van Komen, Wendy Bussen, David Schild, Joanna S. Albala, and Patrick Sung. "Mediator Function of the Human Rad51B-Rad51C Complex in Rad51/RPA-Catalyzed DNA Strand Exchange." Genes \& Development 15, no. 24 (December 15, 2001): 3308-18. https://doi.org/10.1101/gad.935501.

Sonoda, Eiichiro, Masao S. Sasaki, Jean-Marie Buerstedde, Olga Bezzubova, Akira Shinohara, Hideyuki Ogawa, Minoru Takata, Yuko Yamaguchi-Iwai, and Shunichi Takeda. "Rad51-Deficient Vertebrate Cells Accumulate Chromosomal Breaks Prior to Cell Death." The EMBO Journal 17, no. 2 (January 15, 1998): 598-608. https://doi.org/10.1093/emboj/17.2.598.

Speer, Rachel M., Catherine F. Wise, Jamie L. Young, AbouEl-Makarim Aboueissa, Mark Martin Bras, Mike Barandiaran, Erick Bermúdez, Lirio Márquez-D’Acunti, and John Pierce Wise. "The Cytotoxicity and Genotoxicity of Particulate and Soluble Hexavalent Chromium in Leatherback Sea Turtle Lung Cells." Aquatic Toxicology 198 (May 1, 2018): 149-57. https://doi.org/10.1016/j.aquatox.2018.03.003.

Speer, Rachel M., Sandra S. Wise, Tayler J. Croom-Perez, AbouEl-Makarim Aboueissa, Mark Martin-Bras, Mike Barandiaran, Erick Bermúdez, and John Pierce Wise. "A Comparison of Particulate Hexavalent Chromium Cytotoxicity and Genotoxicity in Human and Leatherback Sea Turtle Lung Cells from a One Environmental Health Perspective." Toxicology and Applied Pharmacology 376 (August 1, 2019): 70-81. https://doi.org/10.1016/j.taap.2019.05.013.

Speer, Rachel M. and John P. Wise, Sr. "Current status on chromium research and its implications for health and risk assessment" Chemistry Molecular Sciences and Chemical Engineering, (2018):1-16. https://doi.org/10.1016/B978-0-12-4095472.14283-0.

Stackpole, Megan M., Sandra S. Wise, Britton C. Goodale, Eliza Grlickova Duzevik, Ray C. Munroe, W. Douglas Thompson, John Thacker, Larry H. Thompson, John M. Hinz, and John Pierce Wise. "Homologous Recombination Repair Protects against Particulate Chromate-Induced Chromosome Instability in Chinese 
Hamster Cells." Mutation Research/Fundamental and Molecular Mechanisms of Mutagenesis 625, no. 1 (December 1, 2007): 145-54. https://doi.org/10.1016/j.mrfmmm.2007.06.003.

Standeven, Andrew M., Karen E. Wetterhahn, and Ryuichi Kato. "Ascorbate Is the Principal Reductant of Chromium(VI) in Rat Lung Ultrafiltrates and Cytosols, and Mediates Chromium-DNA Binding in Vitro." Carcinogenesis 13, no. 8 (August 1, 1992): 1319-24. https://doi.org/10.1093/carcin/13.8.1319.

Stearns, Diane M., John P. Wise, Steven R. Patierno, and Karen E. Wetterhahn. "Chromium(III) Picolinate Produces Chromosome Damage in Chinese Hamster Ovary Cells1." The FASEB Journal 9, no. 15 (1995): 1643-49. https://doi.org/10.1096/fasebj.9.15.8529845.

Stewart, Kelly R., and Peter H. Dutton. "Paternal Genotype Reconstruction Reveals Multiple Paternity and Sex Ratios in a Breeding Population of Leatherback Turtles (Dermochelyscoriacea)." Conservation Genetics 12, no. 4 (August 1, 2011a): 1101-13. https://doi.org/10.1007/s10592-011-0212-2.

Stewart, Kelly R., Jennifer M. Keller, Ryan Templeton, John R. Kucklick, and Chris Johnson. "Monitoring Persistent Organic Pollutants in Leatherback Turtles (Dermochelys Coriacea) Confirms Maternal Transfer." Marine Pollution Bulletin 62, $\begin{array}{lllll}\text { no. } & 7 & \text { (July } & 1, & 2011 b):\end{array}$ https://doi.org/10.1016/..marpolbul.2011.04.042.

Storelli, M. M., G. Barone, A. Storelli, and G. O. Marcotrigiano. "Total and Subcellular Distribution of Trace Elements ( $\mathrm{Cd}, \mathrm{Cu}$ and $\mathrm{Zn}$ ) in the Liver and Kidney of Green Turtles (Chelonia Mydas) from the Mediterranean Sea." Chemosphere 70, no. 5 (January 1, 2008): 908-13. https://doi.org/10.1016/j.chemosphere.2007.06.069.

Storelli, M. M, and G. O Marcotrigiano. "Heavy Metal Residues in Tissues of Marine Turtles." Marine Pollution Bulletin 46, no. 4 (April 1, 2003): 397-400. https://doi.org/10.1016/S0025-326X(02)00230-8.

Stridsklev, Inger Cecilie, Karl-Heinz Schaller, and Sverre Langård. "Monitoring of Chromium and Nickel in Biological Fluids of Stainless Steel Welders Using the Flux-Cored-Wire (FCW) Welding Method." International Archives of Occupational and Environmental Health 77, no. 8 (November 1, 2004): 587-91. https://doi.org/10.1007/s00420-004-0560-z.

Sulak, Michael, Lindsey Fong, Katelyn Mika, Sravanthi Chigurupati, Lisa Yon, Nigel P Mongan, Richard D Emes, and Vincent J Lynch. "TP53 Copy Number Expansion Is Associated with the Evolution of Increased Body Size and an Enhanced DNA Damage Response in Elephants." Edited by Joaquín M Espinosa. ELife 5 (September 19, 2016): e11994. https://doi.org/10.7554/eLife.11994.

Sun, Hong, Harriet A. Clancy, Thomas Kluz, Jiri Zavadil, and Max Costa. "Comparison of Gene Expression Profiles in Chromate Transformed BEAS-2B Cells." PLoS ONE 6, no. 3 (March 18, 2011). https://doi.org/10.1371/journal.pone.0017982. 
Sun, Hong, Xue Zhou, Haobin Chen, Qin Li, and Max Costa. "Modulation of Histone Methylation and MLH1 Gene Silencing by Hexavalent Chromium." Toxicology and Applied Pharmacology 237, no. 3 (June 15, 2009): 258-66. https://doi.org/10.1016/j.taap.2009.04.008.

Sung, Patrick, and Donald L Robberson. "DNA Strand Exchange Mediated by a RAD51-SsDNA Nucleoprotein Filament with Polarity Opposite to That of RecA." Cell 82, no. 3 (August 11, 1995): 453-61. https://doi.org/10.1016/00928674(95)90434-4.

Takahashi, Yuji, Kazuya Kondo, Sumiyo Ishikawa, Hiroshi Uchihara, Haruhiko Fujino, Naruhiko Sawada, Takanori Miyoshi, Shoji Sakiyama, Keisuke Izumi, and Yasumasa Monden. "Microscopic Analysis of the Chromium Content in the Chromium-Induced Malignant and Premalignant Bronchial Lesions of the Rat." Environmental Research 99, no. 2 (October 1, 2005): 267-72. https://doi.org/10.1016/j.envres.2004.10.001.

Tamblyn, Laura, Erica Li, Haya Sarras, Prarthana Srikanth, M. Prakash Hande, and J. Peter McPherson. "A Role for Mus81 in the Repair of Chromium-Induced DNA Damage." Mutation Research/Fundamental and Molecular Mechanisms of Mutagenesis 660, no. 1 (January 15, 2009): 57-65. https://doi.org/10.1016/j.mrfmmm.2008.10.013.

Terasawa, Masahiro, Akira Shinohara, and Miki Shinohara. "Canonical NonHomologous End Joining in Mitosis Induces Genome Instability and Is Suppressed by M-Phase-Specific Phosphorylation of XRCC4." PLOS Genetics 10, no. 8 (August 28, 2014): e1004563. https://doi.org/10.1371/journal.pgen.1004563.

Tian, Qingshan, Jing Bai, Bin Chen, and Guozhu Zhang. "Chromium-Catalyzed Asymmetric Dearomatization Addition Reactions of Halomethyl Heteroarenes." Organic Letters 18, no. 8 (April 15, 2016): 1828-31. https://doi.org/10.1021/acs.orglett.6b00559.

Tola, Sakari, Jukka Kilpio, Matti Virtamo, and Kauko Happa. "Urinary Chromium as an Indicator of the Exposure of Welders to Chromium." Scandinavian Journal of Work, Environment \& Health 3, no. 4 (1977): 192-202.

Toledo, S. M. de, E. I. Azzam, P. Keng, S. Laffrenier, and J. B. Little. "Regulation by lonizing Radiation of CDC2, Cyclin A, Cyclin B, Thymidine Kinase, Topoisomerase llalpha, and RAD51 Expression in Normal Human Diploid Fibroblasts Is Dependent on P53/P21Waf1." Cell Growth \& Differentiation: The Molecular Biology Journal of the American Association for Cancer Research 9, no. 11 (November 1998): 887-96.

Tossavainen, A., M. Nurminen, P. Mutanen, and S. Tola. "Application of Mathematical Modelling for Assessing the Biological Half-Times of Chromium and Nickel in Field Studies." Occupational and Environmental Medicine 37, no. 3 (August 1, 1980): 285-91. https://doi.org/10.1136/oem.37.3.285.

Toya, Tadao, Kazuo Fukuda, Norihiko Kohyama, Hiroko Kyono, and Heihachiro Arito. "Hexavalent Chromium Responsible for Lung Lesions Induced by Intratracheal 
Instillation of Chromium Fumes in Rats." Industrial Health 37, no. 1 (1999): 36-46. https://doi.org/10.2486/indhealth.37.36.

TRI. TRI Explorer Chemical Report. U.S. Environmental Protection Agency. Last updated: 2016. http://www.epa.gov/triexplorer and select Chromium Compounds (Except Chromite Ore Mined in The Transvaal Region) (2016).

Tsapakos, Michael J., and Karen E. Wetterhahn. "The Interaction of Chromium with Nucleic Acids." Chemico-Biological Interactions 46, no. 2 (September 1, 1983): 265-77. https://doi.org/10.1016/0009-2797(83)90034-0.

Vincent, John B. "New Evidence against Chromium as an Essential Trace Element." The Journal of Nutrition 147, no. 12 (October 11, 2017): 2212-19. https://doi.org/10.3945/in.117.255901.

Vlachos, loannis S., Konstantinos Zagganas, Maria D. Paraskevopoulou, Georgios Georgakilas, Dimitra Karagkouni, Thanasis Vergoulis, Theodore Dalamagas, and Artemis G. Hatzigeorgiou. "DIANA-miRPath v3. 0: deciphering microRNA function with experimental support." Nucleic acids research (2015): gkv403.

Wakeman, Timothy P., Wan-Ju Kim, Shannon Callens, Arthur Chiu, Kevin D. Brown, and Bo Xu. "The ATM-SMC1 Pathway Is Essential for Activation of the Chromium [VI]-Induced S-Phase Checkpoint." Mutation Research/Fundamental and Molecular Mechanisms of Mutagenesis 554, no. 1 (October 4, 2004): 241-51. https://doi.org/10.1016/j.mrfmmm.2004.05.006.

Wang, H., V. Eyert, and U. Schwingenschlögl. "Electronic Structure and Magnetic Ordering of the Semiconducting Chromium Trihalides $\mathrm{CrCl} 3, \mathrm{CrBr} 3$, and $\mathrm{Cr} 3$." Journal of Physics: Condensed Matter 23, no. 11 (March 2011): 116003. https://doi.org/10.1088/0953-8984/23/11/116003.

Wang, Lin, Jian-Ge Qiu, Jun He, Wen-Jing Liu, Xin Ge, Feng-Mei Zhou, Ying-Xue Huang, Bing-Hua Jiang, and Ling-Zhi Liu. "Suppression of MiR-143 Contributes to Overexpression of IL-6, HIF-1 $\alpha$ and NF-KB P65 in $\mathrm{Cr}(\mathrm{VI})$-Induced Human Exposure and Tumor Growth." Toxicology and Applied Pharmacology 378 (September 1, 2019): 114603. https://doi.org/10.1016/i.taap.2019.114603.

Wang, Yafei, Hong Su, Yuanliang Gu, Xin Song, and Jinshun Zhao. "Carcinogenicity of Chromium and Chemoprevention: A Brief Update." OncoTargets and Therapy 10 (August 16, 2017): 4065-79. https://doi.org/10.2147/OTT.S139262.

Wang, Yemin, Jen-Wei Huang, Philamer Calses, Christopher J. Kemp, and Toshiyasu Taniguchi. "MiR-96 Downregulates REV1 and RAD51 to Promote Cellular Sensitivity to Cisplatin and PARP Inhibition." Cancer Research 72, no. 16 (August 15, 2012): 4037-46. https://doi.org/10.1158/0008-5472.CAN-12-0103.

Wang, Zhishan, Hsuan-Pei Lin, Yunfei Fi, Hua Tao, Ping Yang, Jie Xie, Drew Maddy, Kazuya Kondo and Chengfeng Yang. "Chronic hexavalent chromium exposure inducescancer stem cell-like property and tumorigenesis by increasing c-myc expression." Toxicological Sciences 172 no. 2 (2020). 
Wei, Yu-Dan, Katherine Tepperman, Ming-ya Huang, Maureen A. Sartor, and Alvaro Puga. "Chromium Inhibits Transcription from Polycyclic Aromatic HydrocarbonInducible Promoters by Blocking the Release of Histone Deacetylase and Preventing the Binding of P300 to Chromatin." Journal of Biological Chemistry 279, no. 6 (February 6, 2004): 4110-19. https://doi.org/10.1074/ibc.M310800200.

Wetterhahn, Karen E., and Joshua W. Hamilton. "Molecular Basis of Hexavalent Chromium Carcinogenicity: Effect on Gene Expression." Science of The Total Environment, The Chromium Paradox in Modern Life, 86, no. 1 (October 1, 1989): 113-29. https://doi.org/10.1016/0048-9697(89)90199-X.

Willard Machle, and Frederick Gregorius. "Cancer of the Respiratory System in the United States Chromate-Producing Industry." Public Health Reports (1896-1970) 63, no. 35 (1948): 1114-27. https://doi.org/10.2307/4586677.

Williams, R. Scott, Jessica S. Williams, and John A. Tainer. "Mre11-Rad50-Nbs1 Is a Keystone Complex Connecting DNA Repair Machinery, Double-Strand Break Signaling, and the Chromatin TemplateThis Paper Is One of a Selection of Papers Published in This Special Issue, Entitled 28th International West Coast Chromatin and Chromosome Conference, and Has Undergone the Journal's Usual Peer Review Process." Biochemistry and Cell Biology 85, no. 4 (August 1, 2007): 50920. https://doi.org/10.1139/007-069.

Wise, Catherine F., Sandra S. Wise, W. Douglas Thompson, Christopher Perkins, and John Pierce Wise. "Chromium Is Elevated in Fin Whale (Balaenoptera Physalus) Skin Tissue and Is Genotoxic to Fin Whale Skin Cells." Biological Trace Element Research 166, no. 1 (July 1, 2015): 108-17. https://doi.org/10.1007/s12011-0150311-X.

Wise, John Pierce, Jan Marc Orenstein, and Steven R. Patierno. "Inhibition of Lead Chromate Clastogenesis by Ascorbate: Relationship to Particle Dissolution and Uptake." Carcinogenesis 14, no. 3 (March 1, 1993): 429-34. https://doi.org/10.1093/carcin/14.3.429.

Wise, John Pierce, Roger Payne, Sandra S. Wise, Carolyne LaCerte, James Wise, Christy Gianios, W. Douglas Thompson, et al. "A Global Assessment of Chromium Pollution Using Sperm Whales (Physeter Macrocephalus) as an Indicator Species." Chemosphere 75, no. 11 (June 1, 2009): 1461-67. https://doi.org/10.1016/j.chemosphere.2009.02.044.

Wise, John Pierce, Sandra S. Wise, and Jennifer E. Little. "The Cytotoxicity and Genotoxicity of Particulate and Soluble Hexavalent Chromium in Human Lung Cells." Mutation Research/Genetic Toxicology and Environmental Mutagenesis 517, no. 1 (May 27, 2002): 221-29. https://doi.org/10.1016/S1383-5718(02)000712.

Wise, Sandra S., Abou El-Makarim Aboueissa, Julieta Martino, and John Pierce Wise. "Hexavalent Chromium-Induced Chromosome Instability Drives Permanent and Heritable Numerical and Structural Changes and a DNA Repair-Deficient 
Phenotype." Cancer Research 78, no. 15 (August 1, 2018): 4203-14. https://doi.org/10.1158/0008-5472.CAN-18-0531.

Wise, Sandra S., Amie L. Holmes, Qin Qin, Hong Xie, Spiros P. Katsifis, W. Douglas Thompson, and John Pierce Wise. "Comparative Genotoxicity and Cytotoxicity of Four Hexavalent Chromium Compounds in Human Bronchial Cells." Chemical Research in Toxicology 23, no. 2 (February 15, 2010): 365-72. https://doi.org/10.1021/tx900363j.

Wise, Sandra S., Amie L. Holmes, and John Pierce Wise. "Particulate and Soluble Hexavalent Chromium Are Cytotoxic and Genotoxic to Human Lung Epithelial Cells." Mutation Research/Genetic Toxicology and Environmental Mutagenesis, 1st Workshop on Chromium and Human Health, 610, no. 1 (November 7, 2006a): 2-7. https://doi.org/10.1016/j.mrgentox.2006.06.005.

Wise, Sandra S., Amie L. Holmes, Hong Xie, W. Douglas Thompson, and John Pierce Wise. "Chronic Exposure to Particulate Chromate Induces Spindle Assembly Checkpoint Bypass in Human Lung Cells." Chemical Research in Toxicology 19, no. 11 (November 1, 2006b): 1492-98. https://doi.org/10.1021/tx0601410.

Wise, Sandra S., Julie H. C. Schuler, Spiros P. Katsifis, and John Pierce Wise. "Barium Chromate Is Cytotoxic and Genotoxic to Human Lung Cells." Environmental and Molecular Mutagenesis 42, no. 4 (2003): 274-78. https://doi.org/10.1002/em.10203.

Wise, Sandra S., Lynne W. Elmore, Shawn E. Holt, Jennifer E. Little, Peter G. Antonucci, Bronwyn H. Bryant, and John Pierce Wise Sr. "Telomerase-Mediated Lifespan Extension of Human Bronchial Cells Does Not Affect Hexavalent Chromium-Induced Cytotoxicity or Genotoxicity." Molecular and Cellular Biochemistry 255, no. 1 (January 1, 2004): 103-12. https://doi.org/10.1023/B:MCBI.0000007266.82705.d9.

Wu, Jiguo, Ana P. Ferragut Cardoso, Vanessa A. R. States, Laila Al-Eryani, Mark Doll, Sandra S. Wise, Shesh N. Rai, and J. Christopher States. "Overexpression of HsaMiR-186 Induces Chromosomal Instability in Arsenic-Exposed Human Keratinocytes." Toxicology and Applied Pharmacology 378 (September 1, 2019): 114614. https://doi.org/10.1016/..taap.2019.114614.

Wu, Minghui, Xue Wang, Natalie Mcgregor, Kenneth J. Pienta, and Jingsong Zhang. "Dynamic Regulation of Rad51 by E2F1 and P53 in Prostate Cancer Cells upon Drug-Induced DNA Damage under Hypoxia." Molecular Pharmacology 85, no. 6 (June 1, 2014): 866-76. https://doi.org/10.1124/mol.113.090688.

Wu, Quili, Yangyang Qu, Xing Li, and Dayong Wang. "Chromium Exhibits Adverse Effects at Environmental Relevant Concentrations in Chronic Toxicity Assay System of Nematode Caenorhabditis Elegans." Chemosphere 87, no. 11 (June 1, 2012): 1281-87. https://doi.org/10.1016/..chemosphere.2012.01.035.

Xia, Bo, Xiao-hu Ren, Zhi-xiong Zhuang, Lin-qing Yang, Hai-yan Huang, Li Pang, Desheng $\mathrm{Wu}$, et al. "Effect of Hexavalent Chromium on Histone Biotinylation in 
Human Bronchial Epithelial Cells." Toxicology Letters 228, no. 3 (August 4, 2014): 241-47. https://doi.org/10.1016/j.toxlet.2014.05.010.

Xie, Chengzhi, Christina Drenberg, Holly Edwards, J. Timothy Caldwell, Wei Chen, Hiroto Inaba, Xuelian Xu, et al. "Panobinostat Enhances Cytarabine and Daunorubicin Sensitivities in AML Cells through Suppressing the Expression of BRCA1, CHK1, and Rad51." PLOS ONE 8, no. 11 (November 11, 2013). https://doi.org/10.1371/journal.pone.0079106.

Xie, Hong, Amie L. Holmes, Sandra S. Wise, Nancy Gordon, and John Pierce Wise. "Lead Chromate-Induced Chromosome Damage Requires Extracellular Dissolution to Liberate Chromium lons but Does Not Require Particle Internalization or Intracellular Dissolution." Chemical Research in Toxicology 17, no. 10 (October 1, 2004): 1362-67. https://doi.org/10.1021/tx0498509.

Xie, Hong, Amie L. Holmes, Jamie L. Young, Qin Qin, Kellie Joyce, Stephen C. Pelsue, Cheng Peng, et al. "Zinc Chromate Induces Chromosome Instability and DNA Double Strand Breaks in Human Lung Cells." Toxicology and Applied Pharmacology 234, no. 3 (February 1, 2009): 293-99. https://doi.org/10.1016/j.taap.2008.10.010.

Xie, Hong, Sandra S. Wise, Amie L. Holmes, Bo Xu, Timothy P. Wakeman, Stephen C. Pelsue, Narendra P. Singh, and John Pierce Wise. "Carcinogenic Lead Chromate Induces DNA Double-Strand Breaks in Human Lung Cells." Mutation Research/Genetic Toxicology and Environmental Mutagenesis 586, no. 2 (October 3, 2005): 160-72. https://doi.org/10.1016/j.mrgentox.2005.06.002.

Xie, Hong, Sandra S. Wise, and John P. Wise. "Deficient Repair of Particulate Hexavalent Chromium-Induced DNA Double Strand Breaks Leads to Neoplastic Transformation." Mutation Research/Genetic Toxicology and Environmental Mutagenesis 649, no. 1 (January $8, \quad 2008$ ): 230-38. https://doi.org/10.1016/j.mrgentox.2007.09.008.

Ye, Jianping, and Xianglin Shi. "Gene Expression Profile in Response to ChromiumInduced Cell Stress in A549 Cells." Molecular and Cellular Biochemistry 222, no. 1 (June 1, 2001): 189-97. https://doi.org/10.1023/A:1017974415052.

Zecevic, Alma, Haley Menard, Volkan Gurel, Elizabeth Hagan, Rosamaria DeCaro, and Anatoly Zhitkovich. "WRN Helicase Promotes Repair of DNA Double-Strand Breaks Caused by Aberrant Mismatch Repair of Chromium-DNA Adducts." Cell Cycle 8, no. 17 (September 1, 2009): 2769-78. https://doi.org/10.4161/cc.8.17.9410.

Zhang, Fan, Qiang Fan, Keqin Ren, and Paul R. Andreassen. "PALB2 Functionally Connects the Breast Cancer Susceptibility Proteins BRCA1 and BRCA2." Molecular Cancer Research 7, no. 7 (July 1, 2009): 1110-18. https://doi.org/10.1158/1541-7786.MCR-09-0123.

Zhang, Yujing, Yuanyuan Xiao, Yu Ma, Ningjuan Liang, Yuehui Liang, Chan Lu, and Fang Xiao. "ROS-Mediated MiR-21-5p Regulates the Proliferation and Apoptosis of $\mathrm{Cr}(\mathrm{VI})$-Exposed L02 Hepatocytes via Targeting PDCD4." Ecotoxicology and 
Environmental Safety $191 \quad$ (March $15, \quad 2020): \quad 110160$. https://doi.org/10.1016/j.ecoenv.2019.110160.

Zhitkovich Anatoly, Quievryn George, Messer Joseph, and Motylevich Zhanna. "Reductive Activation with Cysteine Represents a Chromium(III)-Dependent Pathway in the Induction of Genotoxicity by Carcinogenic Chromium(VI)." Environmental Health Perspectives 110, no. suppl 5 (October 1, 2002): 729-31. https://doi.org/10.1289/ehp.02110s5729.

Zhitkovich, Anatoly, Victoria Voitkun, and Max Costa. "Formation of the Amino Acid-DNA Complexes by Hexavalent and Trivalent Chromium in Vitro: Importance of Trivalent Chromium and the Phosphate Group." Biochemistry 35, no. 22 (January 1, 1996): 7275-82. https://doi.org/10.1021/bi960147w.

Zhou, Lu, Yunguo Liu, Shaobo Liu, Yicheng Yin, Guangming Zeng, Xiaofei Tan, Xi Hu, et al. "Investigation of the Adsorption-Reduction Mechanisms of Hexavalent Chromium by Ramie Biochars of Different Pyrolytic Temperatures." Bioresource Technology 218 (October 1, 2016): 351-59. https://doi.org/10.1016/j.biortech.2016.06.102.

Zinsstag, J., E. Schelling, D. Waltner-Toews, and M. Tanner. "From 'One Medicine' to 'One Health' and Systemic Approaches to Health and Well-Being." Preventive Veterinary Medicine 101, no. 3 (September 1, 2011): 148-56. https://doi.org/10.1016/..prevetmed.2010.07.003.

Zou, Yue, Yiyong Liu, Xiaoming Wu, and Steven M. Shell. "Functions of Human Replication Protein A (RPA): From DNA Replication to DNA Damage and Stress Responses." Journal of Cellular Physiology 208, no. 2 (2006): 267-73. https://doi.org/10.1002/jcp.20622. 


\section{APPENDIX I}

Chapter 1: Introduction of this dissertation was modified from Speer and Wise, 2018. Rights for use are below.

\section{ELSEVIER LICENSE TERMS AND CONDITIONS}

May 29, 2020

This Agreement between 232 Clay Street ("You") and Elsevier ("Elsevier") consists of your license details and the terms and conditions provided by Elsevier and Copyright Clearance Center.

The publisher has provided special terms related to this request that can be found at the end of the Publisher's Terms and Conditions.

License Number $\quad 4744840416429$

License date Jan 09, 2020

Licensed Content Publisher Elsevier

Licensed Content Publication Elsevier Books

Licensed Content Title

Reference Module in

Chemistry, Molecular

Sciences and Chemical

Engineering

Licensed Content Author Rachel M. Speer, John

Pierce Wise

Licensed Content Date Jan 1, 2018

Licensed Content Pages 1

Start Page End Page

Type of Use: reuse in a thesis/dissertation

I am an academic or government institution with a full-text subscription to this journal and the audience of the material consists of students and/or employees of this institute? No 
Portion: full chapter

Circulation: 1

Format: electronic

Are you the author of this Elsevier chapter? Yes

Will you be translating? No

Title: Chromate-Induced E2F1 Suppression of RAD51: A One Environmental Health

Approach

Institution name: University of Louisville

Expected presentation date Mar 2020

Publisher Tax ID 98-0397604

Terms and Conditions

INTRODUCTION

1. The publisher for this copyrighted material is Elsevier. By clicking "accept" in connection with completing this licensing transaction, you agree that the following terms and conditions apply to this transaction (along with the Billing and Payment terms and conditions

established by Copyright Clearance Center, Inc. ("CCC"), at the time that you opened your Rightslink account and that are available at any time at $h$ ttp://myaccount.copyright.com).

\section{GENERAL TERMS}

2. Elsevier hereby grants you permission to reproduce the aforementioned material subject to the terms and conditions indicated.

3. Acknowledgement: If any part of the material to be used (for example, figures) has

appeared in our publication with credit or acknowledgement to another source, permission must also be sought from that source. If such permission is not obtained then that material may not be included in your publication/copies. Suitable acknowledgement to the source must be made, either as a footnote or in a reference list at the end of your publication, as follows:

"Reprinted from Publication title, Vol /edition number, Author(s), Title of article / title of chapter, Pages No., Copyright (Year), with permission from Elsevier [OR APPLICABLE SOCIETY COPYRIGHT OWNER]." Also Lancet special credit - "Reprinted from The Lancet, Vol. number, Author(s), Title of article, Pages No., Copyright (Year), with permission from Elsevier." 
4. Reproduction of this material is confined to the purpose and/or media for which permission is hereby given.

5. Altering/Modifying Material: Not Permitted. However figures and illustrations may be

altered/adapted minimally to serve your work. Any other abbreviations, additions, deletions and/or any other alterations shall be made only with prior written authorization of Elsevier Ltd. (Please contact Elsevier at permissions@elsevier.com). No modifications can be made to any Lancet figures/tables and they must be reproduced in full.

6. If the permission fee for the requested use of our material is waived in this instance, please be advised that your future requests for Elsevier materials may attract a fee.

7. Reservation of Rights: Publisher reserves all rights not specifically granted in the combination of (i) the license details provided by you and accepted in the course of this licensing transaction, (ii) these terms and conditions and (iii) CCC's Billing and Payment terms and conditions.

8. License Contingent Upon Payment: While you may exercise the rights licensed immediately upon issuance of the license at the end of the licensing process for the transaction, provided that you have disclosed complete and accurate details of your proposed use, no license is finally effective unless and until full payment is received from you (either by publisher or by CCC) as provided in CCC's Billing and Payment terms and conditions. If full payment is not received on a timely basis, then any license preliminarily granted shall be deemed automatically revoked and shall be void as if never granted. Further, in the event that you breach any of these terms and conditions or any of CCC's Billing and Payment terms and conditions, the license is automatically revoked and shall be void as if never granted. Use of materials as described in a revoked license, as well as any use of the materials beyond the scope of an unrevoked license, may constitute copyright infringement and publisher reserves the right to take any and all action to protect its copyright in the materials.

9. Warranties: Publisher makes no representations or warranties with respect to the licensed material.

10. Indemnity: You hereby indemnify and agree to hold harmless publisher and CCC, and their respective officers, directors, employees and agents, from and against any and all claims arising out of your use of the licensed material other than as specifically authorized pursuant to this license.

11. No Transfer of License: This license is personal to you and may not be sublicensed, 
assigned, or transferred by you to any other person without publisher's written permission.

12. No Amendment Except in Writing: This license may not be amended except in a writing signed by both parties (or, in the case of publisher, by CCC on publisher's behalf).

13. Objection to Contrary Terms: Publisher hereby objects to any terms contained in any purchase order, acknowledgment, check endorsement or other writing prepared by you, which terms are inconsistent with these terms and conditions or CCC's Billing and Payment terms and conditions. These terms and conditions, together with CCC's Billing and Payment terms and conditions (which are incorporated herein), comprise the entire agreement between you and publisher (and CCC) concerning this licensing transaction. In the event of any conflict between your obligations established by these terms and conditions and those established by CCC's Billing and Payment terms and conditions, these terms and conditions shall control.

14. Revocation: Elsevier or Copyright Clearance Center may deny the permissions described in this License at their sole discretion, for any reason or no reason, with a full refund payable to you. Notice of such denial will be made using the contact information provided by you. Failure to receive such notice will not alter or invalidate the denial. In no event will Elsevier or Copyright Clearance Center be responsible or liable for any costs, expenses or damage incurred by you as a result of a denial of your permission request, other than a refund of the amount(s) paid by you to Elsevier and/or Copyright Clearance Center for denied permissions.

\section{LIMITED LICENSE}

The following terms and conditions apply only to specific license types:

15. Translation: This permission is granted for non-exclusive world English rights only unless your license was granted for translation rights. If you licensed translation rights you may only translate this content into the languages you requested. A professional translator must perform all translations and reproduce the content word for word preserving the integrity of the article.

16. Posting licensed content on any Website: The following terms and conditions apply as follows: Licensing material from an Elsevier journal: All content posted to the web site must maintain the copyright information line on the bottom of each image; A hyper-text must be included to the Homepage of the journal from which you are licensing at http://www.sciencedirect.com/science/journal/xxxxx or the Elsevier homepage for books at $\mathrm{h}$ ttp://www.elsevier.com; Central Storage: This license does not include permission for a scanned version of the material to be stored in a central repository such as that provided by Heron/XanEdu. 
Licensing material from an Elsevier book: A hyper-text link must be included to the Elsevier homepage at $\mathrm{h}$ ttp://www.elsevier.com . All content posted to the web site must maintain the copyright information line on the bottom of each image.

Posting licensed content on Electronic reserve: In addition to the above the following clauses are applicable: The web site must be password-protected and made available only to bona fide students registered on a relevant course. This permission is granted for 1 year only. You may obtain a new license for future website posting.

17. For journal authors: the following clauses are applicable in addition to the above:

Preprints:

A preprint is an author's own write-up of research results and analysis, it has not been peer- reviewed, nor has it had any other value added to it by a publisher (such as formatting, copyright, technical enhancement etc.).

Authors can share their preprints anywhere at any time. Preprints should not be added to or enhanced in any way in order to appear more like, or to substitute for, the final versions of articles however authors can update their preprints on arXiv or RePEc with their Accepted Author Manuscript (see below).

If accepted for publication, we encourage authors to link from the preprint to their formal publication via its DOI. Millions of researchers have access to the formal publications on ScienceDirect, and so links will help users to find, access, cite and use the best available version. Please note that Cell Press, The Lancet and some society-owned have different preprint policies. Information on these policies is available on the journal homepage.

Accepted Author Manuscripts: An accepted author manuscript is the manuscript of an article that has been accepted for publication and which typically includes author- incorporated changes suggested during submission, peer review and editor-author communications.

Authors can share their accepted author manuscript: immediately via their non-commercial person homepage or blog by updating a preprint in arXiv or RePEc with the accepted manuscript via their research institute or institutional repository for internal institutional uses or as part of an invitation-only research collaboration work-group directly by providing copies to their students or to research collaborators for their personal use for private scholarly sharing as part of an invitation-only work group on commercial sites with which Elsevier has an agreement. After the embargo period via noncommercial hosting platforms such as their institutional repository via commercial sites with which Elsevier has an agreement 
In all cases accepted manuscripts should link to the formal publication via its DOI bear a CC-BY-NC-ND license - this is easy to do if aggregated with other manuscripts, for example in a repository or other site, be shared in alignment with our hosting policy not be added to or enhanced in any way to appear more like, or to substitute for, the published journal article.

Published journal article (JPA): A published journal article (PJA) is the definitive final record of published research that appears or will appear in the journal and embodies all value-adding publishing activities including peer review co-ordination, copy-editing, formatting, (if relevant) pagination and online enrichment.

Policies for sharing publishing journal articles differ for subscription and gold open access articles:

Subscription Articles: If you are an author, please share a link to your article rather than the full-text. Millions of researchers have access to the formal publications on ScienceDirect, and so links will help your users to find, access, cite, and use the best available version.

Theses and dissertations which contain embedded PJAs as part of the formal submission can be posted publicly by the awarding institution with DOI links back to the formal publications on ScienceDirect.

If you are affiliated with a library that subscribes to ScienceDirect you have additional private sharing rights for others' research accessed under that agreement. This includes use for classroom teaching and internal training at the institution (including use in course packs and courseware programs), and inclusion of the article for grant funding purposes.

Gold Open Access Articles: May be shared according to the author-selected end-user license and should contain a CrossMark logo, the end user license, and a DOI link to the formal publication on ScienceDirect.

Please refer to Elsevier's posting policy for further information.

18. For book authors the following clauses are applicable in addition to the above:

Authors are permitted to place a brief summary of their work online only. You are not allowed to download and post the published electronic version of your chapter, nor may you scan the printed edition to create an electronic version. Posting to a repository: Authors are permitted to post a summary of their chapter only in their institution's repository.

19. Thesis/Dissertation: If your license is for use in a thesis/dissertation your thesis may be submitted to your institution in either print or electronic form. Should your thesis be published commercially, please reapply for permission. These requirements include permission for the Library and 
Archives of Canada to supply single copies, on demand, of the complete thesis and include permission for Proquest/UMI to supply single copies, on demand, of the complete thesis. Should your thesis be published commercially, please reapply for permission. Theses and dissertations which contain embedded PJAs as part of the formal submission can be posted publicly by the awarding institution with DOI links back to the formal publications on ScienceDirect.

\section{Elsevier Open Access Terms and Conditions}

You can publish open access with Elsevier in hundreds of open access journals or in nearly 2000 established subscription journals that support open access publishing. Permitted third party re-use of these open access articles is defined by the author's choice of Creative

Commons user license. See our o pen access license policy for more information.

Terms \& Conditions applicable to all Open Access articles published with Elsevier:

Any reuse of the article must not represent the author as endorsing the adaptation of the article nor should the article be modified in such a way as to damage the author's honour or reputation. If any changes have been made, such changes must be clearly indicated.

The author(s) must be appropriately credited and we ask that you include the end user license and a DOI link to the formal publication on ScienceDirect.

If any part of the material to be used (for example, figures) has appeared in our publication with credit or acknowledgement to another source it is the responsibility of the user to ensure their reuse complies with the terms and conditions determined by the rights holder.

Additional Terms \& Conditions applicable to each Creative Commons user license:

CC BY: The CC-BY license allows users to copy, to create extracts, abstracts and new works from the Article, to alter and revise the Article and to make commercial use of the Article (including reuse and/or resale of the Article by commercial entities), provided the user gives appropriate credit (with a link to the formal publication through the relevant DOI), provides a link to the license, indicates if changes were made and the licensor is not represented as endorsing the use made of the work. The full details of the license are available at $\mathrm{h}$ ttp://creativecommons.org/licenses/by/4.0. CC BY NC SA: The CC BY-NC-SA license allows users to copy, to create extracts, abstracts and new works from the Article, to alter and revise the Article, provided this is not done for commercial purposes, and that the user gives appropriate credit (with a link to the formal publication through the relevant $\mathrm{DOI}$ ), provides a link to the 
license, indicates if changes were made and the licensor is not represented as endorsing the use made of the work. Further, any new works must be made available on the same conditions. The full details of the license are available at $\mathrm{h}$ ttp://creativecommons.org/licenses/by-nc-sa/4.0.

CC BY NC ND: The CC BY-NC-ND license allows users to copy and distribute the Article, provided this is not done for commercial purposes and further does not permit distribution of the Article if it is changed or edited in any way, and provided the user gives appropriate credit (with a link to the formal publication through the relevant $\mathrm{DOI}$ ), provides a link to the license, and that the licensor is not represented as endorsing the use made of the work. The full details of the license are available at http://creativecommons.org/licenses/by-nc-nd/4.0. Any commercial reuse of Open Access articles published with a CC BY NC SA or CC BY NC ND license requires permission from Elsevier and will be subject to a fee.

Commercial reuse includes:

Associating advertising with the full text of the Article Charging fees for document delivery or access Article aggregation Systematic distribution via email lists or share buttons posting or linking by commercial companies for use by customers of those companies.

20. Other Conditions: Posting of the full article online is not permitted. You may post an abstract with a link to the Elsevier website www.elsevier.com , or to the article on ScienceDirect if it is available on that platform.

v1.9

Questions? c ustomercare@copyright.com or +1-855-239-3415 (toll free in the US) or

+1-978-646-2777. 


\section{LIST OF ABBREVIATIONS}

\begin{tabular}{ll} 
ATM & Ataxia telangiectasia mutated \\
BER & Base excision repair \\
BRCA1 & Breast cancer type 1 susceptibility protein \\
BRCA2 & Breast cancer type 2 susceptibility protein \\
BrdU & 5-bromodeoxyuridine \\
CDNA & complementary DNA \\
CHX & Cycloheximide \\
NHEJ & Non-homologous end joining \\
CMV & Cytomegalovirus \\
Cr & Chromium \\
Cr(III) & Trivalent chromium \\
Cr(VI) & Hexavalent chromium \\
CRISPR & Clustered regularly interspaced short palindromic repeats \\
CT & Cycle threshold \\
DAPI & 4',6-diamidino-2-phenylindole \\
DNA & Deoxyribonucleic acid \\
DREAM & dimerization partner, RB-like, E2F and multi-vulval class B \\
DR-GFP & Direct repeat green fluorescent protein \\
EGR1 & Early Growth Response \\
\hline
\end{tabular}




\begin{tabular}{|c|c|}
\hline EPA & Environmental protection agency \\
\hline E2F1 & E2 Transcription Factor 1 \\
\hline E2F4 & E2 Transcription Factor 4 \\
\hline EDTA & Ethylenediaminetetraacetic acid \\
\hline GAPDH & Glyceraldehyde 3-phosphate dehydrogenase \\
\hline GSH & Glutathione \\
\hline H3 & Histone 3 \\
\hline $\mathrm{H} 4$ & Histone 4 \\
\hline hTERT & Human telomerase \\
\hline KEGG & Kyoto encyclopedia of genes and genetics \\
\hline MaxIP & Maximum image projection \\
\hline miRNA & microRNA \\
\hline mirSVR & microRNA vector regression \\
\hline MMR & Mismatch repair \\
\hline MLH1 & MutL homolog 1 \\
\hline MLH2 & MutL homolog 2 \\
\hline MRN & MRE11, RAD50 and Nbs1 complex \\
\hline mRNA & Messenger RNA \\
\hline NADPH & Nicotinamide adenine dinucleotide phosphate \\
\hline OSHA & Occupational Safety and Health Administration \\
\hline PGDC9-1LU & Playa Grande Dermochelys coriacea 9-1 lung \\
\hline Pre-miRNA & precursor-miRNA \\
\hline Pri-miRNA & primary-miRNA \\
\hline
\end{tabular}




$\begin{array}{ll}\text { qPCR } & \text { Quantitative real-time polymerase chain reaction } \\ \text { RAD51 } & \text { RAD51 recombinase } \\ \text { RAD51B } & \text { RAD51 paralog B } \\ \text { RAD51C } & \text { RAD51 paralog C } \\ \text { RB } & \text { Retinoblastoma Protein } \\ \text { RNA } & \text { Ribonucleic acid } \\ \text { ROI } & \text { Region of interest } \\ \text { RPA } & \text { Replication protein A } \\ \text { RNAseq } & \text { RNA sequencing } \\ \text { SEM } & \text { Standard error of the mean } \\ \text { siRNA } & \text { small interfering RNA } \\ \text { SSDNA } & \text { Single stranded DNA } \\ \text { U.S. } & \text { United States } \\ \text { UTR } & \text { Untranslated region } \\ \text { WTHBF-6 } & \text { hTERT-immortalized human bronchial fibroblasts }\end{array}$




\title{
CURRICULUM VITAE
}

\author{
Rachel M. Speer, M.S.
}

Mailing Address: Wise Laboratory of Environmental and Genetic Toxicology

Department of Pharmacology and Toxicology, School of Medicine University of Louisville

500 S. Preston St.

HSC-A, room 1403

Louisville, KY 40202

E-Mail: $\quad$ rachel.speer@louisville.edu

\section{Education}

2017-Present

2015-2017

2014-2015

2010-2013
Ph.D. Candidate in Pharmacology and Toxicology, University of Louisville, Louisville, KY.

M.S. in Pharmacology and Toxicology, University of Louisville, Louisville, KY.

Ph.D. Student in Biochemistry and Molecular Biology, University of Maine, Orono, ME. (Transferred with mentor after first year)

B.S. in Biotechnology and Molecular Bioscience, Rochester Institute of Technology, Rochester, NY.

\section{Current Appointments}

2020-Present

Dissertation Completion Fellowship, The Graduate School, University of Louisville

2019-Present Member, FUTURE Committee, Society of Toxicology

2019-Present Member, Programming Subcommittee, Graduate Student Leadership Committee, Society of Toxicology

2018-Present Graduate Student Representative, Metals Specialty Section, Society of Toxicology

2018-Present Policy Coordinator, Science Policy and Outreach Group, University of

\section{Professional Experience}


2014-Present Graduate Student, Wise Laboratory of Environmental and Genetic Toxicology, University of Southern Maine (2014-2015) and University of Louisville (2015-Present).

2013-2014 Research Associate. Wise Laboratory of Environmental and Genetic Toxicology, University of Southern Maine, Portland, ME.

$2013 \quad$ Graduate Research Assistant. "Sound behaviour of humpback whales (Megaptera novaeangliae) on summer feeding grounds in Northeast Icelandic waters." Húsavík Research Center, University of Iceland, Húsavík, Iceland.

$2012 \quad$ Field Assistant. "Abundance and Survival of Pacific Humpback Whales in a Proposed Critical Habitat Area." North Coast Cetacean Society, British Columbia, Canada.

2012 Research Assistant. "Applications of a new in vivo tumor spheroid based shell-less chorioallantoic membrane 3D model in bioengineering research." Rochester Institute of Technology and Rochester General Hospital, Rochester, NY.

\section{Fellowships and Awards}

2020 Celebrating Women in Toxicology Award, Women in Toxicology Special Interest Group, Society of Toxicology

2020 Graduate Student Travel Award, University of Louisville, for travel to the 59th annual meeting of the Society of Toxicology.

2020 Doctoral Dissertation Completion Award, competitive stipend award to complete degree, University of Louisville, Louisville, KY.

2019-2020 Graduate Research Fellowship, NIEHS R01 award to Dr. John Wise

2019 Ph.D. Poster Award, First Place, Ohio Valley Regional Chapter of the Society of Toxicology (OVSOT) Annual Meeting, Cincinnati, $\mathrm{OH}$.

2019 Tox on the Clock Presentation Award, Third Place, Ohio Valley Regional Chapter of the Society of Toxicology (OVSOT) Annual Meeting, Cincinnati, OH.

2019 K.C. Huang Outstanding Graduate Student Award, Department of Pharmacology and Toxicology, University of Louisville, Louisville, KY.

2019 Graduate Student Travel Award, Society of Toxicology, for travel to the 58th annual meeting of the Society of Toxicology, Baltimore, MD.

2019 Graduate Student Travel Award, University of Louisville, for travel to the International Sea Turtle Symposium, Charleston, SC.

2017-2019 T32 Environmental Health Sciences Predoctoral Training Grant, National Institute of Environmental Health Sciences.

2018 Ph.D. Poster Award, Second Place, Ohio Valley Society of Toxicology Regional Meeting, Louisville, KY. 
2018 Graduate Student Oral Presentation Award, 20th Annual Midwest DNA Repair Symposium, Columbus, $\mathrm{OH}$.

2018 Graduate Student Travel Award, University of Louisville, for travel to the 10th Conference on Metal Toxicity \& Carcinogenesis, Albuquerque, NM.

2018 Graduate Student Travel Award, University of Louisville, for travel to the 57th annual meeting of the Society of Toxicology.

2018 Graduate Student Council Research Award, University of Louisville, and $\$ 500$ award for RNAseq analysis.

2017 Graduate Dean's Citation Award, University of Louisville.

2017 Graduate Student Travel Award, University of Louisville, for travel to the 56th annual meeting of the Society of Toxicology.

2016 Graduate Student Council Research Award, University of Louisville, and $\$ 500$ award for ICP-MS analysis of leatherback sea turtle samples.

2015 Master's Basic Science Graduate Student Award, Second place for Research!Louisville poster presentation, University of Louisville.

2015 Graduate Student Award, Second place for the 54th annual meeting of the Society of Toxicology from the Northeast Regional Chapter of the Society of Toxicology.

2015 Graduate Student Travel Support Award for travel to the 54th Annual Meeting of the Society of Toxicology from the Maine Economic Improvement Fund, University of Southern Maine.

\section{Publications}

1. Speer, R.M., The, T., Xie, H., Liou, L., Adam, R., Wise, J.P., Sr. (2017) Cytotoxicity and Genotoxicity of Particulate and Soluble Cobalt in Human Urothelial Cells. Biological and Trace Element Research. 180: 48. doi: 10.1007/s12011-017-0989-z.

2. Browning, C.L., Speer, R.M., and Wise, J.P., Sr. (2017) "Molecular Mechanisms of Chromium-Induced Carcinogenesis," in Mudipalli, A., Zelikoff, J.T. (Eds) Essential and Non- Essential Metals: Carcinogenesis, Prevention and Therapeutics, Springer, UK, ISBN 978-3-319-55448-8.

3. Speer, R.M., Wise, C.W., Young, J.L., Aboueissa, A.M., Martin Bras, M., Barandiarin, M., Bermúdez E., Marquez-D’Acunti, L., Wise, J.P., Sr. (2018) The Cytotoxicity and Genotoxicity of Particulate and Soluble Hexavalent Chromium in Leatherback Sea Turtle Lung Cells. Aquatic Toxicology. 198:149-157. doi: 10.1016/j.aquatox.2018.03.003.

4. Speer, R.M., Wise, J.P., Sr. (2018) Current Status on Chromium Research and its Implications for Health and Risk Assessment. Chemistry Molecular Sciences and Chemical Engineering. 1-16. doi.org/10.1016/B978-0-12-409547-2.14283-0. 
5. Wise Jr., J.P., Croom-Perez, T.J., Meaza Isusi, I., Aboueissa, A.M., Lopez Montalvo, C.A., Martin Bras, M., Speer, R.M., Bonilla Garzon, N.A., Urban, J.R., Perkins, C., Wise Sr., J.P. (2019) A Whale of a Tale: A One Environmental Health Approach to Study Metal Pollution in the Sea of Cortez. Toxicology and Applied Pharmacology. 376: 58-69. https://doi.org/10.1016/j.taap.2019.05.005.

6. Speer, R.M., Wise, S.S., Croom-Perez, T.J., Aboueissa, A.M., Martin Bras, M., Barandiaran, M., Bermúdez, E., Wise, J.P., Sr. (2019) A Comparison of Particulate Hexavalent Chromium Cytotoxicity and Genotoxicity in Human and Leatherback Sea Turtle Lung Cells from a One Environmental Health Perspective. Toxicology and Applied Pharmacology. 376: 70-81. https://doi.org/10.1016/j.taap.2019.05.013.

7. Meaza, I., Speer, R.M., Toyoda, J.H., Lu, H., Wise, S.S., Croom-Perez, T.J., Aboueissa, A., and Wise, J.P., Sr. (2020) Prolonged exposure to particulate $\mathrm{Cr}(\mathrm{VI})$ is cytotoxic and genotoxic to fin whale cells. Journal of Trace Elements in Medicine and Biology. https://doi.org/10.1016/j.jtemb.2020.126562.

\section{Abstracts}

1. Speer, R.M., The, T., and Wise, Sr., J.P. The Cytotoxicity and Genotoxicity of Particulate and Soluble Cobalt in Human Urothelial Cells. Toxicological Sciences, 144: 75, 2015.

2. Speer, R.M., The, T., and Wise, Sr., J.P. Comparison of the Cytotoxicity and Genotoxicity of Particulate and Soluble Hexavalent Chromium in Human and Leatherback Sea Turtle (Dermochelys coriacea) Skin Cells Toxicological Sciences, 150(1): 154 LB, 2016.

3. Speer, R.M., Young, J.L., Martin Bras, M., Barandiarin, M., Marquez, L., and Wise, Sr., J.P. A Comparison of the Cytotoxicity and Genotoxicity of Particulate and Soluble Hexavalent Chromium in Human and Leatherback Sea Turtle (Dermochelys coriacea) Skin Cells. Proceedings of the Annual Meeting of the International Association of Aquatic Animal Medicine (IAAAM), 2016.

4. Speer, R.M., Young, J.L., Martin Bras, M., Barandiaran, M., Marquez-D'Acunti, L., and Wise, Sr., J.P. A Comparison of the Cytotoxicity and Genotoxicity of Particulate and Soluble Hexavalent Chromium in Human and Leatherback sea Turtle (Dermochelys coriacea) Lung Cells. Proceedings of the 9th Conference on Metal Toxicity and Carcinogenesis, 4, 2016, Lexington, KY.

5. Young, J.L., Wise, S.S., Wise, C.F., Speer, R.M., Raph, S.M. Lowers, R., Hall, C., Phillipps, L., Guillette, Jr., L.J., and Wise, Sr., J.P. Using the American alligator (Alligator mississippiensis) as a Representative Species to Study Environmental Toxicology using a One Environmental Health Approach at Kennedy Space Center. Proceedings of the $3^{\text {rd }}$ Biennial Symposium on the Biology and Ecotoxicology of the American Alligator, 2016.

6. Speer, R.M., Young, J.L., Martin Bras, M., Barandiaran, M., Marquez-D'Acunti, L., and Wise, Sr., J.P. A Comparison of the Cytotoxicity and Genotoxicity of Particulate and Soluble Hexavalent Chromium in Human and Leatherback Sea Turtle (Dermochelys coriacea) Lung Cells. Proceedings of the 8th Aquatic Animal Models of Human Disease Conference, 2017. 
7. Speer, R.M., Young, J.L., Wise, S.S., Raph, S.M., Martin Bras, M., Barandiarin, M., Marquez-D'Acunti, L., and Wise, Sr., J.P. Using Leatherback Sea Turtles (Dermochelys coriacea) as a Model Species for Metal Toxicology Research and Public Education in Vieques, Puerto Rico. Toxicological Sciences, 156(1): 263, 2017.

8. Wise, Sr., J.P., Browning, C.L., Wise, S.S., Speer, R., and Lu, H. Homologous Recombination Repair in Chemical Carcinogenesis: Hexavalent Chromium Induces DNA Strand Breaks while Targeting Rad51 to Inhibit Their Repair. Presented at the 19th Annual Midwest DNA Repair Symposium, p. 16, Dayton, OH, May, 2017.

9. Speer, R.M., Browning, C.L. and Wise, Sr., J.P. Chromate-Induced Suppression of E2F1 and RAD51 in the Homologous Recombination Response. Presented at the Ohio Valley Chapter of the Society of Toxicology (OVSOT) annual meeting, December, 2017.

10. Wise, Jr., J.P. Montalvo, C.L., Wise, C.F., Wise, S.S., Wise, J.T.F., Speer, R.M., Li Chen, T., Abouiessa, A., Perkins, C., Bras, M.M., Savery, L.C., Urbán, J. and Wise, Sr., J.P. A Whale of a Tale: Using a One Health Approach to Study Metal Pollution in the Sea of Cortez. Presented at the annual meeting of the Southern California Marine Mammal Workshop (SCMMW), Newport Beach, CA, January, 2018.

11. Speer, R.M., Browning, C.L. and Wise, Sr., J.P. Chromate-Induced Suppression of E2F1 and RAD51 in the Homologous Recombination Response. Toxicological Sciences, 150(1): 480, 2018.

12. Wise, Jr., J.P. Montalvo, C.L., Wise, C.F., Wise, S.S., Wise, J.T.F., Speer, R.M., Li Chen, T., Abouiessa, A., Perkins, C., Bras, M.M., Savery, L.C., Urbán, J. and Wise, Sr., J.P. Of Whales and Men: A One Health Approach to Study Metal Pollution in the Sea of Cortez. Presented at the annual meeting of the International Association for Aquatic Animal Medicine (IAAAM), Long Beach, CA, May, 2018.

13. Speer, R.M., Browning, C.L., and Wise, Sr. J.P. Mechanisms of E2F1 Suppression of RAD51 in Chromate-Induced Failure of Homologous Recombination. Presented at the 20th Annual Midwest DNA Repair Symposium, Columbus, OH, May, 2018.

14. Wise, Sr., J.P., Wise, S.S., Speer, R.M., Toyoda, J.H. and Meaza, I. Caracterización de los Efectos Toxicológicos del Cromo Particulado Hexavalente en Cultivos Celulares Primarios de Rorcual Común y Yubarta (Characterization of the Toxicological Effects of Particulate Hexavalent Chromium in Fin Whale and Humpback Whale Primary Cell Cultures). Congreso de la Sociedad Española de Cetaceos (Spanish Society of Cetaceans Congress), Bilbao, Spain, October 2018.

15. Speer, R.M., Browning, C.L., and Wise, Sr., J.P. Suppression of E2F1 and RAD51 in Chromate-Induced Failure of Homologous Recombination. Presented at the annual meeting of the Ohio Valley Regional Chapter of the Society of Toxicology (OVSOT), Louisville, KY, November, 2018.

16. Speer, R.M., Wise, C.F., Wise, S.S., Martin Bras, M., Barandiarin, M., Marquez, L., Bermudez, E., and Wise, Sr., J.P. Environmental Impacts on Leatherback Sea Turtle Health: Using a One Health Approach to Study Metal Pollution in Wlldlife. Presented at the International Sea Turtle Symposium, February, 2019. 
17. Speer, R.M., Browning, C.L., and Wise, Sr., J.P. Suppression of E2F1 and RAD51 in Chromate-Induced Failure of Homologous Recombination. Presented at the annual meeting of the Society of Toxicology (SOT), Baltimore, MD, March, 2019.

18. Lu, H., Browning, C.L., Wise, S.S., Toyoda, J.H., Speer, R.M., Raph, S., Wise, J.P., Sr. Prolonged Particulate Chromate Exposure Does Not Inhibit Homologous Recombination Repair in Bowhead Whale Lung Cells. Presented at the Annual Meeting of the Society of Toxicology (SOT), Baltimore, MD, March, 2019.

19. Wise, Jr., J.P., Croom-Perez, T.J., Meaza, I., Montalvo, C.L., Wise, C.F., Wise, S.S., Wise, J.T.F., Speer, R.M., Abouiessa, A., Bras, M.M., Savery, L.C., Urbán, J., Young, J.L., and Wise, Sr., J.P. A Whale of a Tale: A One Environmental Health Approach to Study Metal Pollution in the Sea of Cortez. Presented at the Annual Meeting of the Society of Toxicology (SOT), Baltimore, MD, March, 2019.

20. Lu, H., Browning, C.L, Wise, S.S., Toyoda, J.H., Speer, R.M., and Wise, Sr., J.P. Bowhead Whale Lung Cells Maintain Homologous Recombination Repair and Resist Genomic Instability during Prolonged Particulate Chromate Exposure. Presented at the Annual Meeting of the Environmental Mutagenesis and Genomics Society (EMGS), Washington, D.C., September, 2019.

21. Wise, Sr., J.P., Wise, Jr., J.P., Toyoda, J.H., Croom-Perez, T.J., Aboueissa, A., , Montalvo, C.L., Isusi, I.M., Wise, S.S., Wise, C.F., Wise, J.T.F., Li Chen, T., Perkins, C.R., Bras, M.M., Speer, R.M., and Urbán, J. Of Whales and Men: Understanding Metal Pollution in the Sea of Cortez through a One Environmental Health Approach. Presented at the World Marine Mammal Science Conference, Barcelona, Spain, December, 2019.

22. Isusi, I.M., Speer, R.M., Toyoda, J.H., and Wise, Sr., J.P. The Characterization of the Toxicologic Effects of Particulate Hexavalent Chromium in Female and Male Fin Whale Cells. Presented at the World Marine Mammal Science Conference, Barcelona, Spain, December, 2019.

23. Speer, R.M., Zhou, X., Liu, K.J., Browning, C.L., Kondo, K., Wise, Sr., J.P. ChromateInduced Loss of E2F1 Inhibits RAD51 Response in Homologous Recombination Repair. Presented at the Ohio Valley Chapter of the Society of Toxicology (OVSOT) annual meeting, October, 2019.

24. Meaza, I., Speer, R.M., Toyoda, J.H. Wise, J.P., Sr. Particulate Hexavalent Chromium Induces Cytotoxicity and Genotoxicity in Female and Male Fin Whale Primary Fibroblasts. Presented at the Ohio Valley Chapter of the Society of Toxicology (OVSOT) annual meeting, October, 2019.

25. Wise, J.P., Jr., Lu, H., Meaza, I., Wise, S.S., Croom-Perez, T., Speer, R.M., Toyoda, J.H., Ali, Abdulmehdi, Cai, L., Liu, K.J., Wise, J.T.F., Young, J.L., Wise, J.P., Sr. An Environmental Toxicology Assessment of Heavy Metal Accumulation in American Alligators in Florida. Presented at the Ohio Valley Chapter of the Society of Toxicology (OVSOT) annual meeting, October, 2019.

26. Meaza, I.M., Speer, R.M., Toyoda, J.H., Wise, Sr., J.P. Particulate Hexavalent Chromium Induces Cytotoxicity and Genotoxicity in Female and Male Fin Whale Cells. 
Official abstract for the Society of Toxicology annual meeting, March 2020 (Canceled Covid-19).

27. Speer, R.M., Zhou, X., Liu, K.J., Browning, C.L., Kondo, K., Wise, Sr., J.P. ChromateInduced Loss of E2F1 Inhibits RAD51 Response in Homologous Recombination Repair. Official abstract for the Society of Toxicology annual meeting, March 2020 (Canceled Covid-19).

28. Lu, H., Browning, C.L., Wise, S.S., Speer, R.M., Lu, K.J., Wise, Sr., J.P. How Chromium Induces Genomic Instability: Lessons from Human and Whale Cells. Presented at the Sixteenth International Symposium on Recent Advances in Environmental Health Research, March, 2020 (Postponed - Covid-19).

\section{University Student Research Day Presentations}

1. Speer, R.M., The, T., and Wise, Sr., J.P. The Cytotoxicity and Genotoxicity of Particulate and Soluble Cobalt in Human Urothelial Cells. Presented at Research!Louisville, University of Louisville, 2015.

2. Speer, R.M., Young, J.L., Martin Bras, M., Barandiaran, M. Marquez-D'Acunti, L. and Wise, Sr., J.P. A Comparison of the Cytotoxicity and Genotoxicity of Particulate and Soluble Hexavalent Chromium Leatherback Sea Turtle (Dermochelys coriacea) Lung Cells. Research!Louisville, 2016.

3. Rossman, J., Speer, R.M., Wise, S.S. and Wise, Sr., J.P. Cytotoxic Effects of Chromate Exposure on Alligotr Skin and Bronchial Cells. Presented at Research!Louisville, University of Louisville, 2016.

4. Speer, R.M., Browning, C.L. and Wise, Sr., J.P. Chromate-Induced Suppression of E2F1 and RAD51 in the Homologous Recombination Response. Presented at Research!Louisville, University of Louisville, 2017.

5. McBride, D.E., Perez, A.A., Raph S.M., Speer R.M., Croom-Perez T.J., Wise S.S. and Wise, Sr., J.P. A One Health Case Study: Comparison of DNA Damage Response to Hexavalent Chromium in Alligator and Human Lung Fibroblasts. Presented at Research!Louisville, University of Louisville, 2017.

6. Toyoda, J.H., Martino, J., Speer, R.M., and Wise, Sr., J.P. Mechanisms of Hexavalent Chromium-Induced Centriole Disengagement and Centrosome Amplification. Presented at Research!Louisville, University of Louisville, 2017.

7. Speer, R.M., Young, J.L., Wise, S.S., Raph, S.M., Martin Bras, M., Barandiarin, M., Marquez-D'Acunti, L., and Wise, Sr., J.P. Using Leatherback Sea Turtles (Dermochelys coriacea) as a Model Species for Metal Toxicology Research and Public Education in Vieques, Puerto Rico. Presented at the Graduate Student Regional Research Conference, University of Louisville, 2018.

8. Speer, R.M., Browning, C.L, and Wise, Sr., J.P. Suppression of E2F1 and RAD51 in Chromate-Induced Failure of Homologous Recombination. Presented at Research!Louisville, 2018. 
9. Speer, R.M., Zhou, X., Liu, K.J., Browning, C.L., Kondo, K., Wise, Sr., J.P. ChromateInduced Loss of E2F1 Inhibits RAD51 Response in Homologous Recombination Repair. Presented at

Research!Louisville!, 2019.

10. Wise, S.S., Miller, E., Daniel, S., Meaza, I., Toyoda, J.H., Lu, H., Speer, R. M., Young, J. L., Isakov, R., Jaggers, H., Wise, Jr., J. P., Croom-Perez, T. J., Cai, L., Hoyle, G., Wise, Sr., J. P. Effects of Chronic Exposure to Particulate Chromate in Rat Lungs. Presented at Research!Louisville, 2019.

\section{Seminars/Oral Presentations}

2019 Tox on the Clock, Three Minute Thesis Competition, Ohio Valley Regional Chapter of the Society of Toxicology (OVSOT) annual meeting, Cincinnati, Ohio.

2019 Speer, R.M., Browning, C.L., Wise, J.P., Sr. "The Role of E2F1 in ChromateInduced RAD51 Suppression" Graduate Student Research Conference, University of Louisville, Louisville, KY.

2019 Speer, R.M., Wise, C.F., Wise, S.S., Martin Bras, M., Barandiaran, M., Marquez, L., Bermudez, E., Wise, J.P., Sr. Environmental Impacts on Leatherback Sea Turtle Health: Using a One Health Approach to Study Metal Pollution in Wildlife. International Sea Turtle Symposium, Charleston, SC.

2019 Speer, R.M. "Methods to Characterize and Assess Genotoxicity in Leatherback Sea Turtles." Environmental Contaminants in Sea Turtles Workshop, International Sea Turtle Symposium, Charleston, SC.

2018 "Mechanisms of E2F1 Suppression of RAD51 in Chromate-Induced Failure of Homologous Recombination." 20th Annual Midwest DNA Repair Symposium, Columbus, OH. May, 2018.

2017 "A Comparison of the Cytotoxicity and Genotoxicity of Particulate and Soluble Hexavalent Chromium in Human and Leatherback Sea Turtle (Dermochelys coriacea) Lung Cells." 8th Meeting of Aquatic Animal Models of Human Disease, University of Alabama, Birmingham, AL. January, 2017.

2016 "Developing a Thesis: The Role of E2F1 in $\mathrm{Cr}(\mathrm{VI})$-Induced Carcinogenesis." Cancer Center Colloquia Series, University of Louisville, Louisville, KY. April, 2016.

2014 "Cytotoxicity and Genotoxicity of Particulate and Soluble Cobalt in Human Urothelial Cells." Department of Applied Medical Sciences Seminar Series. University of Southern Maine, Portland, ME.

\section{Public Presentations}

2018 "One Environmental Health: Investigating Toxicology with Sea Turtles and Humans." Vieques Conservation and Historical Trust Speaker Series, Vieques, Puerto Rico.

2017 "The What, How, and What Now of Toxicology." Future Problem Solvers Mentor Training, Kentucky Association Academic Conference, Louisville, KY. 
2016 "Wise Laboratory Research in Vieques: Implications and Future Directions." Vieques Conservation and Historical Trust Speaker Series, Vieques, Puerto Rico.

\section{Field Work}

2018

Conducted alligator sampling expedition at Kennedy Space Center, Lake Woodruff and Lake Apopoka, Florida.

2017 Conducted sample collecting in the Gulf of California (Sea of Cortez), Mexico during the spring season. Biopsies were taken from fin, humpback, minke, Bryde's, blue, pilot and sperm whales.

2017-Present Conducted sample collecting in the Gulf of Maine during the fall season. Biopsies were taken from fin, humpback and minke whales.

2015-Present Conducted alligator sampling expeditions at Kennedy Space Center, Florida.

2015-Present Developed a marine field research laboratory in Vieques, Puerto Rico. Conducted sampling programs for fish and sea turtles.

\section{Committees}

2018-Present Policy Coordinator, Science Policy and Outreach Group, University of Louisville

2019-2020 Member, FUTURE Committee, Society of Toxicology

2019-2020 Member, Programming Subcommittee, Graduate Student Leadership Committee, Society of Toxicology

2018-2020 Metals Specialty Section Graduate Student Representative

2018-2019 President of the Pharmacology and Toxicology student body, Department of Pharmacology and Toxicology, University of Louisville

2018-2019 Research Grant Review Committee, Graduate Student Council, University of Louisville

2018-2019 Member, Continuing Education Committee Graduate Student Representative, Society of Toxicology

2018-2019 Member Professional Development Subcommittee, Graduate Student Leadership Committee, Society of Toxicology

2017-2018 President of third year graduate student class, Department of Pharmacology and Toxicology, University of Louisville

\section{Continuing Education Coursework}

2020 Professional Development Webinar, "Navigating the K99/R00 Grant Process," American Society for Cell Biology.

2020 Professional Development Webinar, "Transitioning to Independence Webinar Series Part 3: How to Get the Most out of Your Mentoring Relationships," Postdoctoral Assembly, Society of Toxicology. 
2019 Continuing Education Course, "Assay Development Principles and Good Research Practices for Rigor and Reproducibility in In Vitro Toxicology," Society of Toxicology.

2018 Superfund Seminar Series, "Superfund Research Program Progress in Research Webinar Part 2: University of Louisville, University of New Mexico, and University of Washington,"

2018 Superfund Seminar Series, "Superfund Research Program Progress in Research Webinar Part 3: Columbia University, Massachusetts Institute of Technology, and University of Rhode Island,"

2018 Superfund Seminar Series, "Superfund Research Program Progress in Research Webinar Part 4: Boston University, Texas A\&M University, and University of California, Davis,"

2017 Webinar, "Defining a cancer cell-specific mechanism of resistance to Topoisomerase I poisons," Society of Toxicology Webinar.

2017 Webinar, "Finding Your Dream Job in Regulatory Toxicology," Society of Toxicology Webinar.

2017 Continuing Education Course, "Basic Principles of Human Risk Assessment," Society of Toxicology.

2014 Webinar, "New Frontiers in Chemical Carcinogenesis, Association of Scientists of Indian Origin," Society of Toxicology.

2014 Webinar, "Increasing Your Visibility and Participation in SOT as an Early Career Toxicologist, SOT Postdoctoral Assembly," Society of Toxicology.

2014 Webinar, "Postdoctoral Representative Fall Webinar," SOT Postdoctoral Assembly, Society of Toxicology.

Professional Memberships \& Societies:

2020-Present Graduate Student Member, Society of Environmental Toxicology and Chemistry

2017-Present Graduate Student Member, Women in Toxicology Special Interest Group, Society of Toxicology

2016-Present Graduate Student member, National Postdoctoral Association

2015-Present Graduate Student Member, Science Policy and Outreach Group

2015-Present Graduate Student Member, American Association for the Advancement of Science,

2015-Present Graduate Student Member, Ohio Valley Regional Chapter, Society of Toxicology 
2014-Present Graduate Student Member, Society of Toxicology

2014-Present Graduate Student Member, Carcinogenesis Specialty Section, Society of Toxicology

2014-Present Graduate Student Member, Metals Specialty Section, Society of Toxicology

2014-2015 Northeast Regional Chapter, Society of Toxicology

\section{Volunteer and Community Work}

2020 Head Poster Judge, Kentucky Science Fair, Kentucky Science Center, Louisville, $\mathrm{KY}$.

2019 Activity Leader, Girls Rule STEM+Health Summit, Speed School of Engineering, University of Louisville, Louisville, KY.

2019 Event Leader, Louisville Regional Science and Engineering Fair Advocacy Day at the Capital, Frankfort, KY.

2019 Head Poster Judge, Kentucky Science Fair, Kentucky Science Center, Louisville, $\mathrm{KY}$.

2018 Project Mentor, Central High School Students for Kentucky Science Fair, Kentucky Science Center, Louisville, KY.

2018 Presenter and Program Organizer, Manta Environmental Summer Education Programs, Vieques Conservation and Historical Trust, Vieques, Puerto Rico.

2017 Program Organizer, Future Problem Solver's Competition Preparation Workshop, Kentucky Association for Academic Competition, University of Louisville, Louisville, KY.

2017 Poster Judge, Kentucky Science Fair, Kentucky Science Center, Louisville, KY.

2017 Program Assistant, Manta Environmental Summer Education Program, Vieques Conservation and Historical Trust, Vieques, Puerto Rico.

2016 Volunteer, U.S. Fish and Wildlife Service beach clean-up program, Vieques, Puerto Rico.

2016 Program Assistant, Manta Environmental Summer Education Program, Vieques Conservation and Historical Trust, Vieques, Puerto Rico.

2016 Head Poster Judge, Kentucky Science Fair, Kentucky Science Center, Louisville, $\mathrm{KY}$. Judged posters for middle school students.

2015 Program Assistant, Manta Environmental Summer Education Program, Vieques Conservation and Historical Trust, Vieques, Puerto Rico. 
2015 Project Mentor, Science Fair Student Mentoring Session, Science Policy and Outreach Group, University of Louisville and Kentucky Science Center, Louisville, $\mathrm{KY}$.

2015 Project Assistant, Research!Louisville High School Student Graduate School Information Session, Science Policy and Outreach Group, University of Louisville and Kentucky Science Center, Louisville, KY.

2014 Event Volunteer, Annual Wild \& Scenic Film Festival, Friends of Casco Bay, Portland, ME.

Volunteer, Annual beach clean-ups, Environmental Health and Toxicology Club, University of Southern Maine, Portland, ME. 